MARCELO SCHNECK DE PAULA PESSÔA

\title{
PROCESSOS E PROJETOS EM UMA FÁBRICA DE SOFTWARE eLab-TI
}

\begin{abstract}
Análise Crítica da Obra Acadêmica apresentada à Escola Politécnica da Universidade de São Paulo para a obtenção do título de Livre Docente em Engenharia.
\end{abstract}

SÃO PAULO 
[Termo de julgamento] 
MARCELO SCHNECK DE PAULA PESSÔA

\title{
PROCESSOS E PROJETOS EM UMA FÁBRICA DE SOFTWARE eLab-TI
}

\begin{abstract}
Análise Crítica da Obra Acadêmica apresentada à Escola Politécnica da Universidade de São Paulo para a obtenção do título de Livre Docente em Engenharia.
\end{abstract}

Área de Concentração:

Engenharia de Produção

SÃO PAULO

2009 
[Ficha catalográfica]

Pessoa, Marcelo Schneck de Paula

Processos e projetos em uma fábrica de software - eLab-TI / M.S.P. Pessoa. -- São Paulo, 2009.

$210 \mathrm{p}$.

Tese (Livre-Docência) - Escola Politécnica da Universidade de São Paulo. Departamento de Engenharia de Produção.

1.Fábrica de software 2.Tecnologia da informação 3.Enge nharia de software 4.Processo de software 5.Projeto de software

I. Universidade de São Paulo. Escola Politécnica. Departamento de Engenharia de Produção II. t. 


\section{ERRATA}

PAULA PESSÔA, Marcelo Schneck de.

Projetos e Processos de uma Fábrica de Software eLab-TI. (Tese de Livre Docência) Escola Politécnica, Universidade de São Paulo, São Paulo, 2009.

\begin{tabular}{|l|l|l|l|}
\hline Página & Linha & Onde se lê & Leia-se \\
\hline & & & \\
\hline & & & \\
\hline & & & \\
\hline & & & \\
\hline
\end{tabular}




\section{DEDICATÓRIA}

Dedico este trabalho à Mieko, minha companheira de todos os momentos e aos meus pais, Eduardo e Susi que me deram as forças necessárias para terminar mais esta empreitada. Fernando José Barbin Laurindo e Mauro de Mesquita Spínola também recebem esta dedicatória pois, sem

eles, este trabalho não existiria. 


\section{AGRADECIMENTOS}

Os primeiros agradecimentos são aos colegas de GTI, professores Fernando José Barbin Laurindo e Mauro de Mesquita Spinola que muito me incentivaram a fazer esse trabalho. Ao professor Tamio Shimizu que me recebeu no Departamento quando ainda era um forasteiro proveniente da elétrica. Ao professor André Leme Fleury que foi aluno na graduação, que se apaixonou por nosso tema de $\mathrm{Tl}$, e hoje é nosso colega de grupo de pesquisa. Finalmente ao Professor Renato Moraes, recém chegado ao Departamento, mas que já era colega de pesquisa do projeto Proenge da Capes por outra universidade.

Aos meus orientados que, sem eles este trabalho não teria conteúdo. São muitos mas é importante lembrar de cada um.

- José Francisco de Castilho Filho, meu primeiro orientado. Foi quem me ensinou a orientar.

- Alberto Medeiros, Luciano Raizer Moura, Gerson Prando, Venício Vilas Boas, José Carlos Jacintho, Hélio Pekelman e Luiz Alberto de Campos Louzada que formam o primeiro grupo de orientados que ajudou a identificar a necessidade de se estruturar melhor o grupo de pesquisa.

- Luci Vicari que permitiu uma grande participação na primeira fase do projeto Tidia e me ensinou pedagogia

O grupo que ajudou a pensar a Fábrica de Software e participou das grandes discussões sobre o modelo de referência:

- Ivanir Costa, Marcos Antonio Rodrigues Silva

- O pessoal de Ourinhos e Assis: André Luiz Presende Trindade (orientado de mestrado e doutorado), José Augusto Fabri e Alexandre L'Érario

- Paulo-Marques, que terminou o mestrado mas infelizmente parou por aí.

- Rodrigo ·Franco Gonçalves, campeão na captação de bolsas

- Kleber Oliveira, orientado de mestrado e que acabou de encerrar o doutorado, 
À Maria Alice Frontini que foi uma das primeiras orientadas de trabalho de formatura, contribuiu chamando atenção para o tema Fábrica de Software e que é hoje recém doutora pelo nosso Departamento,

Fábio Massashi Okumura que, em seu trabalho de formatura, me fez acreditar em modelos matemáticos estatísticos,

Ao Edval da Silva Tavares, Marcelo Marçula e André Trindade (já citado) que me ensinaram Gestão do Conhecimento,

À Sarah Kohan, a quem conheço desde o tempo em que era estagiária, que nos acompanha há mais de dez anos mas não se encoraja para o doutorado,

À Sheila Reinehr colega de ABNT, que virou orientada e hoje é colega de pesquisa,

Ao Paulo Marcelo Lessa Moreira, Valério del Maschi, Roque Rabechini Jr, Cássio Sodré Cooke que fizeram contribuições importantes para este trabalho,

Ao André Ramos Carrara e Raphael Damini Moreira sempre solícitos para ajudar a montar este trabalho, o memorial e o que surgir pela frente.

Ao Tomás Kameyama e Antonio Carlos Tonini fiéis escudeiros do eLab-TI que sempre estão à disposição para enfrentar novos desafios.

Não poderia também deixar de agradecer à Ivelise Moreira que sempre está organizando a nossa vida, fazendo "blindagens" para não sermos interrompidos na elaboração deste trabalho e resolver todos os problemas que aparecem ao longo do caminho.

Enfim, os demais orientados que de alguma forma contribuíram para as pesquisas realizadas: Luis Ricardo Napolitano Freitas, Arthur Bataglia, Izaias Porfírio Filho, Luciano Grubba, Sérgio dos Santos, Reinaldo Nogueira, Edvaldo Antonio Sartor e Aurélio José Vitorino.

Para encerrar, Carlos Eduardo Salomé Pereira (in memorian) não poderia deixar de ser lembrado também pois foi alguém que acreditou no projeto da Fábrica de Software em sua fase inicial e me acompanhou inúmeras vezes em diversos órgãos de fomento como Fapesp, BNDES, MCT, Secretaria de Planejamento do Estado de São Paulo, e até na Alemanha em uma visita à Universidade de Hamburgo. 
[Epígrafe] 


\section{RESUMO}

O eLab-TI é um laboratório de pesquisa, também conhecido como Fábrica de Software, cuja principal finalidade é estudar os diversos aspectos da produção de software aplicando os conceitos da Engenharia de Produção à Produção de Software. Esse laboratório foi criado como um grande desafio de pesquisa no qual foram desenvolvidos diversos trabalhos de iniciação científica, trabalhos de formatura, dissertações de mestrado, teses de doutorado e mais recentemente, de livre docência. Este autor orientou um total de 36 dissertações e teses nos últimos dez anos, das quais foram selecionadas 22 para a realização de uma análise crítica da obra acadêmica. Inicialmente é feito um breve histórico da evolução da Engenharia de Software e uma discussão sobre os problemas existentes na produção de software. A seguir é apresentado o modelo de referência de uma Fábrica de Software a partir do qual as pesquisas foram desenvolvidas. Cada pesquisa é apresentada resumidamente com seus principais resultados e no final é realizado um balanço geral das pesquisas desenvolvidas mostrando que o modelo de referência foi muito importante para formar um todo coerente das pesquisas. Foi mostrado também como os métodos de pesquisa evoluíram nesse período analisado e que a produção de conhecimento desses trabalhos foi muito grande mas, a produção acadêmica poderia ter sido maior se tivesse havido maior foco nesse tipo de resultado. A graduação e a pós-graduação também usufruíram desses resultados através do oferecimento de novos cursos e da melhoria do conteúdo dos cursos oferecidos.

Palavras-chave: software, processo de software, produção de software, definição de processo de software, melhoria de processo de software, fábrica de software, estratégia e processo de software, engenharia de software 


\begin{abstract}
The eLab-TI is a research laboratory, also known as Software Factory, which main purpose is to study the various aspects of software production using concepts of Industrial Engineering applied to Software Production. This laboratory was established as a major challenge of research where several works were developed from undergraduate researches, final undergraduate works, master's and doctoral thesis, and more recently, associate professor thesis. This Author oriented (guided) a total of 36 dissertations and thesis in the last ten years, 22 of these were selected to undergo a critical analysis of its academic work. Initially it is made a brief Software Engineering evolution history and a discussion about the existing problems in software production. After that, it is introduced a reference model of a Software Factory from which researches were developed. Each research summary is presented with its main results and, after that, an overall balance is made showing how important was to have the Software Factory reference model to perform a coherent set of researches. It was also shown how research methods evolved in the analyzed period and that the production of knowledge of these works was very great. Even though the academic production could have been bigger if a major focus in this type of result was an important goal. Under graduation and graduation also benefit from those results through the offering of new courses and the improvement of existing ones.
\end{abstract}

Keywords: software, software process, software production, software process definition, software process improvement, software factory, strategy and software process, software engineering 


\section{SUMÁRIO}

I INTRODUCÃ̃

$\mathbf{I}-\mathbf{1}$

I.1 A Questão da PeSQuisa

I-5

II ENGENHARIA DE SOFTWARE

II-7

II.1 ANÁlISE ESTRUTURADA

II-8

II.2 ORIENTAÇÃO A OBJETOS

II-9

II.3 A VISÃO DO PROCESSO DE SOFTWARE

II-10

II.4 O MOVIMENTO ÁGIL

II-11

II.5 ENGENHARIA DA INFORMAÇÃO

II-12

II.6 A CULTURA DA TOLERÂNCIA

II-15

II.7 O PERFIL do Profissional de TI

II-17

III A CRIACÃO DO AMBIENTE DE PESOUISA

III-18

III.1 A PRIMEIRA VISÃo DE FÁBRICA DE SOFTWARE

III-18

III.2 O MODELO DE REFERENCIA DE FÁBRICA DE SOFTWARE DO GTI

III-21

IV ANÁLISE DE NEGÓCIO

IV-30

IV.1 ANALISTA DE NEGócios

IV-30

IV.2 GESTÃo INTEGRADA DA INFORMAÇÃO

IV-40

IV.3 ANÁLISE DE INVESTIMENTOS EM TI

IV-51

IV.4 GeSTÃo do CONHECIMENTO EM PEQUENAS ORGANIZAÇÕeS

IV-55

IV.5 GESTÃo DE SERVIÇOS

IV-61

IV.6 Novas TeCnOlogias de COMUniCAÇão

IV-64

IV.7 DIRETRIZES ESTRATÉGICAS PARA EMPRESAS DE SOFTWARE

IV-68

IV.8 RASTREAMENTO DE REQUISITOS

IV-77

IV.9 ENGENHARIA WEB.

IV-87 
V.1 Métricas, OrÇamento e Planejamento V-93

V.2 CompetênCia e Maturidade em GeStão de Projetos V-96

V.3 Gestão do Conhecimento em Projetos V-101

VI IMPLEMENTACÃO DE SISTEMAS DE TI

VI.1 INSPEÇÃO DE RECEBIMENTO EM UMA FS VI-106

VI.2 Processo de DeSenvolvimEnTo de SoftWare VI-112

VI.3 Processo de DeSEnVolvimento para UMA FÁbrica de SoFTWARE VI-113

VI.4 ORGANIZAÇÃO DOS PROCESSOS DE UMA FS VI-127

VI.5 GESTÃo DO CONHECIMENTO EM FS VI-136

VI.6 DDS-DESENVOLVIMENTO DISTRIBUIDO DE SOFTWARE VI-140

VI.7 REUSO SISTEMATIZADO DE SOFTWARE VI-145

$\begin{array}{lll}\text { VI.8 Produtividade EM FS } & \text { VI-162 }\end{array}$

VI.9 QUICKLOCUS: AVALIAÇÃO DE PROCESSO VI-174

VI.10 CONSIDERAÇÕES FINAIS SOBRE PROCESSO DE SOFTWARE VI-182

VII ANÁLISE CRÍTICA DA OBRA $\quad$ VII-183

VII.1 O GRUPO DE PESQUISA VII-183

VII.2 CONTEÚDO DAS PESQUISAS VIII-184

$\begin{array}{lll}\text { VII.3 OS ALUNOS PESQUISADORES } & \text { VII-186 }\end{array}$

$\begin{array}{lll}\text { VII.4 RESULTADOS ACADÊMICOS } & \text { VII-187 }\end{array}$

VII.5 RESULTADOS NÃO ACADÊMICOS VII-188

$\begin{array}{lll}\text { VII.6 CONSIDERAÇÕES FINAIS } & \text { VII-189 }\end{array}$

\begin{tabular}{lr} 
REFERENCIAS & VII-192 \\
\hline
\end{tabular}

APÊNDICE A - QUESTIONÁRIO DA PESQUISA DE SILVA (2004) V VII-206 


\section{LISTA DE ILUSTRAÇÕES}

FIGURA 1 - ÁREAS TEMÁTICAS DO PRO E LINHAS DE PESQUISA DO GTI ..................................... I-3

FIGURA 2 - PROCESSO E SEUS COMPONENTES (PAUK, 1995) ………….........................................II-10

FIGURA 3 - FASES DA ENGENHARIA DA INFORMAÇÃO (ADAPTADO DE MARTIN,1991).............II-13

FIGURA 4 - BLOCOS QUE COMPÕEM A ENGENHARIA DA INFORMAÇÃO (MARTIN, 1991)..........II-14

FIGURA 5 - MODELO DE REFERÊNCIA DA FÁBRICA DE SOFTWARE (AUTOR: GTI) .....................III-22

FIGURA 6 ANÁLISE DE NEGÓCIO ……………...................................................................

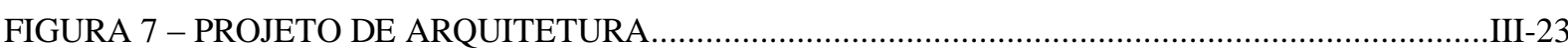

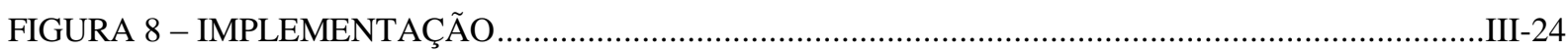

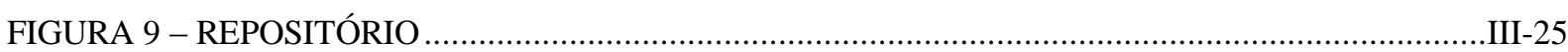

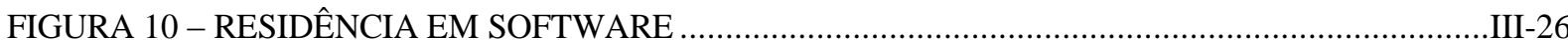

FIGURA 11 - PESQUISAS REALIZADAS EM ANÁLISE DE NEGÓCIO ....................................................III-27

FIGURA 12 - PESQUISAS REALIZADAS EM GESTÃO DE PROJETOS .................................................III-28

FIGURA 13 -PESQUISAS REALIZADAS EM PROCESSO DE SOFTWARE ..........................................III-29

FIGURA 14 - MODELO BABOK (BABOK , 2008) .......................................................................... IV-31

FIGURA 15 - ALINHAMENTO ENTRE OS CURSOS DE NEGÓCIO E TECNOLOGIA (FABRI ET ALL,

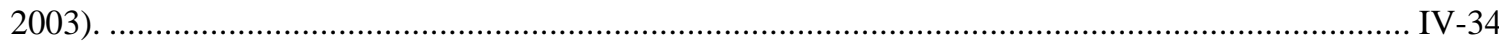

FIGURA 16 - RESULTADO DOS CURSOS DE NEGÓCIO (FABRI ET AL, 2003). ................................ IV-35

FIGURA 17 - RESULTADO DOS CURSOS DE TECNOLOGIA (FABRI ET AL, 2003)......................... IV-36

FIGURA 18 - OS TRÊS FLUXOS DE INFORMAÇÃO NAS EMPRESAS (MOURA, 1999)..................... IV-41

FIGURA 19 - TIPOS DE INFORMAÇÃO: DECISÕES MÉTODOS E RESULTADOS (MOURA , 1999)IV-43

FIGURA 20 - PIRÂMIDE DE ANTHONY (MOURA, 1999) ........................................................... IV-44

FIGURA 21 - ELEMENTOS DE UM SISTEMA E SUA RELAÇÃO COM A EMPRESA (MOURA, 1999). IV-

46

FIGURA 22 - IDENTIFICAÇÃO DOS PROCESSOS DO FLUXO DO PRODUTO E DA INFORMAÇÃO

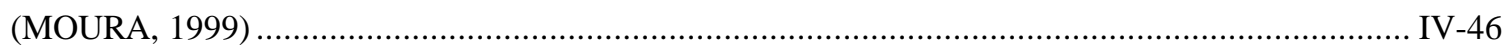

FIGURA 23 - SISTEMAS DE COORDENAÇÃO (MOURA, 1999) ................................................. IV-47

FIGURA 24 - VISÃO GERAL DOS ELEMENTOS QUE COMPÕEM O MODELO DE ORGANIZAÇÃO

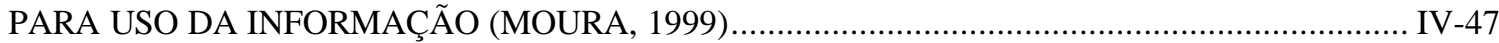

FIGURA 25 - SISTEMÁTICA PARA AVALIAÇÃO DE PROJETOS DE TI (JACINTHO, 2000) .............. IV-52 FIGURA 26 - RELACIONAMENTO ENTRE DADO, INFORMAÇÃO E CONHECIMENTO (MARÇULA,

2001) IV-57

FIGURA 27 - MODELO SECI - NONAKA E TAKEUSHI (1997) IV-58

FIGURA 28 - ETAPAS DE IMPLANTAÇÃO E MANUTENÇÃO DA GESTÃO DO CONHECIMENTO

(MARÇULA, 2001) IV-59

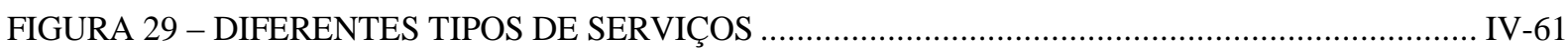

FIGURA 30 - ENQUADRAMENTO DOS REQUISITOS ..................................................................... IV-63 
FIGURA 31-ENQUADRAMENTO DA PROGRAMAÇÃO. IV-63

FIGURA 32 - CADEIA DE VALOR DE PORTER \& MILLAR (1985)... IV-65

FIGURA 33 - SISTEMA DE VALOR DE PORTER \& MILLAR (1985)... IV-65

FIGURA 34 - MACRO FLUXO DA PESQUISA-AÇÃO (DEL MASCHI, 2009)..... IV-68

FIGURA 35 - UMA ABORDAGEM DE REQUISITOS (OLIVEIRA, 2002). IV-78 FIGURA 36 - MODELO PROPOSTO (OLIVEIRA, 2002) IV-81

FIGURA 37 - OBJETIVOS DA EXTRAÇÃO DE REQUISITOS (OLIVEIRA, 2002)............................... IV-82 FIGURA 38 - PROCESSO DE DESENVOLVIMENTO PARA WEB (GONÇALVES, 2002) .................... IV-90 FIGURA 39 - ABORDAGEM PROPOSTA PARA PROJETOS WEB (GONÇALVES, 2002)................... IV-91 FIGURA 40 - DIMENSÕES DO MODELO (GONÇALVES, 2009) IV-92 FIGURA 41 - COMPARAÇÃO ENTRE ESTIMATIVAS DO COCOMO E RESULTADOS REAIS (OKUMURA, 1988). V-94 FIGURA 42 - MODELO DE COMPETÊNCIAS EM GERENCIAMENTO DE PROJETOS (RABECHINI JR., 2003) ... V-98

FIGURA 43 - MATRIZ DE MATURIDADE (RABECHINI JR, 2003) ... $\mathrm{V}-100$ FIGURA 44 - PROCESSO DE PROGRAMAÇÃO EM UMA FÁBRICA DE SOFTWARE (COSTA, 2003). VI108

FIGURA 45 - INTERFACE ENTRE O CLIENTE E A FÁBRICA DE SOFTWARE (COSTA, 2003) ..... VI-109 FIGURA 46 - PROCESSOS PROPOSTOS PARA UMA FÁBRICA DE SOFTWARE (COSTA, 2003) .. VI-109 FIGURA 47 - MODELO IMPLEMENTADO DA FÁBRICA DE SOFTWARE (COSTA, 2003)............. VI-110 FIGURA 48 - VISÃO GERAL DO SCRUM (RODRIGUES SILVA, 2005) ……...................................... VI-121 FIGURA 49 - FÁBRICA EXPERIMENTAL DE BASILI (FABRI, 2007) ………................................... VI-127 FIGURA 50 - FÁBRICA PROPOSTA POR FERNANDES E TEIXEIRA (2004) ..................................... VI-128 FIGURA 51 - PROPOSTA DE MODELO PARA O ELAB-TI (FABRI, 2007) .......................................... VI-129 FIGURA 52 - PROCESSO FABRIL (FABRI, 2007) ...................................................................... VI-133 FIGURA 53 - VISÃO DE META-PROCESSO (FABRI, 2007) ............................................................. VI-134 FIGURA 54 - META-PROCESSO PROPOSTO (FABRI, 2007) ……............................................... VI-135 FIGURA 55 - O BINÔMIO ENSINAGEM-APRENDIZAGEM (TRINDADE, 2006)................................ VI-136 FIGURA 56 - A ESCADA DO APRENDIZADO (TRINDADE, 2006) .................................................... VI-137 FIGURA 57 - A ESCADA DO APRENDIZADO EM PERSPECTIVA (TRINDADE, 2006).................... VI-137 FIGURA 58 - MODELO FINAL DE ENSINAGEM (TRINDADE, 2006) ............................................... VI-138 FIGURA 59 - MODELO DE ENSINAGEM E A ESCADA DE CONHECIMENTO COM EXEMPLO

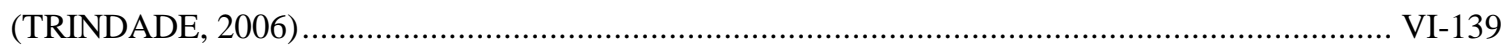
FIGURA 60 - PROPRIEDADES DOS AMBIENTES DDS (L ÉRARIO 2006) ....................................... VI-141 FIGURA 61 - GRAU DE COMUNICAÇÃO ENTRE OS GRUPOS (BORGHOFF, 2000) …................... VI-142 FIGURA 62 - RELAÇÃO ENTRE OS MECANISMOS DE COORDENAÇÃO E AS PROPRIEDADES DO

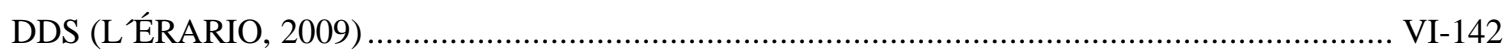
FIGURA 63 - MODELO PROPOSTO M3DS (L ÉRARIO, 2009)..................................................... VI-143 FIGURA 64 - CLASSIFICAÇÕES DE REUSO DE SOFTWARE ............................................................. VI-146 FIGURA 65 - ESTRATÉGIAS DE REUSO (REINEHR, 2008)............................................................. VI-148 
FIGURA 66 - EVOLUÇÃO DO USO SISTEMATIZADO DE SOFTWARE VI-148

FIGURA 67 - CARACTERÍSTICAS DE UM SISTEMA DESENVOLVIDO COM BASE EM COMPONENTES VI-150

FIGURA 68 - NÍVEIS DE ABSTRAÇÃO DE KOMPONENTE . VI-151

FIGURA 69 - MODELO DE REFERÊNCIA DO PROCESSO DO ESAPS (REINEHR, 2008). VI-153

FIGURA 70 - MODELO BAPO (ADAPTADO DE REINEHR, 2008) VI-154

FIGURA 71 - PROPOSIÇÕES DA PESQUISA DE CAMPO (REINEHR, 2008) ... VI-156

FIGURA 72 - PONTOS DE ANÁLISE (REINEHR, 2008). VI-157

FIGURA 73 - EXEMPLO DE PONTO DE ANÁLISE PA-10 (REINEHR, 2008). VI-157

FIGURA 74 - PROPOSIÇÃO P1 - (REINEHR, 2008). VI-158

FIGURA 75 - PROPOSIÇÃO P2 - (REINEHR, 2008). VI-158

FIGURA 76 - PROPOSIÇÃO P3 - (REINEHR, 2008) VI-159

FIGURA 77 - PROPOSIÇÃO P4 - (REINEHR, 2008). VI-159

FIGURA 78 - PROPOSIÇÃO P5 - (REINEHR, 2008). VI-160

FIGURA 79 - TAXA DE MUDANÇA X PRODUTIVIDADE (MOREIRA, 2007). VI-166

FIGURA 80 - PRODUTIVIDADE VERSUS TAXA DE ERROS (MOREIRA, 2007) VI-167

FIGURA 81 - MODELO DE PRODUTIVIDADE OBTIDO (MOREIRA, 2007) VI-170

FIGURA 82 - MODELO DA QUALIDADE OBTIDO (MOREIRA, 2007) VI-171

FIGURA 83 - PERCEPÇÃO DA EQUIPE COM RELAÇÃO AOS FATORES DE PRODUTIVIDADE

(MOREIRA, 2007) VI-172

FIGURA 84 - MÉTODOS DE AVALIAÇÃO DO SEI (KOHAN, 2003) VI-175

FIGURA 85 - MÉTODOS DE AVALIAÇÃO DA ISO (KOHAN, 2003). VI-176

FIGURA 86 - DIMENSÕES DAS ESTRATÉGIAS DE AVALIAÇÃO (KOHAN, 2003). VI-176

FIGURA 87 - FASES DO QUICKLOCUS.. VI-178

FIGURA 88 - EXEMPLO DE RESULTADO CONSOLIDADO DO QUICKLOCUS . VI-180

FIGURA 89 - ACCURACY (KOHAN, 2003) VI-180 


\section{LISTA DE QUADROS}

QUADRO 1- TIPOS BÁSICOS DE PRODUÇÃO (ADAPTADO DE PESSOA, SPINOLA, 2006) .III-19 QUADRO 2 - CLASSIFICAÇÃO DAS INFORMAÇÕES USADAS NA GESTÃO DE EMPRESAS (MOURA, 1999) IV-45

QUADRO 3 - MOTIVAÇÃO PARA IMPLANTAÇÃO DE EDI (MEDEIROS JR. 2002) IV-66

QUADRO 4 - PRINCIPAIS DIFICULDADES PARA IMPLANTAÇÃO DE EDI (MEDEIROS JR. 2002) IV-66 QUADRO 5 - PROTOCOLO DE PESQUISA (DEL MASCHI, 2009). IV-69

QUADRO 6 - AÇÕES PROPOSTAS PRIORIZADAS (DEL MASCHI, 2009) IV-74

QUADRO 7 -CICLOS DAS AÇÕES PROPOSTAS PRIORIZADAS (DEL MASCHI, 2009). IV-75 QUADRO 8 - AGRUPAMENTO DAS HIPÓTESES E QUESTÕES DA PESQUISA (TAVARES, 2003).V-102 QUADRO 9 - MODELO DE TRANSFERÊNCIA DE CONHECIMENTO PARA PROJETOS DE TI

(TAVARES, 2003) V-103

QUADRO 10 - RESULTADO DA PESQUISA EM 31 FÁBRICAS DE SOFTWARE (COSTA, 2003) ... VI-107 QUADRO 11- PRODUTIVIDADE X NÍVEL DE MATURIDADE (MOREIRA, 2007) VI-165

QUADRO 12 - RESUMO DOS FATORES CONSIDERADOS NO MODELO (MOREIRA, 2007) VI-169 


\section{LISTA DE ABREVIATURAS E SIGLAS}

ABNT - Associação Brasileira de Normas Técnicas

ACM - Association for Computer Machinery

AHP - Analytical Hierarchic Process

APF - Análise por Pontos de Função

BABoK - Business Analysis Body of Knowledge

BPMS - Business Process Management System

CFA - Conselho Federal de Administração

DDS -Desenvolvimento Distribuído de Software

EDI - Electronic Data Interchange

EOE - Empresa Objeto de Estudo

ESPITI - European Software Process Improvement Initiative

GSD - Global Software Development

GTI - Gestão da Tecnologia da Informação

IEEE - Institute of Electrical and Electronic Engineers

ISO - International Organization for Standardization

OMG - Object Management Group

$O O$ - Orientação a Objetos

PDCA - Plan, Do, Check, Act

PF - Ponto de Função

PMBoK - Project Management Body of Knowledge

$\mathrm{RE}$-Requirements Engineering

SBC - Sociedade Brasileira de Computação

SECI - Socialização, Externalização, Combinação, Internalização

SPE - Sistema de Ponto Eletrônico

UML - Unified Modeling Language

VAN - Value Addes Network 


\section{INTRODUÇÃO}

Este documento realiza uma análise crítica da obra acadêmica desenvolvida por este Autor nesses últimos 11 anos, ou seja, de 1998 a 2009. Durante esse período houve a coincidência de diversos fatores que levaram à produção acadêmica mais significativa deste Autor : a criação formal do grupo de pesquisa GTI em meados de 1998, o início das orientações de mestrado e doutorado e a seguir a criação do eLab-TI o laboratório de pesquisas de métodos e processos de software.

As pesquisas desenvolvidas foram realizadas concentrando-se na área de Tecnologia da Informação, abordando aspectos referentes ao Processo de Software, focando os problemas referentes à questão dos métodos e processos do "fazer software" e na área Sistemas de Informação, onde há mais a preocupação com o "usar software" no sentido de utilizá-lo para organizar a informação para uso, envolvendo, nesse último caso, as questões do alinhamento estratégico, dos processos de trabalho, de organização do trabalho, enfim o ambiente mais sistêmico no qual a tecnologia da informação se insere.

Há também duas outras áreas onde foram produzidas pesquisas que são a Gestão de Projetos e a Gestão do Conhecimento. No entanto tais temas não foram vistos como tema central das pesquisas em si mas como uma necessidade surgida para complementar os temas anteriores para melhor compreendê-los.

Em 1998 o Departamento de Engenharia de Produção (PRO, 2009) elaborou um projeto acadêmico, reestruturou sua organização interna e criou cinco áreas temáticas:

- EPEF - Economia da Produção e Engenharia Financeira

Pesquisa de aspectos ligados à modelagem econômico-financeira de empreendimentos, à contabilidade, às metodologias de custos, à análise de investimentos de sistemas de operações e aos aspectos econômicos 
relacionados às cadeias produtivas e às aglomerações de empresas (clusters e arranjos produtivos locais).

- GOL - Gestão de Operações e Logística

Linha de pesquisa com ênfase em gestão física de sistemas de operações e logísticos com temas em planejamento, programação e controle da produção e de estoques, logística e cadeia de suprimentos e produtividade.

- GTI - Gestão da Tecnologia da Informação

Aborda a gestão da Tecnologia da Informação, envolvendo seu planejamento e implementação, visando o estabelecimento de uma estratégia integrada (envolvendo a tecnologia, a estratégia de negócios e os aspectos organizacionais), bem como o projeto, a implantação e a administração de Sistemas de Informação, de Gestão do Conhecimento e de Apoio à Decisão.

- QEP - Qualidade e Engenharia do Produto

Abrange a discussão de estratégias, políticas, planejamento, operacionalização e controle de sistemas, metodologias e técnicas de qualidade, visando o aumento da eficácia e/ou competitividade da organização, assim como discute métodos e técnicas relacionados com a concepção, desenvolvimento e implantação de produtos, estudando sua viabilidade técnica, econômica e logística.

- TTO - Trabalho, Tecnologia e Organização

Trata da organização do trabalho em todas as instâncias da atividade produtiva e dedica especial atenção à relação dinâmica entre trabalho e tecnologia. Parte da abordagem sócio-técnica para diagnóstico, projeto e gestão dos processos de produção de bens e serviços, aplica os ensinamentos da ergonomia para a o estudo do trabalho humano e busca o relacionamento entre a Engenharia e as Ciências Sociais Aplicadas. 
O GTI organizou suas atividades em duas linhas de pesquisa, conforme ilustrado na Figura 1: (1) Planejamento e (2) Implementação de Sistemas de Tecnologia da Informação.

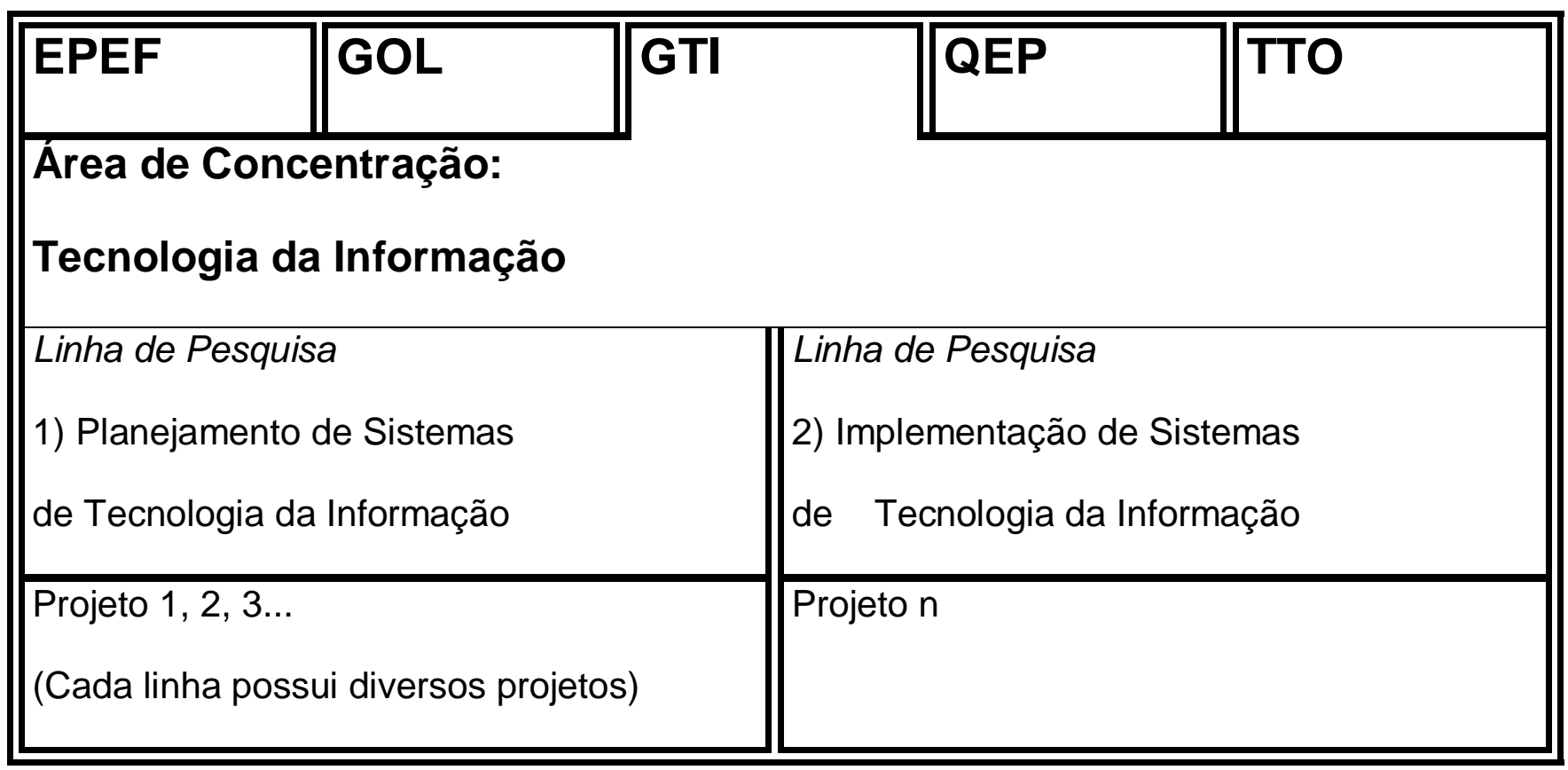

Figura 1 - Áreas temáticas do PRO e linhas de pesquisa do GTI

A linha de pesquisa Planejamento de Tecnologia da Informação envolve planejamento e gestão da tecnologia da informação nas empresas, alinhamento estratégico da $\mathrm{TI}$ com as estratégias de negócio das empresas, a avaliação da viabilidade econômico-financeira de aplicações de TI e sistemas integrados de gestão (ERP).

A linha de pesquisa Implementação de Sistemas de Tecnologia da Informação envolve essencialmente dois aspectos: o primeiro com relação aos métodos e processos para a construção de software e o segundo com relação à construção e definição de algoritmos e outras técnicas para aplicações em engenharia de produção. O primeiro trata de temas como qualidade da informação, qualidade de software, arquitetura de sistemas de tecnologia da informação, processo de 
desenvolvimento de software, segurança e privacidade de sistemas de informação e de software. O segundo tema trata de metodologias para avaliação quantitativa e qualitativa das estratégias de decisão, de sistemas flexíveis e inteligentes de informação e sistemas de apoio decisão.

Este Autor desenvolveu projetos de pesquisa em ambas as linhas acima descritas conforme será apresentado neste documento. Porém, na segunda linha de pesquisa Implementação de Sistemas de Tecnologia da Informação, houve uma maior dedicação em função da criação do eLab-TI (a ser detalhado neste documento). Nas discussões sobre processo de software, qualidade de software, enfim, investigações sobre como desenvolver software com qualidade e produtividade, foi percebido que estava "faltando alguma coisa" para aglutinar as pessoas envolvidas com esse tema. Esse sentimento de falta era de algo maior, como um grande desafio, à semelhança dos projetos de pesquisa vividos por este Autor no início de sua carreira: projeto de um computador, de uma central telefônica digital, de um sistema de controle de trens, entre outros. Esses temas integravam as atividades dos pesquisadores, forçavam a sua interação e a busca conjunta de solução de problemas e temas de investigação. Desses citados projetos foram desenvolvidas muitas pesquisas, cada uma delas abordando aspectos específicos, todos necessários para o projeto como um todo. Surgiu, dessa forma, a idéia de se criar a Fábrica de Software - este tornou-se o grande tema a ser estudado. Esse tema já havia sido objeto de um trabalho de formatura (FRONTINI, 1998) há vários anos atrás, mas nunca havia sido levando adiante como objeto de pesquisa.

Vale, por fim, ressaltar que a idéia de se caracterizar uma Fábrica de Software como objeto de pesquisa foi também inspirada na forma com que outros grupos de pesquisa organizam suas atividades. Um exemplo desse tipo que pode ser citado é um grupo de pesquisas em automação que escolheu o robô como tema maior: as pesquisas variaram de modelar a trajetória da pinça do robô, passando pelo estudo de sensores táteis e acionamento de motores. 
Outro aspecto importante na escolha do tema Fábrica de Software é o seu caráter prático, pois o estudo dos aspectos de produção de software, implantação de sistemas de informação e temas afim, são essencialmente experimentais e necessitam de situações reais para serem estudadas.

\section{I.1 A QUESTÃO DA PESQUISA}

$\mathrm{Na}$ profissão do engenheiro que trabalha com tecnologias avançadas (que é o caso da Tecnologia da Informação), o limite entre a atividade profissional e a atividade de pesquisa é muito tênue: um pesquisador pode estar desenvolvendo um trabalho profissional e um profissional pode estar desenvolvendo uma pesquisa.

A primeira diferença entre o pesquisador e o profissional é com relação aos objetivos:

- $\quad$ o pesquisador está preocupado com as questões básicas da pesquisa: procura identificar se há um padrão no fenômeno estudado, se é possível fazer generalização, procura demonstrar a validade e a capacidade de repetição do que foi feito. A pesquisa tem preocupação com a rastreabilidade para permitir que outros reconstituam a trajetória seguida e examinem o processo de trabalho. O produto, de certa forma, fica em segundo plano. O objetivo é gerar conhecimento - inclusive, se for o caso - demonstrar que algo não dá certo.

- o profissional tem o objetivo muito claro de resolver o problema que está sendo enfrentado, não interessando muito o método a ser utilizado. Normalmente a pressão de tempo faz com que não haja reflexões sobre o tema, a pesquisa bibliográfica (quando há pesquisa bibliográfica) resume-se ao encontro de uma e apenas uma solução pois este é apenas um ponto a ser resolvido dentro de um contexto com muitos outros problemas a serem resolvidos. Muitas outras coisas precisam ser feitas e não há tempo para digressões. 
Um pesquisador que faz um projeto que não dá certo cumpriu seu papel, demonstrando que não dá certo. O profissional que realiza um projeto que não dá certo, precisa consertar e achar outra forma de resolver o problema.

Agora, por outro lado, um profissional que trabalha em uma organização, na área de desenvolvimento de produto, muitas vezes denominada P\&D, Pesquisa e Desenvolvimento, realiza -talvez sem saber- atividades muito similares às atividades de pesquisa acadêmica, o que torna importante que ele conheça os métodos de pesquisa adequados a serem aplicados e qual sua diferença em relação a projetos rotineiros, sem nenhum tema desconhecido.

Na realidade, o que foi denominado projeto rotineiro, é assim considerado hoje, mas um dia certamente foi objeto de pesquisa, pois se tratava de um conhecimento novo, avançado na época de sua criação. Ao ser tal conhecimento detalhado, desdobrado em partes fáceis de serem manipuladas, de tal forma que o conhecimento de "como fazer" torna-se comum, uma "commodity", e pode ser encontrado em livros ou manuais técnicos. A pesquisa de Trindade (2006) detalha bem a relação entre o conhecimento que se encontra em qualquer lugar e o conhecimento específico de um ambiente de trabalho. Talvez uma evidência desta evolução do conhecimento avançado tornar-se comum, "commodity", está nas ciências básicas: o que aprendemos nas escolas hoje é a condensação, a estruturação de muitas pesquisas realizadas pela humanidade há muitos anos atrás. Um exemplo que muito impressionou este Autor foi aprender que a numeração base 10 e a notação posicional dos números provocaram uma evolução enorme na forma de realizar cálculos, operações aritméticas simples, pois, esses mesmos algoritmos (que para nós hoje são óbvios e intuitivos) eram praticamente impossíveis de serem desenvolvidos, por exemplo, com algarismos romanos (Boyer, 1974).

O escopo das pesquisas realizadas por este Autor é contribuir para o desenvolvimento de métodos e processos para projetos de Tecnologia da Informação, visando obter sistemas com a qualidade desejada, no preço e no custo planejados. Este escopo será justificado adiante. 


\section{ENGENHARIA DE SOFTWARE}

Os sistemas de computação começaram a existir nos anos 50 e 60 (PRESSMAN, 1987). Nessa época, a preocupação maior era com o hardware, pois além de ser muito mais caro que o software, possuía muitas limitações. A primeira manifestação da necessidade e de transformar a programação de arte para ciência (ou engenharia) foi publicada numa carta ao editor por Bauer, Juncosa e Perlis (1959):

"Para que a atividade de processamento eletrônico de dados se torne uma parte importante da pesquisa e do desenvolvimento, uma mudança no caráter da programação deve ser efetuada no sentido de transformá-la de arte em ciência".

Postley (1960), em sua carta ao editor, também reclamou que as publicações da $\mathrm{ACM}^{1}$ não estavam atendendo as necessidades desses novos profissionais que estavam surgindo na área de processamento de dados comerciais (business data processing). Relatava que na SAE - Sociedade dos Engenheiros Automotivos existia uma representação desses profissionais nos respectivos campos de atuação e, no entanto, as publicações da ACM não tinham foco similar, mas sim muito acadêmico. Essa reclamação tratava da falta de pesquisas na área de processamento de dados não de como fazer algoritmos para resolver um problema, mas a falta pesquisas voltadas para responderem a questões do tipo "Quais são os problemas organizacionais que impedem 0 progresso da automação no gerenciamento?" Por que? "O que poderia ser feito sobre isso?" Porque? Interessante observar que esse espaço até hoje não foi ocupado pela ACM, a mais antiga associação na área de computação! Foi ocupado pelos pesquisadores da área de gestão e portanto quem estuda esses temas são da área de administração e engenharia de produção e não de computação.

A Engenharia de Software é a disciplina da engenharia que se ocupa de todos os aspectos da produção de software (SOMMERVILLE,2003). Foi em uma conferência da NATO (North Atlantic Treaty Organization ou OTAN em português) em 1968 que nasceu a Engenharia de Software em virtude dos problemas que estavam ocorrendo com a proliferação de software pelo mundo (BAUER,1969). A década de 70 foi a transição onde começou o reconhecimento da importância do software. Segundo

\footnotetext{
${ }^{1}$ ACM - Association for Computer Machimery - primeira associação na área de computação
} 
Knuth (1974) foi em 1970 que foram dados os primeiros passos para "transformar a arte de programar em uma ciência". A rápida expansão da informática em aplicações comerciais visando automação de tarefas administrativas acabou produzindo uma série de pesquisas para avaliação dos efeitos desta expansão nos processos de produção industrial e no papel do trabalhador e seu processo de trabalho (TAVARES, 1983).

Pode-se observar como a Engenharia de Software é uma disciplina recente pois, conforme já relatado, em 1960 reclamava-se da falta de pesquisas nessa área e em 1968 foi formalmente criada ou batizada esta disciplina. Esses 40 anos comparados com outras áreas como a engenharia civil, mecânica, entre outras, mostra quão "jovem" é a Engenharia de Software.

Para a implementação de um sistema de informação é necessário entender o problema a ser resolvido, o domínio da aplicação. Definida e compreendida a necessidade do cliente, passa-se a escolher e estruturar uma solução, ou seja, definir o sistema de tecnologia da informação a ser construído. A grande limitação dos computadores em termos de velocidade de processamento e capacidade de memória tanto de trabalho como de armazenamento, levaram à formação de profissionais competentes em modelagem e construção de algoritmos, enfim, com grande conhecimento em computação, métodos e técnicas de programação. Isto deixou em segundo plano a preocupação com o domínio da aplicação, ou seja, aprofundamento na definição e compreensão da atividade para a qual o sistem a se destina.

\section{II.1 ANÁLISE ESTRUTURADA}

Os primeiros métodos de projeto eram centrados em dados e as operações com eles realizadas: é a análise estruturada que procura identificar os dados existentes nas operações do mundo real, estruturá-los e representar seu fluxo e operações (modelo de dados e fluxo de dados). Segundo Pressman (1987), contribuíram para a elaboração dessas "metodologias" ${ }^{2}$ autores como Jackson, Trembley, Horowitz,

\footnotetext{
2 Metodologia era o termo utilizado na época para designar o método de análise e de projeto. Hoje esses métodos fazem parte do "processo de projeto" que envolve, além dessas técnicas, outros passos como o gerenciamento de projeto.
} 
Wulf, Guttag, Warnier e Orr. Acrescente-se a estes, autores como Tom deMarco (1989), Gane e Sarson (1983) que aperfeiçoaram e disseminaram a análise estruturada. Nesse método já havia a preocupação de separar o trabalho de análise (definindo o que o sistema fará) do trabalho de projeto (definindo como o sistema fará), ou seja, separa a concepção da implementação. Comparando com a abordagem de hoje, denominada análise de negócios (a ser discutida mais a frente nesse trabalho), a análise ainda estava muito atrelada à solução do problema e não à descrição do domínio da aplicação.

É importante lembrar que a análise estruturada consolidou-se como um bom método de análise. Percebeu-se, entretanto, que a utilização deste nas organizações e empresas que desenvolviam as aplicações reais, era muito baixa. Surgiu a Crise do Software. A origem desta crise pode ser entendida como uma defasagem entre a demanda pelo desenvolvimento de novas aplicações e a respectiva capacidade de oferta, a falta de uso dos métodos existentes, somado à complexidade de sua aplicação quando não são usadas ferramentas de apoio (muitos diagramas, muito detalhe e dificuldade de manter a documentação atualizada) (PRESSMAN, 1987; PRESSMAN, 2006; SOMMERVILLE,2003).

\section{II.2 ORIENTAÇÃO A OBJETOS}

A orientação a objetos $(\mathrm{OO})$ é o método de análise que substitui a estruturada. A origem da orientação a objetos remonta da década de 70 quando foram desenvolvidas pesquisas voltadas a simulação e prototipação como Simula e Smaltalk (PRESSMANN, 1987). Nessa época, a pouca capacidade dos sistemas computacionais, a falta de ferramentas de apoio a projeto e a falta de métodos mais operacionais de análise e projeto, não tornaram a $\mathrm{OO}$ uma técnica utilizada na prática. Na década de 90 , diversos autores procuraram contribuir para um melhor detalhamento das técnicas para a análise e projeto orientados a objetos. Uma série de métodos se sucederam (DeMARCO, Tom, 1989); (SHLAER, S; MELLOR, Stephen J. 1990); (SHLAER, S; MELLOR, Stephen J. 1992); (COAD, Peter; YOURDON, Edward, 1992) ; (YOURDON, 1994); (BOOCH, Grady, 1996); (FOWLER, Martin; SCOTT, Kendall , 1997) e cada autor apontava falhas nos métodos e representações existentes, e propunham novas soluções até que, 
finalmente, foi fundada a OMG, que acabou consolidando a UML - Unified Modeling Language - como uma representação universal para a orientação ao objetos.

Diferentemente da análise estruturada, na orientação a objetos o projetista pensa em termos de "coisas" (objetos) ao invés de operações ou funções. O sistema em funcionamento é constituído de objetos que interagem entre si e cada um mantém o controle de seu estado de funcionamento, realizam internamente as funções e operações, conforme as solicitações de outros objetos (SOMMERVILLE, 2003).

\section{II.3 A VISÃO DO PROCESSO DE SOFTWARE}

$\mathrm{Na}$ década de 80 surgiu, de uma forma mais clara, o conceito de processo de software proposto por Humprey (1989). A Figura 2 identifica os três componentes de um processo: pessoas, ferramentas e procedimentos (PAULK et al., 1995, p. 9). SEI - Software Engineering Institute - define particularmente processo de software (HUMPHREY, 1989 e 1995, p. 441-470; PAULK et al., 1995; PESSÔA e SPINOLA, 1996), aplicando a definição acima para as atividades específicas de desenvolvimento de software:

"O processo de software pode ser definido como um conjunto de atividades, métodos, práticas, e transformações que as pessoas empregam para desenvolver e manter software e os produtos associados (ex. planos de projeto, documentos de projeto (design), código, casos de teste, e manual do usuário)." (PAULK et al., 1995, p. 8)

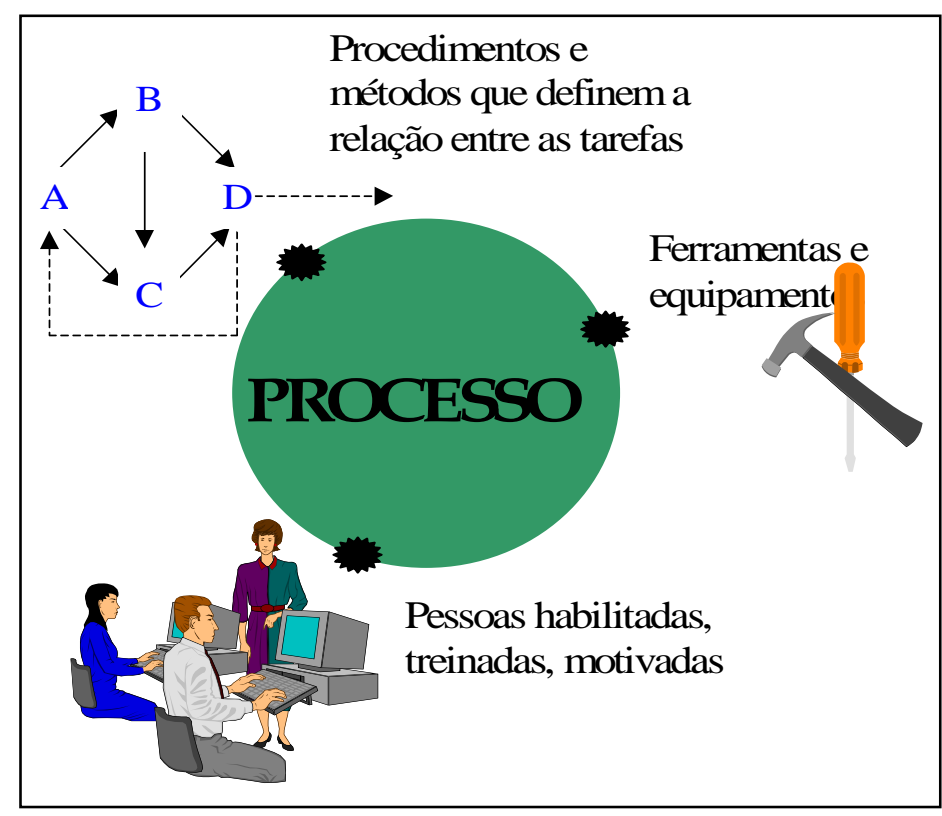

Figura 2 - Processo e seus componentes (PAUK, 1995) 
Essa abordagem representa uma visão mais abrangente do que aquela que existia nos métodos de análise (tanto estruturada como OO). Trata de uma visão do processo do ciclo de vida, onde se estabelecem atividades para cada uma das fases do projeto de software (PAULK,1995; CMMI,2002). Por exemplo, são estabelecidas atividades para os processos de gerenciamento de requisitos, planejamento de projeto, gerenciamento da configuração, entre outros. Esta visão depois foi consolidada na Norma NBR/ISO 12207 (ABNT,1997; ISO,2008).

Nessa linha de pensamento de se criar processos para cada uma das atividades pertinentes ao processo de desenvolvimento de software, o IEEE ${ }^{3}$ criou uma série de Normas. Essa abordagem, entretanto, tornou o processo de desenvolvimento de software uma tarefa muito pesada, de alto custo de difícil aplicação. Utilizavam tais processos os grupos voltados à elaboração de aplicações mais críticas, como o caso da NASA e outras similares mas em mercados de alta concorrência como a área financeira e aplicações administrativas onde o risco de bugs não é tão crítico, nunca chegaram a adotar completamente tais abordagens

\section{II.4 O MOVIMENTO ÁGIL}

Conforme relatado por Sommerville (2003) em 2001, Kent Beck e outros 16 especialistas em desenvolvimento de software elaboraram a um documento que ficou conhecido como o Manifesto para o desenvolvimento ágil de software. Foi declarado:

\footnotetext{
Estamos descobrindo melhores formas de desenvolvimento de software fazendo e ajudando outros a fazê-lo. Por meio desse trabalho passamos a valorizar:

- Indivíduos e interações ao invés de processos e ferramentas.

- Software funcionando ao invés de documentação abrangente.

- Colaboração do cliente ao invés de negociação de contratos.

- Resposta a modificações em vez de seguir um plano.
}

3 IEEE Institute of Electrical and Electronic Engineers - associação da área elétrica (e de computação) que possui muitas publicações acadêmicas e normas técnicas 
Este documento foi uma "reação" ao movimento que vinha crescendo dos métodos orientados a processo como o $\mathrm{CMM}$ e o $\mathrm{CMMl}$ que exigem, particularmente dos programadores uma disciplina de trabalho quase Taylorista (os programadores reclamavam do excesso de rigidez e burocracia desses processos).

Vale lembrar que no final dos anos 70 e início dos anos 80 os métodos de análise e projeto eram valorizados pelos profissionais devido à pouca disponibilidade dos computadores. Uma submissão do programa para ser "rodado" no computador ocorria uma ou poucas vezes ao dia, fato que forçava o analista/programador a preparar muito bem sua tarefa. Portanto era feita uma boa documentação, antes do programa eram elaborados fluxogramas, entre outras tarefas de verificações manuais. A grande disseminação do $P C$ tornou $O$ acesso à máquina $e$, particularmente ao ambiente de programação, muito fácil, fato que levou aos profissionais deixarem de lado uma maior preparação dos programas no momento de codificar passando a realizar a tarefa por tentativa e erro, deixando de lado a disciplina de "fazer certo da primeira vez". Por um lado surgiu o movimento das empresas criarem processos de trabalho mais rígidos (como o $\mathrm{CMMI}$ ) o que provocou esse manifesto.

Desses métodos, à primeira vista antagônicos com os modelos de processo, surgiram propostas interessantes como o Extreme-Programming, Scrum entre outros (SOMMERVILLE, 2003; RODRIGUES SILVA, 2005).

\section{II.5 ENGENHARIA DA INFORMAÇÃO}

Martin (1991) foi o criador do termo Engenharia da Informação. Relata que na década de 70 criou esse termo para ressaltar a importância de organizar a informação na empresa como um todo, particularmente no sentido de estruturá-la com uma abordagem top-down (de cima para baixo), diferente da forma com que eram realizadas naquele momento com modelos de dados criados isoladamente na forma bottom-up (de baixo para cima).

A proposta da Engenharia da Informação é realizar um levantamento minucioso de todos os dados e informações necessárias para a cooperação da empresa, identificados a partir da alta administração, seguindo para os níveis operacionais, 
elaborando diagramas e fluxos de informações, até se chegar a um modelo consolidado (MARTIN, 1991). Cita que a Engenharia da Informação possui 4 fases: estratégia, análise, projeto e construção, conforme ilustrado na Figura 3

Martin (1991) estabelece como objetivos da Engenharia da Informação:

- investigar como o uso da tecnologia pode proporcionar à empresa vantagens sobre a concorrência.

- estabelecer metas para a empresa e fatores críticos de sucesso.

- usar a análise dos fatores críticos de sucesso para orientar a empresa sobre como atingir melhor os seus objetivos.

- determinar quais informações podem fazer com que os gerentes desempenhem melhor o seu trabalho.

- priorizar a construção de sistemas de informação em termos de seus efeitos globais na base.

- criar um modelo global da organização, seus processos e informações.

- subdividir o modelo global em áreas de negócios, formando a base de análise das áreas de negócio (nível 2 da pirâmide).

- determinar quais as áreas de negócio a serem analisadas em primeiro lugar.

- permitir à alta administração visualizar a sua empresa em termos objetivos, funções, informações, fatores críticos de sucesso e estrutura organizacional

Observar que esta é uma abordagem sistêmica de necessidade de informação vista pelo lado do usuário e, para tanto utiliza o modelo dos Fatores críticos de Sucesso de Rockart (1979). A definição do modelo de dados é somente estabelecida na fase de análise onde são consolidadas as necessidades de informação.

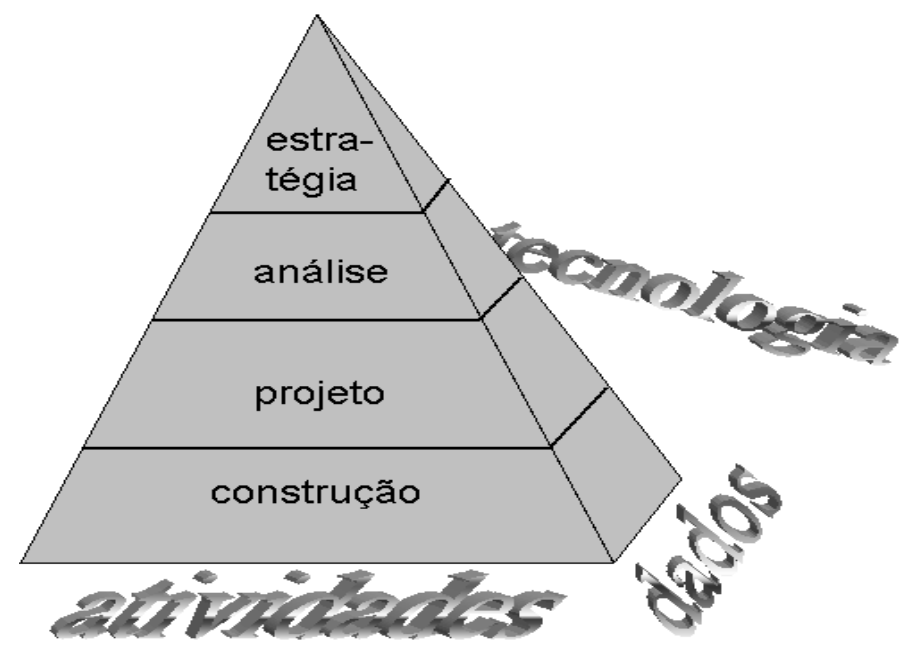

Figura 3 - Fases da Engenharia da Informação (adaptado de Martin,1991) 
As 4 fases ocorrem no tempo (Figura 3) e a pirâmide de etapas sucessivas top-down possuem 3 perspectivas a serem trabalhadas: dados, atividades e tecnologia (MARTIN, 1991; FELICIANO, 1988).

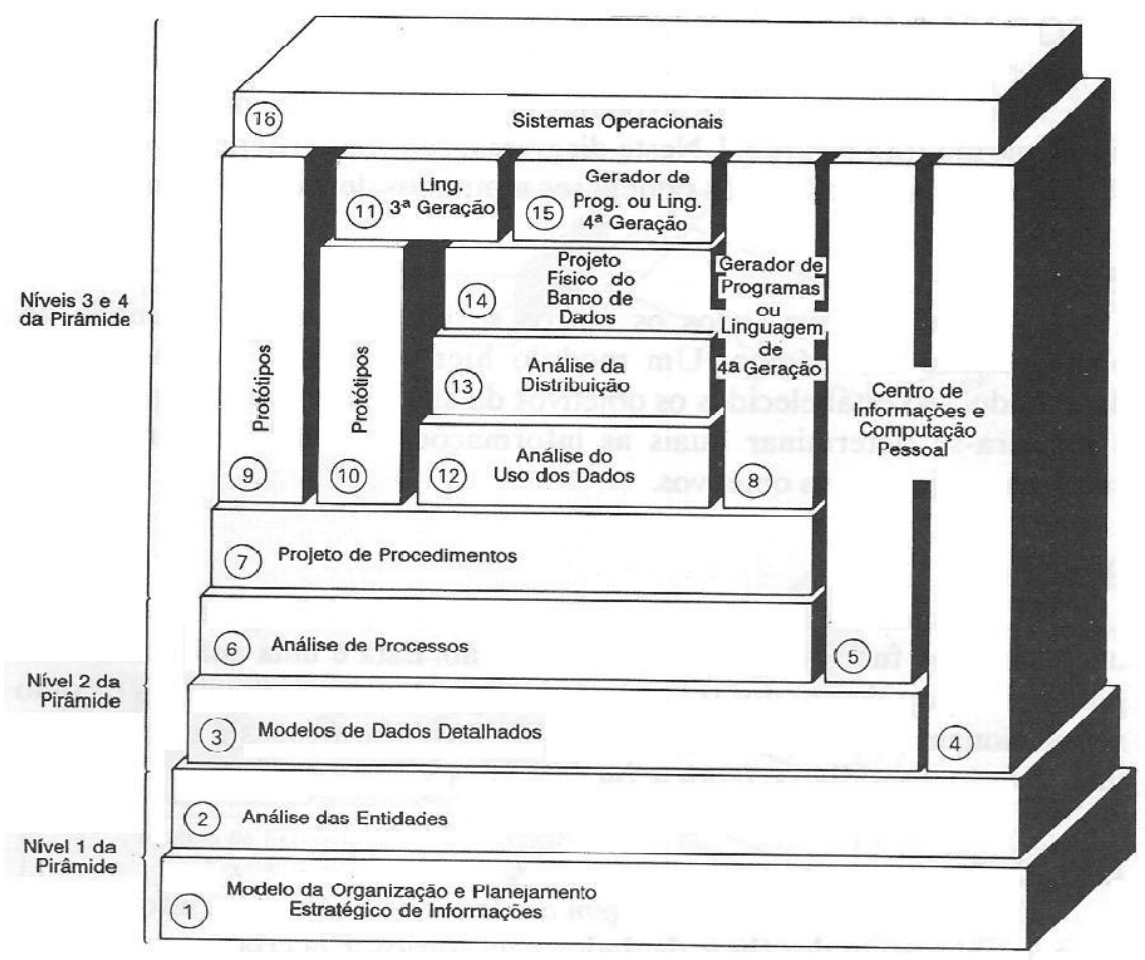

Figura 4 - Blocos que compõem a Engenharia da Informação (Martin, 1991).

A Figura 4 mostra como está estruturada a Engenharia da Informação. Do lado esquerdo estão representadas as fases, demonstrando que as atividades iniciam-se nos blocos 1 e 2 (abaixo) e evoluem para os demais blocos que representam as diversas tecnologias. Vale observar também que a abordagem proposta fazia uso intensivo de geradores de quarta geração, prototipação, as tecnologias mais avançado na época.

Este método é similar ao utilizado nos levantamentos realizados para a implantação atualmente dos sistemas ERP, com a diferença que hoje o levantamento não é apenas das informações, mas também dos processos de trabalho. 
Outro aspecto interessante abordado por Martin (1991) é a proposta do uso intensivo de ferramentas $\mathrm{CASE}^{4}$, por ele chamada de I-CASE (integrada) que envolve todo o ciclo de vida: para representar o fluxo das informações, modelo de dados, dicionário de dados, diagrama de fluxo de dados, geração automática de código e testes, além de manter a rastreabilidade da documentação. Afirma claramente que sem um sistema que automatize o desenvolvimento e a manutenção dos sistemas de informação é muito difícil manter o sistema com qualidade. A ferramenta apresentada é o IEF da Texas ${ }^{5}$ que é utilizada até os dias de hoje com outro nome comercial.

A desvantagem da proposta realizada por Martin (1991) é a demora no levantamento e na implantação dos sistemas (a proposta é levar aproximadamente seis meses somente na fase de levantamento de informações), além do alto custo da ferramenta integrada.

A importância de Martin (1991) foi o fato de ter sido o precursor da Engenharia de Requisitos e da Análise de Negócios, utilizadas atualmente.

\section{II.6 A CULTURA DA TOLERÂNCIA}

Nos itens anteriores, foi apresentado de forma resumida o esforço realizado nesses mais de 40 anos de Engenharia de Software para se conseguir organizar os processos de trabalho e atender às necessidades dos usuários na construção de Sistemas de Informação.

Inicialmente havia uma restrição muito grande com relação ao que era possível ser automatizado e devido às grandes limitações do hardware e aproximadamente na década de 80 houve uma queda expressiva no preço do hardware fazendo com que o software venha se tornando mais caro nos projetos e tenha se transformado no gargalo para atendimento às demandas das organizações. Nos dias de hoje, apesar

\footnotetext{
${ }^{4}$ Ferramenta CASE - Computer Aided Software Engineering é o conjunto de aplicativos que automatizam a facilitam a atividade de projeto e desenvolvimento de software

${ }^{5}$ IEF é uma ferramenta CASE desenvolvida por James Martin
} 
do baixo custo do hardware e da disponibilidade de novas tecnologias, o desafio continua sendo similar ao de sempre: como desenvolver software com a qualidade necessária, no tempo e no custo adequados?

A proliferação em massa das aplicações dos anos 70 para cá piorou a situação identificada na crise de software: a alta demanda por novas aplicações e a rápida obsolescência das aplicações existentes. Portanto o mercado não suportava mais prazos de desenvolvimento de aplicações com duração e 2 a 3 anos devido à necessidade de uso do próprio sistema e da dinâmica de alterações dos requisitos de negócio durante o desenvolvimento do projeto. Isso forçou a Engenharia de Software buscar novas soluções como os ciclos de vida não em cascata mas, incrementais, e evolucionários (SOMERVILLE, 2003; PRESSMAN, 2006).

Ao mesmo tempo foi criada a cultura da tolerância com relação à qualidade de software: todos conhecem os defeitos que alguns (ou muitos) aplicativos de software apresentam e, mesmo assim, as pessoas convivem com a sua utilização. Weinberg (1994) cita um caso onde um jogo de xadrez tinha alguns "bugs" mas era um excelente jogo e nem por isso era considerado de baixa qualidade.

Evidentemente há situações de aplicações críticas onde não há tolerância a falhas, ou seja uma falha pode provocar perdas financeiras ou até humanas. Para esses casos sempre foram seguidas as boas práticas da engenharia de software. No entanto isso possui um custo que não é baixo e talvez o maior deles não seja financeiro, mas sim de prazo (o concorrente lança um produto pior, mas lança antes!). Mesmo em mercados onde havia uma preocupação muito grande com relação à qualidade técnica também houve um relaxamento com relação a tolerar falhas e defeitos de funcionamento. O melhor exemplo é o celular: um indicador da qualidade da comunicação é a continuidade (sem interrupção) mesmo com a movimentação do assinante (chamador ou chamado). Esse conceito definitivamente não é atendido. Os celulares possuem funções cada vez mais sofisticadas mas a função básica de comunicação contínua não é atendida! Aparentemente nem a Anatel considera isso importante pois não há sanções com relação a chamadas interrompidas! É a cultura da tolerância: o novo modelo desse produto que apresenta um defeito provavelmente não mais apresentará na próxima versão, é o que pensam os usuários! 


\section{II.7 O PERFIL DO PROFISSIONAL DE TI}

As mudanças ocorridas nesses 40 anos de Engenharia de Software foram muito grandes e talvez uma das maiores, conforme já comentado, tenha sido a passagem de uma situação liderada pela tecnologia para uma situação liderada pelo negócio. Explicando melhor, nas decisões para escolha pela implantação de um sistema de $\mathrm{TI}$, quem tomava as decisões mais importantes era o responsável pela tecnologia pois, dadas as grandes limitações existentes antigamente, somente um técnico especialista seria capaz de dizer o que é e o que não é possível implementar. Hoje a situação é exatamente inversa pois, em princípio, a tecnologia oferece uma grande gama de opções e a escolha é aquela que dê maior retorno para o negócio e não mais aquela que dá para fazer. Isso criou uma geração de profissionais que tinham, inclusive uma postura diferenciada dentro das organizações pois eram pessoas com poder de decisão e, além disso, com conhecimento que poucas pessoas tinham na época. Evidentemente não há aqui qualquer conotação de atribuir maior ou menor valor para esse ou aquele profissional, mas apenas tornar claro de quem é (ou deve ser) a liderança dentro de uma equipe.

O fato desse período ter sido tão curto, de apenas 40 anos, leva a uma questão interessante a ser investigada. Muitos dos profissionais que vivenciaram essa primeira fase da $\mathrm{TI}$ estão ainda em atividade profissional, muitas vezes ocupando hoje posições de comando. Se essas pessoas continuam com a mesma postura, tomando decisões sem analisar os impactos na organização, sem avaliar o retorno esperado, estarão contribuindo com o "paradigma da produtividade", que é uma abordagem questionadora sobre os investimentos em $\mathrm{TI}$ sem avaliar os benefícios diretos para o negócio (LAURINDO, 2002). Um corolário também identificado, que vai ser detalhado neste documento no capítulo referente ao analista de negócio, é a questão da formação do profissional de TI. 


\section{A CRIAÇÃO DO AMBIENTE DE PESQUISA}

Conforme já citado anteriormente, o primeiro trabalho desenvolvido pensando na aplicação dos conceitos da engenharia de produção à engenharia de software foi o de Frontini (1988).

A idéia de Fábrica de Software não é nova, pois na conferência onde foi criada a Engenharia de Software (BAUER,1969) houve um comentário de Bennett onde ele denominou Fabrica de software um ambiente de produção controlado por máquinas. $\mathrm{Na}$ verdade estava se referindo ao que hoje é denominado ambiente de desenvolvimento. Interessante observar que nessa mesma conferência também foi discutida a questão de reuso e o desenvolvimento de componentes de software. No sumário é dito:

Eu gostaria de ver catálogos de rotinas, classificados por precisão, robustez, desempenho tempo-espaço, limitações de tamanho e um roteiro de parâmetros.

É a preocupação com a produção de software com qualidade e a minimização de retrabalho.

\section{III.1 A PRIMEIRA VISÃO DE FÁBRICA DE SOFTWARE}

O primeiro passo dado por Frontini (1998) para propor uma Fábrica de Software foi fazer uma análise dos diversos tipos básicos de produção existentes na engenharia de produção, conforme ilustrado Quadro 1, e procurar compreender como o processo de produção de software se enquadra nesse contexto (FRONTINI, 1988; PESSOA, SPINOLA, 2006). 


\begin{tabular}{|c|c|c|c|c|}
\hline \multirow{5}{*}{ 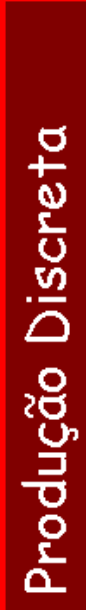 } & \multirow{2}{*}{$\begin{array}{l}\text { O } \\
\text { y } \\
\text { O } \\
\text { E } \\
\text { E } \\
\text { Q }\end{array}$} & pura & Ford modelo " $T$ " preto & grande volume só 1 modelo \\
\hline & & $\begin{array}{l}\text { com } \\
\text { diferenciação }\end{array}$ & Eletrodomésticos & $\begin{array}{l}\text { grande volume } \\
\text { alguns modelos }\end{array}$ \\
\hline & \multirow{2}{*}{$\begin{array}{l}\frac{N}{t} \\
\frac{E}{N} \\
\frac{E}{E} \\
\frac{c}{N} \\
. E\end{array}$} & repetitiva & Móveis & \multirow{2}{*}{$\begin{array}{l}\text { menor volume } \\
\text { de produçãoe } \\
\text { maior volume } \\
\text { de produtos } \\
\text { fabricação em lotes } \\
\text { com diferenciação }\end{array}$} \\
\hline & & sob encomenda & Bens de Capital & \\
\hline & \multicolumn{2}{|c|}{ grandes projetos } & Construção naval, civil & $\begin{array}{l}\text { serviços de longa duração } \\
\text { muitas atividades }\end{array}$ \\
\hline \multicolumn{3}{|c|}{ Fluxo Contínuo } & $\begin{array}{l}\text { Refino de Petróleo } \\
\text { Alto-forno } \\
\text { Tratamento água } \\
\text { Energia elétrica }\end{array}$ & $\begin{array}{l}\text { operações conínuas } \\
\text { de ciclo novo } \\
\text { baixa } \\
\text { intervenção } \\
\text { humana }\end{array}$ \\
\hline
\end{tabular}

Quadro 1- tipos básicos de produção (adaptado de Pessoa, Spinola, 2006)

A primeira divisão é dos processos discretos e contínuos. O fluxo contínuo trata da produção de itens como petróleo, energia elétrica, água para um cidade e não se enquadram no foco deste estudo.

A produção discreta é subdividida em três categorias: a produção em massa, produção intermitente e grandes projetos.

- A produção em massa caracteriza-se pela produção em grandes quantidades de um único produto (em massa pura) ou produtos com pequenas variações (em massa com diferenciação).

- A produção intermitente caracteriza-se pela produção de uma quantidade maior de produtos com um volume menor de itens produzidos. Pode ser intermitente repetitiva quando são produzidos os mesmos produtos em determinados intervalos ou intermitente por encomenda quando são elaborados a partir de um projeto de um produto com posterior fabricação de um ou mais lotes.

- Grandes projetos caracterizam por serem de longa duração, são produtos com atividades bastante diferenciadas. Há uma grande variação na seqüência dos processos ou atividades de produção, e normalmente 
existem muitos processos em um projeto. Projetos são considerados únicos e não se repetem (PMI,2004).

Dentro dessas alternativas, o processo de desenvolvimento de software pode ser enquadrado no tipo de produção grandes projetos, uma vez que o trabalho é desenvolvido sob encomenda e possui muitas atividades. Além disso, cada produto elaborado normalmente é diferenciado e com volume de vendas normalmente baixo. Software vendido em grande volume é denominado software produto e não é esse o foco, uma vez que a reprodução do software é trivial e o projeto de software produto é similar ao software sob encomenda (FRONTINI, 1988).

O objetivo de se pesquisar Fábrica de Software é procurar evoluir do enquadramento grandes projetos para a categoria intermitente sob encomenda ou até em massa com diferenciação. Essa evolução visa identificar novos recursos, métodos e processos para que se consiga obter as vantagens da manufatura, ou seja, ganhar produtividade e reduzir o tempo de passagem. Essa transformação é possível, pois ao analisar as atividades realizadas em cada um dos projetos, estas são similares e, em geral, não dependem do software específico que está sendo produzido, o que varia é o conteúdo. Portanto a analogia com a fábrica faz sentido (FRONTINI, 1988).

Frontini (1988) também discutiu os aspectos organizacionais em uma fábrica de software e concluiu que a abordagem de grupos semi-autônomos seria adequada para esta aplicação, mas considera que a questão fica ainda em aberto.

Frontini (1988) ao discutir sobre produtividade, considera importante o uso de ferramentas CASE para automatizar ao máximo as atividades.

O processo para produção de software no trabalho de Frontini (1988) envolvia algumas técnicas específicas com base na análise estruturada, o método consolidado na época. Também utilizava alguns métodos propostos por empresas de consultoria e utilizava a infra-estrutura existente na ferramenta CASE. Finaliza o trabalho concluindo que esta abordagem contribui para a solução da crise de software.

Em resumo, os elementos propostos por Frontini (1998) para a Fábrica de Software são os seguintes: 
- estabelecimento de um organograma, identificando, segregando e operacionalizando funções bem definidas (que na empresa estudada estavam pouco definidas e difusas)

- transformação do processo produtivo do tipo grandes projetos em produção em massa com diferenciação através da divisão do trabalho, e utilização de ferramenta CASE para permitir integração entre as tarefas, padronização do processo de desenvolvimento e automação das atividades

- consideração dos aspectos humanos na implementação de novas técnicas, ferramentas e metodologias.

- adoção do grupo semi autônomo como forma de organização do trabalho

- adoção de abordagens distintas na fase de codificação para sistemas estáticos e sistemas que constantemente sofrem alterações.

\section{III.2 O MODELO DE REFERENCIA DE FÁBRICA DE SOFTWARE DO GTI}

As primeiras discussões sobre Fábrica de Software visavam procurar entender qual seria o escopo do estudo, qual o objeto de pesquisa. O paradigma tradicional para a produção de software é a visão de projeto, ou seja, cada software a ser criado é uma empreitada única, com início, desenvolvimento e término, conforme definido no PMBoK (PMI, 2004). O que o grupo de pesquisa desejava era aplicar os conceitos da engenharia de produção à produção de software, ou seja, transformar uma atividade vista como única em uma atividade repetitiva, procurando observar como a manufatura tratava esse tema e aplicar esses conceitos da melhor maneira possível. Muitas iniciativas nesse sentido já existiam, entre as quais pode-se citar o reuso a definição de processos criada pelo SEI. Dessa discussão foram definidos os objetivos específicos do eLab-TI (Spinola, 2008):

1. Aplicar modelos de processo e metodologias de desenvolvimento no ambiente de fábrica e avaliar seus resultados.

2. Descrever um processo padrão de desenvolvimento de software para fábricas de software.

3. Identificar e estabelecer diretrizes para os processos críticos de uma fábrica. 
4. Estabelecimento de um processo de medição de processo para fábrica de software.

5. Desenvolver métodos e técnicas próprios para o ambiente de fábrica, fortemente calcados em automação e reuso.

A partir dessas premissas foi elaborado um modelo de referência de Fábrica de Software, representado na Figura 5. Esta figura representa na parte superior o fluxo do processo de fabricação como um todo. Na parte inferior foi criado o centro de residência em software, responsável pelas questões de treinamento da equipe e capacitação profissional.

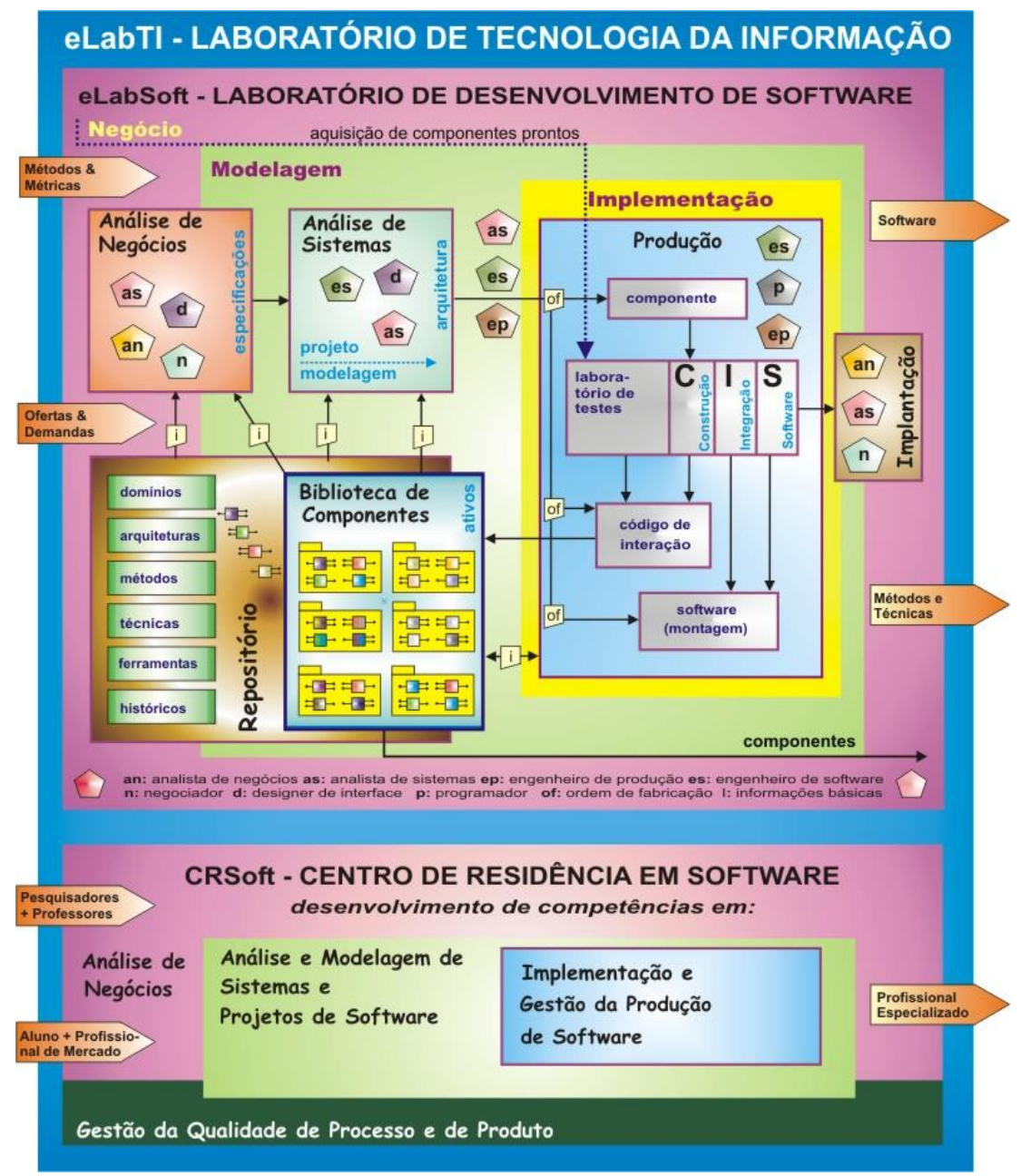

Figura 5 - Modelo de referência da Fábrica de Software (autor: GTI)

O processo da Fábrica foi organizado da seguinte forma: 


\section{III.2.1 Análise de Negócio}

Atividade responsável por entender o ambiente de negócios (Figura 1) e identificar oportunidades para a TI auxiliar a organização a melhorar seu negócio, tanto do ponto de vista de eficácia como de eficiência, usando a abordagem de alinhamento estratégico proposta por Laurindo (2000; 2002). Essas atividades são realizadas seguindo os processos estabelecidos no repositório.

- Entradas: necessidade de negócio, métodos e medições.

- Envolvidos com essa atividade estão an=analista de negócios, as=analista de sistema, $d=$ projetista de interface e $\mathrm{N}=$ negociador.

- Resultado: especificação que descreve a visão do cliente descrita na linguagem do cliente (Juran,1991).

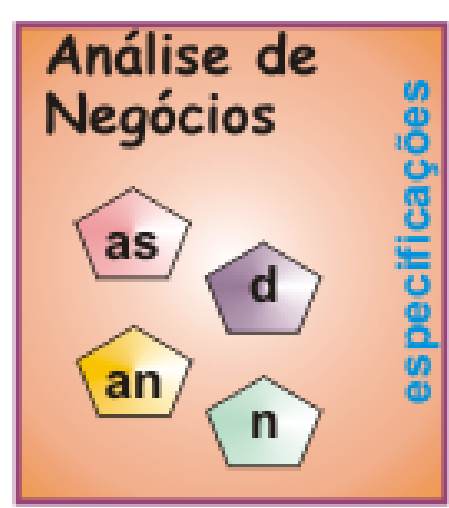

Figura 6 Análise de Negócio

\section{III.2.2 Análise de Sistemas}

Atividade de concepção da solução para operar no ambiente alvo (Figura 7), ou seja, considerando os aspectos da realidade da organização com relação à infraestrutura existente, técnica e de processos (i=recebe informações do repositório). $O$ primeiro passo é definir a necessidade do cliente na linguagem interna da organização (Juran, 1991) e depois estabelecer a arquitetura da solução.

- Entrada: especificação da análise de negócio

- Envolvidos com essa atividade estão as=analista de sistema, es=engenheiro de software e $d=$ projetista de interface.

- Resultado: arquitetura da solução e modelagem do projeto.

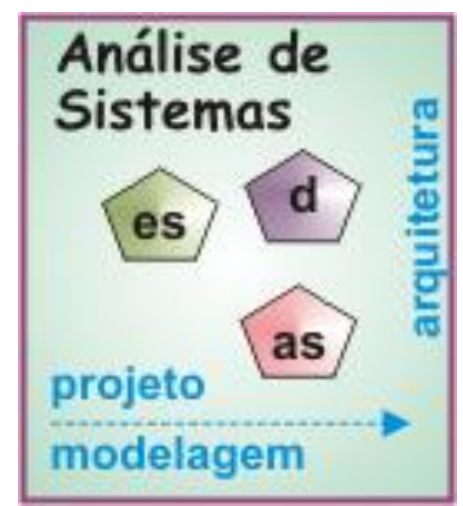




\section{III.2.3 Implementação}

Trata-se da construção do software, ou seja, a codificação (Figura 8). Na concepção da Fábrica, como os projetos são altamente baseados em reuso, os novos produtos são construídos a partir do repositório existente, ou seja, são "montados" à imagem e semelhança da indústria automobilística que monta o veículo (montadora). Componentes são adquiridos externamente, retirados do repositório ou construídos no projeto (bloco componente). Uma linha de atividades realiza os testes (laboratório de testes), construção de componentes (C), integração (I) até chegar ao software (S) através das atividades de montagem do produto final de software. Uma vez obtido o produto, este está pronto para implantação no ambiente definitivo. Há uma troca de informações com o repositório para armazenar as informações sobre o processo, medições do projeto e armazenamento de componentes e produtos para a biblioteca de componentes.

- Entrada: of=ordem de fabricação, ou seja a especificação do produto a ser montado (a idéia da montadora) e dos componentes a serem construídos (novos)

- Envolvidos com essa atividade estão as=analista de sistema, es=engenheiro de software, ep=engenheiro de projeto e $\mathrm{p}=$ programador.

- Resultado: software pronto para instalar, informações sobre o processo e projeto e componentes para biblioteca.

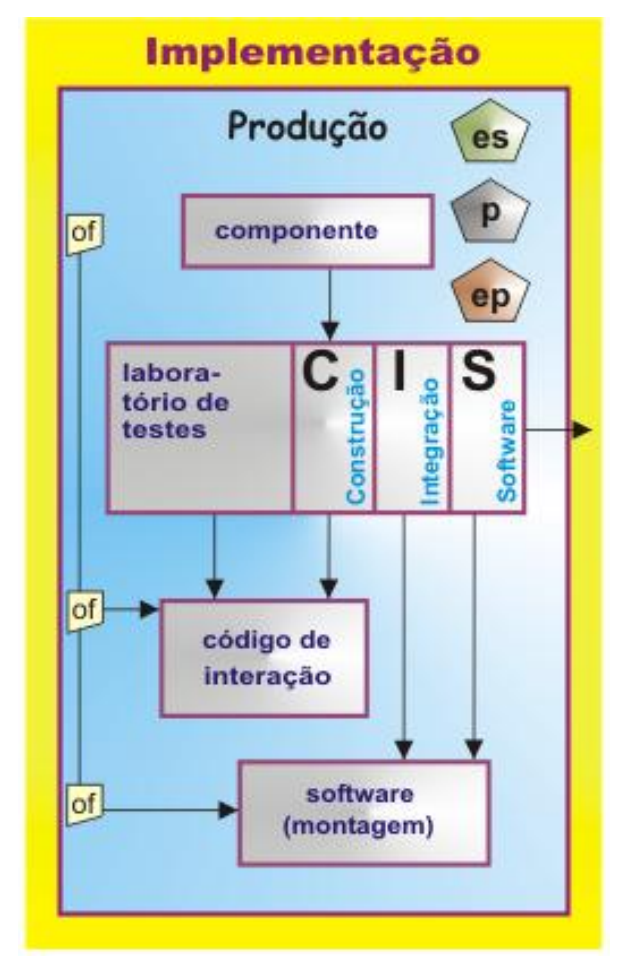

Figura 8 - Implementação 


\section{III.2.4 Repositório}

O repositório é o acervo da Fábrica de Software (Figura 9) - os ativos da organização em linguagem do $\mathrm{CMMI}$ ). Nele estão armazenadas as informações sobre o campo de aplicação, arquiteturas métodos, técnicas, ferramentas e dados históricos dos projetos e rastreabilidade dos produtos.

Além disso, o repositório possui a biblioteca de componentes que é depositária dos projetos realizados e dos componentes que podem ser utilizados para projetos novos. Esses componentes poderão ser também comercializados.

O repositório não é uma etapa do processo, mas possui um processo interno rígido de gestão da configuração de todo o acervo.

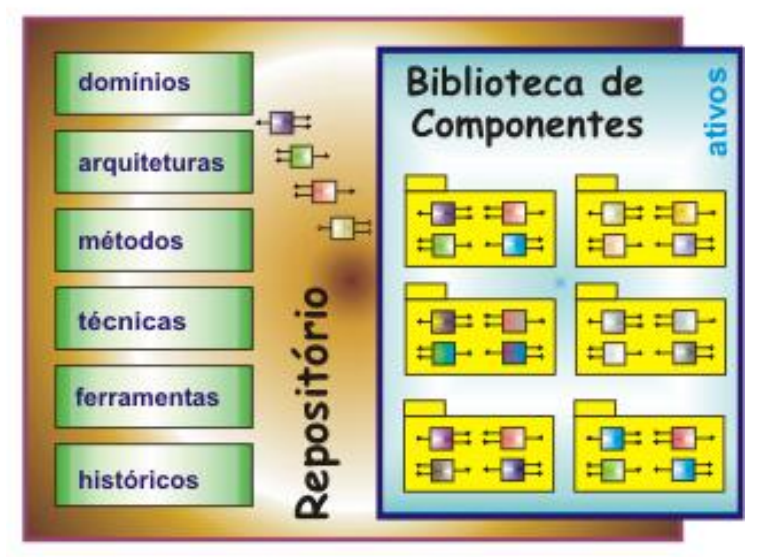

Figura 9 - repositório

\section{III.2.5 Implantação}

A implantação é uma atividade realizada fora da Fábrica de Software e trata da colocação do software em funcionamento em seu ambiente definitivo de produção.

- Entrada: software pronto, após montagem em fábrica.

- Envolvidos com essa atividade estão an=analista de negócio, as=analista de sistema e $n=$ negociador

- Resultado: software instalado e operando no ambiente de produção

\section{III.2.6 Disseminação}

Os tópicos acima descreveram as atividades e processos diretamente ligados à estrutura de uma Fábrica de Software. Há, entretanto, outras atividades que envolvem mais de uma Fábrica de Software e que foram tema de outras pesquisas.

Uma delas é o repasse de uma Fábrica de Software para outra unidade. Isto pode ocorrer em empresas que abrem filiais em outras localidades e precisam replicar 
seus processos de desenvolvimento. Este é o tema de uma das pesquisas realizadas (FABRI, 2007).

O trabalho cooperativo entre Fábricas de Software, partilhando o desenvolvimento de um mesmo software é denominado DDS- Desenvolvimento Distribuído de Software, também é tema de pesquisa realizada (L'Erário, 2009).

\section{III.2.7 Residência em Software}

A residência em software surgiu através de uma demanda do MCT - Ministério da Ciência e Tecnologia. Trata-se de uma necessidade de identificada pelo governo como uma forma de atender a uma demanda em nível mundial, de profissionais que atuam em tecnologia da informação. A proposta deste programa seria a realização de atividades profissionais para estudantes de graduação que teriam a oportunidade de, quando se formarem, já tenham experiência profissional, à semelhança do que ocorre na área da medicina. Também este programa poderia ser utilizado para a reciclagem de profissionais mais experientes.

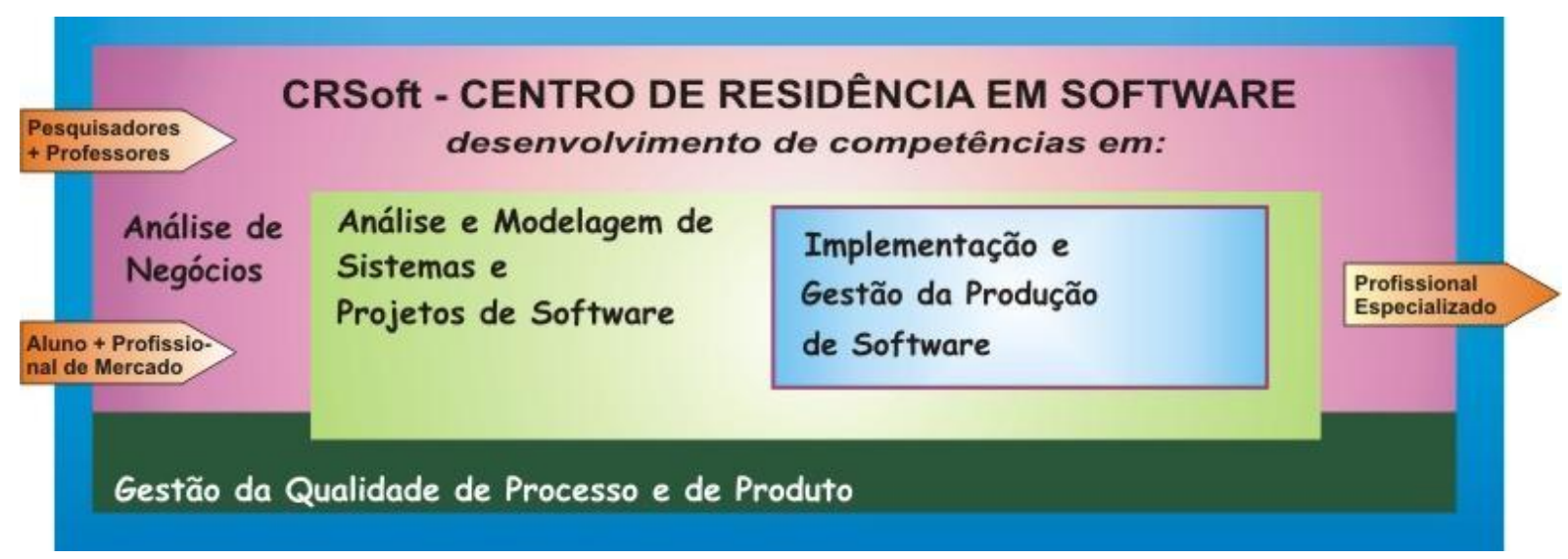

Figura 10 - Residência em Software

Dessa forma, foram elaborados algumas propostas de treinamento, para formação dos diversos tipos de profissionais que atuam na área. A concepção da estrutura de treinamento versus atividades dentro da fábrica de software, os aspectos de aprendizagem e a questão da preservação do conhecimento nesse ambiente que normalmente é de alta rotatividade, motivou o desenvolvimento de pesquisas nessa área. 


\section{III.2.8 O mapa das pesquisas realizadas}

Da Figura 11 até a Figura 13 apresentadas a seguir, pode-se observar um quadro geral das pesquisas orientadas por este Autor e em que pontos do modelo de referência da fábrica de software as mesmas se enquadram. As pesquisas serão apresentadas conforme o tipo de assunto abordado. É importante lembrar que há diversas outras pesquisas desenvolvidas sob a orientação do Professor Associado Mauro de Mesquita Spinola. Na classificação feita, essas pesquisas foram organizadas em três grupos, a saber:

- 1-Análise de negócio, onde foram desenvolvidos nove trabalhos

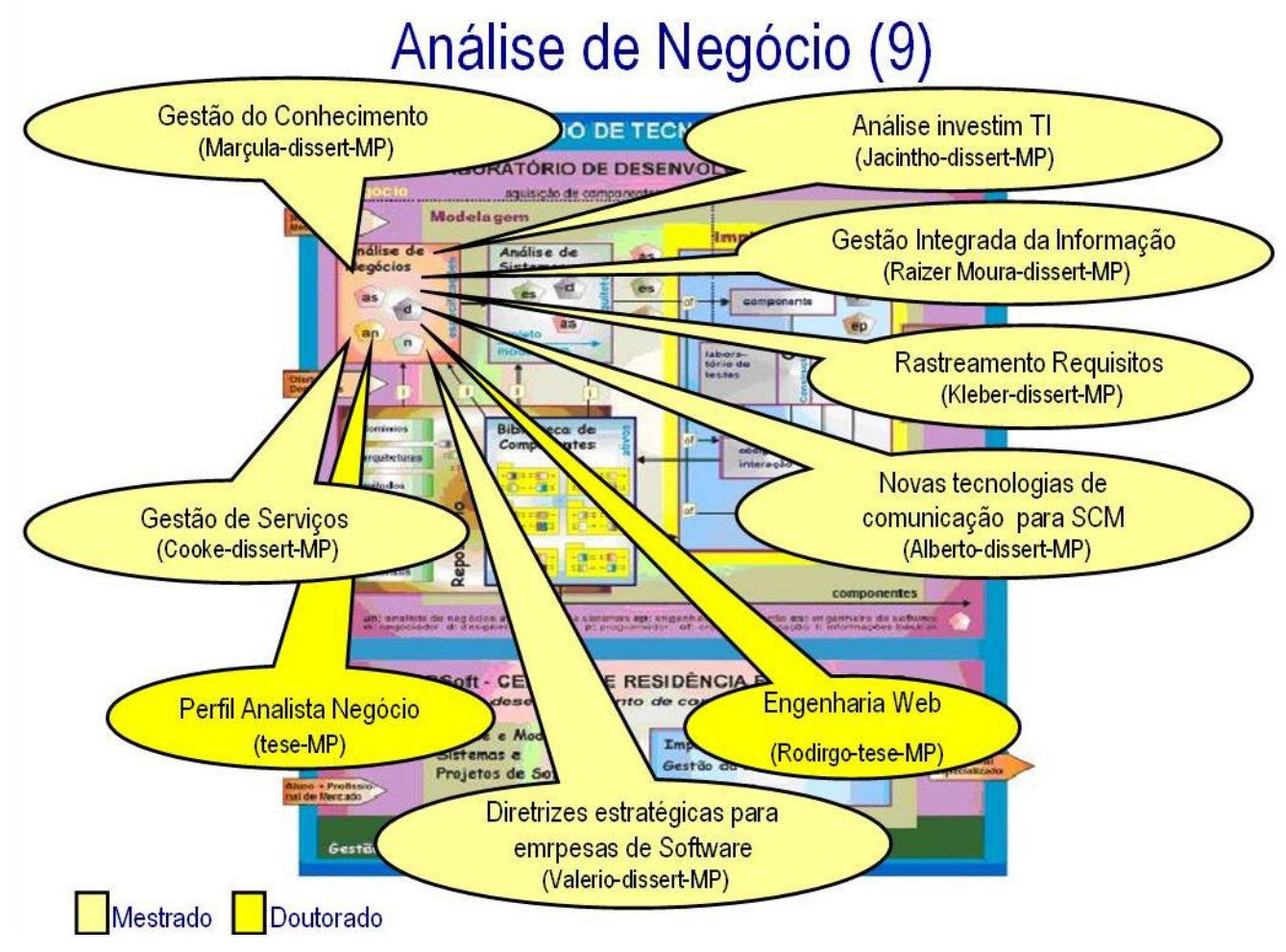

Figura 11 - Pesquisas realizadas em Análise de Negócio 
- 3-Gestão de projetos, com três trabalhos. No modelo de referência, esses trabalhos podem ser enquadrados na Análise de Sistemas.

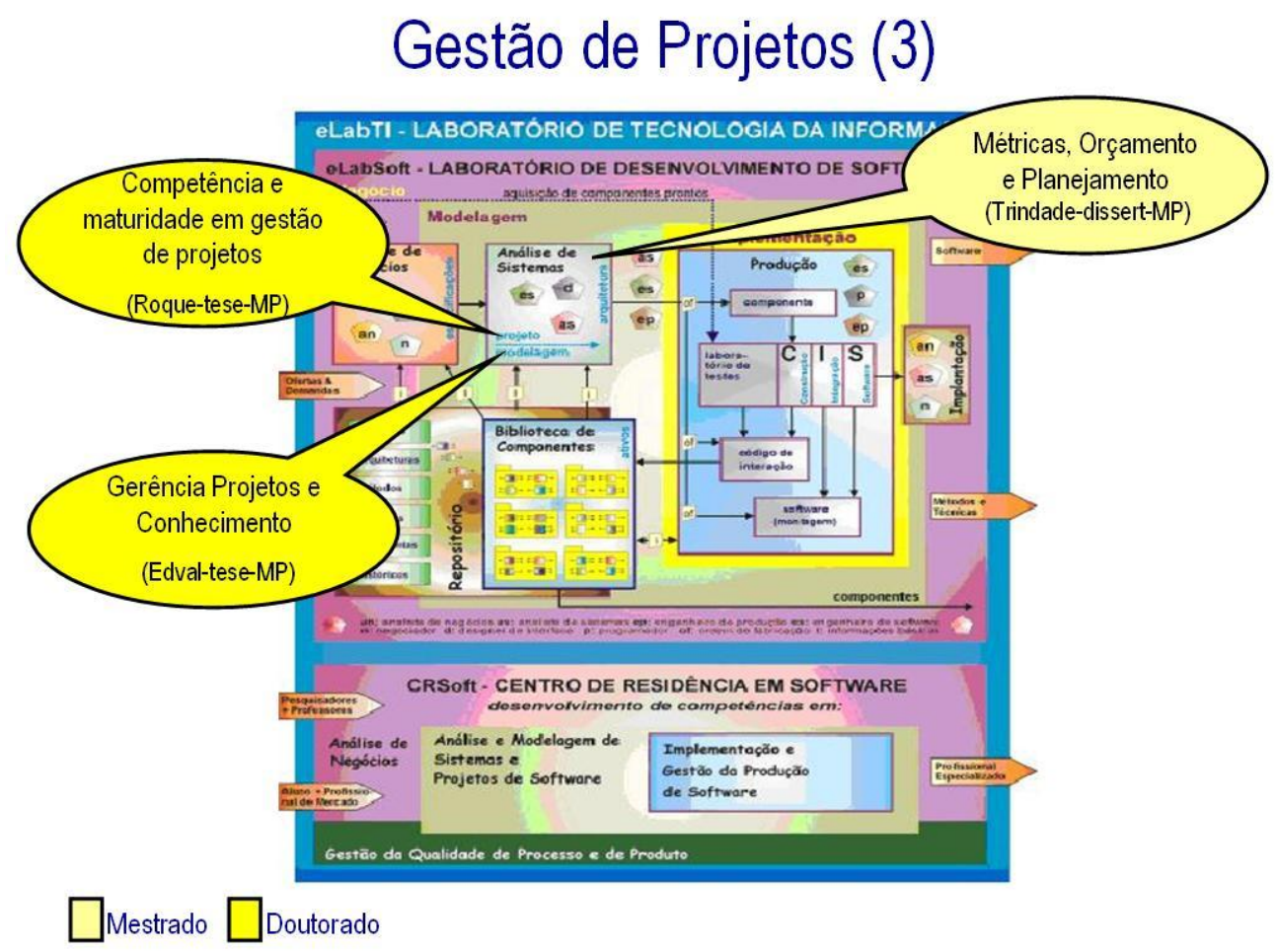

Figura 12 - Pesquisas realizadas em Gestão de Projetos 
- 4-Na área de processo de software, que envolve no modelo de referência a análise de sistemas (arquitetura), repositório e a produção propriamente dita, há um total de nove trabalhos desenvolvidos.

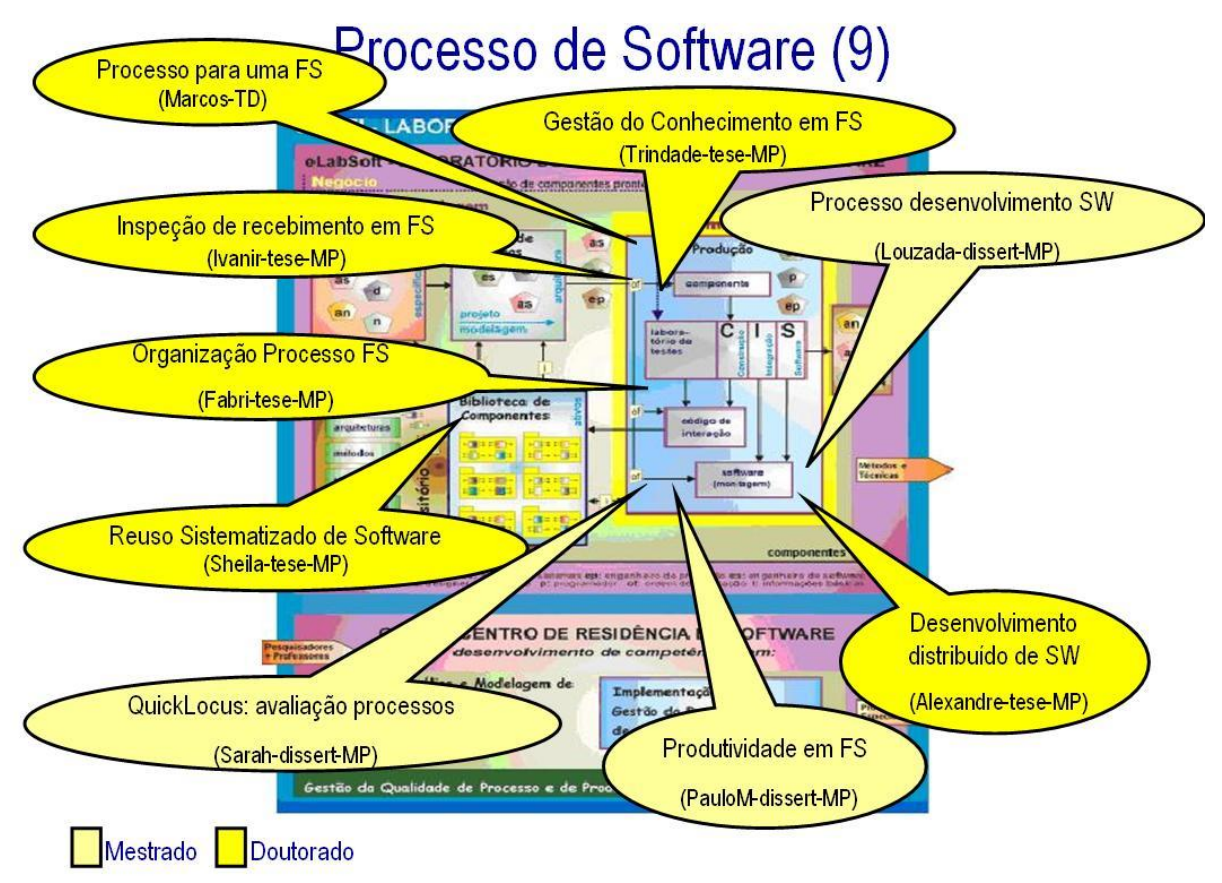

Figura 13 -Pesquisas realizadas em Processo de Software

Este Autor orientou um total de 36 dissertações e teses e, no momento do fechamento deste texto, há em andamento mais seis orientados com pesquisas em diferentes estágios. Nas apresentações a seguir há um total de 22 pesquisas desenvolvidas. Essa diferença refere-se a pesquisas que abordaram outros assuntos diferentes de processos e projetos em uma Fábrica de Software, o tema foco desta pesquisa. São eles:

- 5 pesquisas abordaram aspectos de aplicação de sistemas de tecnologia da informação

- 6 pesquisas abordaram sistemas integrados de informação (ERP)

- 3 pesquisas voltadas à educação

Os próximos capítulos detalham as 22 pesquisas desenvolvidas. 


\section{ANÁLISE DE NEGÓCIO}

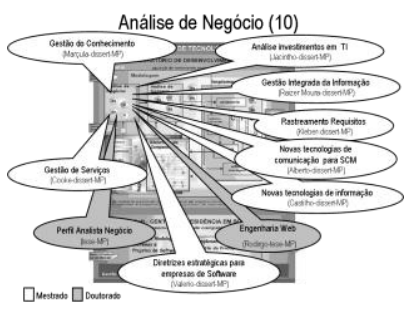

Análise de Negócio - Na área de Análise de Negócios foram desenvolvidas 10 pesquisas orientadas por este Autor, a saber:

- Perfil do Analista de Negócio

- Gestão Integrada da Informação

- Análise de Investimentos em TI

- Gestão do conhecimento

- Gestão de Serviços

- Novas Tecnologias de TI

- Diretrizes Estratégicas empresas Sw

- Rastreamento de Requisitos

- Engenharia Web

\section{IV.1 ANALISTA DE NEGÓCIOS}

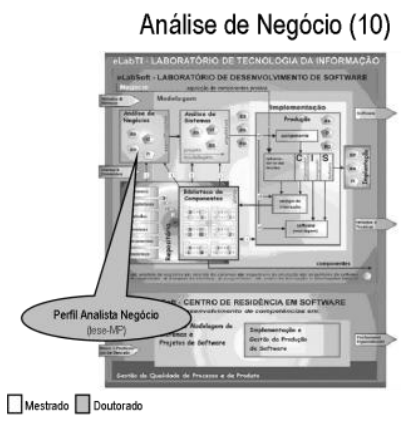

A figura do analista de negócios tem tomado importância maior nesses últimos anos, conforme já relatado nesse documento no item II.7 referente ao perfil do profissional de TI. Considerando que há, por parte das organizações, uma pressão cada vez maior por soluções tecnológicas para atendimento às operações e estabelecimento de vantagens competitivas, a capacidade de realizar estas atividades é do analista de negócios. $\mathrm{O}$ analista de negócios é o profissional que atua como elo de ligação entre os vários envolvidos em um projeto dentro de uma organização, de forma a identificar, analisar, comunicar e validar requisitos para mudanças em processos de negócio, políticas e sistemas de informação. O Analista de Negócios deve ser capaz de entender o problema do negócio, as oportunidades no contexto e recomendar soluções que habilitam a organização a atingir seus objetivos. (BABoK, 2008; PESSOA, LAGUNA, MACEDO, 2009).

Em 2002 essa questão havia sido identificada por este Autor como uma das pesquisas a serem realizadas: qual deve ser o perfil de conhecimento do analista de negócios? Os profissionais que atuavam no mercado exercendo essa função haviam adquirido esse conhecimento na vida profissional e não existia, na época, uma 
clareza com relação a qual seria o corpo de conhecimento necessário para desempenhar essa função. A idéia da tese seria, inspirado no PMBoK e no SwEBoK, criar um corpo de conhecimento para o analista de negócio. O fato do aluno envolvido com esse tema não ter dado continuidade à pesquisa, deixou esse assunto "hibernado". Em 2003, no Canadá, foi criada uma entidade similar ao PMI, que lançou o BABoK - Business Analist Body of Knowledge em 2005 um modelo criado exatamente na linha do que se havia pensado antes. Embora esse tema não tenha gerado esse fruto acadêmico, ao menos demonstrou que o caminho a ser seguido estava certo. O modelo BABoK foi estudado por este Autor e tem sido objeto de novas pesquisas. Como esse modelo ficou muito similar ao que se imaginava desenvolver no contexto do eLabSoft, a seguir é feita uma apresentação resumida do mesmo.

\section{IV.1.1 O modelo BABoK}

O BABoK (BABOK, 2008) é um modelo similar ao PMBoK (PMI, 2004) que estabelece o corpo de conhecimento para o analista de negócio e também oferece uma certificação aos profissionais que passarem em um exame de avaliação. $O$ modelo está organizado em áreas de conhecimento, conforme ilustrado na Figura 14. No modelo, cada um dos retângulos corresponde a um capítulo do documento.Portanto o documento possui um capítulo introdutório mais 7 referentes às áreas de conhecimento. São elas:

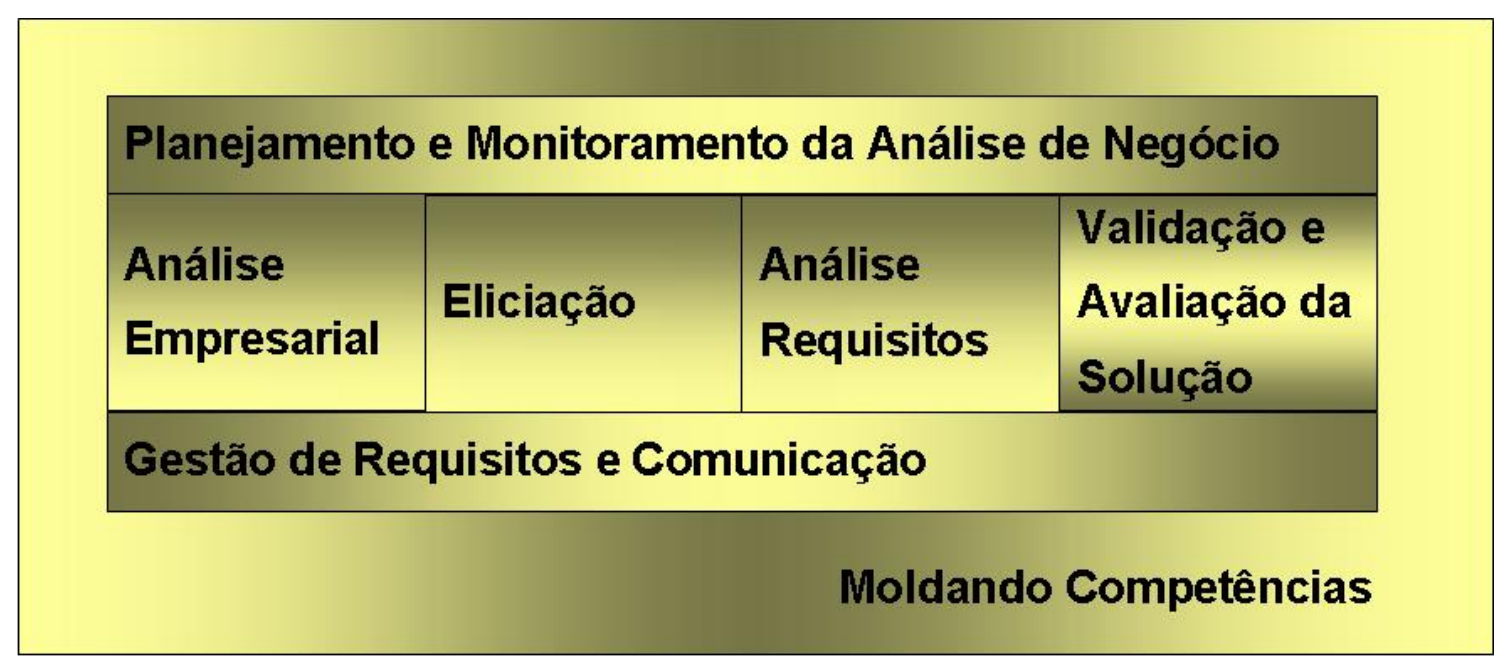

Figura 14 - Modelo BABoK (BABOK, 2008). 
- Planejamento e Monitoramento da Análise de Negócio - é a área de conhecimento que determina que atividades são necessárias para realizar a análise de negócio. Identifica os stakeholders, seleciona as técnicas de análise de negócio, seleciona o processo de gerenciamento de requisitos e como vai ser avaliado o progresso do trabalho.

- Gestão de Requisitos e Comunicação - descreve como gerenciar conflitos, questões e mudanças para garantir que os stakeholders e a equipe de projeto se mantenham em acordo com relação ao escopo da solução.

- Análise Empresarial - descreve como se considera uma necessidade de negócio, realiza o refinamento e clarifica a definição daquela necessidade e define o escopo da solução que pode ser implementada de forma viável pelo negócio.

- Eliciação ${ }^{6}$ - descreve como trabalhar com os stakeholders para identificar suas necessidades e garantir que estas foram compreendidas de maneira correta e completa.

- Análise de Requisitos - descreve como a solução é elaborada progressivamente para garantir que a equipe faça o projeto e construa a solução que atenda as necessidades de negócio e dos stakeholders.

- Validação e Avaliação da Solução - descreve como devem ser avaliadas soluções propostas para determinar que solução melhor se adequa às necessidades do negócio, identifica gaps e aponta caminhos a serem seguidos e alterações na solução.

- Moldando Competências - descreve o comportamento, conhecimento e outras características que suporta as tarefas de análise de negócio.

Cada uma das áreas de conhecimento é descrita em termos de tarefas e técnicas. Uma crítica em relação a esse modelo é a pouca importância dada (mesmo na segunda versão) às questões referentes à inovação tecnológica. 


\section{IV.1.2 Pesquisa dos cursos que formam os futuros analistas de negócios}

Conforme anteriormente exposto, como os analistas de negócio desenvolveram suas competências no exercício da profissão, foi realizada uma pesquisa para avaliar o grau de conhecimento adquirido nos cursos de graduação. Foram estudadas as grades curriculares dos cursos de graduação ligados às áreas de Negócio e de Tecnologia (da Informação) (FABRI, et all, 2003).

O foco da pesquisa foi identificar se os cursos tinham, em sua grade, temas relacionados ao alinhamento estratégico entre a tecnologia da informação e o negócio. Esta pesquisa restringiu-se à análise dos documentos disponíveis descritivos dos cursos. Segundo Henderson e Venkatraman (1993) o alinhamento estratégico corresponde à adequação estratégica e integração funcional entre os ambientes externos (mercado, política, fornecedores, etc.) e internos (estrutura administrativa e recursos financeiros, tecnológicos e humanos) para desenvolver competências e maximizar o desempenho organizacional. Isto requer para o analista de negócio conhecimentos não somente nas áreas de Negócio das organizações mas também referentes à área de Tecnologia (FABRI, et all, 2003).

No Brasil, em 2003, foram identificados 23.356 cursos de graduação. Os cursos da área de Negócio forma considerados aqueles das mais variadas ênfases da Administração e Engenharia de Produção. Para a área de Tecnologia foram considerados os cursos de Sistemas de Informação, Ciência da Computação, Tecnologia em Processamento de Dados e Engenharia da Computação, assim quantificados:

- 2.421 cursos de Administração de Empresas

- 108 cursos de Engenharia de Produção

- 830 cursos na área de Tecnologia (os demais citados)

$\mathrm{Na}$ análise foram estudadas as ementas curriculares de 90 cursos na área de negócios e 60 cursos na área de tecnologia. Para que os cursos atendam o conceito de alinhamento estratégico (ambos os cursos) devem contemplar os conceitos de Estratégia; Paradoxo da Produtividade; Alinhamento Estratégico; Sistemas de 
Informação; Enterprise Resource Systems (ERP); Sistema de Suporte a Decisão; Ecommerce; Ebusiness e Tendências e novas Tecnologias (FABRI, et all, 2003).

Verifica-se que os conceitos de Estratégia, Paradoxo da Produtividade; Alinhamento Estratégico são temas da área de negócios, os demais conceitos são considerados temas da área de tecnologia. Na formação do profissional de negócios devem ser apresentados os temas de tecnologia (o profissional deve ter condições de verificar as tecnologias emergentes, avaliar sua viabilidade e traçar um plano estratégico de negócio que utilize esta tecnologia da melhor forma possível). O profissional da área de tecnologia deve ter conceitos sobre a área de negócios para que possa priorizar determinadas áreas da $\mathrm{TI}$ afim de atender melhor a estratégia da organização. A Figura 15 ilustra alguns conhecimentos de alinhamento estratégico para $\mathrm{O}$ profissional de $\mathrm{TI}$ e para o profissional de negócio. Nesta figura, verifica-se a presença do quadro interdisciplinaridade onde os conceitos de TI ultrapassam a fronteira do profissional de negócios e os conceitos de negócios ultrapassam a fronteira do profissional de TI (FABRI, et all, 2003).

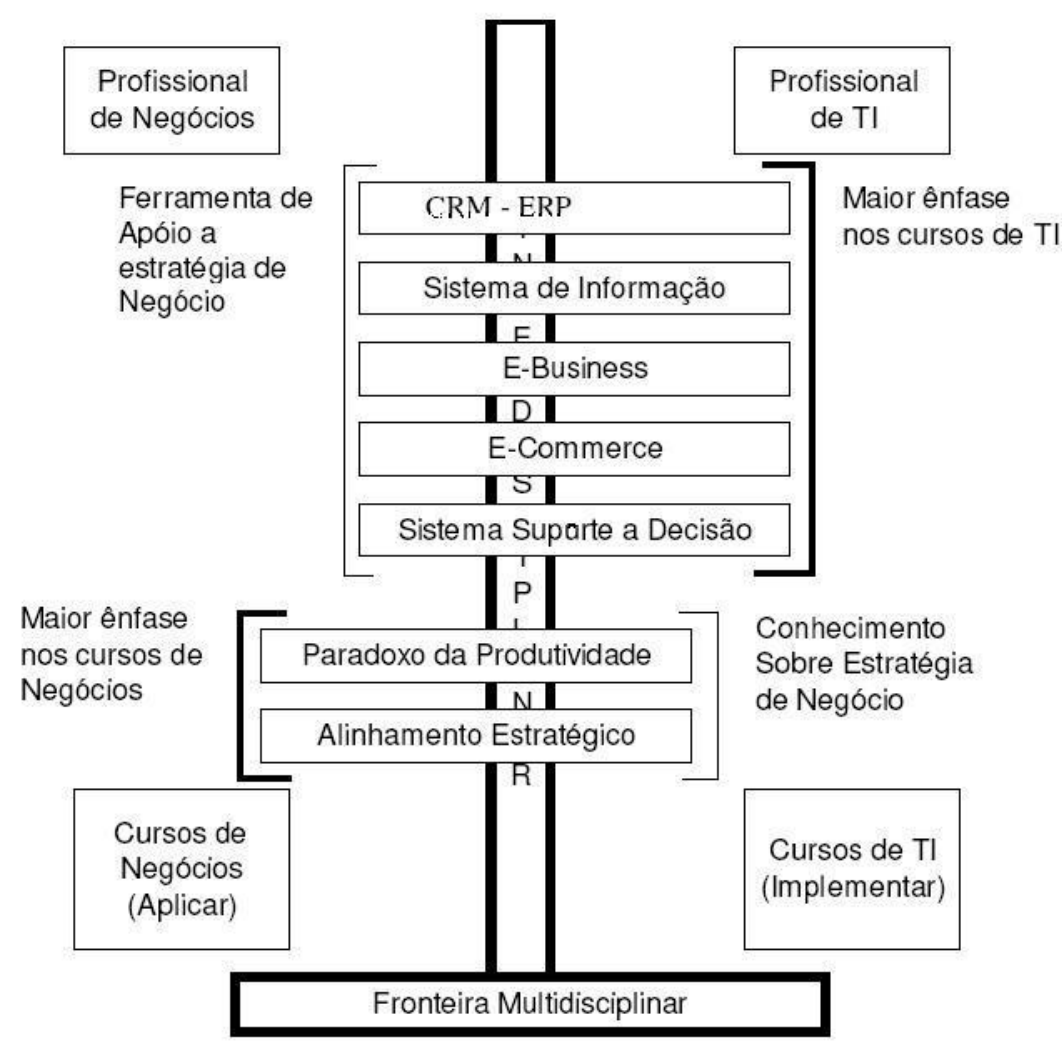

Figura 15 - Alinhamento entre os cursos de Negócio e tecnologia (Fabri et all, 2003). 


\section{IV.1.2.1 Cursos da Área de Negócio}

Conforme já explicitado são os cursos da área de Administração de Empresas e de Engenharia de Produção.

Dos 66 cursos de Administração analisados 72\% contemplam o conceito de Sistemas de Informação, 69\% abordam sistemas de suporte à decisão, 23\% o conceito de alinhamento e apenas 7,7\% aplicam os conceitos de ERP, E-business e E-commerce. Há, entretanto, 27,7\% dos cursos analisados que não apresentam nenhum conceito relacionado à área de TI (FABRI, et all, 2003).

Dos 24 cursos de Engenharia de Produção analisados 100\% contemplam Sistemas de Informação e Sistemas de Suporte à Decisão e 40\% abordam ERP, E-business e E-commerce $20 \%$ aplica o conceito de Estratégia e Sistemas de Informação, Paradoxo da Produtividade e Alinhamento (FABRI, et all, 2003).

A Figura 16 apresenta os resultados em formato de gráfico de barras.

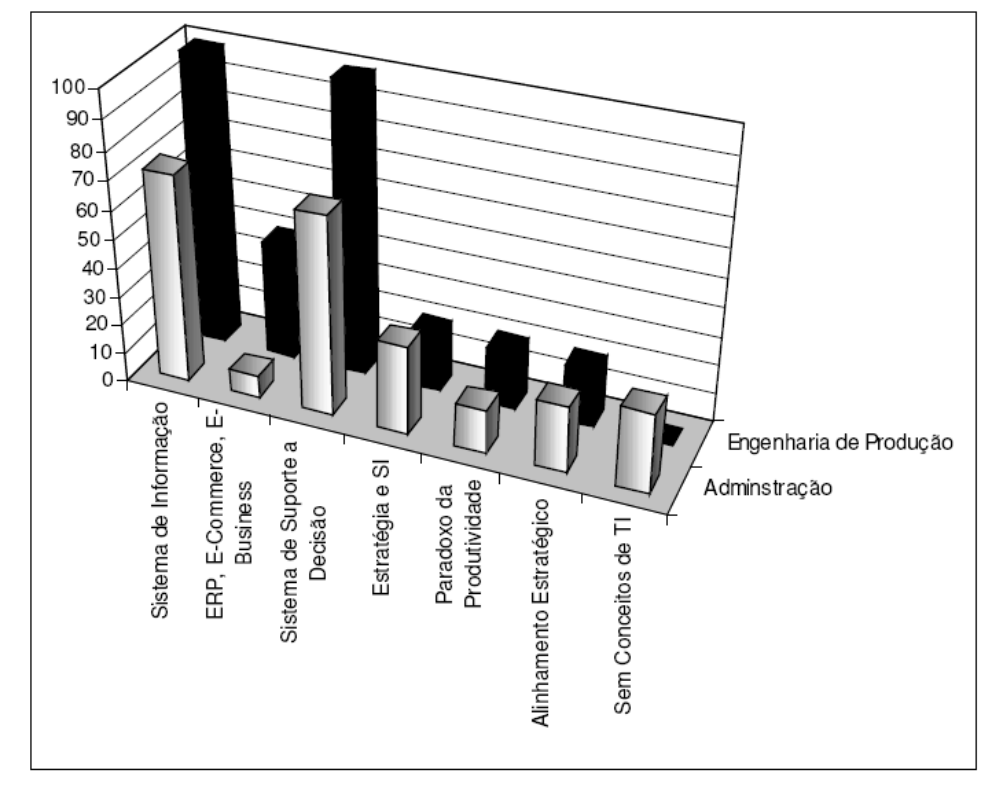

Figura 16 - Resultado dos cursos de negócio (Fabri et al, 2003).

A partir do próximo item são analisadas quantitativamente os levantamentos realizados. 


\section{IV.1.2.2 Cursos da Área de Tecnologia}

Os cursos da área de Tecnologia foram classificados em cursos de Ciência da Computação, Sistemas de Informação e Engenharia da Computação.

A pesquisa verificou que $58,33 \%$ dos cursos da área de Tecnologia possuem disciplinas da área de negócios e contemplam somente o conceito de planejamento em suas ementas (FABRI, et all, 2003).

O conceito de Estratégia é apresentado em 8,33\%, o conceito de Alinhamento em $4,17 \%$ e o conceito de Paradoxo da Produtividade não é apresentado em nenhum curso da área de tecnologia (FABRI, et all, 2003).

Os cursos de Sistemas de Informação atingem um percentual de 66,67\% na apresentação dos conceitos de planejamento e 33,33\% destes cursos trabalham a questão de alinhamento ( $F A B R I$, et all, 2003).

Foi observado também que $41,67 \%$ destes cursos não apresentam conceitos relacionados à área de negócios (FABRI, et all, 2003).

Analisando os números acima, verifica-se que, na amostra pesquisada, os cursos da área de tecnologia estão distantes dos conceitos de alinhamento estratégico entre $\mathrm{TI}$ e negócios. Os conceitos de Paradoxo da Produtividade, Alinhamento e Estratégia devem ser contemplados nos cursos da área de Tecnologia (FABRI, et all, 2003).

A Figura 17 apresenta os resultados desta pesquisa.

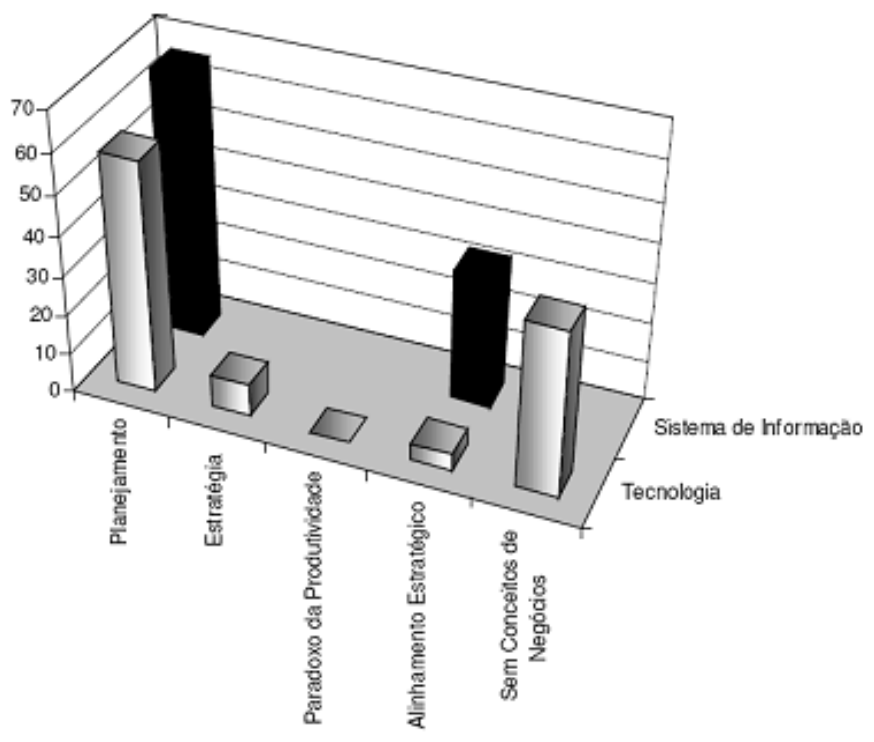

Figura 17 - Resultado dos cursos de tecnologia (Fabri et al, 2003). 


\section{IV.1.2.3 A proposta dos órgãos direcionadores}

Outra abordagem dessa pesquisa foi analisar as propostas dos órgãos direcionadores dos cursos de Tecnologia e Negócios: Sociedade Brasileira de Computação (SBC) e Conselho Federal de Administração (CFA). É importante deixar claro que essas instituições são classificadas como órgãos direcionadores neste trabalho, pois atuam diretamente junto ao Ministério de Educação e Cultura (MEC) (FABRI, et all, 2003).

\section{Sociedade Brasileira de Computação (SBC)}

A SBC divide os cursos de área tecnológica em duas linhas (página 2 do currículo de referência de 1999 (CR99)): atividade meio (cursos de Sistemas de Informação e Informática); atividade fim (cursos de Ciência da Computação e Engenharia de Computação). A proposta da SBC para os cursos da área de tecnologia indica preocupação com o conceito de alinhamento estratégico entre TI e Negócios, pois no texto de referência é citada a necessidade de formação em negócios, para ter uma visão da dinâmica organizacional, atendimento às necessidades empresariais, desenvolver sistemas de informação para solução de problemas organizacionais, entre outros (FABRI, et all, 2003).

Disciplinas propostas pelo currículo de referência para os cursos de tecnologia.

- Gestão da Informação que apresenta como ementa: Tecnologia da informação. Planejamento estratégico da informação. Os papéis do profissional na gestão da informação: infomanagers, knowledge workers, analistas de negócios. Ferramentas utilizadas na gestão da informação.

- Gerência de Projetos: Gerenciamento de expectadores: superiores, usuários, membros da equipe e outros membros relacionados ao projeto. Determinação dos requisitos de habilidade e alocação de equipes ao projeto. Análise de custo e eficiência. Técnicas de apresentação e comunicação. Gerenciamento efetivo de aspectos técnicos e comportamentais do projeto. Gerenciamento das mudanças. 
- Administração que apresenta como ementa: Visão de problemas e ferramentas usadas no processo decisório do departamento de O\&M das organizações. Visão sistêmica das organizações.

Analisando a proposta da SBC conclui-se que, nos cursos onde a TI é atividade meio, recomenda-se que seja apresentado o conceito de alinhamento estratégico através de conceitos de planejamento estratégico da informação, gestão da informação e análise de negócios. Já, nos cursos onde a TI é atividade fim, a SBC sugere que se apresente apenas a disciplina de Administração (FABRI, et all, 2003).

\section{Conselho Federal de Admnistração (CFA)}

O CFA elenca um conjunto de disciplina de formação básica e instrumental em seu currículo, entre estas disciplinas encontra-se a Informática. Porém informática é um termo genérico, pode tratar desde os conceitos básicos de hardware e software até conceitos de redes de computadores, tecnologia da informação etc. Por meio disto verifica-se que as instituições de ensino não possuem um norteamento para implementar seus currículos (FABRI, et all, 2003).

\section{IV.1.2.4 Conclusões sobre a pesquisa}

Verificou-se que a maioria dos cursos pesquisados não apresenta o conceito de alinhamento estratégico entre TI e Negócios. Os cursos da área de negócios (Administração e Engenharia da Produção) levam uma vantagem na formação de profissionais com conceito de alinhamento estratégico se comparados aos cursos de Tecnologia (demais cursos citados no parágrafo anterior). É importante citar que estas conclusões foram extraídas, segundo a amostra dos cursos pesquisados (FABRI, et all, 2003).

Esses resultados demonstram que o perfil do analista de negócios ainda não é claro e que há o que se pesquisar para melhor atender as necessidades de mercado. $O$ BABoK poderá auxiliar nessa atividade pois, se realmente virar uma referência como 
é o PMBoK, os cursos de graduação poderão usá-lo como referência e os curricula passarão a dar uma cobertura melhor nesta área.

Na opinião deste Autor, o curso de Engenharia de Produção da EPUSP hoje cobre boa parte dos conhecimentos para um analista de negócios pois aos poucos foram sendo incorporadas disciplinas que atendem a esse corpo de conhecimento. Há entretanto que se fazer um trabalho mais sistemático de avaliação da cobertura do BABoK (BABoK, 2008). 


\section{IV.2 GESTÃO INTEGRADA DA INFORMAÇÃO}

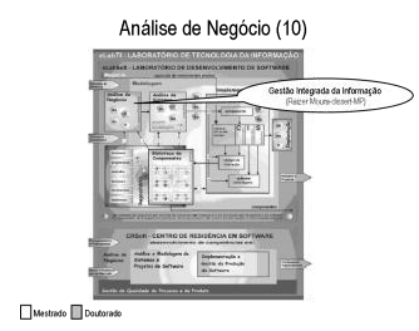

$\mathrm{Na}$ pesquisa realizada com Moura (1999) foi levantada a seguinte questão: qual um modelo de gestão apropriado para que as empresas possam ser competitivas na era da informação?

A tecnologia da informação é utilizada para acessar, difundir e memorizar conhecimentos, uma vez que a memória humana é limitada e o volume de informações necessário para a gestão das empresas é muito grande. Outro uso importante da $\mathrm{TI}$ está na redução do risco de oportunismo ou problemas nas transações entre empresas, face e a falta de confiança existente nas relações comerciais, registrando e guardando os dados das transações (MOURA, 1999, MAGGIOLINI,1996).

Talvez o uso mais importante da TI seja nas atividades econômicas visando reduzir os custos de produção, a coordenação e o controle das transações nas empresas (MOURA, 1999, MAGGIOLINI,1996). Segundo Moura (1999), o grande desafio das empresas é de atingir os objetivos estabelecidos pela sua missão. No mundo capitalista, esses objetivos passam pela geração de resultados financeiros compatíveis com o capital investido, mas também, como característica da empresa moderna nos tempos atuais, o respeito pela sociedade, colaboradores e meio ambiente. O sucesso do negócio segundo Honda (1998) apud Moura (1999) está diretamente relacionado à capacidade da organização responder adequadamente ao seu ambiente e às suas mudanças. A velocidade com que essas mudanças ocorrem tem sido cada vez maior, obrigando as empresas a terem também respostas mais rápidas. Uma empresa com uma estrutura adequada de tecnologia da informação pode viabilizar este requisito de agilidade.

\section{IV.2.1 Gestão Integrada da Informação}

A informação é um recurso, um instrumento de vital importância para o sucesso da empresa. Como recurso, a informação é usada nos processos e nas atividades da empresa para agregar valor ao produto. Como instrumento de gestão, é utilizada 
para controlar e coordenar as atividades visando alcançar os objetivos desejados. Existem três fluxos de informações nas organizações: ambiental, interna e corporativa, conforme ilustrado na Figura 18 (MOURA, 1999).
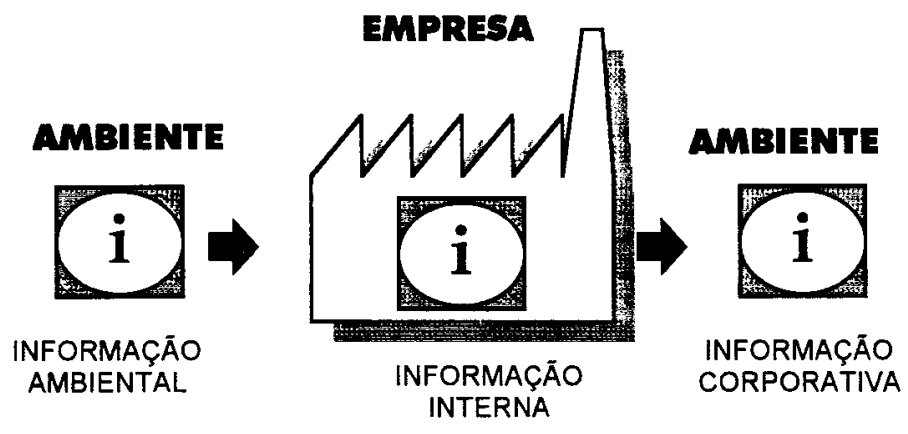

Figura 18 - Os três fluxos de informação nas empresas (Moura, 1999)

\section{A Informação Ambiental}

O conjunto de informações provenientes do ambiente é denominado, como apresentado, por informação ambiental, e se refere aos elementos do ambiente com as quais as empresas estão relacionadas: clientes, concorrentes, governos, sociedade, novas tecnologias, entre outros. Essas informações possibilitam à empresa se posicionar em relação ao ambiente, identificando oportunidades e ameaças que possam surgir para definição de sua estratégia de negócio. A informação ambiental é, portanto, um recurso estratégico e de grande importância para a empresa definir a direção a ser seguida, o mercado como foco de atuação, a forma de relacionamento com o mercado, como identificar as necessidades dos clientes, como saber das ações da concorrência, das restrições impostas pelos governos, das aspirações e pressões da sociedade, entre outras. Esse tipo da informação é o insumo (entrada) do processo de planejamento estratégico e a base para definição da estratégia de negócio dos objetivos empresariais e das políticas e diretrizes a serem seguidas (MOURA, 1999).

\section{Informação Interna}

Com base na informação ambiental, a informação interna representa o uso da informação dentro da empresa para gerenciamento de seu negócio, para execução 
dos seus processos e geração dos produtos. Segundo Itamo, apud Moura (1999) é necessário que a informação recebida pela empresa seja armazenada e dirigida rápida e precisamente às pessoas que tomam decisões. Sem um fluxo interno, a informação acumulada não tem muito valor. Quando essa informação é usada em decisões estratégicas, passa a agregar valor para a empresa (MOURA, 1999).

Podem ser identificadas duas grandes categorias de informações internas. Por um lado, as empresas geram e fazem uso de um grande volume de informações operacionais, como catálogo de clientes e fornecedores, resultados de produção, dados contábeis, métodos, entre outros. Normalmente essas informações estão armazenadas em algum tipo de registro físico ou meio eletrônico. Por outro lado, as empresas, notadamente as pessoas que dela fazem parte, geram conhecimento, como resultado da assimilação e uso da informação e, ainda, advindas de suas experiências e capacidade criativa (CORNELLA, 1994 apud MOURA, 1999).

A informação interna, seja ela do tipo operacional ou conhecimento das pessoas, representa a essência do gerenciamento dos processos e atividades da empresa, sendo usada para desdobrar os objetivos estratégicos, definir os mais adequados métodos de execução, registrar dados para controle das atividades e promover as melhorias e solução de problemas da empresa. A informação em uma organização somente tem sentido se é utilizada para alguma finalidade (CORNELLA, 1994 apud MOURA, 1999).

\section{Informação Corporativa}

A informação corporativa constitui-se como sendo aquela que deve ser comunicada aos clientes (mercado) e à sociedade em geral com a expectativa de tornar a empresa e/ ou suas ações conhecidas. Pode ser usada como uma ação de marketing para divulgar os produtos aos clientes, ou mesmo para ajudá-los a perceber que suas expectativas são atendidas pelas características dos produtos. A comunicação com o mercado é também usada para criar uma imagem positiva e adequada da empresa, podendo destacar sua identidade e ser feita de acordo com sua estratégia de negócio (Moura, 1999).

Nesse sentido, pode desejar criar o valor, percebido pelo cliente, de que seus produtos são diferentes, ou que são mais baratos ou, ainda, que é adequado a um determinado tipo de mercado. Esse tipo de comunicação voltada para o mercado se 
constitui como uma ação direta da comunicação sendo, por exemplo, como uma campanha publicitária. A comunicação da empresa pode ser voltada para dar a ela uma conotação social, criando uma imagem positiva (Moura, 1999).

\section{IV.2.2 A Informação como Recurso de Gestão}

Nesta pesquisa realizada com Moura (1999), foi estudada apenas a informação interna, ou seja, a informação usada na operação rotineira e na gestão empresarial, uma vez que seu enfoque é a definição de um modelo de gestão baseado no uso da informação. As informações internas podem ser classificadas em três grandes grupos: decisões, métodos e resultados conforme a Figura 19 e o Quadro 2.

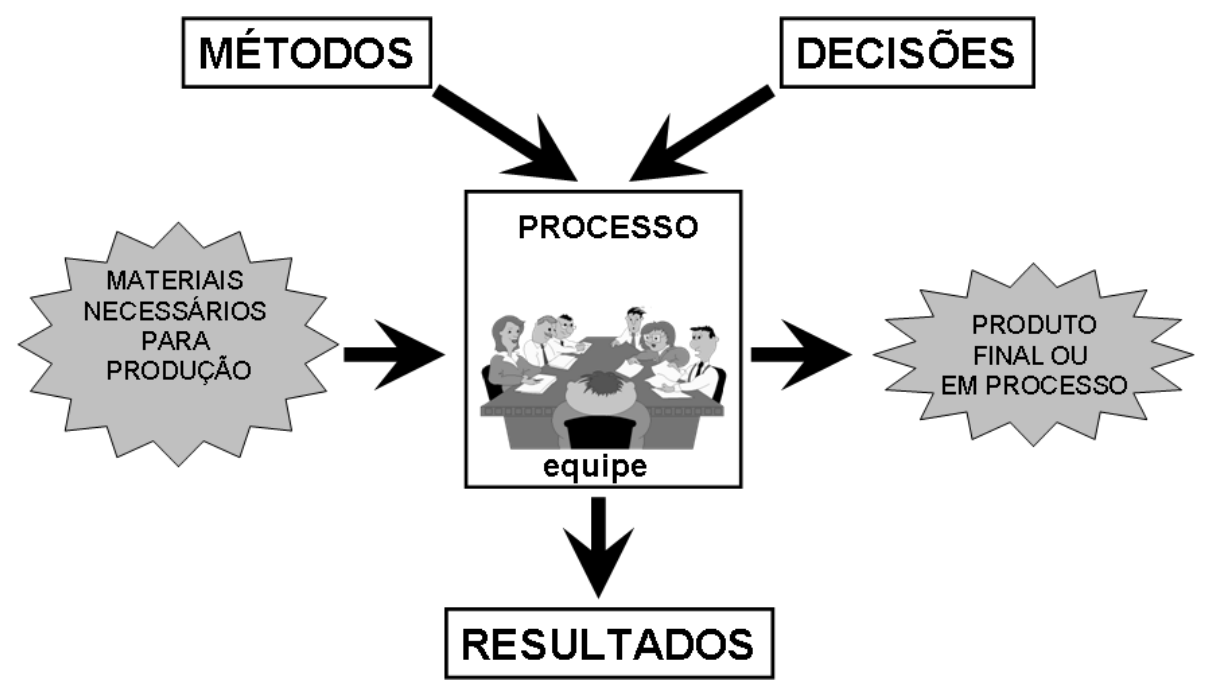

Figura 19 - Tipos de Informação: decisões métodos e resultados (Moura , 1999)

As decisões representam a definição de uma opção entre alternativas a respeito do uso de recursos. Decisão é o resultado de um processo de planejamento e são apresentadas em forma de políticas, planos e programas.

Os métodos são orientações que definem a forma de execução dos processos, indicando às pessoas como executar suas atividades. Esse grupo de informação é constituído por métodos, procedimentos e instruções.

Os resultados representam a identificação e a notificação dos fatos ocorridos nos processos da empresa relacionados ao uso de recursos e resultados alcançados. É constituído por dados, indicadores e relatórios. 
Os exemplos apresentados no Quadro 2 mostram o grau de abstração dos diferentes tipos de informação. A pirâmide de Anthony (1965 apud MOURA, 1999) estabelece a relação entre as posições hierárquicas da empresa e as necessidades de informação. Quanto mais alto o nível nessa pirâmide, conforme ilustrado na Figura 20, mais agregada e abrangente deve ser a informação e quanto menor o nível, mais específica e detalhada deve ser a informação.

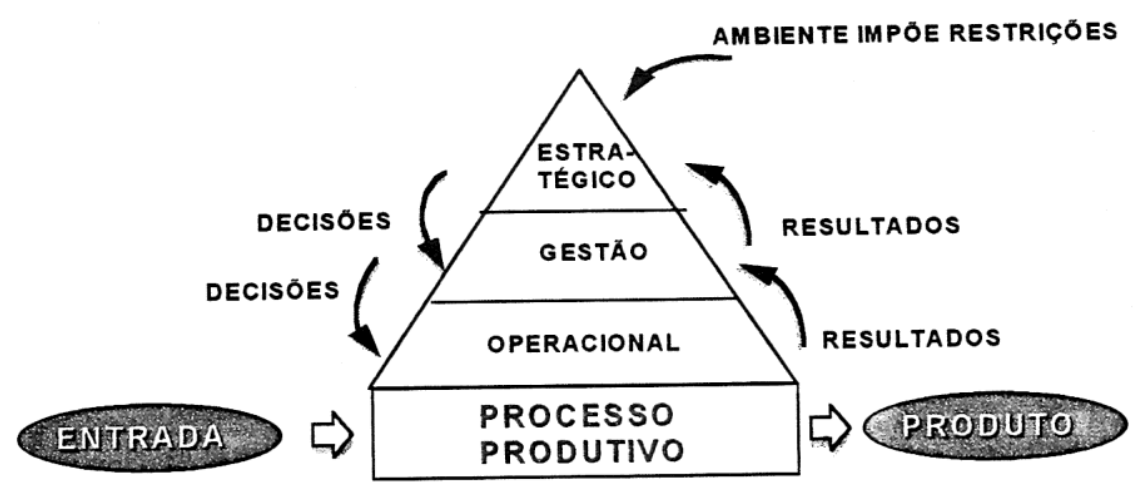

Figura 20 - Pirâmide de Anthony (Moura, 1999)

Esse modelo de Anthony propõe uma estrutura de informações com base no fluxo vertical (de baixo para cima e de cima para baixo) que é criticado em função da falta de rapidez de resposta necessária para as empresas atuais. Segundo Moura (1999), Marchand propôs um modelo que evoluiu esse conceito para um fluxo horizontal de informações fluindo entre os processos de maneira mais ampla (que é o conceito usado atualmente nas estruturas por processo, segundo Laurindo (2006)). Tapscott apud Moura (1999) afirma que a estrutura hierárquica com muitas camadas está se transformando em redes horizontais ou então negócios relativamente autônomos. A nova empresa está se baseando na informação. A informação, portanto, é um recurso para a empresa e deve ser gerenciada adequadamente. Dentro desta idéia, surgiu uma nova linha de pensamento, baseada na necessidade de gerenciamento dos recursos informacionais, denominado IRM - Information Resources Management. Segundo Moura (1999) esse movimento ocorreu nos anos 80 


\begin{tabular}{|c|c|c|}
\hline \multirow{3}{*}{ 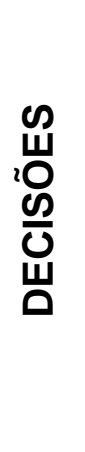 } & POLÍTICAS & $\begin{array}{l}\text { São regras claras a respeito de critérios usados nas decisões } \\
\text { da empresa sobre assuntos como: finanças, pessoal, } \\
\text { qualidade, meio ambiente, etc. }\end{array}$ \\
\hline & PLANOS & $\begin{array}{l}\text { Contém decisões a respeito do uso de recursos definindo os } \\
\text { objetivos, as metas e os meios para obter os resultados } \\
\text { desejados. }\end{array}$ \\
\hline & PROGRAMAS & $\begin{array}{l}\text { São decisões executáveis, definindo claramente o que será } \\
\text { feito, quem vai fazer, quanto e quando produzir }\end{array}$ \\
\hline \multirow{3}{*}{ 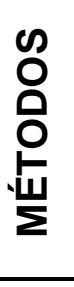 } & MÉTODOS & $\begin{array}{l}\text { Representa a base de conhecimento sob determinado assunto, } \\
\text { devidamente organizada e documentada. }\end{array}$ \\
\hline & PROCEDIMENTOS & $\begin{array}{l}\text { São orientações a respeito da seqüência de atividades a ser } \\
\text { seguida em um processo. }\end{array}$ \\
\hline & INSTRUÇÕES & São orientações detalhadas de atividades dos processos. \\
\hline \multirow{3}{*}{ 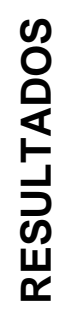 } & DADOS & $\begin{array}{l}\text { Identificam e quantificam os fatos ocorridos nos processos, } \\
\text { sendo coletados e documentados de modo adequado. }\end{array}$ \\
\hline & INDICADORES & $\begin{array}{l}\text { Expressão da relação de resultados obtidos com os recursos } \\
\text { necessários para obtê-los. }\end{array}$ \\
\hline & RELATÓRIOS & $\begin{array}{l}\text { São documentos que contêm dados e indicadores e } \\
\text { informações de análise sobre fatos, setores e períodos da } \\
\text { empresa. }\end{array}$ \\
\hline
\end{tabular}

Quadro 2 - Classificação das informações usadas na gestão de empresas (Moura, 1999)

pesquisado por autores como Cornella, Taylor, Olaisen, Synnott e Gruber. A proposta é estabelecer uma maior preocupação com o conteúdo da informação e sua qualidade e entender que os gastos com informação e Tecnologia da Informação devem ser considerados investimentos.

\section{IV.2.3 Modelo proposto de organização para uso da informação}

Moura (1999) aborda a empresa com um sistema, conforme representado na Figura 21. A visão sistêmica aplicada a uma organização mostra que a empresa possui recursos de entrada como matéria-prima, insumos e informações e o obtém na saída produtos e serviços que são oferecidos ao mercado. A administração interna é realizada através dos componentes desse sistema, que são os processos internos. 
Esses processos precisam ser organizados de forma a atender as diversas atividades que se integram para a realização do produto ou serviço.

A idéia é representar a empresa como uma cadeia de processos, conforme está na Figura 22. Enquanto o fluxo do produto é do fornecedor dos insumos, passando pelas etapas de construção do produto ou realização do serviço na direção do cliente, o fluxo de informações ocorre de maneira inversa, ou seja, do cliente, através das pesquisas de mercado ou equivalente, para a necessidade de insumos e a respectiva compra.

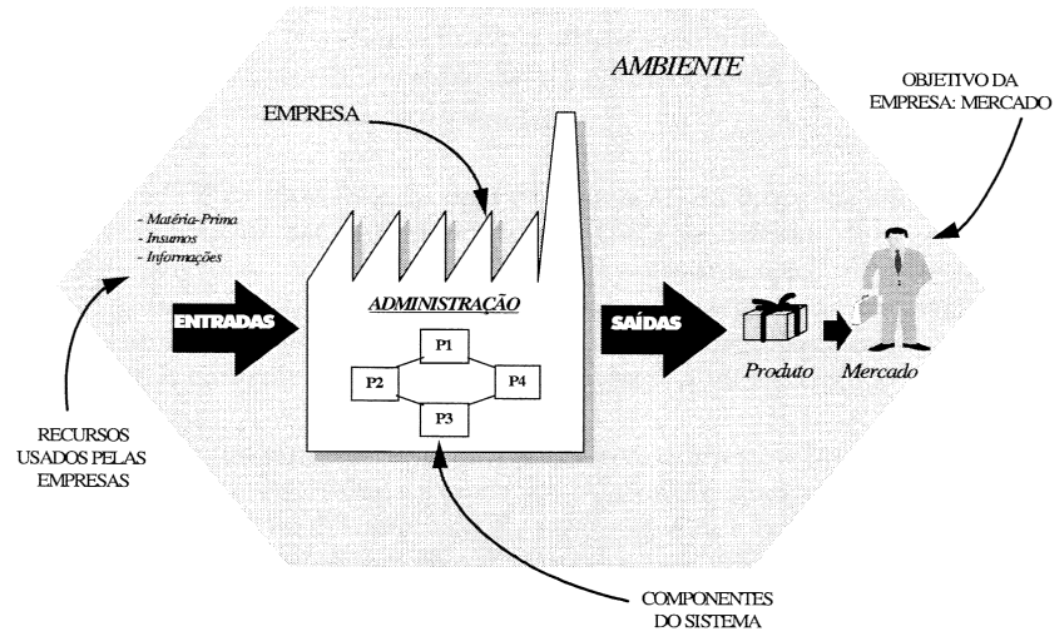

Figura 21 - Elementos de um sistema e sua relação com a empresa (Moura, 1999)

Os processos são unidades da rede organizacional da empresa que fazem uso de recursos para agregar valor ao produto ou serviço, e são integrados e coordenados através do recurso informação.

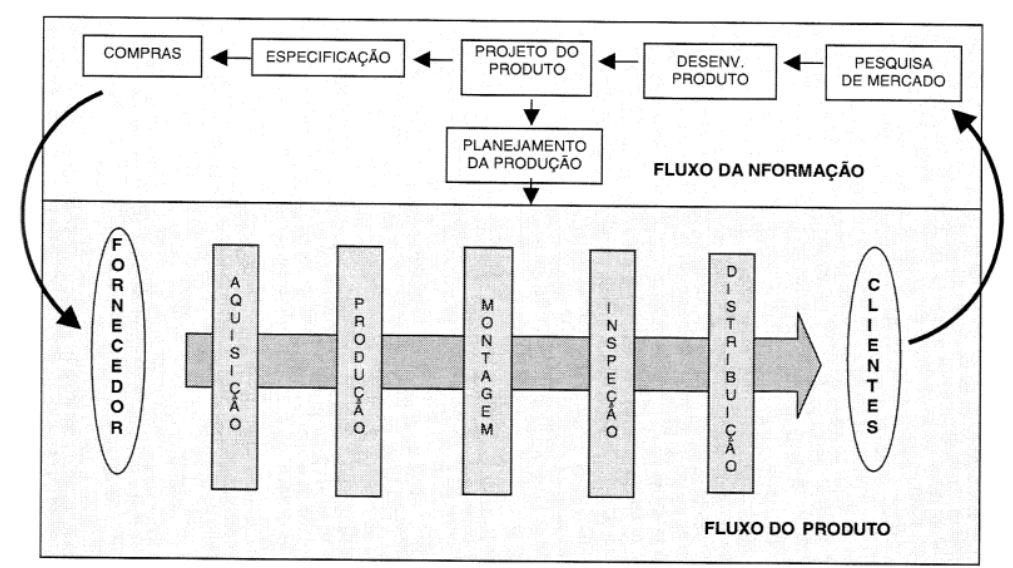

Figura 22 - identificação dos processos do fluxo do produto e da informação (Moura, 1999) 
O modelo proposto por Moura (1999) considera o fluxo de informações como um instrumento de controle e de sincronismo dos processos. Identificando os tipos de informação usados para a gestão dos processos e o inter-relacionamento dessas informações, é possível estabelecer um mecanismo de controle, possibilitando melhorar o desempenho da empresa. A Figura 23 acrescenta três sistemas na Figura 19, já apresentada anteriormente: o sistema da qualidade de que vai criar os métodos, o sistema de planejamento, que vai gerar as decisões e o sistema de controle, que vai fechar o ciclo de gestão.

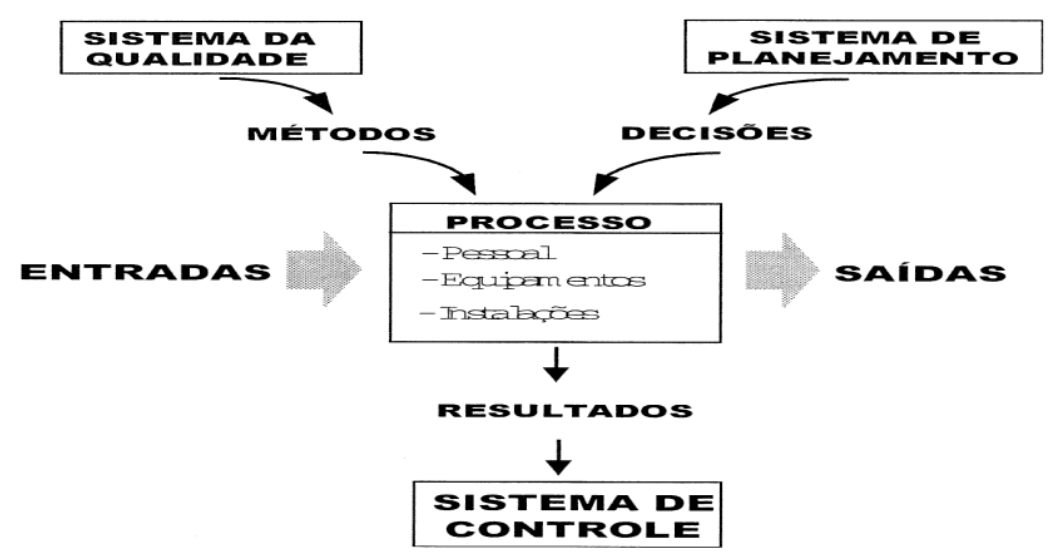

Figura 23 - Sistemas de coordenação (Moura, 1999)

Portanto, o modelo de organização com base na informação é composto por seis elementos: estratégia, produto e processo com base da estrutura da organização, sistema de planejamento, sistema da qualidade e sistema de controle como elementos de coordenação da empresa, conforme representado na Figura 24.

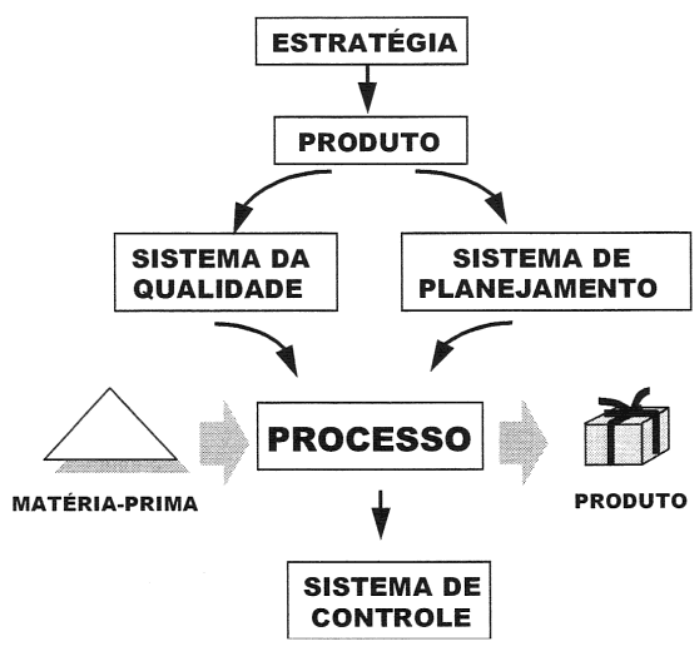

Figura 24 - visão geral dos elementos que compõem o modelo de organização para uso da informação (Moura, 1999) 


\section{Aplicação do modelo}

O modelo proposto foi aplicado em três organizações dentro de um programa de gestão da qualidade total (TQM), seguindo orientações dadas por autores da qualidade tais como Main, Shiba, Deming, entre outros. A orientação utilizada para a aplicação do modelo foi seguir um processo contendo as seguintes atividades (MOURA, 1999):

- Definição da visão estratégica - atividades como definição dos objetivos da empresa, mercado alvo de sua atuação.

- Diagnóstico empresarial - levantamento das atividades da empresa e comparação com as melhores práticas (benchmark) e utilizando como referência o modelo de excelência PNQ - Prêmio Nacional da Qualidade

- Conscientização e mobilização das pessoas - as pessoas que fazem parte da empresa precisam ser preparadas para atuar de maneira harmônica e integrada a um novo modelo a ser adotado. Dessa forma são realizadas diversas atividades com a direção, com as equipes técnicas e com as equipes operacionais.

- Visão sistêmica - após o diagnóstico e a conscientização, a empresa deve ser vista de uma forma sistêmica, por todos, aplicando esse conceito. Uma representação da empresa é modelada com os envolvidos para identificar como são as relações externas com fornecedores e clientes e as relações internas entre funções e processos.

- Modelagem dos processos - os processos de negócio são definidos como a célula da organização no modelo de gestão baseado no uso da informação. Após a visão sistêmica, cada processo deve ser analisado, identificando suas entradas, saídas e atividades de transformação. Isso possibilita definir responsabilidades, resultados esperados e uma visão clara do funcionamento da empresa. Deve haver também um sincronismo entre os processos tendo como base a agregação do valor ao produto. Nessa etapa são identificadas as informações que são usadas nos processos do sistema da qualidade, planejamento e controle. 
- Sistema da qualidade - uma vez definida a modelagem dos processos, é iniciado o sistema da qualidade que documenta as informações usadas nos processos e orienta como as pessoas devem atuar para que os resultados esperados sejam alcançados.

- Sistema de planejamento - representa a organização para a tomada de decisão e seu desdobramento na empresa. Baseada na visão estratégica, devem ser organizados os processos de planejamento tático e o operacional, gerando informações sobre o que, quanto, quando e com que produzir. Neste item enquadram-se as atividades como programação da produção e planos anuais, mensais, entre outros.

- Sistema de controle - os dados gerados nos processos, e registrados, devem ser tratados como informação para realimentar o processo decisório. A empresa deve definir os indicadores que serão usados para controle dos principais processos, os indicadores gerenciais de cada função, e por fim os macro indicadores, ou indicadores estratégicos. Esses indicadores são apresentados em forma de relatórios que possibilitam a análise dos resultados obtidos.

- Monitoramento - as informações obtidas, apresentadas em forma de indicadores e relatórios, serão usadas para comparar os resultados alcançados com as metas desejadas. Deve haver uma interligação entre os indicadores para permitir uma análise global dos resultados, com a medição da produtividade.

- Revisão e Melhorias - a partir do monitoramento dos resultados são identificadas as necessidades de melhoria ou necessidade de ajustes no modelo de estratégia do negócio. Esta análise permite a adequação ou revisão da estratégia, dos produtos e da empresa, sendo reiniciado o ciclo.

\section{Conclusões com relação à pesquisa.}

Os casos estudados permitiram a observação de diversos pontos interessantes aqui relacionados (MOURA, 1999): 
- É importante a aplicação da visão sistêmica a uma empresa para identificar os elementos internos (processos). As empresas fazem parte de uma cadeia de valor e devem entender a sua dependência de fornecedores e clientes.

- O investimento em TI para a gestão das empresas é uma necessidade importante, pois permite a agilização no fluxo das informações e reduz trabalhos manuais desnecessários.

- A TI representa um meio, um instrumento para que a empresa possa atingir seus objetivos e, portanto, deve ser dimensionada e planejada para tanto (alinhamento estratégico).

- A informação é o instrumento pelo qual os processos, funções e pessoas podem ser sincronizados e articulados em direção aos objetivos da empresa.

- Os modelos de organização tradicionais não são adequados ao dinamismo atual. É necessário que seja adotado um modelo que possibilite um intensivo uso da informação em todos os níveis da organização de modo descentralizado e flexível, apoiando a atuação das equipes de trabalho.

- As pessoas devem ser preparadas para um modelo de organização baseado no uso da informação, atuando com agentes de informação, sabendo usar e gerir a informação.

- Antes de investir em tecnologia da informação é necessário que a empresa possa ser estruturada e adote um modelo de organização com base na gestão da informação.

- A empresa deve definir e organizar a informação que usa em sua gestão.

- O investimento em gestão da informação e tecnologia da informação proporciona uma descentralização no uso da informação, fazendo com que as pessoas tenham grande acesso às informações necessárias ao seu trabalho. Isso altera a estrutura do poder das empresas e as chefias, anteriormente donas das informações, devem ter o seu papel readequado, sendo mais um apoiador e orientador do que o elemento de decisão de autorização. 


\section{IV.3 ANÁLISE DE INVESTIMENTOS EM TI}

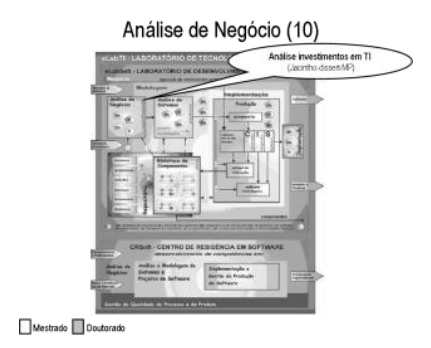

As organizações têm tido um investimento cada vez maior em tecnologia da informação, fato que traz uma preocupação com as escolhas realizadas, seja na seleção de novos projetos, seja na implantação de novas tecnologias ou na determinação de prioridades dos projetos a serem implantados. As técnicas clássicas de avaliação econômica mostram ser inadequadas para justificar por completo desses investimentos e por essa razão são questionados. A determinação do custo é simples, uma vez que se trata do custo de desenvolvimento e implantação do projeto. O problema é determinar o benefício, ou seja, quantificar financeiramente qual o benefício que o novo projeto trará para a organização (JACINTHO, 2000).

Em algumas situações os investimentos em TI são facilmente justificáveis pelas técnicas clássicas de avaliação econômica, como por exemplo, quando há a substituição de mão-de-obra onde se sabe o custo atual para a realização da atividade e o investimento no novo projeto. Nesse caso, a relação custo/benefício pode ser calculada diretamente. Há situações, entretanto, onde não é tão fácil avaliar financeiramente o benefício obtido, como por exemplo, em um sistema de apoio à decisão.

Farbey (1995) propõe um modelo, denominado Escada de Farbey, onde o sistema pretendido é primeiramente classificado em um de 8 degraus. Para cada um deles Farbey faz recomendações sobre os critérios a serem adotados para a decisão de implementação ou não do sistema. Quanto mais próximo o sistema estiver da eficácia (necessidade da organização), mais difícil será avaliar financeiramente o benefício obtido e critérios alternativos são propostos para a decisão de implementar ou não o sistema.

Há também um questionamento com relação aos benefícios que os sistemas de tecnologia da informação trazem para a organização, conforme relatado por Laurindo (2002). A esse fenômeno dá-se o nome de Paradoxo da Produtividade. Este autor relata também diversos casos da literatura onde os pesquisadores procuram estabelecer a relação entre os investimentos em $\mathrm{Tl}$ e indicadores financeiros, e a conclusão que se chega é que não é possível estabelecer uma 
relação direta da eficácia da TI usando unicamente os indicadores financeiros. Mais recentemente Carr (2003) coloca que a TI não é mais uma forma da organização obter vantagem competitiva pois está se tornando uma commodity.

Esta pesquisa se propõe a encontrar uma solução de compromisso entre as técnicas tradicionais de investimentos e o os novos estudos que envolvem uma orientação integrada para a tomada de decisão sobre investimentos em tecnologia da informação. $O$ trabalho visa também detectar os custos e benefícios intangíveis, bem como identificar os fatores críticos de sucesso, de modo a atender às expectativas de todos os envolvidos com a empresa.

A sistemática proposta por Jacintho (2000) está representada na Figura 25.

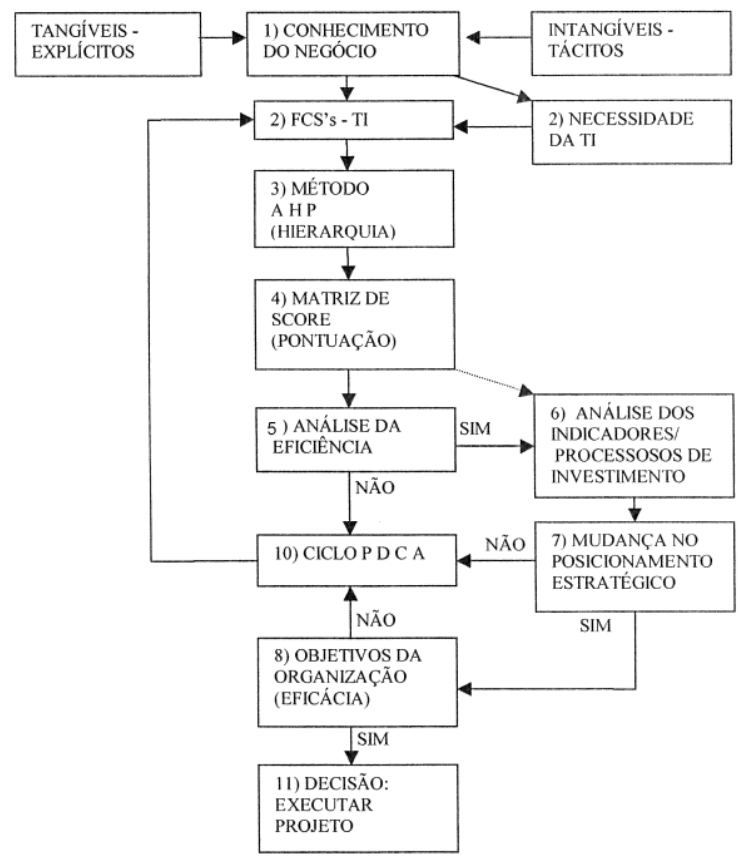

Figura 25 - Sistemática para avaliação de projetos de TI (Jacintho, 2000)

O primeiro passo é justificar o investimento de $\mathrm{TI}$ procurando, a partir do conhecimento do negócio, estabelecer os benefícios tangíveis e intangíveis do novo sistema.

O segundo passo é identificar os fatores críticos de sucesso para que se possa determinar a real necessidade de aquisição do sistema.

No terceiro passo aplica-se o método AHP - Análise Hierárquica de Processo, uma técnica estruturada para se lidar com decisões complexas. Para o uso do AHP, primeiramente deve-se decompor o problema decisório em uma hierarquia de sub- 
problemas mais fáceis de compreender, cada um dos quais a ser analisado de forma independente. Os elementos da hierarquia podem estar relacionados com algum aspecto do problema decisório (tangível ou intangível), cuidadosamente medidos ou estimados grosseiramente, claramente ou pobremente entendidos, qualquer elemento que se tiver em mãos para ser aplicado à decisão.

O quarto passo leva estabelecer uma matriz de pontuação (Score).

O quinto passo realiza a análise da eficiência dos sistemas. Caso a eficiência seja positiva segue-se para os passos 6 e 7 (eficiência adequada).

Nesse sexto passo é realizada a análise dos indicadores ou dos processos de investimento.

O sétimo passo avalia se o novo projeto vai levar a uma mudança no posicionamento estratégico da empresa.

Caso negativo (não leva a mudança no posicionamento estratégico), segue-se para o passo 10, que é realizar o PDCA, retornando para o passo no 2.e refazendo todo o ciclo.

No caso do projeto estabelecer positivamente mudanças no posicionamento estratégico, segue-se para o passo 8 onde se analisa a eficácia do sistema.

Caso a eficácia seja positiva, positivo a decisão seria executar o projeto e caso negativo volta-se ao passo 10 para realizar o ciclo novamente a partir do passo 2 .

Este método foi aplicado em duas empresas da área industrial: a primeira delas é uma empresa montadora multinacional que produz caminhões e ônibus e a segunda uma indústria do ramo de papel e celulose. São empresas que atuam em mercados diferentes, uma globalmente e a outra apenas no Brasil. O resultado obtido na aplicação da sistemática proposta por Jacintho (2000) foi adequado para os dois casos. Essa sistemática, aplicada nas duas organizações, demonstrou que os projetos analisados visavam uma mudança no posicionamento estratégico de cada organização. Cabe salientar que uma avaliação apenas financeira é condição necessária mas não suficiente para a tomada de decisão quanto à execução e implantação dos projetos de TI. No primeiro caso a viabilidade era evidente e a sistemática indicou esse resultado no primeiro ciclo. No segundo caso a avaliação 
da eficiência (passo 6) foi negativa por ser este um projeto ruim ou por estar no limiar dos resultados esperados. Desse modo foi possível refazer o ciclo PDCA de forma a abordar a mesma questão sob outra ótica e assim, após pequenos ajustes, viabilizar o projeto. Esta sistemática é um processo que exige conhecimento político da organização, do mercado global e da equipe envolvida. 


\section{IV.4 GESTÃO DO CONHECIMENTO EM PEQUENAS ORGANIZAÇÕES}

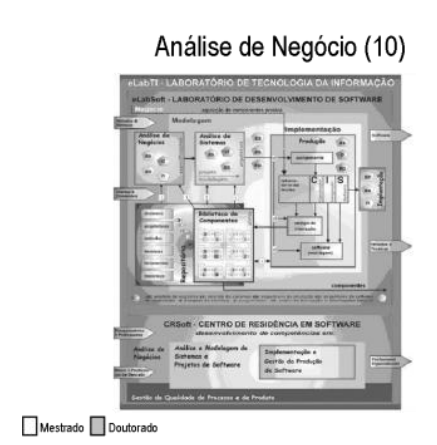

$\mathrm{Na}$ pesquisa realizada com Marçula (2001, 2001a) foi desenvolvido um modelo para Gestão do Conhecimento em pequenas organizações. Entende-se por organização uma empresa de pequeno porte, uma seção, ou departamento de uma grande empresa. O conceito de Conhecimento está ligado à tripla Dado/Informação/ Conhecimento.

\section{Dado}

É um conjunto de fatos relativos a eventos e estão ligados aos estímulos que as pessoas recebem pelos seus sentidos. Nas empresas eles são registros estruturados de transações, normalmente armazenados em sistemas tecnológicos. Os dados possuem pouca relevância ou propósito, pois dizem pouco sobre as transações (por exemplo, porque foram feitas, se vão se repetir, etc.). $O$ mais importante é que os dados não possuem significado inerente, descrevem apenas o que aconteceu. Não servem como base para a tomada de ações, no máximo podem ser a matéria prima. (MARÇULA, 2001).

\section{Informação}

A informação diferente dos dados possui significado, relevância e propósito. Apresenta-se na forma de documentos ou de comunicações sonoras. É quem recebe, não quem emite, que decide se a mensagem passada pelos dados constitui uma informação. Nas empresas a informação pode movimentar-se por redes hard (cabos, centrais de correio, caixas postais eletrônicas, Internet, etc.) ou soft (modos menos formais e visíveis, como por exemplo, a cópia de um artigo de jornal com uma marcação). Para que os dados se transformem em informações, esses devem ganhar significados. Alguns métodos podem ser considerados para isso:

- Contextualização: é sabida a finalidade dos dados coletados.

- Categorização: são conhecidos os componentes essenciais dos dados.

- Cálculo: os dados podem ser analisados matemática ou estatisticamente.

- Correção: os erros são eliminados dos dados. 
- Condensação: os dados podem ser resumidos para uma forma mais concisa.

A TI auxilia em todos esses processos de conversão, mas não consegue fazer o trabalho sozinha em várias situações.

\section{Conhecimento}

O conhecimento é mais amplo, profundo e rico do que as informações e normalmente quando se fala em conhecimento, refere-se a pessoas e não a documentos ou sistemas. Em uma empresa o conhecimento pode ser definido como (MARÇULA, 2001):

"uma mistura fluída de experiência condensada, valores, informação
contextual e insight experimentado, a qual proporciona uma estrutura para a
avaliação de novas experiências e informações. Ele tem origem na mente
dos conhecedores. Nas organizações, costuma estar embutido não só em
documentos, mas também em rotinas, processos, práticas e normas
organizacionais". O conhecimento deriva das informações, e a transformação pode ocorrer através de (MARÇULA, 2001):

- Comparação: comparar informações sobre uma situação com outras já conhecidas.

- Conclusões: que conseqüências estas informações trazem para as decisões e para realização de ações?

- Conexões: quais as relações deste novo conhecimento com aqueles já acumulados?

- Conversação: o que as outras pessoas pensam desta informação?

Todas essas atividades acontecem na mente das pessoas e no contato entre elas, podendo ocorrer com o auxílio de ferramentas de TI.

Após o processo, surge um novo conhecimento que, armazenado com aqueles existentes, constitui o Conhecimento Acumulado. Este, por sua vez, é usado novamente nas transformações de dados em informações e essas em novos conhecimentos.

O conhecimento é entregue através de meios estruturados (livros, documentos, etc.) e de contatos pessoais (conversas, relações de aprendizado, etc.). 
Um exemplo disso é a pessoa que recebe o dado de que hoje a temperatura é de $33^{\circ} \mathrm{C}$. A pessoa compreende e cria a informação de que o dia está muito quente para essa época do ano e conclui que o aquecimento global está aumentando (conhecimento). A Figura 26, baseada em Alter (1992), apresenta essas transformações.

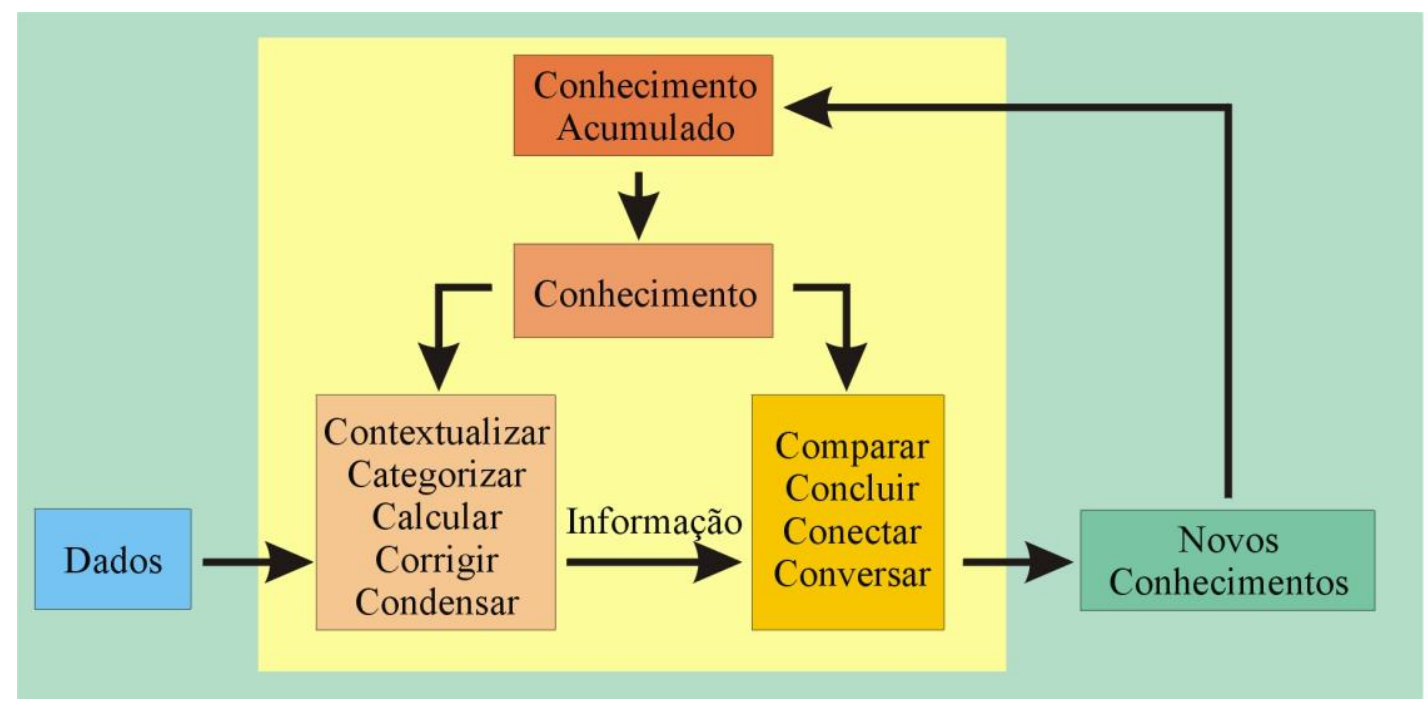

Figura 26 - Relacionamento entre dado, informação e conhecimento (Marçula, 2001)

Nas organizações, o conhecimento é usado como uma ferramenta importante para a realização das atividades, sejam elas operacionais, gerenciais ou estratégicas. Para isso é usado o modelo SECI de Nonaka e Takeushi (1997), ilustrado na Figura 27. Esse modelo SECI: Socialização, Externalização, Combinação e Internalização representa os quatro modos de conversão do conhecimento. $O$ conhecimento explícito é aquele que está registrado e organizado de forma que possa facilmente ser transferido de uma pessoa para outra. O conhecimento tácito é aquele intrínseco às pessoas, resultado de sua educação, experiência de vida e capacidade individual de elaboração e aprendizado.

Nesse modelo, a primeira fase, de socialização, trata do contato entre duas pessoas que compartilham e experiências, como por exemplo, um aprendiz que trabalha com seu mestre, não através da linguagem, mas através da observação e imitação e prática. O segredo para aquisição do conhecimento tácito é a experiência.

A segunda fase, de externalização, é a articulação do conhecimento tácito em conceitos e explícitos. É um processo de criação do conhecimento perfeito, na 
verdade na medida em que o conhecimento tácito se torna explícito, na forma de metáforas, analogias, conceitos, hipóteses ou modelos.

A terceira fase, combinação, é um processo de sistematização de conceitos em um sistema de conhecimento desse modo de conversão envolve a combinação de conjuntos diferentes de conhecimento explícito.

A quarta fase, internalização é o processo de incorporação do conhecimento explícito no conhecimento tácito. Está intimamente ligada ao aprender fazendo.

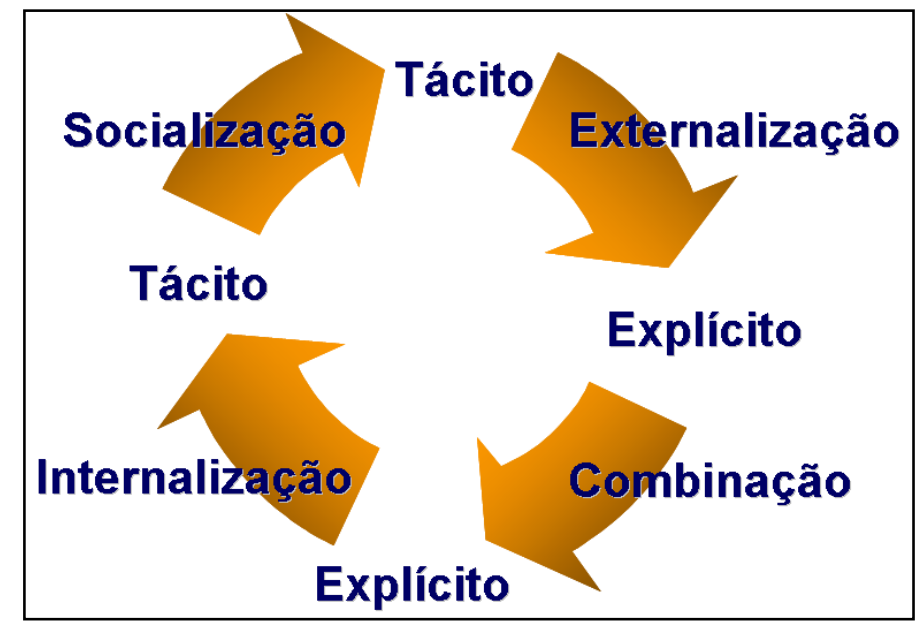

Figura 27 - modelo SECI - Nonaka e Takeushi (1997)

Com base nesses conceitos, Marçula (2001) propôs um modelo para a gestão do conhecimento em pequenas organizações, representado na Figura 28. Nas organizações é comum encontrar atividades que são realizadas por apenas uma pessoa. Nesse modelo, a idéia é fazer (passo A) um estudo preliminar na empresa e identificar os problemas existentes (passo B), considerando que "problema" é uma atividade importante para a operação, cujo conhecimento para sua realização está em posse de apenas uma pessoa de maneira não formalizada (tácito). Em outras palavras, a idéia é perguntar para o gerente ou o responsável por uma atividade: "qual atividade(s) ficará prejudicada se quais pessoas pararem imediatamente de trabalhar aqui?" Provavelmente, por uma ou outra razão, o domínio sobre a realização de algumas atividades está na mão de algumas poucas pessoas e esta situação precisa ser mudada. 


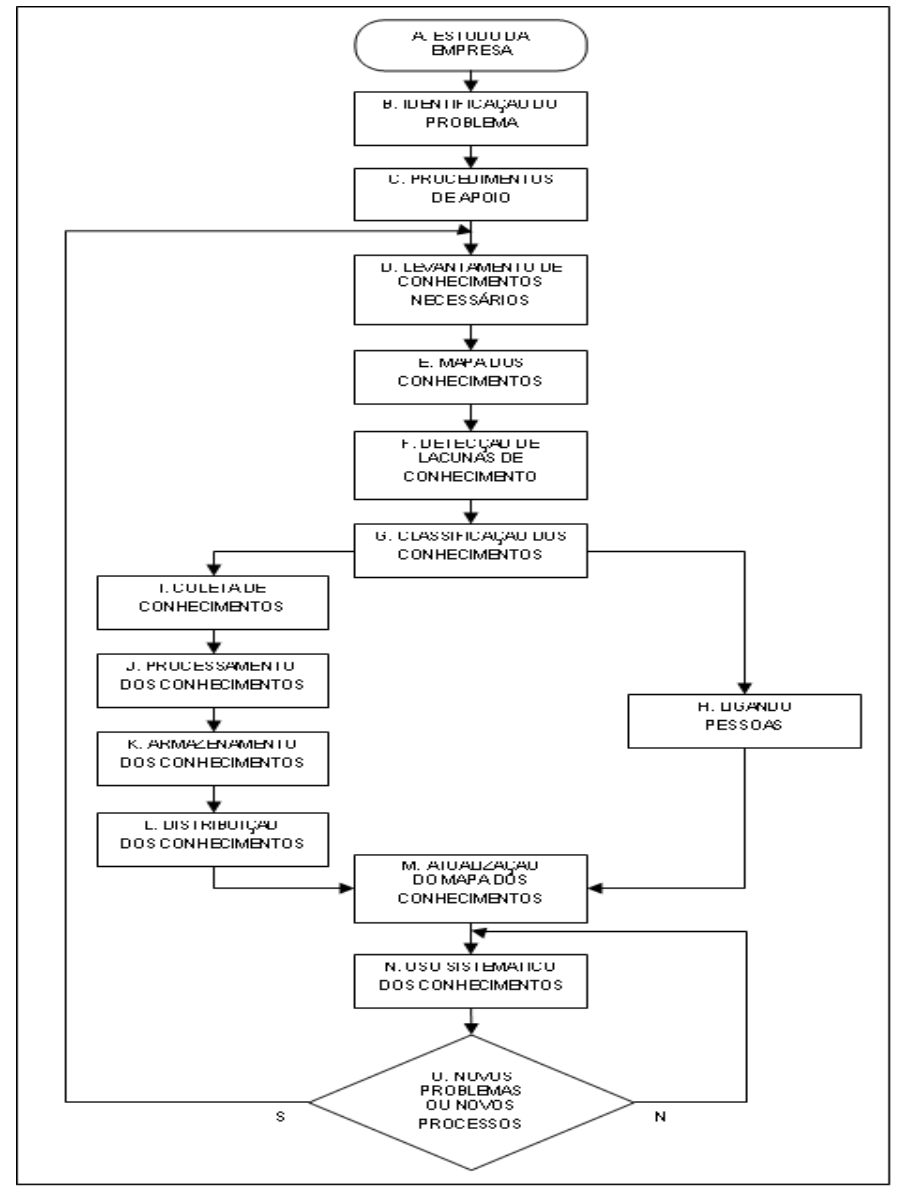

Figura 28 - Etapas de Implantação e Manutenção da Gestão do Conhecimento (Marçula, 2001)

Devem ser elaborados os procedimentos de apoio, que é transformar o conhecimento em explícito (passo $\mathrm{C}$ ) e identificar os conhecimentos necessários para a realização das atividades (passo $D$ ), pois nem todas as atividades podem ser transformadas em explícitas com facilidade (MARÇULA, 2001).

No passo $E$ obtém-se o mapa de conhecimentos necessário a toda a operação escopo do trabalho. Analisando o perfil das pessoas que estão nas diversas posições realizando as atividades, pode-se identificar as lacunas de conhecimento (passo F). Um trabalho importante a ser realizado é a classificação dos conhecimentos para definir a melhor forma de desenvolve-los (passo G), como um sistema de informação (ramo esquerdo da Figura 28), ou como um tipo de conhecimento mais tácito, onde a forma de tratar mais adequada é através da socialização (ramo da direita) (MARÇULA, 2001).

Conforme já explicado, no ramo da esquerda, o conhecimento pode ser tratado como um sistema de informação através da coleta, processamento, armazenamento e distribuição (passos I até L). Forma similar de tratamento é aquele dado pela 
implantação da ISO 9001, pois os processos de trabalho são identificados, descritos, registrados e controlados (MARÇULA, 2001).

No caso de conhecimento voltado a atividades mais tácitas, como por exemplo, atendimento a cliente ou mesmo o desenvolvimento de uma habilidade para uma tarefa mecânica, a melhor forma é fazer com que as pessoas trabalhem juntas, uma o aprendiz outra o mestre (passo H). Observar que isso precisa ser feito de maneira clara para as partes envolvidas para que haja a postura de ensinamento e de aprendizagem (MARÇULA, 2001).

O modelo de Gestão da Qualidade, a Norma ISO 9001 tem a finalidade similar de garantir que as atividades importantes para a qualidade são realizadas por pessoas treinadas e capacitadas. Para tanto, os processos são identificados, explicitados, treinados e controlados. Analisando o modelo proposto por Marçula (2001), foi observado que há uma similaridade com esse modelo, pois em uma pequena organização, a gestão do conhecimento é implantada para garantir que não há perda de conhecimento quando há rotatividades das pessoas. Foi realizada uma pesquisa e identificado que a gestão do conhecimento pode ser um primeiro passo, anterior à implantação de um sistema de gestão da qualidade, conforme publicado por Hegedus et.al (2002). 


\section{IV.5 GESTÃO DE SERVIÇOS}

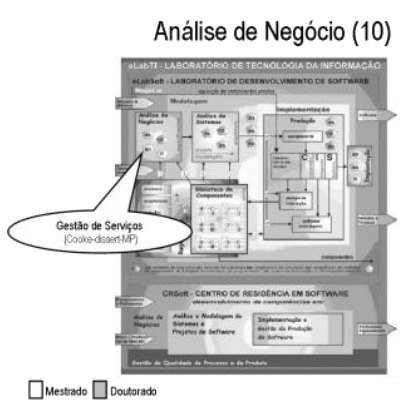

Na pesquisa realizada com Cooke (2000) sobre Gestão de Serviços, foi desenvolvido um modelo visando, através de uma série de técnicas, fidelizar o cliente. Há, nesse trabalho, um modelo que propõe uma taxonomia dos diferentes tipos de serviços, em função do contato com o consumidor e o valor agregado, conforme ilustrado na Figura 29. Esse modelo é útil para ser analisado do ponto de vista da Fábrica de Software. Nas colunas está representado o grau de contato com o cliente: à esquerda o cliente possui contato direto com o realizador do serviço (pessoas), como por exemplo assistência técnica domiciliar e à direita o cliente somente tem contato com os bens facilitadores como é o caso do cinema. A coluna do meio representa uma situação híbrida. Nas linhas está representado o valor agregado do serviço prestado, se é na presença do cliente ou isolado do cliente. Há também uma situação híbrida. Com isso configuram-se 9 células com as combinações duas a duas dessas possibilidades.

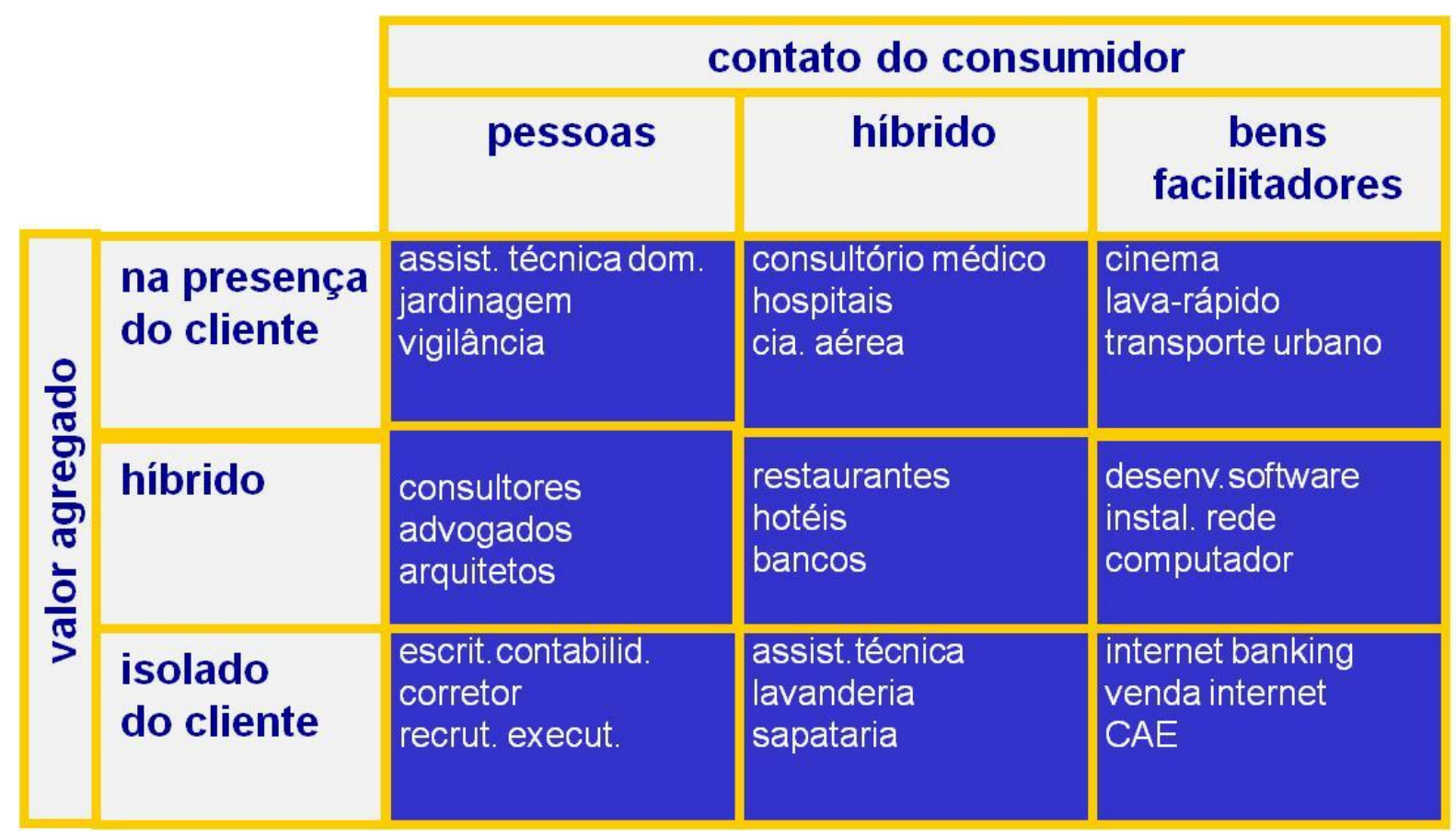

Figura 29 - Diferentes tipos de serviços 
Os exemplos facilitam a compreensão Cooke (2000):

- Um cinema é um serviço com valor agregado na presença do cliente é realizado com bens facilitadores (a sala e o projetor de filme)

- Uma assistência técnica domiciliar é realizada na presença do cliente e é realizada por uma pessoa

- Um corretor procura os imóveis para seu cliente longe do mesmo e esse trabalho é realizado sem bem facilitador

- Uma venda pela internet é realizada através de bens facilitadores (a internet) e é efetivada isolada do cliente.

As demais células são casos mistos onde há pessoas e bens facilitadores ou parte do valor é agregado na presença do cliente Cooke (2000).

Esse modelo pode ser observado de duas formas:

- sob a ótica de analista de negócio, que vai analisar um serviço do cliente para implementar um sistema de tecnologia da informação, ou

- sob a ótica da prestação de serviços de TI.

\section{IV.5.1 A ótica do analista de negócio}

A TI tem sido muito utilizada como bem facilitador para prestação de serviços. Caso o serviço esteja situado na coluna da direita, onde o prestador de serviço não tem pessoas para realizarem o atendimento, é necessário considerar esse fato nos requisitos do sistema a ser projetado. Quando a situação é híbrida, onde o prestador de serviço possui uma pessoa para apoiar ou orientar, isso não é tão importante pois o cliente tem alguém a quem recorrer se houver algum problema.

\section{IV.5.2 A ótica de prestação de serviços de TI}

Essa ótica tem por utilidade organizar o próprio serviço prestado. 
Dessa forma, o levantamento de requisitos é uma atividade realizada na presença do cliente e o valor agregado está na presença do cliente, ou seja, o cliente percebe que a área de Tl está interessada nos seus problemas. Nessa mesma célula estão as atividades de implantação de software (Figura 30).

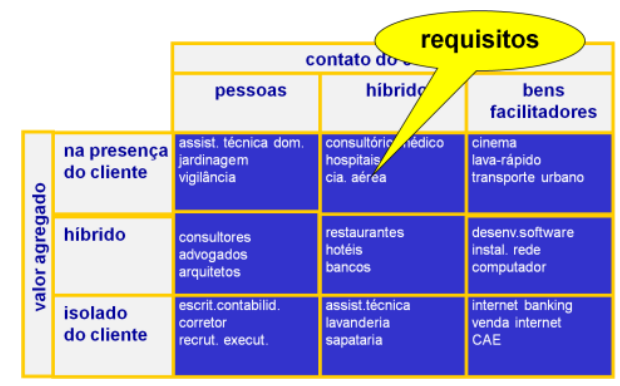

Figura 30 - enquadramento dos requisitos

A atividade de programação, por outro lado é realizada com bens facilitadores e o valor agregado é isolado do cliente e, portanto, encontra-se em outra célula do modelo (Figura 31).

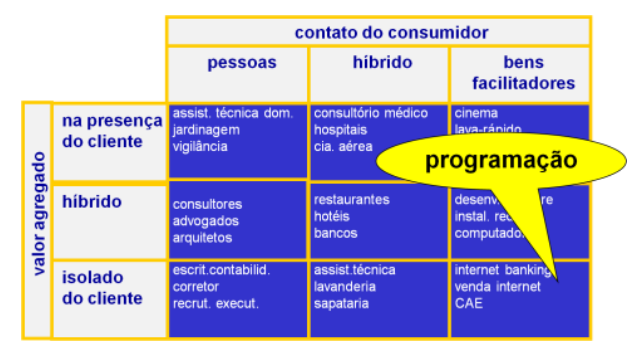

Figura 31-enquadramento da programação

Esse modelo auxilia no planejamento dos processos de relacionamento com o cliente. É comum encontrar nas organizações pessoas que têm dificuldade de realizar um bom atendimento ao cliente, como por exemplo um técnico de rede de computador. Para desempenharem bem suas tarefas, é fundamental que as pessoas sejam adequadamente treinadas, principalmente aquelas que têm contato com o cliente para realizar suas atividades. Se nessas atividades houver a maior parte do valor agregado isso é mais importante ainda. 


\section{IV.6 NOVAS TECNOLOGIAS DE COMUNICAÇÃO}

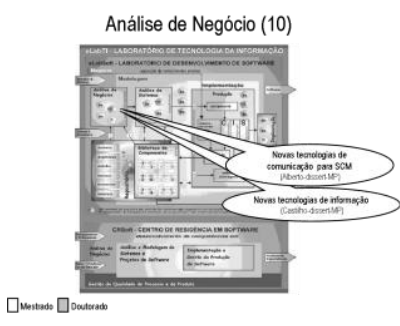

Foram desenvolvidas duas pesquisas que analisaram a aplicação da Internet no ambiente corporativo: Castilho (1998) e Medeiros Jr. (2002). No primeiro trabalho, desenvolvido por Castilho (1998), foi realizado um levantamento de alguns casos de aplicação da internet nas empresas. Naquela época, a novidade era a utilização da Intranet e foi identificado que houve um aumento expressivo dos recrutamentos internos em uma das organizações estudadas. Antes do $\mathrm{RH}$ disponibilizar na Intranet as vagas para recrutamento interno, essa informação era colocada em um mural. No entanto, as pessoas ficavam constrangidas de analisar essas oportunidades na frente dos colegas. Com a Intranet, essa atividade poderia ser feita de forma discreta no próprio posto de trabalho, sem a exposição à qual ficava o profissional na situação anterior. Nesse trabalho não foi identificada nenhuma empresa que utilizava o conceito de Extranet, ou seja, uma Intranet na qual participavam também outras empresas (clientes ou fornecedores).

A segunda pesquisa, desenvolvida por Medeiros Júnior (2002), realizou uma análise das novas tecnologias de comunicação de dados utilizadas na cadeia de suprimentos. Segundo Medeiros (2002) e Porter \& Millar (1985), a cadeia de valor é o conjunto das atividades tecnológicas e economicamente distintas que empresa utiliza para realizar seus negócios. Cada uma dessas atividades seria uma "atividade de valor". A cadeia de valor compõe-se de uma série de atividades independentes conectadas através das ligações presentes sempre que uma atividade afetar o custo ou a eficiência de outras atividades. Agregar valor nessa cadeia de maneira mais significativa que seus concorrentes torna a empresa mais competitiva. A Figura 32 apresenta a cadeia de valor com as atividades meio e as atividades fim de uma empresa. 


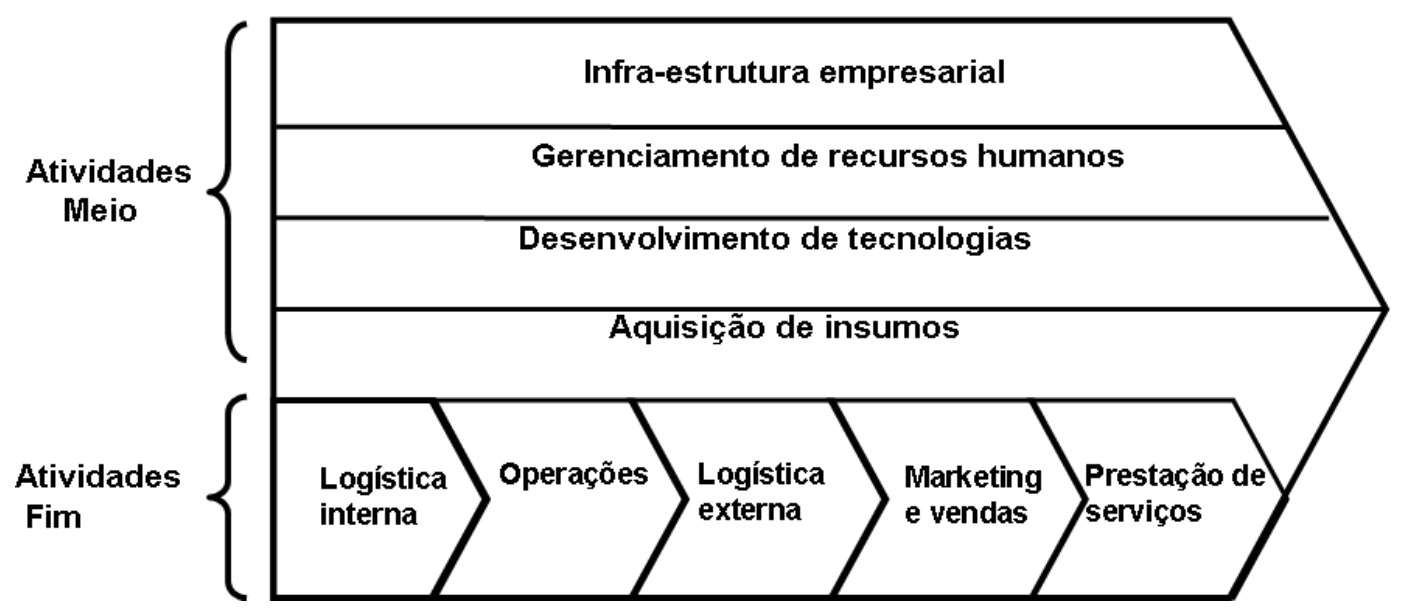

Figura 32 - Cadeia de Valor de Porter \& Millar (1985)

Em um plano mais macro, onde se observa a cadeia de fornecimento, ou seja, os diversos clientes e fornecedores que se encadeiam para prestar um serviço ou vender um produto para um usuário final, é formado o sistema de valor (Figura 33).

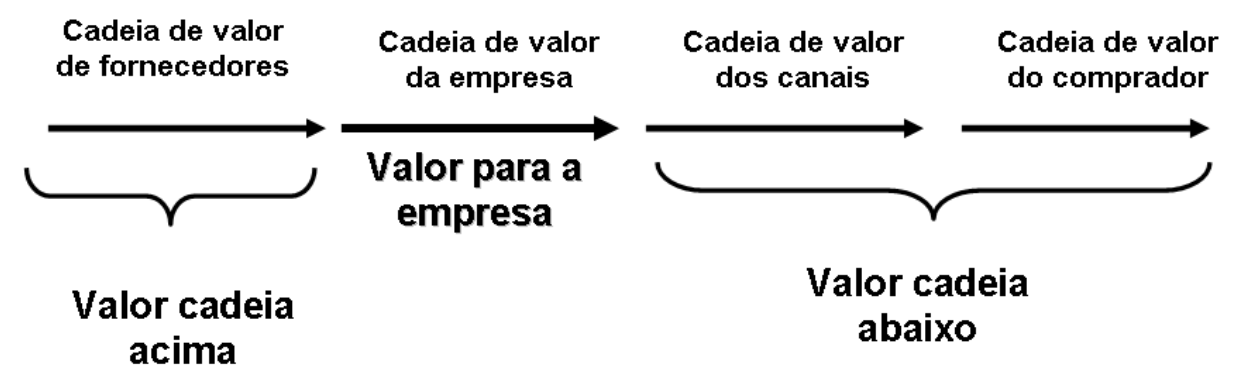

Figura 33 - Sistema de valor de Porter \& Millar (1985)

A tecnologia da informação altera a execução das atividades e a natureza das ligações entre elas. Isso ocorre tanto na cadeia de valor (dentro da empresa) como no sistema de valor (na cadeia de fornecimento). $O$ uso da internet também permite mudanças estratégicas em manufaturas descentralizadas (RABECHINI JR, 2001). A pesquisa realizada por Medeiros Jr. (2002), estudou a aplicação das novas tecnologias na cadeia de suprimentos, ou seja, no sistema de valor .

A conexão entre as empresas, fornecedores e clientes, na cadeia de suprimentos é feita através do uso de EDI (Electronic Data Interchange). Essa tecnologia existe desde a década de 60. Nessa época utilizavam-se padrões proprietários e foram criadas organizações para desenvolver padrões intra e inter-empresariais. A ONU 
liderou um grupo de trabalho e criou um padrão hoje é conhecido como EDIFACT. Os bancos no Brasil criaram, em 1979, um padrão denominado CNAB para realizar as transações inter-bancárias, além da criação de uma empresa, na qual diversos bancos eram sócios, para viabilizar tecnicamente essas conexões. O Quadro 3 apresenta a pesquisa realizada pela entidade ECR Brasil em 1998 que apontou as vantagens de se adotar o EDI (MEDEIROS JR, 2006).

\begin{tabular}{|l|c|c|c|c|}
\hline & Indústria & $\begin{array}{c}\text { Atacadista } \\
\text { e } \\
\text { Distribuidor }\end{array}$ & $\begin{array}{c}\text { Transportador } \\
\text { e } \\
\text { Operador } \\
\text { Logístico }\end{array}$ & Varejo \\
\hline Agilidade na cadeia de suprimentos & $\mathrm{X}$ & & & \\
\hline Atendimento a solicitação de parceiro & $\mathrm{X}$ & & $\mathrm{X}$ & \\
\hline Avanço tecnológico & $\mathrm{X}$ & & $\mathrm{X}$ & \\
\hline Agilidade nas informações & & $\mathrm{X}$ & & $\mathrm{X}$ \\
\hline Redução de papéis & & $\mathrm{X}$ & & \\
\hline Qualidade das informações & & $\mathrm{X}$ & & $\mathrm{X}$ \\
\hline Redução de erros operacionais & & & & $\mathrm{X}$ \\
\hline $\begin{array}{l}\text { Agilidade no relacionamento com } \\
\text { embarcadores }\end{array}$ & & & $\mathrm{X}$ & \\
\hline
\end{tabular}

Quadro 3 - Motivação para implantação de EDI (Medeiros Jr. 2002)

A mesma pesquisa apontou, conforme ilustra o Quadro 4, as dificuldades apontadas para a implantação do EDI.

\begin{tabular}{|l|c|c|c|c|}
\hline & Indústria & $\begin{array}{c}\text { Atacadista } \\
\text { e } \\
\text { Distribuidor }\end{array}$ & $\begin{array}{c}\text { Transportador } \\
\text { e } \\
\text { Operador } \\
\text { Logístico }\end{array}$ & Varejo \\
\hline Integração com sistemas internos & $\mathrm{X}$ & $\mathrm{X}$ & $\mathrm{X}$ & $\mathrm{X}$ \\
\hline Resistência de parceiros & $\mathrm{X}$ & & & \\
\hline Adequação do layout & $\mathrm{X}$ & $\mathrm{X}$ & $\mathrm{X}$ & $\mathrm{X}$ \\
\hline Resistência interna & $\mathrm{X}$ & $\mathrm{X}$ & & \\
\hline Dificuldades com o parceiro & & $\mathrm{X}$ & $\mathrm{X}$ & $\mathrm{X}$ \\
\hline Desconhecimento do assunto pelo parceiro & & $\mathrm{X}$ & $\mathrm{X}$ & \\
\hline
\end{tabular}


Pode-se observar que a dificuldade apontada por todos é a integração dos sistemas internos e a adequação do layout, ou seja, ajuste detalhado das informações que circulam entre as empresas.

O problema da utilização desta tecnologia é o alto custo da rede de comunicação de dados. A Internet fez com que esse custo caísse drasticamente, permitindo que os serviços de comunicação de dados ficassem em níveis de preço mais acessíveis (inclusive os anteriormente existentes). Embora tenha a vantagem de custo, a internet possui uma disponibilidade inferior àquela das redes fechadas. Por essa razão, atividades que exigem grande volume de dados que circulam pela rede, fazem com que ainda se adote serviços especializados denominados VAN (Value Added Network).

Vale comentar que, decorridos sete anos dessa pesquisa, continuam valendo os mesmos conceitos e o que há de novidade, que na época era muito incipiente, é comunicação móvel. Esse fato traz mais um fator positivo para a cadeia de fornecimento, pois os sistemas de informação aumentam sua abrangência geograficamente, ou seja, há a possibilidade de se entrar com os dados em tempo real, no momento do fato gerador. Isso melhora a questão do apontamento mais exato (no tempo certo), reduz a possibilidade de erros de digitação (normalmente são dispositivos de captura de dados como código de barras), melhorando os sistemas de gerenciamento. Outra tecnologia que evoluiu nesse período foi o RFID (Radio Frequency Identification) que deverá substituir o código de barras e facilitar o acompanhamento de materiais internamente à empresa ou na distribuição (Glover, Himanshu, 2007). 


\section{IV.7 DIRETRIZES ESTRATÉGICAS PARA EMPRESAS DE SOFTWARE}

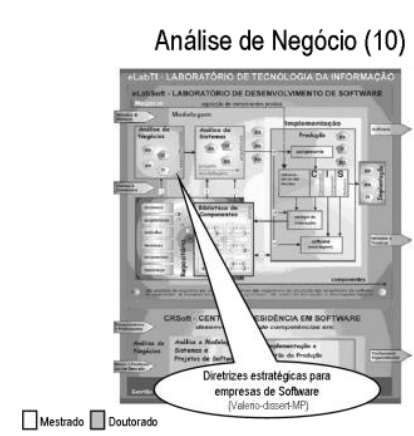

$\mathrm{Na}$ pesquisa desenvolvida com Del Maschi (2009), foi desenvolvido um trabalho de definição de diretrizes estratégicas para pequenas empresas de software.

O objetivo desta pesquisa foi demonstrar como a revisão da missão da organização e a elaboração de um plano estratégico com abordagem em diferentes perspectivas, contribuem para o aumento da competitividade no curto prazo. Neste trabalho, as características de iteratividade e resolução de problemas demandada pela organização objeto de estudo determinaram a metodologia pesquisa-ação. Esta técnica demonstrou-se muito adequada para esta situação onde havia um problema real a ser resolvido e o aluno teve um papel duplo, como pesquisador e como consultor. Essa situação obrigou-o a sistematizar melhor o trabalho de consultor, fazendo com que cada diagnóstico, identificação de situações peculiares, fosse realizado de forma sistemática. Antes de propor cada ação a ser tomada, todo o trabalho foi precedido de cuidadoso estudo, revisão bibliográfica, enfim todos os cuidados acadêmicos, tornando o trabalho de consultoria mais sólido com embasamento justificado (DEL MASCHI, 2009).

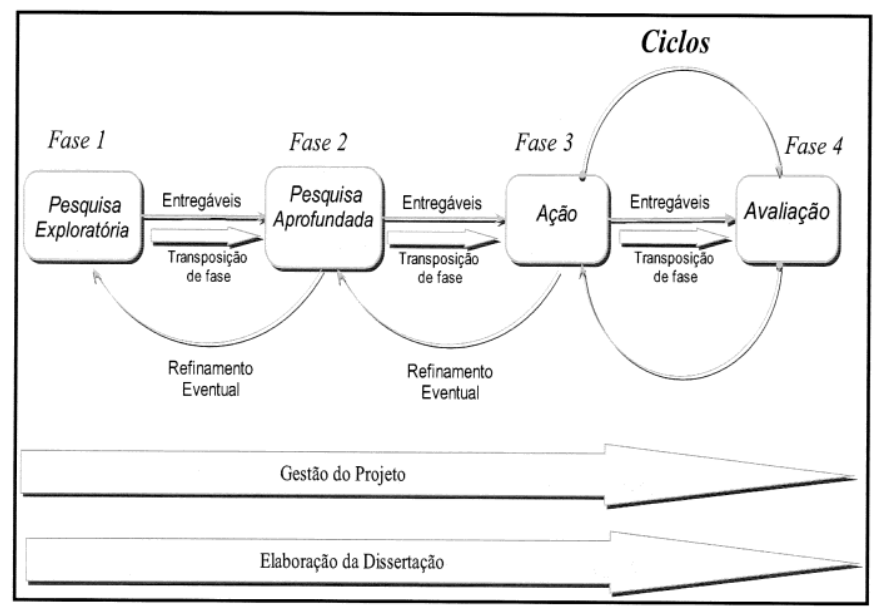

Figura 34 - Macro fluxo da Pesquisa-Ação (Del Maschi, 2009)

O roteiro macro da pesquisa está na Figura 34, elaborada a partir de Thiolent (1997) e outros autores (DELMASCHI, 2009). A primeira fase foi realizar uma pesquisa exploratória, a segunda fase foi uma pesquisa aprofundada cujo resultado foi a 
proposição de ações a serem tomadas na terceira fase. Depois de realizadas essas ações, a quarta fase avalia os resultados e, se necessário, é feita uma realimentação, para novas ações (processo convergente). Nas fases anteriores também podem ocorrer realimentações para correção de eventuais desvios. Todo este trabalho foi considerado como um projeto gerenciado com dois objetivos distintos: a pesquisa e o trabalho de consultoria na empresa (DEL MASCHI, 2009).

O Quadro 5 mostra o protocolo de pesquisa elaborado. Na primeira coluna da esquerda estão as quatro fases já citadas, na segunda coluna foi estabelecido o que detectar, promover ou apresentar. A terceira coluna mostra base teórica utilizada e a quarta coluna apresenta os pontos de análise ou os entregáveis de cada uma das fases.

\begin{tabular}{|c|c|c|c|}
\hline Fase & $\begin{array}{l}\text { O que detectar / } \\
\text { promover / apresentar }\end{array}$ & Base Teórica & $\begin{array}{c}\text { Pontos de } \\
\text { Análise/Entregáveis }\end{array}$ \\
\hline 1 Pesquisa Exploratória & $\begin{array}{c}\text { Iniciativas pré-existentes e } \\
\text { objetivos específicos }\end{array}$ & $\begin{array}{l}\text { Venkatraman, 1994; Porter, 1989; Kaplan \& } \\
\text { Norton, 2001; Zacarelli \& Guimarães, 2007; } \\
\text { Leite (2007); Carvalho \& Laurindo, } 2007\end{array}$ & \\
\hline \multicolumn{4}{|c|}{$\begin{array}{l}\text { 1. A empresa selecionada. } \\
\text { 2. Diagnóstico Inicial, ou seja, pontos fortes, fracos, oportunidades e ameaças. } \\
\text { 3. Atores envolvidos na pesquisa e seus papéis. } \\
\text { 4. Iniciativas existentes alinhadas com os objetivos da pesquisa. } \\
\text { 5. Objetivos específicos da pesquisa. }\end{array}$} \\
\hline 2 Pesquisa Aprofundada & $\begin{array}{l}\text { Revisão da Visão de } \\
\text { Futuro }\end{array}$ & $\begin{array}{l}\text { Todos da fase 1, incluindo: } \\
\text { Costa, 2007; Treacy \& Werrsema, 1995; } \\
\text { Guerrine \& Sacomano, 2002; Troccolli \& } \\
\text { Soares, 2003; Carvalho 2007, Thompson Jr. } \\
\text { \& Strickland, 2004; Tapscott et al., 2000; } \\
\text { Fusco et al., 2004; Arruda \& Arruda, 1998; } \\
\text { Chandler, 1987; Kaplan \& Norton, 1997; } \\
\text { Bower \& Christensen, 1995; Davenport, } \\
\text { 2004. } \\
\end{array}$ & \\
\hline \multicolumn{4}{|c|}{$\begin{array}{l}\text { 6. Revisão da Visão de Futuro. } \\
\text { 7. Elaboração das questões para cada objetivo específico: } \\
\text { - Definição da abordagem de negócio. } \\
\text { - Lidar com fatores impeditivos para o posicionamento estratégico. } \\
\text { - Estabelecer critérios para configuração de novos produtos e serviços. } \\
\text { - Traduzir a estratégia em termos operacionais }\end{array}$} \\
\hline Ação & $\begin{array}{c}\text { Resultados da Aplicação } \\
\text { da Pesquisa }\end{array}$ & Idem fase 2 & \\
\hline \multicolumn{4}{|c|}{ 8. Posicionamento da EOE frente às questões apresentadas na fase 2 - pesquisa aprofundada. } \\
\hline Avaliação & $\begin{array}{c}\text { Esclarecimento dos } \\
\text { Resultados da Pesquisa }\end{array}$ & Idem fase 2 & \\
\hline
\end{tabular}

Quadro 5 - Protocolo de pesquisa (Del Maschi, 2009)

Na pesquisa exploratória foi selecionada uma empresa (denominada EOE- Empresa Objeto de Estudo) que, além de permitir a realização da pesquisa, fosse de pequeno 
porte, que comercializasse produtos de software, que estivesse preocupada com planejamento de longo prazo, e que necessitasse realizar ou revisar um planejamento estratégico (DEL MASCHI, 2009).

\section{IV.7.1 Fase 1 - Pesquisa Exploratória}

\section{IV.7.1.1 A empresa selecionada (entregável 1)}

A empresa selecionada iniciou as atividades em 1985, como uma empresa de desenvolvimento de software sob demanda. Durante os dez primeiros anos seus principais clientes foram empresas de consultoria de maior parte que não tinham mão-de-obra especializada. A partir de 1995, a empresa passou a desenvolver aplicativos voltados para a área de recursos humanos particularmente gestão de freqüência, o ponto eletrônico. $O$ produto comercializado pela empresa tem como principal característica a automação das marcações que tradicionalmente eram realizadas manualmente. O sistema fornecido para os clientes (denominado SPE Sistema de Ponto Eletrônico) é realizado sob encomenda, pois integra-se com os sistemas existentes (ERP ou outro). Cada sistema vendido, depois de entregue e instalado, encerra a venda realizada. $O$ interesse da empresa é que os clientes façam contratos de manutenção e suporte técnico, pois se trata de uma receita constante (DEL MASCHI, 2009).

A partir de 1996 a empresa decidiu reduzir as atividades com desenvolvimento de software sob encomenda para investir no produto de ponto eletrônico denominado SPE. Foi feito um investimento interno para desenvolver esse produto, em 1997 e 1998 o faturamento ficou estabilizado, de 1999 para 2001 houve um crescimento da empresa em função da evolução da qualidade do SPE. A partir de 2002 houve uma queda no faturamento, que é objeto de análise desta pesquisa (DEL MASCHI, 2009).

\section{IV.7.1.2 Diagnóstico inicial (entregável 2)}

Para a a elaboração do diagnóstico Del Maschi (2009) utilizou-se de diversos autores como Porter, Venkatraman, Kaplan \& Norton, Zacarelli \& Guimarães, Carvalho \& Laurindo, conforme apresentado no Quadro 5. No primeiro passo foi 
utilizado o modelo SWOT de Porter (1989): pontos fortes, pontos fracos, oportunidades e ameaças.

Como pontos fortes foram identificados que o produto SPE possui baixo nível de defeitos, existe uma receita constante devido aos contratos de manutenção, a equipe interna é motivada e coesa, existe maturidade no gerenciamento dos projetos internos, a implantação do produto nos clientes hoje requer muito pouco custo, o treinamento e a implantação do produto podem ser realizados a distância, o suporte técnico tem um nível baixo de atividade.

Os pontos fracos são a redução do faturamento, os colaboradores da área de desenvolvimento e suporte possuem alto grau de especialização, o que significa uma ameaça no caso de perda da pessoa, um gerente comercial tem baixo dinamismo, o produto demanda poucas inovações, existe uma limitação da receita devido à não participação mais abrangente na cadeia de fornecimento de produtos e serviços de ponto eletrônico.

Oportunidades: o mercado de ponto eletrônico está em crescimento e várias opções de equipamentos com tecnologias diferentes para marcação de ponto e registro de freqüência podem agregar valor ao SPE. Com pouco esforço podem ser configuradas novas funcionalidades no produto. Os fabricantes de relógio de ponto, catracas, cancelas de estacionamento e cartões de identificação demonstraram interesse em realizar parceria com a empresa.

Ameaças: aumento da concorrência, os fabricantes de equipamentos para ponto eletrônico comercializam soluções a preços inferiores, e as soluções ERP possuem módulos para gerenciamento de freqüência.

\section{IV.7.1.3 Atores envolvidos (entregável 3)}

O entregável 3 é a descrição dos atores envolvidos. Não há interesse de detalhar nesse texto.

\section{IV.7.1.4 Iniciativas pré-existentes (entregável 4)}

O entregável 4 é o conjunto de iniciativas pré-existentes. A empresa já possuía a definição de missão e visão. Objetivos estratégicos também são definidos, mas o acompanhamento de seu cumprimento não é feito de forma sistemática. 
A empresa também possui parcerias, porém informais.

\section{IV.7.1.5 Objetivos específicos da pesquisa (entregável 5)}

A característica da pesquisa-ação é, em sua primeira fase, realizar uma pesquisa exploratória ao fim da qual são definidos os objetivos específicos. São eles:

- (i) definir a abordagem de negócio,

- (ii) identificar e tratar os fatores impeditivos para o posicionamento estratégico,

- (iii) estabelecer critérios para a configuração de novos produtos e serviços,

- (iv) traduzir a estratégia em termos operacionais.

\section{IV.7.2 Fase 2 pesquisa aprofundada.}

\section{IV.7.2.1 Revisão da Visão de Futuro (entregável 6)}

Para se identificar este item foram utilizadas entrevistas semi-estruturadas com os gerentes da área da empresa e posterior divulgação a todos os participantes.

\section{IV.7.2.2 Traduzir a estratégia em termos operacionais (entregável 7)}

A tradução para termos operacionais foi feita a partir da elaboração de questões para os objetivos específicos. Esta abordagem permite melhor direcionamento da pesquisa além de favorecer o registro dos resultados.

Objetivo específico 1 - definir a abordagem do negócio

- Questão A - aumentar a oferta de novos produtos e serviços.

- Questão B - obter dos clientes preferência na aquisição de produtos complementares.

- Questão C - mapear produtos e serviços nos principais concorrentes, buscando um posicionamento estratégico. 
IV.7.2.3 Objetivo específico 2 - lidar com fatores impeditivos para 0 posicionamento estratégico

- Questão D - definir a orientação da empresa se é diferenciação por custo ou enfoque. Dada a especialização da empresa, a orientação é por enfoque, particularmente no atendimento a empresas maiores.

- Questão E - mapear o nível de dependência de fornecedores

- Questão F - criar facilidades exclusivas e outros mecanismos para garantir a conquista de novos clientes

- Questão G - estabelecer iniciativas para que produtos dos concorrentes não sejam produtos substitutos

Objetivo específico 3 - estabelecer critérios para a configuração de novos produtos e serviços

- Questão $\mathrm{H}$ - entender quais fatores podem influenciar positivamente os clientes na aquisição de novos produtos e serviços

- Questão I - formar parceiros e alianças estratégicas com fornecedores de produtos complementares

- Questão J - formar de parcerias ou alianças estratégicas com outras empresas

Objetivo específico 4 - traduzir a estratégia em termos operacionais (BSC)

- Questão K - perspectiva financeira

- Questão $L$ - perspectiva dos clientes

- Questão M - perspectiva de processos internos

- Questão N - perspectiva de aprendizado e crescimento

Nesta etapa é definida uma ação para cada uma das questões e com isso fica encerrado o entregável 7. 


\section{IV.7.3 Fase 3 - Ação}

Na fase 3, a ação trata da implementação dos itens estabelecidos na fase anterior. Cada questão foi transformada em ações. Cada uma das ações definidas foi estruturada na forma de projeto para garantir sua boa implementação. As ações foram priorizadas de acordo com os critérios: facilidade, urgência, margem líquida estimada, o que virou o entregável 8 (Quadro 6).

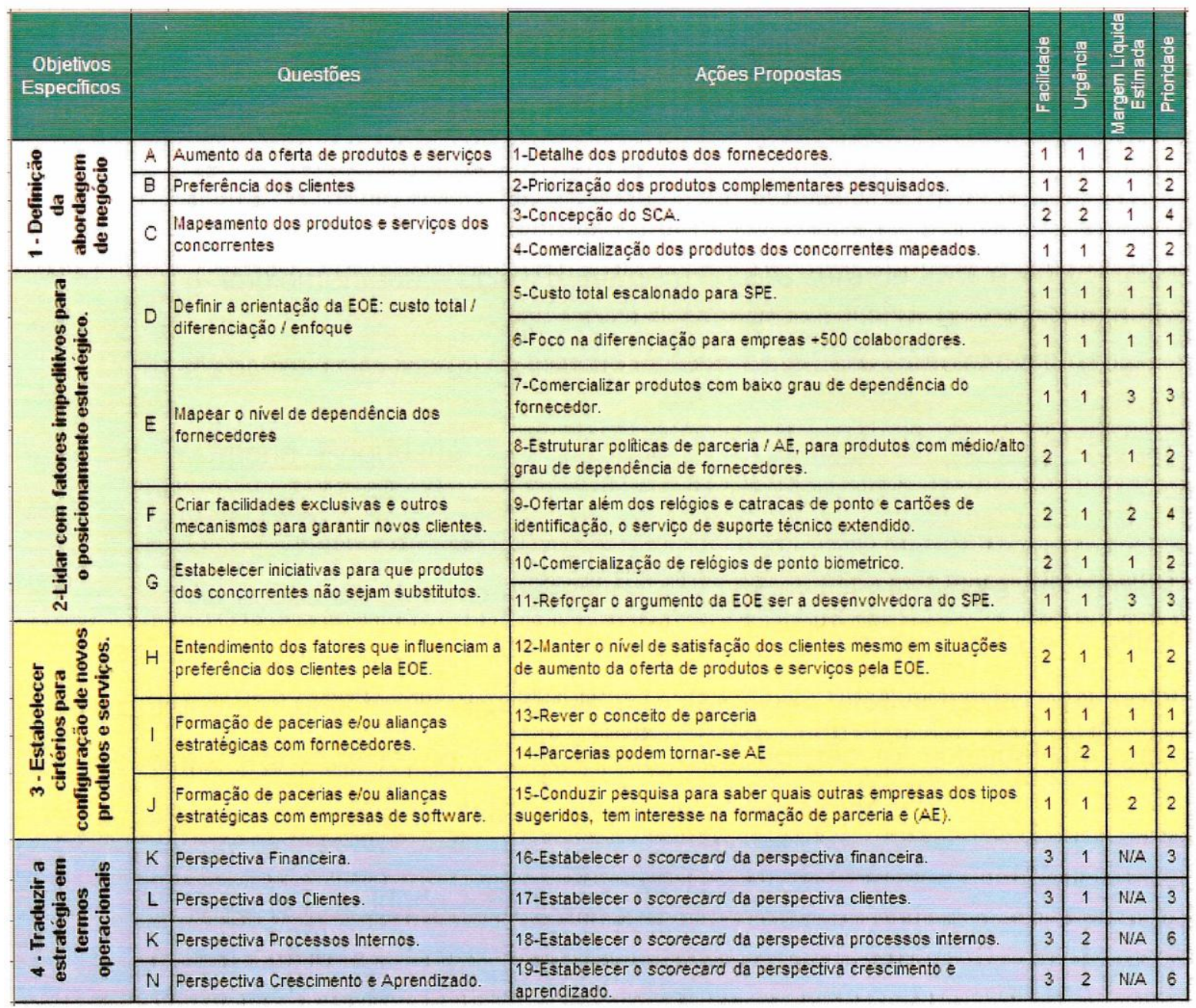

Quadro 6 - Ações propostas priorizadas (Del Maschi, 2009)

Os projetos foram organizados em três grupos e implementados com três ciclos, apresentado no Quadro 7. O primeiro ciclo tem como principais ações da abordagem no custo total na diferenciação clara da empresa, cuja implementação é de baixa complexidade, urgente e traz um aumento na margem líquida atual. O segundo ciclo 
é caracterizado pelo início da comercialização dos produtos complementares. $\mathrm{O}$ terceiro ciclo é marcado pela implementação do BSC (Balanced Scorecard).

\begin{tabular}{|c|c|c|c|c|}
\hline Ações Propostas & $\begin{array}{l}\frac{9}{10} \\
\frac{5}{10} \\
\frac{5}{6} \\
\frac{10}{4}\end{array}$ & $\begin{array}{l}\frac{\sqrt{3}}{6} \\
\frac{20}{60} \\
\frac{51}{5}\end{array}$ & 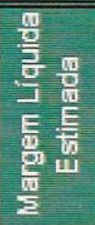 & $\frac{\frac{0}{0}}{\frac{0}{0}} \frac{5}{\frac{0}{5}}$ \\
\hline 5-Custo total escalonado para SPE. & 1 & 1 & 1 & 1 \\
\hline 6-Foco na diferenciação para empreas +500 colaboradores. & 1 & 1 & 1 & 1 \\
\hline 1-Detalhe dos produtos dos fornecedores. & 1 & 1 & 1 & 1 \\
\hline 13-Rever o conceito de parceria. & 1 & 1 & 1 & 1 \\
\hline 2-Priorizaçâo dos produtos complementares pesquisados juntos aos clientes. & 1 & 2 & 1 & 2 \\
\hline 14-Parcerias podem tornar-se AE. & 1 & 2 & 1 & 2 \\
\hline $\begin{array}{l}\text { 8-Estruturar politicas de parceria / AE, para produtos com médio/alto grau de } \\
\text { dependência de fornecedores. }\end{array}$ & 2 & 1 & 1 & 2 \\
\hline 10-Comercialização de relógios de ponto biométrico. & 2 & 1 & 1 & 2 \\
\hline $\begin{array}{l}\text { 12-lilanter o nivel de satisfação dos clientes mesmo em situações de aumento } \\
\text { da oferta de produtos e serviços pela EOE. }\end{array}$ & 2 & 1 & 1 & 2 \\
\hline 4-Comercialização dos produtos dos concorrentes mapeados. & 1 & 1 & 2 & 2 \\
\hline $\begin{array}{l}\text { 15-Conduzir pesquisa para saber quais outras empresas dos tipos sugeridos, } \\
\text { tem interesse na formaçäo de parceria e (AE). }\end{array}$ & 1 & 1 & 2 & 2 \\
\hline 7-Comercializar produtos com baiko grau de dependência do fornecedor. & 1 & 1 & 3 & 3 \\
\hline 11-Reforçar o argumento da EOE ser a desenvolvedora do SPE. & 1 & 1 & 3 & 3 \\
\hline 16-Estabelecer o scorecard da perspectiva financeira. & 3 & 1 & $\mathrm{~N} / \mathrm{A}$ & 3 \\
\hline 17-Estabelecer o scorecard da perspectiva clientes. & 3 & 1 & $\mathrm{~N} / \mathrm{A}$ & 3 \\
\hline 3-Concepção do SCA. & 2 & 2 & 1 & 4 \\
\hline $\begin{array}{l}\text { 9-Ofertar além dos relógios e catracas de ponto e cartôes de identificaçâo, o } \\
\text { serviço de suporte técnico extendido. }\end{array}$ & 2 & 1 & 2 & 4 \\
\hline 18-Estabelecer o scorecard da perspectiva processos internos. & 3 & 2 & $\mathrm{~N} / \mathrm{A}$ & 6 \\
\hline 19-Estabelecer o scorecard da perspectiva crescimento e aprendizado. & 3 & 2 & $\mathrm{~N} / \mathrm{A}$ & 6 \\
\hline
\end{tabular}

\section{Quadro 7-Ciclos das ações propostas priorizadas (Del Maschi, 2009)}

No fechamento desta pesquisa já haviam ocorrido importantes resultados práticos. Esses resultados foram conseqüência da implementação das ações, uma delas foi a reorganização do produto, a formação de parcerias estratégicas com outras empresas para atingir um maior mercado. Os resultados foram o fechamento da venda de vários produtos resultado dessas ações e por conseqüência o aumento de faturamento da empresa. 


\section{IV.7.4 Considerações finais}

A redefinição da abordagem de negócio com vistas à concorrência e aos possíveis parceiros e aliados, utilizando critérios para a configuração de produtos complementares empresa, foram as principais razões para o aumento do faturamento. A introdução de práticas de planejamento estratégico e suas ferramentas, em pequenas empresas, ainda é recente (DEL MASCHI, 2009).

A principal contribuição oferecida por essa pesquisa é o estabelecimento de diretrizes estratégicas para pequena empresa sempre preocupada com competitividade, à luz de um referencial teórico clássico presente somente nas grandes empresas. Outra contribuição importante foi o processo de condução da pesquisa-ação. Este modelo já está contribuindo como um template para novas pesquisas similares que estão em desenvolvimento. 


\section{IV.8 RASTREAMENTO DE REQUISITOS}

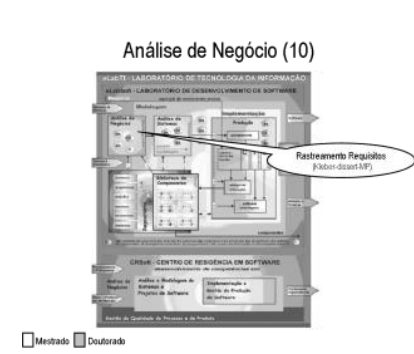

$\mathrm{Na}$ pesquisa desenvolvida com Oliveira (2002), foi desenvolvido um modelo aplicável à produção de software, que contempla todas as fases da engenharia de requisitos. Segundo este autor, em 1996, o projeto ESPITI (European Software Process Improvement Training Initiative) realizou uma investigação sobre os principais problemas no desenvolvimento de software na Europa e identificou que os maiores problemas estavam relacionados com a especificação, a gestão e a documentação de requisitos. Outro fator importante é que o custo das mudanças de requisitos, uma vez entregue o produto, fica entre 60 e 100 vezes superior ao custo representado a mesma mudança durante as fases iniciais do desenvolvimento (PRESSMAN, 2002).

O contexto de descrição de requisitos, conforme ilustrado na Figura 35, compreende a base para o modelo proposto na dissertação. Foram utilizadas figuras geométricas para diferenciar a representação e o significado dos elementos (LEITE, apud OLIVEIRA, 2002):

- os octógonos representam os quatro elementos fundamentais, qual seja, ambiente ou domínio da aplicação, problemas, requisitos e stakeholders;

- os retângulos e caixas de diálogos representam as características associadas aos elementos do modelo;

- o espiral representa os processos da Engenharia de Requisitos e a aplicação das técnicas;-

- a prancheta representa o produto resultante, o documento de requisitos. 


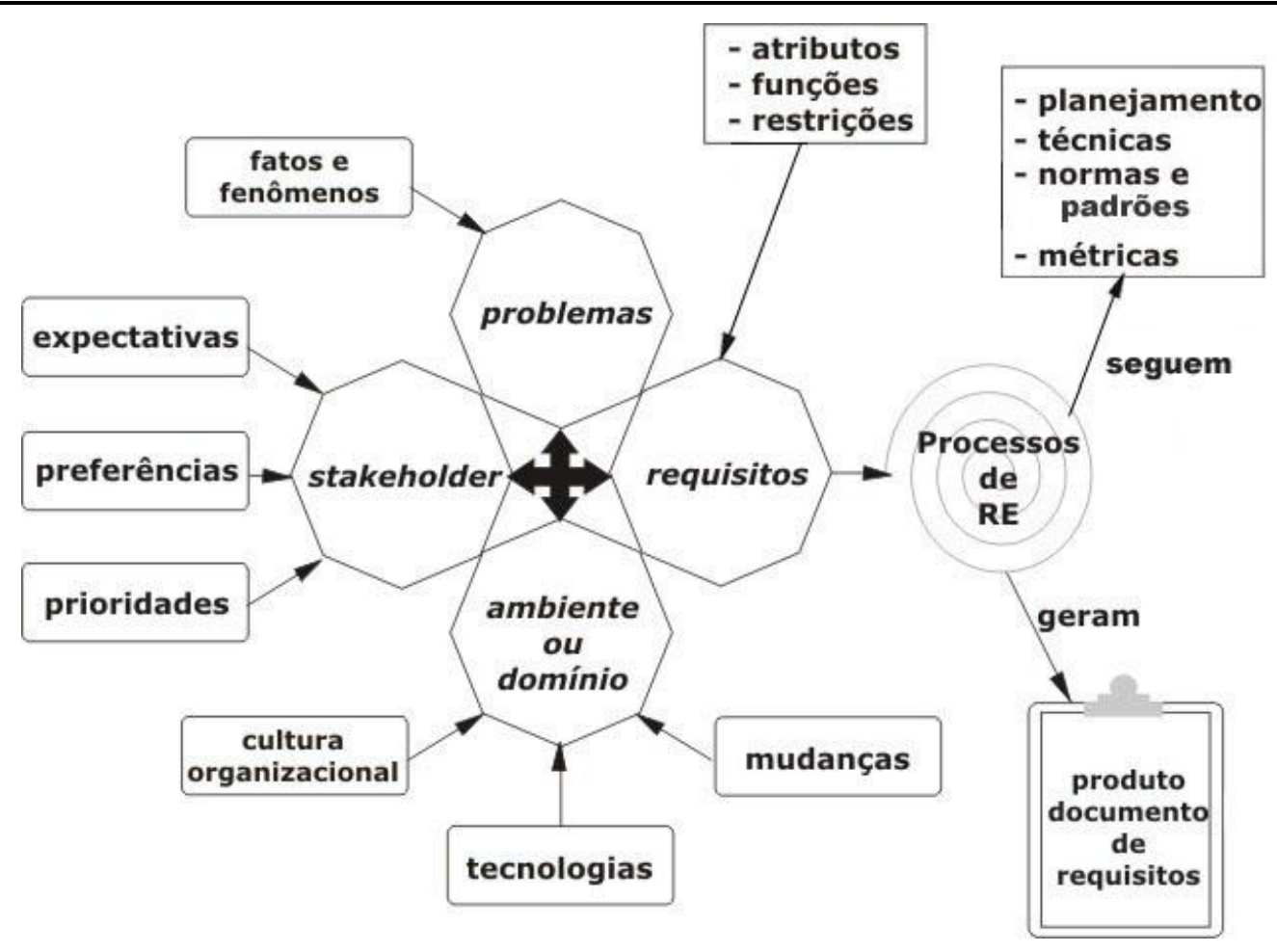

Figura 35 - Uma abordagem de Requisitos (OLIVEIRA, 2002).

$\mathrm{Na}$ Figura 35 estão representados os principais elementos da abordagem de requisitos (OLIVEIRA, 2002):

- Ambiente ou Domínio da Aplicação - é onde ocorrem os fenômenos que caracterizam os problemas referentes aos requisitos particulares do cliente.

- Stakeholders - compreende o conjunto de pessoas ou objetos que, direta ou indiretamente, são afetados pela solução de sistema a ser construída

- Problema - é a diferença de algo como desejado em relação a algo como percebido pela fonte de informação.

- Requisito - é uma declaração descritiva de exigências, escrita do ponto de vista dos stakeholders, para os quais será provida a tecnologia da informação e o compartilhamento de recursos na solução de problemas.

A seguir são descritas as características relacionadas com cada elemento:

\section{Ambiente ou Domínio da Aplicação}

- Cultura Organizacional - refere-se às regras e normas que regulamentam a organização, comportamentos, hábitos e costumes. Também pode ser 
entendida como um conjunto de pressuposições básicas compartilhadas que o grupo de pessoas nela envolvida aprenderam como resolver seus problemas de adaptação externa e integração interna, que tem funcionado suficientemente bem para ser considerada válida.

- Tecnologias - referem-se aos avanços tecnológicos e aos impactos sobre o ambiente e a cultura organizacional.

- Mudanças - refere-se à dinâmica social e organizacional do elemento humano como agente de mudança no ambiente.

\section{Stakeholders}

- Expectativas - as expectativas são declarações do cliente quanto à forma de ver atendida uma demanda. São originadas do conhecimento do problema e do ambiente, cuja satisfação refere-se à solução.

- Preferências - as preferências são condições desejáveis e particulares do cliente, porém opcionais ao produto de software. São condicionadas à definição prévia dos atributos e das restrições dos requisitos. Ou seja, são circunscritas no espaço de solução do problema.

- Prioridades - a definição do que é prioritário pelos stakeholders é uma condição essencial no processo de desenvolvimento de software. $O$ processo é essencialmente limitado pela disponibilidade de recursos (humanos, financeiros, tecnológicos...) e pelo fator custo de produção.

\section{Problema}

- Fatos ou Fenômenos - um fato é uma verdade simples acerca do mundo. Um fenômeno refere-se à forma de ver o mundo, depende de interpretação do contexto e do impacto que causa, sob o ponto de vista de quem o interpreta. $O$ conhecimento de ambos e a identificação de quem os relatam são as bases que permitem o entendimento do problema.

\section{Requisito}


- Funções - as funções são ações nas quais o requisito é declarado. Especificam a produção de algo, a partir de um elemento de entrada e um resultado como produto. Descrevem o que fazer para atender à finalidade proposta.

- Atributos - Os atributos são dimensões das características de funcionalidade e de qualidade dos requisitos. Estes devem ser consistentes, confiáveis e completos, com representatividade de pontos de vista das fontes de informação para que se promova a garantia de qualidade do produto descrito.

- Restrições - as restrições são limitações que delineiam o espaço de solução do problema. Tornam-se critérios de aprovação ou recusa para um produto.

\section{Pocessos de Engenharia de Requisitos (RE)}

A aplicação dos processos (Figura 35) e a utilização de técnicas de Engenharia de Requisitos (RE) devem iniciar antes da definição do software a ser construído e basear-se no conhecimento inicial do problema, fase identificada como de descobrimento de requisitos. As técnicas aplicáveis referem-se a planejamento, métodos, métricas, normas e padrões entre outras (OLIVEIRA, 2002):

\section{Produto da Abordagem de Descobrimento de Requisitos}

O resultado da aplicação dos processos de Engenharia de Requisitos caracteriza-se pelo documento de requisitos(OLIVEIRA, 2002):.

\section{IV.8.1 Modelo proposto}

O modelo proposto foi elaborado a partir dos modelos estudados nesta pesquisa. Representa uma abordagem para consolidar a idéia de orientar o estudo sobre o foco do problema para o gerenciamento dos requisitos. Nesse modelo são apresentadas três possibilidades de iterações, sendo duas internas e uma externa, conforme a Figura 36 (OLIVEIRA, 2002):. 


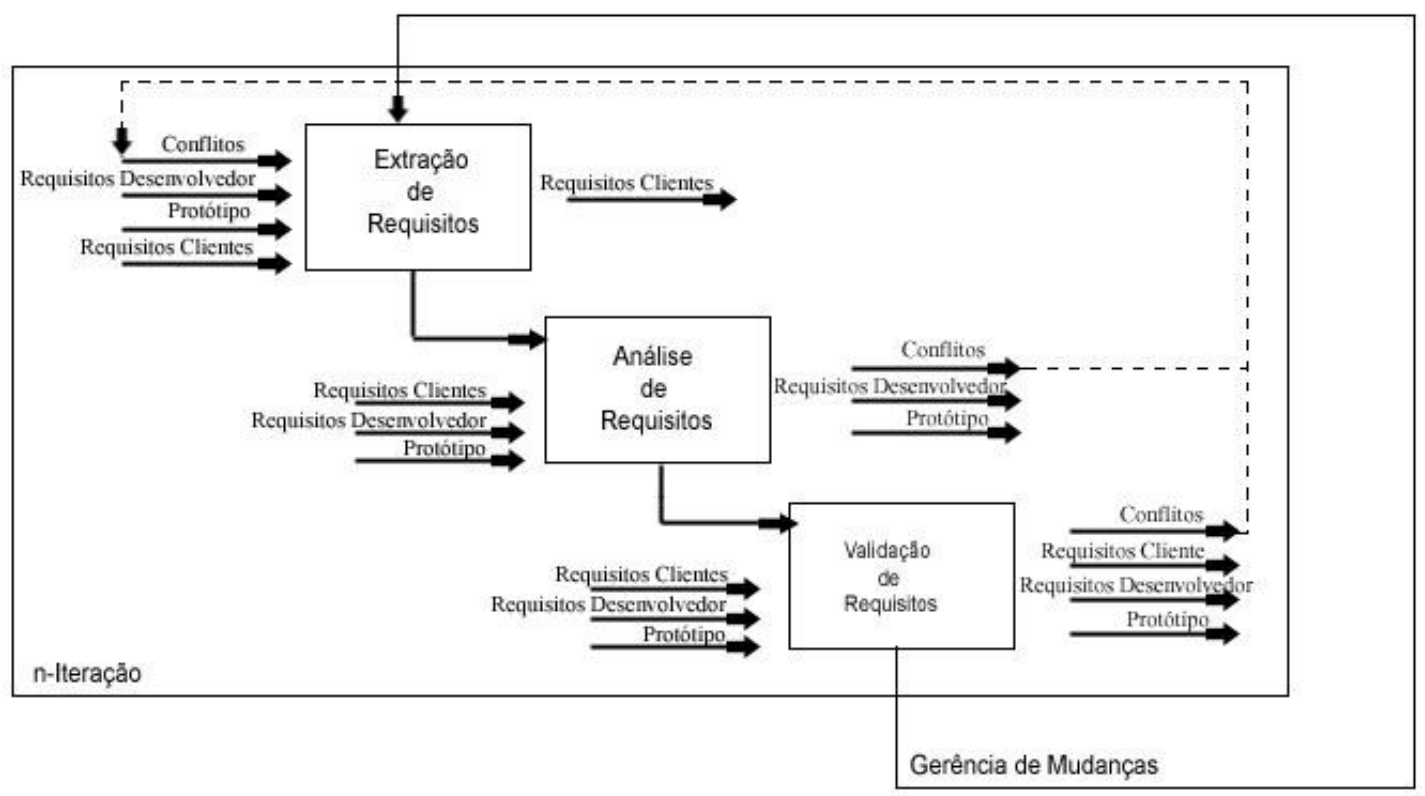

Figura 36 - Modelo proposto (OLIVEIRA, 2002)

\section{IV.8.1.1 Ciclos de uso do modelo}

\section{Ciclo Extração-Análise-Validação}

O ciclo principal extração-análise-validação é um ciclo que indica a possibilidade de que durante o processo de validação dos requisitos por parte dos clientes e usuários, apareçam conflitos ou novos requisitos que até então estavam ocultos. Nestas circunstâncias, é necessário resolver estes conflitos e validar os novos requisitos mediante reuniões para extração e negociação, repetindo as atividades de análise e validação.

\section{Ciclo da Próxima Iteração}

O segundo ciclo, entre o processo de requisito e a próxima iteração, mostra a possibilidade de que durante o restante do desenvolvimento seja necessário retornar a alguma das atividades do processo de requisitos, possivelmente porque é detectada a necessidade de renegociar alguns requisitos de difícil implementação, ou até mesmo por aparecerem novos requisitos durante o desenvolvimento.

\section{Ciclo da Gestão das Mudanças}

O terceiro e último ciclo envolve a gestão de mudanças dos requisitos de software. Uma das razões para isso é que a maioria dos sistemas são geralmente 
desenvolvidos para lidar com problemas complexos. Como o problema não pode ser inteiramente definido, os requisitos de sistemas são necessariamente incompletos. Durante o processo de software, a compreensão dos desenvolvedores sobre o problema está constantemente se modificando, e essas mudanças refletem nos requisitos. Além disso, mudanças nos requisitos de software são geralmente necessários para melhorar o status atual dos sistemas.

\section{IV.8.1.2 Processo da Engenharia de Requisitos}

$O$ processo de Engenharia de Requisitos pode ser descrito em quatro passos distintos (OLIVEIRA, 2002 , SOMMERVILLE, 2003): extração, análise, validação e gerência de requisitos descritos a seguir.

\section{- Extração de requisitos ${ }^{7}$}

No modelo proposto a extração de requisitos é a atividade mais importante, pois mantém uma interação entre clientes e usuários com os engenheiros de requisitos.

A Figura 37 ilustra as principais atividades para a extração de requisitos.

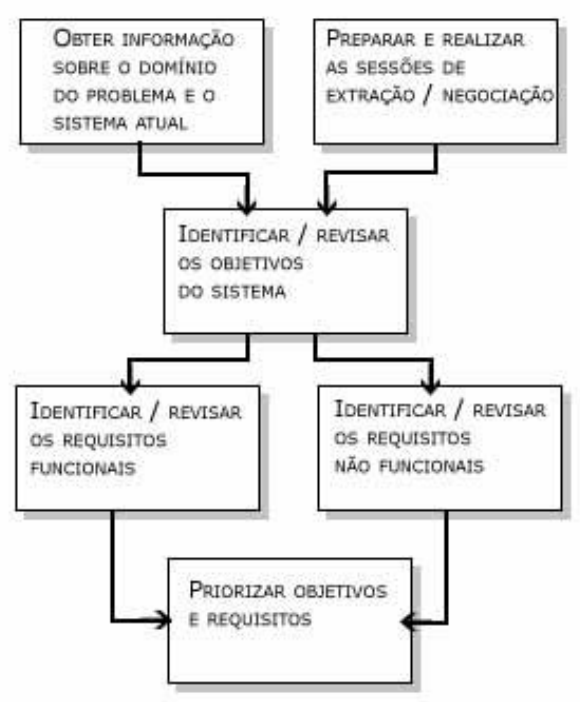

Figura 37 - Objetivos da extração de requisitos (OLIVEIRA, 2002)

\section{- Análise de requisitos}

$7 \quad 0$ termo em inglês para essa atividade é requirement elicitation que, se traduzido sem o devido cuidado, ficaria elicitação de requisitos. No item IV.8.3 há um comentário mais detalhado sobre esse termo. 
Uma vez reunidos, os produtos de trabalho mencionados anteriormente formam a base para a análise de requisitos. A análise categoriza os requisitos e os organiza em subconjuntos relacionados; explora cada um em relação aos demais; examinaos quanto à consistência, omissões e ambigüidade; e ordena-os com base nas necessidades dos clientes e usuários.

À medida que a atividade de análise de requisitos começa, as seguintes perguntas são formuladas e respondidas (OLIVEIRA, 2002, SOMMERVILLE, 2003):

- Cada requisito está consistente com o objetivo global do sistema/produto?

- Todos os requisitos foram especificados no nível de abstração adequado? Isto é, algum requisito fornece um nível de detalhe técnico inadequado neste estágio?

- O requisito é realmente necessário ou representa uma característica adicional que pode não ser essencial para o objetivo do sistema?

- Cada requisito é limitado e não-ambíguo?

- Cada requisito tem atribuição? Isto é, uma fonte (geralmente um indivíduo específico) está associada a cada requisito?

- Algum requisito conflita com outros requisitos?

- Cada requisito é realizável no ambiente técnico que vai alojar o sistema ou o produto?

- Cada requisito pode ser testado, quando estiver implementado?

Não é incomum que clientes e usuários peçam mais do que pode ser conseguido, considerando os recursos limitados do negócio. É também relativamente comum que diferentes clientes ou usuários proponham requisitos conflitantes. O engenheiro de requisitos precisa reconciliar esses conflitos por intermédio de um processo de negociação. Os riscos associados com cada requisito são identificados e analisados.

\section{- Validação de requisitos}

Os produtos de trabalho produzidos como conseqüência de Engenharia de Requisitos são avaliados quanto à qualidade durante o passo de validação. A validação de requisitos examina a especificação para garantir que todos os requisitos do sistema tenham sido declarados de modo não-ambíguo; que as 
inconsistências, omissões e erros tenham sido detectados e corrigidos e que os produtos de trabalho estejam de acordo com as normas estabelecidas para o processo, projeto e produto.

\section{IV.8.1.3 Gerência de mudanças de requisitos.}

Os requisitos para sistemas baseados em computador mudam e o desejo de mudar os requisitos persiste ao longo da vida do sistema. Gestão de mudanças de requisitos é um conjunto de atividades que ajuda a equipe de projeto a identificar, controlar e rastrear requisitos e modificações de requisitos em qualquer época, à medida que o projeto prossegue.

Como em qualquer processo de gerência na Engenharia de Software, a gestão de requisitos começa com identificação. A cada requisito é atribuído um modo único de identificar que pode tomar a forma: <tipo de requisito $><$ requisito $>$. Em que, tipo de requisito toma valores tais como $\mathrm{F}=$ requisito funcional, $\mathrm{N}=$ requisito não-funcional, $\mathrm{T}=$ requisito técnico.

Uma vez identificados os requisitos, tabelas de rastreamento são desenvolvidas. Com esse controle pode-se criar um processo para controle dessas alterações onde podem ser definidas 4 tarefas: registro da solicitação de alteração, identificação e seleção dos requisitos, análise de impacto das mudanças e comunicação das mudanças ocorridas.

\section{IV.8.1.4 Métricas de Requisitos}

A principal meta da Engenharia de Software é produzir um sistema, aplicação ou produto de alta qualidade. Para atingir essa meta, engenheiros de requisitos devem aplicar métodos efetivos combinados com modernas ferramentas dentro do contexto de um processo de software amadurecido.

\section{IV.8.2 Aplicação do modelo proposto e resultados}

O modelo descrito foi aplicado em um caso real. Para a elaboração dos diagramas como casos de uso, diagramas de seqüência, foi utilizado o produto Rose da IBM. Para o gerenciamento dos requisitos e suas alterações, foi desenvolvida uma 
ferramenta específica, onde cada um dos requisitos foi codificado e acompanhado. (OLIVEIRA, 2001, 2002, 2002a).

O fator mais importante de aplicação do modelo de gerenciamento de requisito foi a abordagem de tratamento da informação para a compreensão do problema. Definese um requisito quando se tem um problema e a vontade de solucioná-lo.

A adoção de um formalismo para representação do requisito no processo de software com uma linguagem natural, é apropriada para a fase inicial a que se propõe o modelo, ou seja, de descobrimento e gerência de requisitos, a partir do conhecimento de problemas. Sob este ponto de vista, só é adotada uma estrutura formal para descrever o requisito em forma de sentença simples declarando a funcionalidade, conforme os documentos de descrição de requisitos. As demais informações na qual ficam livres de formalismo para representar opiniões e condições, como registro complementar e de possível reuso posterior.

O processo de gerência gera um custo adicional de tempo ao trabalho de análise, pela exigência da participação dos stakeholders basicamente em todas as fases do processo. Mas, sistematizado e bem entendido, o processo pode ser agilizado desde que $\mathrm{o}$ engenheiro de requisitos aproveite a disponibilidade dos stakeholders, dispense a burocracia de agendar com muita antecedência e controle o tempo requerido para as fases repetitivas de reavaliação dos requisitos, utilizando objetividade sobre o que quer de resposta.

\section{IV.8.3 A questão do termo eliciação de requisitos}

Embora este item não esteja exatamente na linha de descrição das pesquisas realizadas, vale aqui uma observação sobre a displicência que muitos pesquisadores têm com a língua portuguesa. De uma maneira geral, durante o desenvolvimento das pesquisas, um cuidado que este Autor tem tomado é identificar a correção dos termos técnicos utilizados, pois é muito comum a tradução direta de termos de outras línguas e criar neologismos desnecessários. Há muitos termos utilizados conscientemente pelos pesquisadores e profissionais de computação que são neologismos e que, depois de muitos anos de uso, passam a incorporar o léxico brasileiro. Um exemplo é inicialização que, embora saibamos que a tradução de inicialization é iniciação, hoje esse termo consta no vocabulário ortográfico 
brasileiro da Academia Brasileira de Letras (Portella, E. et all, 2004). Os termos resetar e elicitar, no entanto, ainda não constam desse mesmo vocabulário.

No trabalho desenvolvido por Kleber (Oliveira, K.R, 2002) houve esse cuidado. Tanto o texto da dissertação como em todos os artigos escritos nessa época foram escritos utilizando o termo eliciação, escolhido como tradução de elicitation. Eliciação é um termo pouco conhecido, mas tem como significado extrair, obter (Michaelis, 2009) ou o significado expulsar, fazer sair, exconjurar (Ferreira, 1986; Lello, 1968; Priberam, 2009) em referências brasileiras, portuguesas, recentes e antigas. O termo elicitar não consta em nenhum dos dicionários acima referenciados. No entanto, em diversas situações, avaliadores de artigos elaborados por Oliveira e este Autor apontaram o termo eliciar como errado e houve até um caso de rejeição de artigo submetido a um congresso.

Oliveira (2009) defendeu sua tese de doutorado que continuou sua linha de pesquisa no tema Engenharia de Requisitos. Nesta pesquisa o autor passou a utilizar o termo elicitação alegando que não gostaria mais de arriscar ter problemas de aprovação de artigos por causa disso. Talvez esta seja apenas uma questão de tempo para que este termo seja realmente incorporado à língua portuguesa. Talvez não. 


\section{IV.9 ENGENHARIA WEB.}

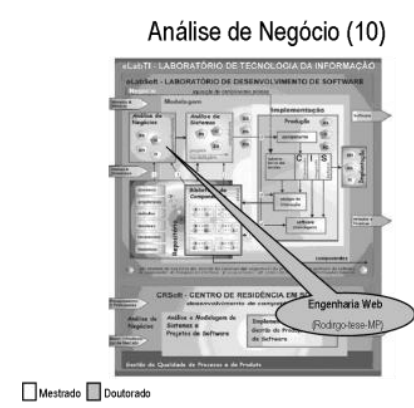

Na pesquisa em desenvolvimento com Gonçalves (2005), foi identificado que a produção de aplicações Web possui características peculiares, pois envolve aspectos multidisciplinares tais como criação de conteúdo, produção de mídias, aspectos estéticos, tecnológicos e de desenvolvimento de software. Os métodos atuais existentes na Engenharia de Software não são satisfatórios para esse tipo de projeto, pois os profissionais envolvidos possuem formações e características ecléticas, que precisam ser harmonizadas no processo, para que as atividades possam ser feitas em paralelo e sem conflito. Alguns autores estão chamando esta área de Engenharia Web.

Para Pressman, uma aplicação Web pode ser desde uma simples página até um Web site completo (PRESSMAN, 2006, GONÇALVES, 2005, 2005 a). Essa gama tão extensa de tipos de sítios encontrados na internet levou a uma proposta de classificação similar à que Nolan propôs (NOLAN, 1979) para aplicações de Sistemas de Informação (MEDEIROS JÚNIOR, 2005). Nessa proposta, foi realizado um levantamento para identificar que os sítios evoluem desde um estágio primitivo com páginas estáticas até sítios com aplicações altamente sofisticadas e complexas como pode ser observado nos sítios das instituições financeiras. Evidentemente o processo utilizado para o desenvolvimento dos sítios em cada um desses estágios é diferente, bem como a qualificação dos profissionais neles envolvidos.

Conallen (1999) apud Gonçalves (2005), considera que aplicação Web é um Web Sítio no qual é implementada uma lógica de negócio e cujo uso altera o estado do negócio. Segundo Paula Filho (2003), Aplicações Web são

"produtos de software ou sistemas de informática que utilizam uma
arquitetura distribuída, pelo menos parcialmente sob protocolo http. Em
conseqüência, pelo menos parte das interfaces com o usuário é acessível
através de um navegador (browser)" Ambas as definições são adotadas neste trabalho, acrescentando que aplicações Web são também baseadas em estrutura de hipertexto e/ou hipermídia. Este trabalho enfoca aplicações Web interativas e com funcionalidade complexa. Por sua 
vez, o termo design é entendido aqui não como na acepção da palavra em inglês projeto ou desenho (nomenclatura normalmente empregada na Engenharia de Software), mas como a atividade de projeto de um produto que busca conciliar e integrar os aspectos técnicos - tanto de produção como do produto em si - com os aspectos estéticos e socioculturais que o produto deve atender. Web Design é o design de páginas Web e Web Sites. Segundo Hauffe (1996),

"o trabalho do designer (profissional de design) tem diversos pontos de foco:
o artístico/estético, o técnico/funcional, a orientação mercadológica
(marketing), o teórico/científico e o organizacional/ administrativo". Gonçalves (2005, 2005 a) afirma que as aplicações Web são tipicamente produzidas em um ambiente de trabalho multidisciplinar. Entretanto, é difícil encontrar na literatura alguma abordagem da produção de aplicações Web que considere de forma sistêmica o aspecto multidisciplinar do desenvolvimento. Muitos trabalhos enfocam somente o aspecto de desenvolvimento de software; outros enfocam o aspecto de design, com foco em estética e mídia; outros enfocam a produção de conteúdo informativo, arquitetura da informação e redação de texto para Web. São deixados de lado aspectos fundamentais do ponto de vista de processo de produção de software:

- Como equipes multidisciplinares trabalham de forma coordenada?

- Quais os papéis desempenhados pelos profissionais no desenvolvimento?

- Quais são as competências, técnicas e ferramentas necessárias? Como as atividades são organizadas em paralelo?

- Qual o processo seguido?

- Como o resultado do trabalho de cada profissional é integrado em um único produto?

Para o desenvolvimento desse trabalho foram estudados diversos aspectos para compreender melhor a produção de software tanto do ponto de vista do profissional que produz o software, como do usuário final que vai utilizar esse tipo de aplicação.

Um dos trabalhos desenvolvido foi estudar a criação de um ambiente de engenharia simultânea aplicado ao projeto de edificações em engenharia civil, utilizando a web como suporte ao trabalho colaborativo da equipe geograficamente distribuída. Esse 
estudo foi publicado em Gonçalves (2008) e discute os desafios referentes a aspetos ergonômicos desses sistemas.

Em Gonçalves (2005b) foram analisados aspectos que são relevantes na modelagem de processos de negócio e que devem ser contemplados pelos diferentes instrumentos de modelagem. Como hipótese, foi estabelecido um aspecto adicional: a importância de representar, na modelagem, as pessoas envolvidas com os processos. Para demonstração da hipótese, é feita uma discussão de diferentes instrumentos de modelagem e da UML, em particular, aplicando-a a reengenharia de processos de negócio.

Em Gonçalves (2005c) é proposto o conceito de entropia associada a postos de trabalho como uma métrica para avaliação quantitativa e qualitativa do estado de desordem associado ao posto de trabalho. São identificados fatores para os quais é favorável o aumento e outros para os quais é favorável a redução da entropia, para a melhoria da condição de trabalho, considerando os aspectos de aprendizagem de tarefas, monotonia, conforto, variabilidade e propensão a problemas músculoesqueléticos.

O trabalho desenvolvido com Gonçalves (2007) discute a abordagem da Engenharia da Web a partir de fundamentos de Engenharia Simultânea, relacionando o processo de desenvolvimento com as características das aplicações, com atividades multidisciplinares e com a participação dos usuários no processo. Dá-se continuidade a pesquisa anterior, baseada em estudo de caso, com uma abordagem de pesquisa-ação. Verifica-se que fundamentos de Engenharia Simultânea podem ser aplicados à produção de aplicações Web, suprindo lacunas ainda imaturas na Engenharia da Web. Para Rodriguez apud Gonçalves (2005), o processo de desenvolvimento para Web pode ser decomposto em dois sub-processos:

- sub-processo de autoria (auth), o qual cria a estrutura de hipermídia

- sub-processo de desenvolvimento de infra-estrutura (inf), o qual providencia a integração com base de dados, desenvolvimento em linguagem de programação, integração com outros sistemas, etc.

As atividades de ambos os processos são realizadas nos fluxos de trabalho do processo de desenvolvimento de software convencional (requisitos, análise, projeto, implementação e testes), conforme representado na Figura 38. Embora os autores 
tenham previsto uma interface entre os sub-processos, não deixam claro como isto se realiza.

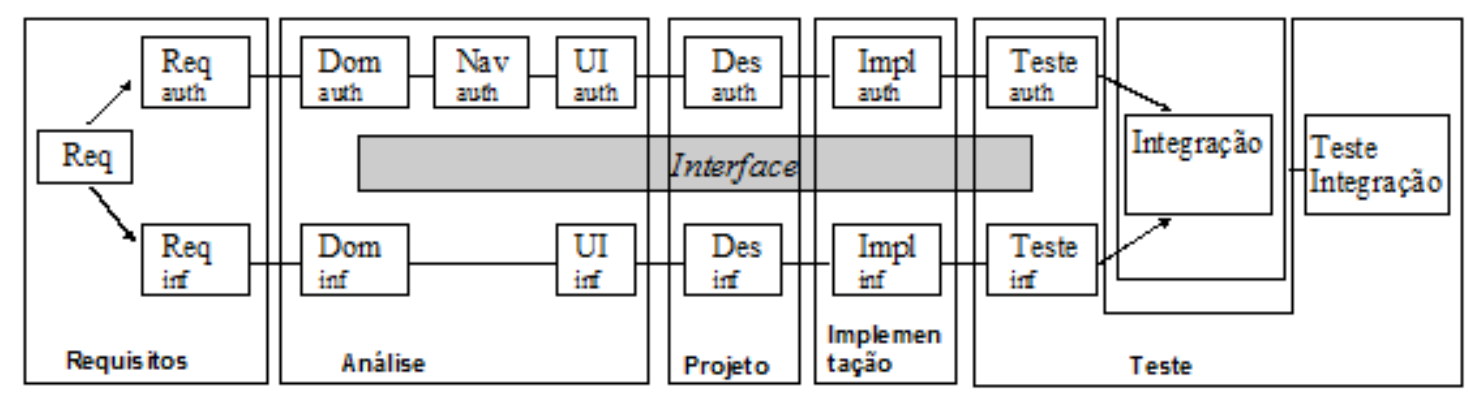

Figura 38 - Processo de desenvolvimento para Web (Gonçalves, 2002)

O termo autoria é utilizado para referenciar o trabalho criativo de produção e organização do conteúdo estético e informativo. Segundo Pressman (2006), as Aplicações Web são inerentemente guiadas por conteúdo. Os provedores de conteúdo são projetistas gráficos, redatores, produtores de mídia, entre outros. O termo autoria está relacionado a tudo que pode ser caracterizado como propriedade intelectual e resultante de trabalho criativo.

Em Laino (2008) é estudada a adoção de uma ferramenta do tipo Wiki para Gestão do Conhecimento em uma grande instituição financeira brasileira. Utiliza-se o método do Estudo de Caso através de analise documental e entrevistas realizadas com analistas e gestores. A ferramenta Wiki foi adquirida há 3 anos atrás porém seu uso não é tão disseminado como esperado. O principal resultado da pesquisa foi identificar que a contribuição da ferramenta para Gestão do Conhecimento é percebida de forma diferente por analistas e gestores. Os primeiros são unânimes em afirmar que a ferramenta garante a realização de todo o ciclo do conhecimento, enquanto os últimos são unânimes em afirmar que não, embora possa contribuir.

A pesquisa está em andamento e seu objetivo é contribuir com a engenharia Web propondo um processo de projeto de Sistemas Web que tenha uma abordagem sistêmica "top-down" (do geral para o particular), permita simultaneidade de tarefas e atenda os demais requisitos aqui apresentados. 


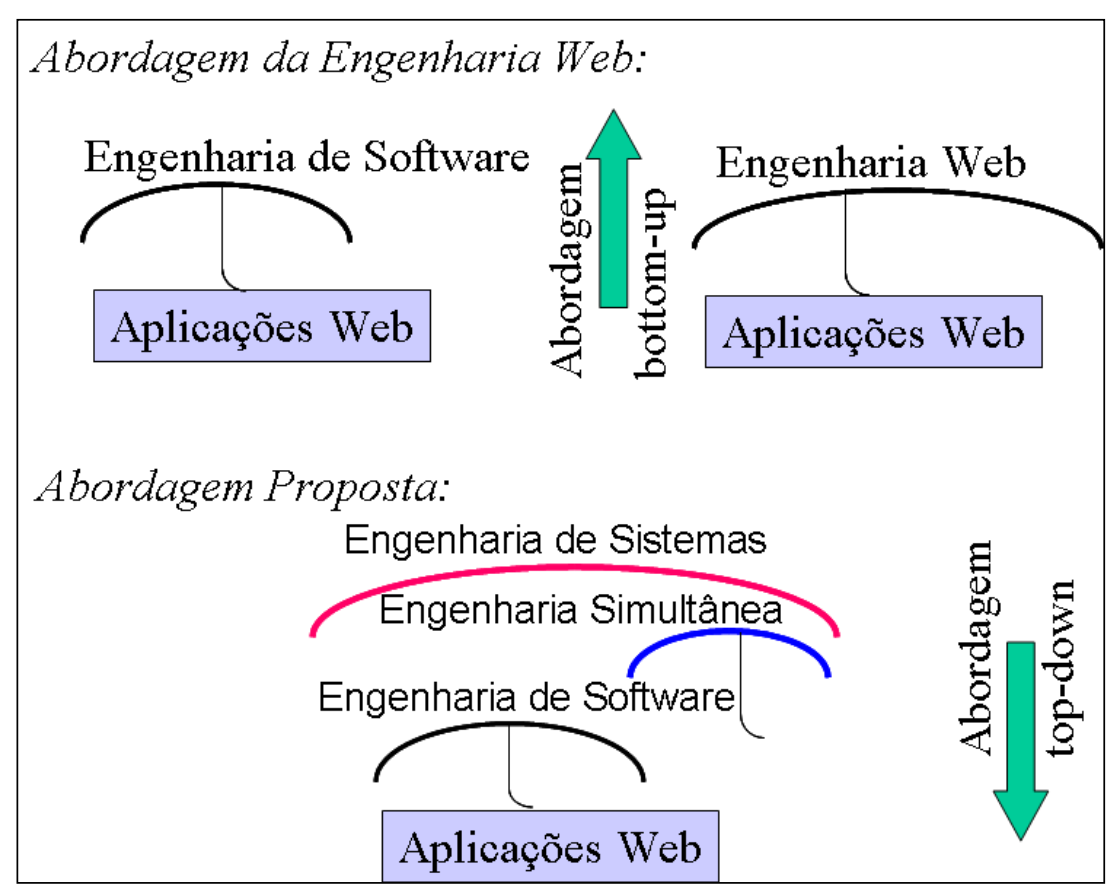

Figura 39 - Abordagem proposta para projetos Web (Gonçalves, 2002)

As características gerais desse modelo estão listadas a seguir:

- deve incorporar uma visão em alto nível dos sub-processos de autoria e de infra-estrutura, conforme modelo de Rodriguez et al. (2002).

- deve oferecer uma representação explícita dos papéis e atividades, caracterizando o desenvolvimento multidisciplinar.

- deve proporcionar o paralelismo da realização das atividades de projeto.

- deve atender aos diferentes padrões de aplicações Web, conforme o conceito de padrões de projeto para Web pode ser utilizado.

- deve permitir que o processo seja instanciado a partir das características do padrão da aplicação a ser desenvolvida.

- deve prover uma interface de integração entre as atividades multidisciplinares. O papel do Engenheiro da Web pode realizar esta função.

- deve permitir a previsão das atividades e papéis (um dos objetivos práticos do trabalho) tendo como entrada as características da aplicação a ser desenvolvida. 
Foi observado nas pesquisas de campo já realizadas é que as dimensões para o projeto de um sistema Web são: Forma, Função e Informação. A Engenharia de Software aborda Função e Informação e não estuda a questão de Forma. Os profissionais de Design estudam os aspectos referentes a Forma e Função, mas não abordam a Informação e os profissionais de Comunicação e Mídia abordam as questões referentes a Forma e Informação, não abordando a Função (Figura 40).

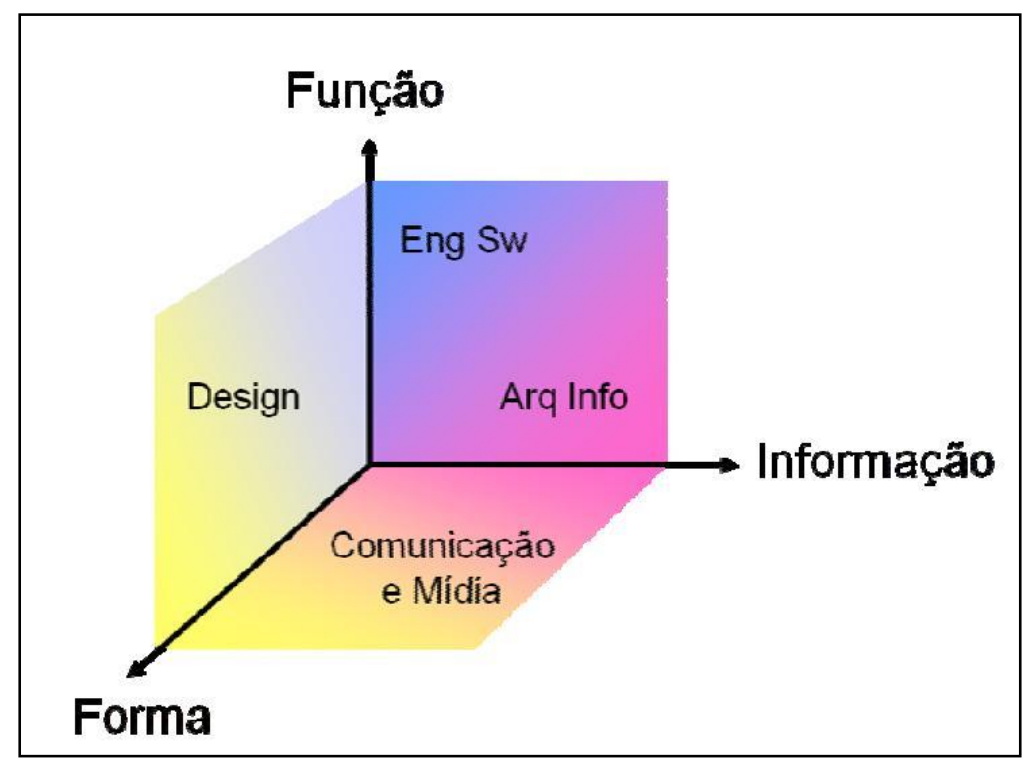

Figura 40 - Dimensões do modelo (Gonçalves, 2009)

Portanto este é o modelo que está se delineando como integrativo das três abordagens para a realização de sistemas Web (Gonçalves, 2009). 


\section{ARQUITETURA DA SOLUÇÃO}

Gestão de Projetos (3)

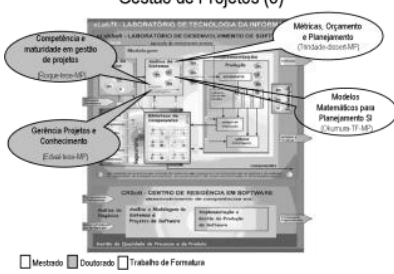

Arquitetura da Solução - este tema possui uma abordagem técnica, voltada à criação da solução e uma abordagem gerencial de definição do projeto. As pesquisas desenvolvidas até 0 momento estão voltadas às questões de gerenciamento. Foram desenvolvidos ao todo 4 trabalhos,sendo um trabalho de formatura, uma dissertação de mestrado e 2 teses de doutroado.

- Modelos Matemáticos para Planejamento de SI

- Métricas, Orçamento e Planejamento

- Competência e Maturidade em gestão de Projetos

- Gerência de Projetos e do Conhecimento

\section{V.1 MÉTRICAS, ORÇAMENTO E PLANEJAMENTO}

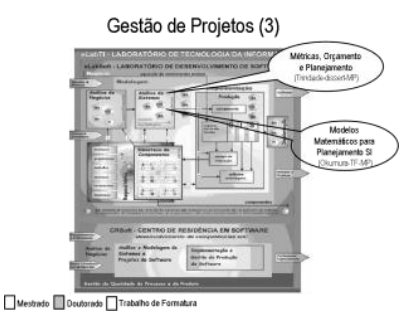

Na pesquisa desenvolvida com Trindade (1999) foi feito um levantamento dos métodos existentes para determinação do tamanho e esforço do software.

A orientação de trabalhos de formatura ofereceu uma oportunidade interessante para se aprofundar no modelo COCOMO de Boehm (1981). O trabalho de Okumura (1988) permitiu fazer a confirmação do funcionamento adequado dos modelos empíricos de estimativa de projeto de software. Bohem (1981) havia publicado o modelo COCOMO cuja finalidade era, através da estimativa do tamanho do software (número de linhas de programação), estimar o esforço necessário e a equipe (número de pessoas). $O$ modelo possuía três níveis de refinamento: o modelo básico, o intermediário e o avançado. A pergunta colocada na época foi: será que um modelo desenvolvido dentro da realidade americana com condições de trabalho diferentes das existentes no Brasil, com cultura e métodos diferentes, seria aplicável aos nossos projetos?

Nessa época (1987) software era essencialmente desenvolvido para mainframe e, portanto, o ambiente era mais uniforme do que é hoje. Foram solicitadas para 25 empresas que fornecesse os dados de projetos já encerrados, ou seja, aqueles que possuíam as informações completas: tamanho (número de linhas de código), esforço (número de homens-hora realizados), equipe (número de participantes) e prazo de 
realização do projeto. Participaram desta pesquisa 14 respondentes e as informações foram tratadas em um software de estatística Statpac para identificar se, o modelo daria resultados similares ou divergentes. Tais informações foram colocadas no modelo COCOMO (modelo semi-detalhado): dado o tamanho do software foi calculada o esforço, equipe e prazo. Os resultados foram muito similares ao dado pelo modelo, demonstrando que também para o ambiente brasileiro o modelo também se aplica (embora o aluno tenha cometido alguns deslizes estatísticos, os resultados foram muito bons). Cabe salientar que foi apenas comprovado que o modelo se aplicaria no Brasil. Não foi verificado se esses projetos foram realizados dentro dos prazos que cada responsável planejou, mas ficou demonstrado que, se cada gerente tivesse condições de estimar corretamente o tamanho do software a ser construído e aplicasse o modelo, o planejamento seria muito próximo do realizado.

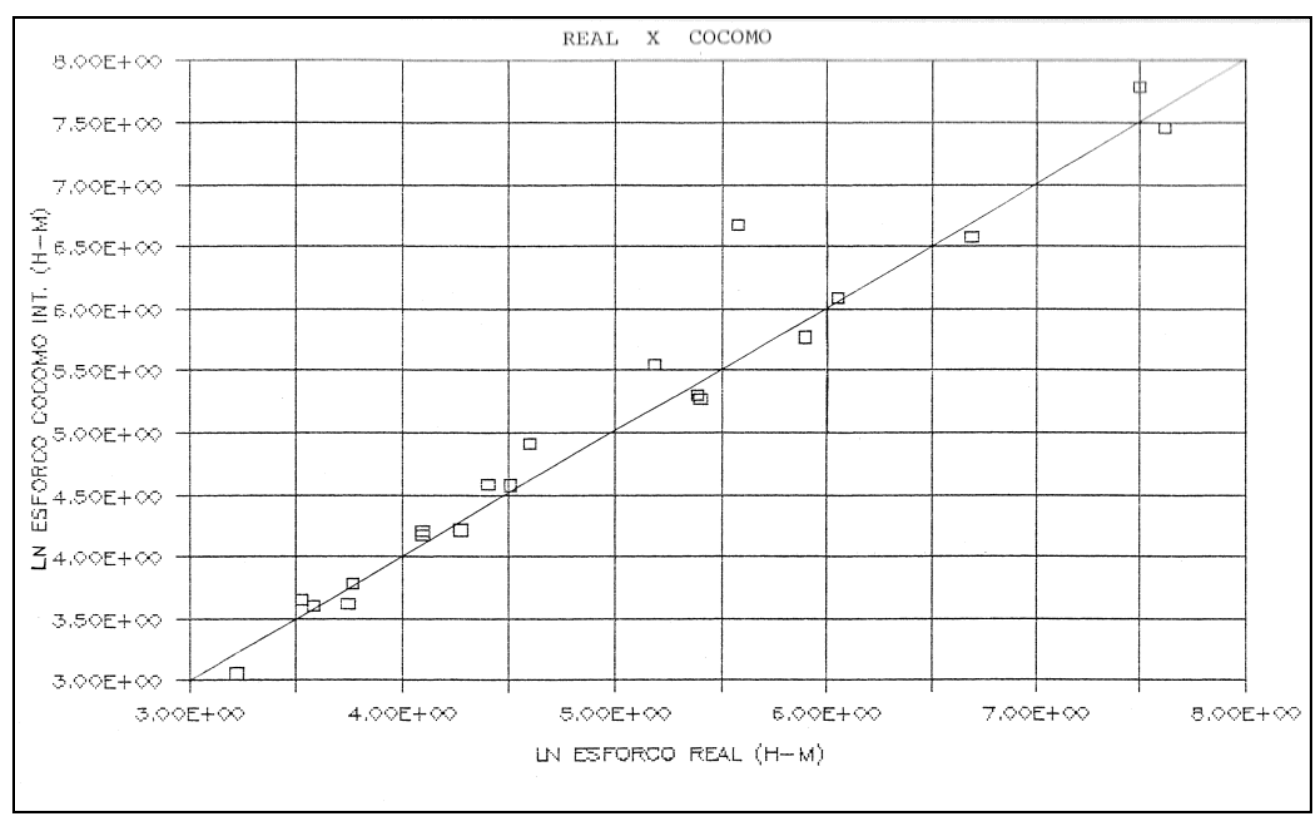

Figura 41 - Comparação entre estimativas do COCOMO e resultados reais (Okumura, 1988)

Esse trabalho motivou realizar uma outra pesquisa, agora de mestrado, com Trindade (1999). A idéia era identificar quais eram os modelos (conceituais) existentes para a realização de orçamento e planejamento de projetos de software. Trindade (1999, 1999 a) identificou (na época) 16 métodos diferentes para estimativas dos quais os mais conhecidos eram o COCOMO, APF (análise por pontos de função) e começava a se esboçar o modelo use case points. Nessa época 
começava a haver uma proliferação grande de aplicações para diferentes ambientes tais como PCs, servidores e mainframe (quase nada para internet ainda). A complexidade para realizar estimativas estava aumentando muito, fato que motivou Boehm a iniciar a pesquisa que gerou a atualização de seu modelo, o COCOMO II. Mais uma vez ficou concluído, em sua pesquisa, que na prática esses modelos eram muito pouco aplicados. Foram contatadas 404 entidades entre empresas, profissionais, associações, universidades, institutos de pesquisa dos quais 108 participaram da pesquisa de campo. Dois resultados são interessantes: apenas $25 \%$ dos participantes utilizam métricas formais no orçamento de projeto. De 34 empresas e profissionais consultados, 19 (56\%) utilizam modelos científicos formalmente publicados para estimativas (ponto de função, Cocomo, etc) , $2(0,6 \%)$ possuem um modelo proprietário e $13(38 \%)$ não utilizam nenhum modelo, mas sim a experiência dos profissionais. Com relação à eficácia, foi obtido um índice de satisfação de $69 \%$ de respondentes que considera satisfeito com o uso dessas ferramentas.

Durante o processo de desenvolvimento $43,5 \%$ dos participantes fazem o uso de algum tipo de medição.

Uma conclusão importante retirada dessa pesquisa é a falta de maturidade das empresas com relação a utilização de métricas para orçamentação, particularmente pelo fato de que poucas empresas possuem um processo para armazenar dados históricos. A realidade hoje (2009) é bem diferente pois é mais comum o uso da técnica pontos de função, fato que mereceria realizar uma nova pesquisa similar a já realizada em 1999. 


\section{V.2 COMPETÊNCIA E MATURIDADE EM GESTÃO DE PROJETOS}

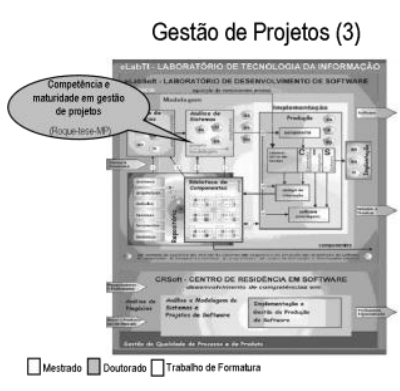

$\mathrm{Na}$ pesquisa desenvolvida com Rabechini Jr. (2003) foi estudada, com uma visão de gerenciamento de projeto, a questão das competências e maturidade na execução de projeto. Através da abordagem de estudo de múltiplos casos, foram investigadas as práticas de maturidade no gerenciamento de projetos e os resultados de levantamentos em três empresas de setores distintos. Inicialmente são apresentados e discutidos dois casos para a proposição de um modelo e o terceiro caso é utilizado para a aplicação desse modelo. A principal questão de pesquisa é: como as empresas podem se estruturar para desenvolver competências, visando a atingir maturidade em gerenciamento de projetos?

A abordagem teórica utilizada partiu da bibliografia sobre projeto, seguindo para o conceito de gerenciamento de projetos, a identificação de fatores críticos de sucesso que garantam o bom desempenho dos projetos, a análise das competências em gestão de projetos e finalmente a maturidade em gestão de projetos (RABECHINI JR, 2003).

Projeto é um processo único, constituído de um grupo de atividades coordenadas e controladas com datas para início e término, empreendido para alcançar um objetivo conforme requisitos específicos, incluindo limitações de tempo, custos e recursos. (ISO 1006 apud Rabbechini Jr, 2003).

O Gerenciamento de Projetos inclui o planejamento, a organização supervisão e controle de todos os aspectos do projeto, em um processo contínuo, para alcançar seus objetivos (ISO 10.006 apud Rabbechini Jr, 2003). O Gerenciamento de Projetos é a aplicação de conhecimentos, habilidades, ferramentas e técnicas às atividades do projeto visando atender ou superar as necessidades e expectativas que os interessados possuem no projeto (PMBoK, 2000); (Rabbechini Jr, 2003).

Os Fatores Críticos de Sucesso são a identificação dos fatores que implicam em sucesso ou fracasso de projetos e fornecem uma excelente fonte de ajuda para identificar competências e maturidade das empresas. 
Para Le Boterf apud Rabechini Jr (2003), competência é saber agir (ou reagir) de forma responsável e validada. São três eixos fundamentais que compõem a competência: características pessoais, formação educacional e experiência profissional. Dessa forma o indivíduo competente não é aquele que tem determinados recursos mas sim aquele que consegue mobilizá-los em momento oportuno, sob a forma de conhecimento, capacidade cognitiva de, capacidade de relacionamento, entre outros.

Em gerenciamento de projetos podem ser observados três tipos de competências: as individuais, as das equipes e as organizacionais (RABECHINI JR, 2003, 2005).

A competência individual refere-se às aptidões e habilidades dos indivíduos na solução de problemas.

As competências de equipe referem-se à possibilidade de indivíduos trabalharem em conjunto visando atingir os objetivos do projeto.

As competências organizacionais referem-se à possibilidade de indivíduos ou equipes conduzirem seus projetos de foram alcançarem os objetivos propostos, dando maior competitividade à empresa.

O conceito de Maturidade em Gerenciamento de Projetos surgiu inspirado no modelo CMM. Uma empresa imatura caracteriza-se pela improvisação do gerenciamento. Uma empresa madura possui a habilidade gerencial para desenvolvimento do processo de administração do projeto. Nesse sentido, a partir do estabelecimento de um planejamento adequado, as especificações são detalhadas, e o projeto é executado e controlado devidamente evitando desperdício de recursos e prazo.

\section{V.2.1 O modelo proposto}

Rabechini Jr $(2003,2005)$ propõe um modelo gerado a partir de tres pilares conceituais básicos: estratégia, processos e efetivação da mudança capazes de dar sustentação às camadas de competências envolvidas na institucionalização de gerenciamento de projetos: indivíduo, equipes e organização (Figura 42). 


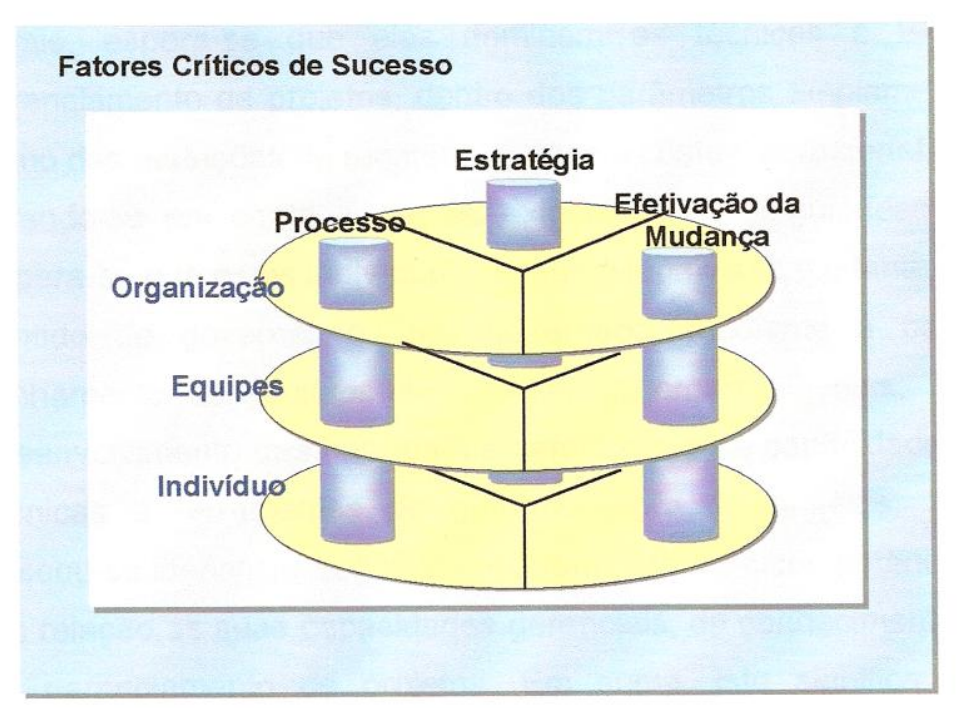

Figura 42 - Modelo de Competências em gerenciamento de Projetos (Rabechini Jr., 2003)

Estas camadas formam uma base conceitual-teórica, apoiada na crença de que a institucionalização do gerenciamento de projetos numa empresa só acontece se forem geradas competências de forma integrada, consistentemente.

As camadas de competências apoiam-se em distintos pilares capazes de viabilizarem seus respectivos desenvolvimentos.

\section{Pilar da Estratégia}

O primeiro pilar se refere às questões da estratégia. Nos termos deste modelo, se refere a definição estratégica de situações de institucionalização de gerenciamento de projetos, considerando-se os indivíduos, equipes e organização.

Este pilar caracteriza-se por apoiar e estabelecer as diretrizes em relação ao desenvolvimento de gerenciamento de projetos, para todas as competencias. Estas diretrizes foram criadas para nortear o desenvolvimento das outras dimensões deste modelo. Entre os aspectos importantes a serem considerados neste pilar, não exaustivamente, destacam-se:

- Desenvolvimento de diretrizes que visa estabelecer um escritório de projetos (project office) que, por sua vez dará suporte a toda a organização no que se refere a gestão de projetos;

- Carreira do gerente de projeto e como consequencia, sua remuneração profissional; 
- Carteira de projetos como opção gerencial de organização e

- Priorização de projetos na organização

- Capacitação das equipes de projetos.

\section{Pilar dos Processos}

A abordagem dos processos refere-se a procedimentos ou maneiras especificadas de se abordar rigidamente situações definidas. Neste contexto, este pilar visa o desenvolvimento das funções que integram os requisitos de gerenciamento de projetos na empresa para as tres camadas propostas. Normalmente este pilar caracteriza a metodologia de gerenciamento de projetos a ser empreendida na empresa. Este pilar, na verdade, dará suporte ao conjunto de estratégias definidas pela organização com relação a como gerenciar por projetos. O desenvolvimento dos processos pode levar em conta os processos sugeridos e detalhados no guia de gerenciamento de projetos proposto pelo PMI Project Management Institute (PMBOK,2000) para as organizações, como também, os processos referentes a formação de equipes e desenvolvimento de profissionais.

\section{Pilar Efetivação das Mudanças}

O terceiro pilar se refere à efetivação da mudança, decorrente das estratégias configuradas e do desenho dos processos. Este pilar representa os elementos necessários para se configurar o entendimento do gerenciamento da mudança organizacional e de suas barreiras ocasionadas durante implantação da gestão por projetos. Este pilar, para efeitos de análise, deverá contemplar os indicadores de desempenho dos projetos e seus respectivos gerenciamentos, considerando-se a possibilidade de analisar as competências das três camadas sugeridas.

As camadas propostas no modelo podem ser enquadradas segundo resultados estratégicos conseguidos e pelo desenvolvimento de suas competências em termos de processos. Desta forma, vê-se a maturidade, do indivíduo, equipes e organização, expressa nos quadrantes, através das mudanças efetivas. Assim, foi possível planificar o modelo, constituindo a matriz de maturidade, composta de quatro cenários distintos conforme se observa na Figura 43. 


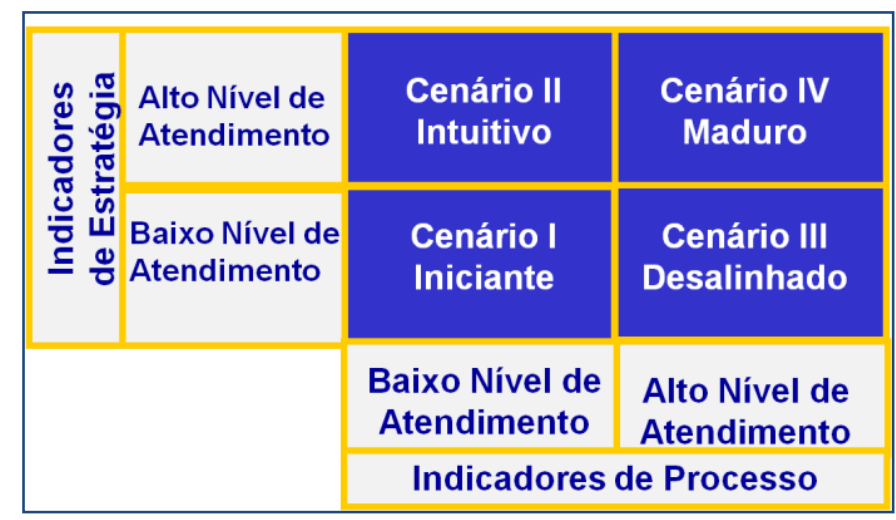

Figura 43 - Matriz de Maturidade (Rabechini Jr, 2003)

\section{V.2.2 Aplicação do modelo}

Esse modelo pode ser aplicado nas organizações para melhorar a maturidade em gerenciamento de projetos. O primeiro passo é identificar os dados gerais da empresa, a sua missão e estratégia. A seguir, identificadar a estrutura organizacional e de que forma os recursos humanos são treinados e capacitados. A seguir, realizar o diagnóstico sobre maturidade gerenciamento de projetos, utilizando o modelo proposto Kerzner. O passo seguinte é realizar a avaliação segundo o modelo OPM3 que considera os seguintes pontos (1) apoio organizacional para projetos, (2) alinhamento dos projetos com as estratégias de negócio; (3) aprendizado organizacional; (4) metodologias e processos de gestão de projetos e (5) fatores de recursos humanos.

Identificar os fatores críticos de sucesso, e mapear na Matriz de maturidade a situação da empresa. O resultado dessas avaliações deve apontar lacunas em gerenciamento de projetos na organização que precisam ser preenchidas. A análise deve ser feita usando o modelo proposto, observando as camadas da organização e com isso pode se elaborar um plano de ação para preencher essas lacunas.

Por fim, este autor solicitou recursos à Fapesp para que o aluno pudesse publicar sua tese, o que ocorreu em 2005 (RABECHINI, 2005a). 


\section{V.3 GESTÃO DO CONHECIMENTO EM PROJETOS}

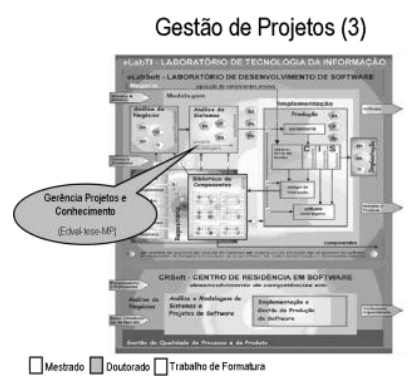

implantando esse projeto.

$\mathrm{Na}$ pesquisa realizada com Tavares (2003), foram estudadas as questões de gerenciamento de projetos que contém inovações tecnológicas. Este tipo de projeto possui a particularidade de necessitar gerenciar, além das atividades tradicionais de qualquer projeto, o conhecimento da inovação, uma vez que ela pode ser uma lacuna na organização que está

O Quadro 8 apresenta uma visão geral da pesquisa, com as hipóteses assumidas e as questões a serem respondidas. $O$ ponto de partida foi a seguinte proposição: um projeto de $\mathrm{Tl}$ sob encomenda com componentes de inovação, em um ambiente tecnológico complexo, demanda novos conhecimentos para a equipe do projeto em tempo de projeto. Existe um "gap" conhecimento em projetos inovativos.

São duas questões formuladas:

- como suprir este gap de conhecimento para a consecução projeto de TI?

- Como garantir a transferência do conhecimento das empresas fornecedoras para a empresa cliente durante o projeto?

Foi elaborado um modelo conceitual para a realização da "transferência de conhecimento em tempo de projeto", e após um estudo de múltiplos casos onde foram estudadas 2 empresas fornecedoras de tecnologia e 3 empresas que adquirirem a tecnologia e atuam na área financeira, esse modelo foi refinado, conforme apresentado no Quadro 9. O modelo opera da forma descrita a seguir.

A empresa cliente necessita implementar projetos de tecnologia da informação que contenham algum tipo de inovação. Para não fugir do foco de seu negócio ("core business"), essa empresa deverá fazer a subcontratação de fornecedores de tecnologia. O que o modelo traz de novidade são os processos referentes à gestão do conhecimento. Isto significa criar um ambiente propício para essa transferência, ou seja, a criação de processo de captura, organização e uso deste novo 
conhecimento. Deverá também buscar o uso de ferramentas de tecnologia da informação para armazenamento e distribuição do novo conhecimento.

\begin{tabular}{|c|c|c|}
\hline \multicolumn{3}{|c|}{$\begin{array}{l}\text { P1: Um projeto de T.I sob encomenda com componentes de inovação, num } \\
\text { ambiente tecnológico complexo, demanda novos conhecimentos para a equipe } \\
\text { do projeto em tempo do projeto. Existe um Gap de conhecimento em } \\
\text { projetos inovativos. (literatura) (Ireland, 1999), (Kamel, 2003), (Takeishi, } \\
2002 \text { ) e (Keil, 1998). }\end{array}$} \\
\hline \multicolumn{3}{|c|}{$\sqrt{2}$} \\
\hline \multicolumn{3}{|c|}{$\begin{array}{l}\text { Como suprir este "gap"de conhecimento para consecução do Projeto } \\
\text { de T.I.? }\end{array}$} \\
\hline \multicolumn{3}{|c|}{$\sqrt{2}$} \\
\hline $\begin{array}{l}\text { H1 : O "gap" do novo conhecimento } \\
\text { para o Projeto de T.I. pode ser } \\
\text { suprido através de: conhecimento } \\
\text { público, mensagens, clientes, con - } \\
\text { correntes, dados comprados comer- } \\
\text { cialmente, conhecimento subscrito, } \\
\text { Internet e Parceiros de entrega e } \\
\text { cadeia de fornecedores. (literatura) } \\
\text { (Harris et al., 1999), (Probst, 2000) }\end{array}$ & $\langle\sqrt{n}\rangle$ & $\begin{array}{l}\text { H2: Cadeias de suprimentos e } \\
\text { networks oferecem considerável } \\
\text { potencial } \\
\text { para tornar disponível } \\
\text { aprendizagem e transferência de } \\
\text { conhecimento. (literatura) } \\
\text { (Bessant \& Kaplinski, 1999) }\end{array}$ \\
\hline
\end{tabular}

Q2 A empresa precisa internalizar este novo conhecimento?

H3- O conhecimento relacionado ao Core Business precisa ser internalizado à empresa (literatura) (Probst, 2000), (McFarlan, 2002), (Byrd \& Turner, 2001), (Takeishi, 2002) e Tidd et al (1997).

\begin{tabular}{|c|c|c|}
\hline & $\sqrt{2}$ & \\
\hline $\begin{array}{l}\text { H4: Deve haver } \\
\text { uma melhoria do } \\
\text { nível de interação } \\
\text { entre as empresas } \\
\text { fornecedoras e a } \\
\text { empresa cliente } \\
\text { Kem \& Willcoks, } \\
(2000 \text {, Tserng \& Lin } \\
\text { (2002) e Frezatti \& } \\
\text { Tavares (1999). }\end{array}$ & $\begin{array}{l}\text { H5: A transferência do } \\
\text { conhecimento em tempo de } \\
\text { projeto poderia ser composta } \\
\text { dos seguintes instrumentos: } \\
\text { treinamento, elaboração de } \\
\text { documentação, "mentoring" } \\
\text { e entrevistas, Tavares et al } \\
\text { (2001) e Kamara et al } \\
\text { (2002). }\end{array}$ & $\begin{array}{l}\text { H6: Deve existir } \\
\text { um ambiente } \\
\text { propício } \\
\text { gerência do } \\
\text { Conhecimento, } \\
\text { Abell (2000). }\end{array}$ \\
\hline
\end{tabular}




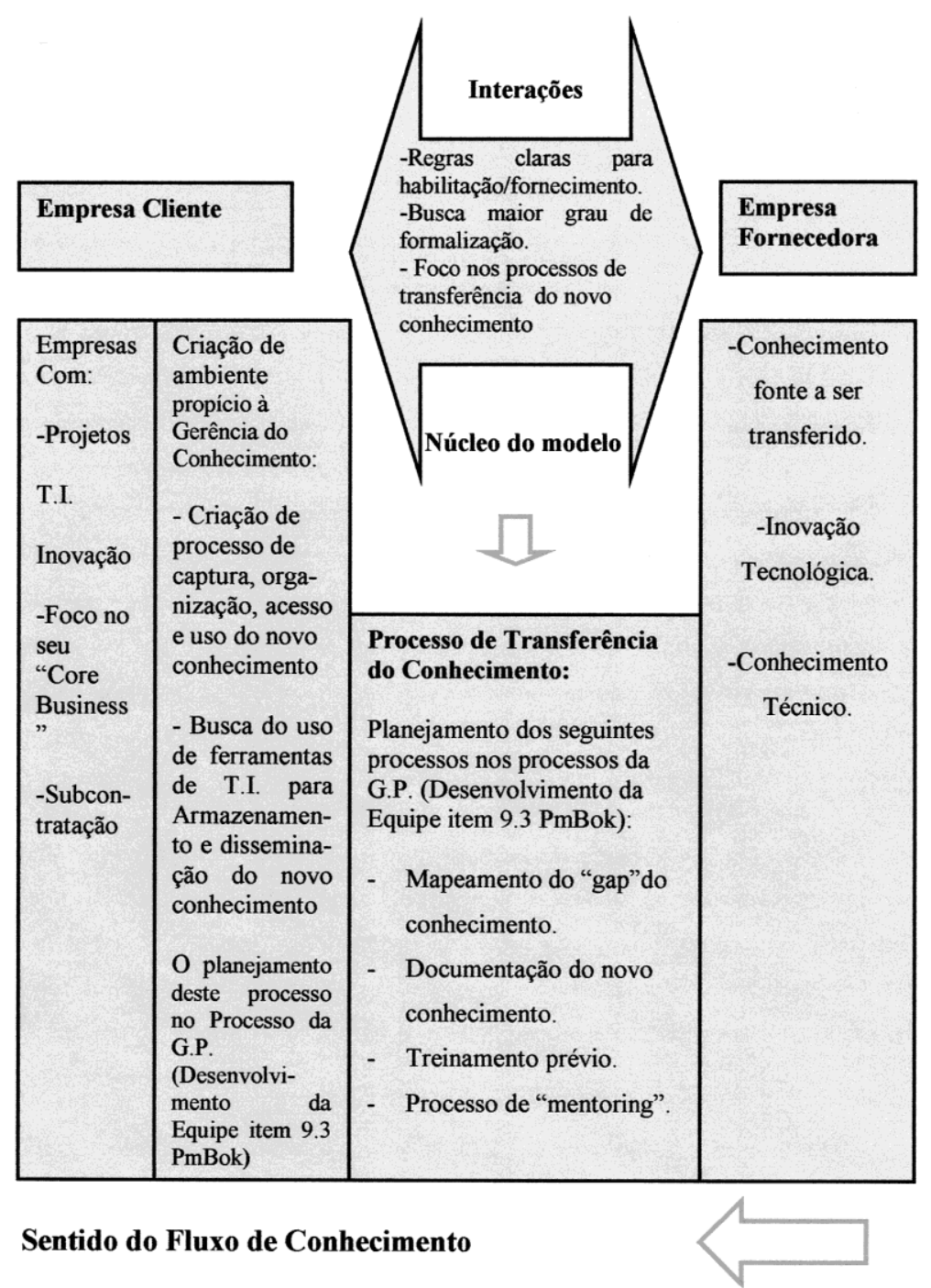

Quadro 9 - Modelo de Transferência de Conhecimento para Projetos de TI (Tavares, 2003)

A empresa fornecedora deve deter o conhecimento a ser transferido, deve ser uma empresa que já possua produtos e serviços que contenham inovação tecnológica, e deve ter, na equipe do projeto, profissionais que tenham o conhecimento técnico necessário a ser transferido.

A transferência do conhecimento deverá ser realizada através de um processo definido:

- mapeamento do gap de conhecimento,

- documentação do novo conhecimento,

- treinamento prévio da equipe envolvida,

- estabelecimento do processo de mentoring. 
No modelo PMBoK (2000), a área da gestão de projetos que trata desta busca de soluções é a Aquisição. Nessa área, a opção pela subcontratação justifica-se pela necessidade da empresa focar nas suas competências essenciais. Esta subcontratação atenderá ao desenvolvimento de aplicações de tecnologia da informação em projetos complexos, com o alto grau de integração, feitos sob encomenda. Quando as empresas buscam os novos conhecimentos através dos fornecedores, deve preocupar-se em atentar para a adequada transferência desses conhecimentos. 


\section{IMPLEMENTAÇÃO DE SISTEMAS DE TI}

Implementação - os temas relacionados à implementação são voltados

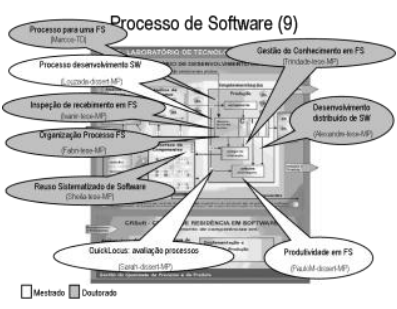
principalmente aos processos de desenvolvimento de software. Nessa área foram desenvolvidas 9 pesquisas:

- Inspeção de recebimento em uma FS

- Processo de desenvolvimento de Software

- Processo para um FS

- Organização dos processos de uma FS

- Gestão do Conhecimento em FS

- DDS-Desenvolvimento Disitribuido de Software

- Reuso sistematizado de Software

- Produtividade em FS

- QuickLocus: avaliação de processo

Conforme já relatado anteriormente, o tema Fábrica de Software já havia sido estudado no trabalho de formatura de Frontini (1988). Houve também, no âmbito do Departamento de Engenharia de Produção, a tese de doutorado de Fernandes (2000) versando sobre este mesmo tema, que depois foi transformada em livro (FERNANDES, TEIXEIRA, 2004). Nesse trabalho, a proposta foi considerar um ambiente de programação com uma visão de gestão de projetos, embora tivesse uma estrutura de processos bem definida.

Outro trabalho sobre Fábrica de Software foi desenvolvido por Jensen (2001)

$\mathrm{Na}$ elaboração do modelo de referência, já apresentado, da fábrica de software eLab-TI, foi discutido exaustivamente o tema produção de software com uma visão de manufatura. Esta abordagem ficará mais clara nos trabalhos de pesquisa que são apresentados neste capítulo. 


\section{VI.1 INSPEÇÃO DE RECEBIMENTO EM UMA FS}

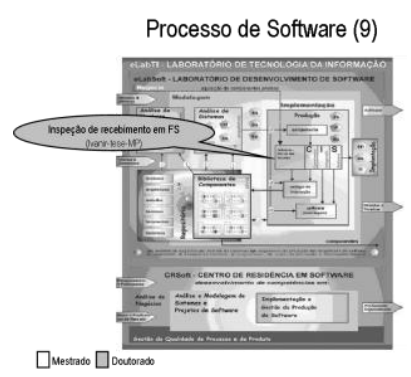

Costa (2003) desenvolveu uma pesquisa com dois pontos a serem destacados: levantamento junto a Fábricas de Software do mercado e a proposta de um processo de inspeção de recebimento na Fábrica de Software.

\section{Vl.1.1 Levantamento junto a Fábricas de Software}

Foi realizada uma pesquisa junto às Fábricas de Software existentes no mercado através de visitas e entrevistas com essas empresas. Esta pesquisa foi realizada de fevereiro a julho de 2002. Existem no Brasil 60 empresas que declararam possuir Fábricas de Software (MCT, 2001 apud Costa, 2003). Dessas, 29 foram desconsiderados pelo fato de serem empresas menos conhecidas ou por terem porte muito pequeno. Por essa razão a pesquisa se concentrou nas 31 maiores empresas existentes na época. Foi elaborado um questionário qualitativo cujo resultado está tabulado no Quadro 10.

Esse questionário foi organizado em 3 blocos: (1) recebimento e entrega, (2) produção (programação) e (3) gerenciamento e equipe, com o seguinte conteúdo:

- No primeiro bloco o levantamento identifica o esquema de recebimento do serviço, como é fornecido prazo e preço (se é usada métrica tipo pontos de função), como é analisado o conteúdo do serviço e se pode ocorrer devolução na entrada;

- No segundo bloco é verificado se existe uma estrutura para cada fase do ciclo de desenvolvimento, qual o profissional que recebe o serviço (gerente, líder, programador), se existe o conceito de ordem de pedidos ou são células dedicadas, se existe planejamento para alocação de recursos, se há especialização por tecnologia, quais as técnicas de verificação utilizadas e se há um processo definido de testes.

- No terceiro bloco é verificado se existe registro de histórico de produtividade e qualidade, se existe algum tipo de certificação, que ferramentas de produtividades são usadas, se é usada tecnologia 
orientada a objeto e se processos como RUP e representações como UML são utilizados.

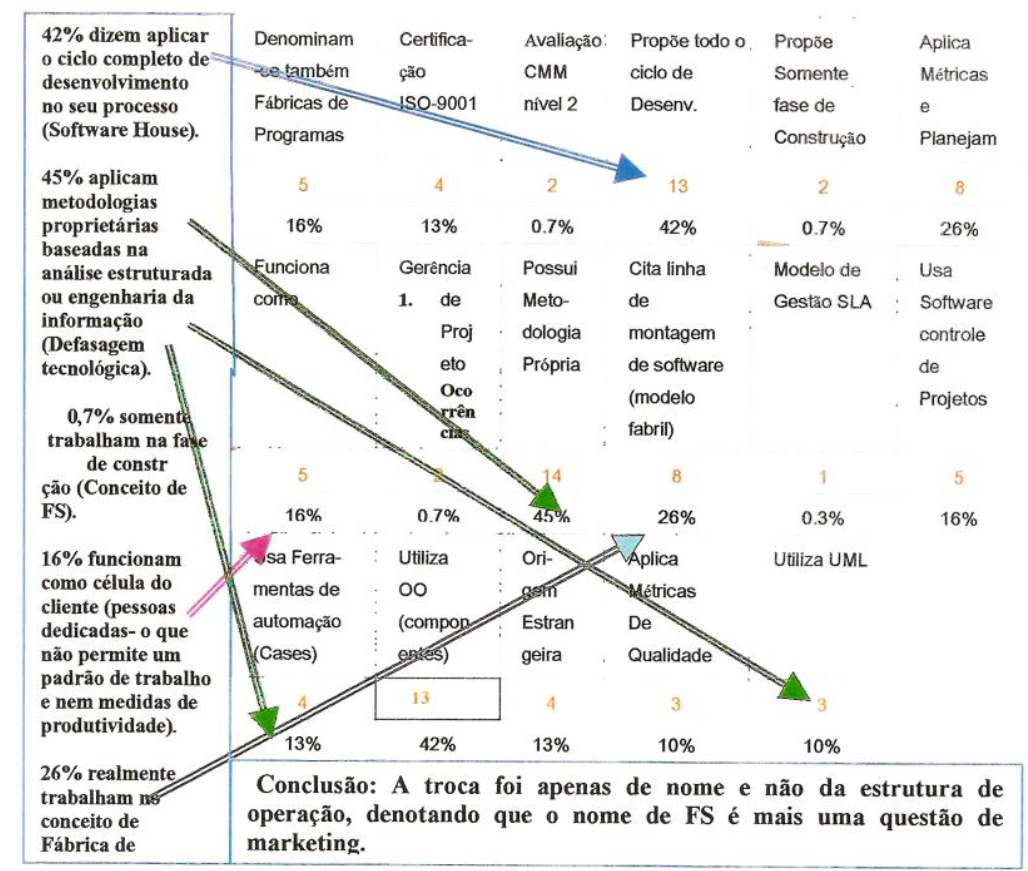

Quadro 10 - Resultado da pesquisa em 31 Fábricas de Software (Costa, 2003)

Vale observar os seguintes pontos:

- $42 \%$ dizem aplicar o ciclo completo de desenvolvimento em seu processo

- $45 \%$ aplicam metodologias proprietárias baseadas na análise estruturada e engenharia da informação, o que denota uma certa defasagem tecnológica

- Apenas 0,7\% afirma trabalhar na fase de construção (que seria o conceito de fábrica de software)

- $16 \%$ funcionam como célula do cliente.

- $26 \%$ realmente trabalha num conceito de fábrica de software.

Foi observado que, apesar de todas afirmarem possuir uma Fábrica de Software, poucas aplicam esse conceito de forma efetiva.

O que foi observado foram estruturas organizadas em células específicas de desenvolvimento de software de que se especializam para atender um determinado cliente. Este modelo não foi considerado, para efeito desse estudo, como fábrica 
de software e sim um ambiente tradicional de desenvolvimento com células dedicadas.

\section{VI.1.2 Processo de Inspeção de Recebimento}

A proposta realizada para a Fábrica de Software, apresentada na Figura 44, apesar de se basear em formatos já existentes, tem como diferença fundamental, o fato de receber qualquer tipo de serviço de construção de software, independente do cliente e do serviço solicitado, local ou remotamente, dentro de um padrão de especificação que traz a independência do tipo de cliente, da plataforma de programação e do tipo de código a ser gerado (Costa, 2003).

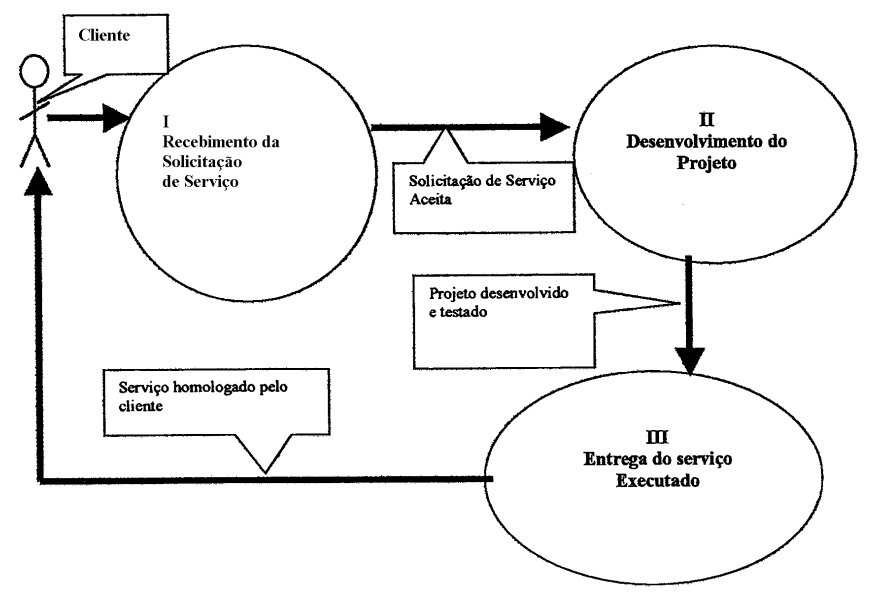

Figura 44 - Processo de programação em uma Fábrica de Software (Costa, 2003)

Outro fator importante nesta proposta está embutido no segundo processo "desenvolvimento do projeto". Nesse processo há uma diferença fundamental com relação às demais fábricas, pois essa atividade não se resume apenas à programação. As atividades desse processo levam em consideração não apenas os requisitos de software constantes no pedido de serviço, mas aplicam técnicas de padrões e componentes, visando aplicar intensivamente o reuso, através de buscas nas bibliotecas da fábrica. Antes da codificação, o processo exige um trabalho de montagem de peças existentes na prateleira. Somente serão codificados os códigos inexistentes e específicos do serviço solicitado. Todo este processo somente é possível utilizando-se ferramentas que automatizem o processo tais como gerência de requisitos, gerência de configuração e controle de projetos e testes integrados (Costa, 2003). 
As atividades de levantamento de requisitos, modelagem do software no nível de negócio e as alternativas de solução apresentadas ao cliente não fazem parte deste processo. Caso a fábrica de software receba pedidos em um formato diferente do padrão, é necessário que exista uma área que faça recepção do pedido no formato do cliente e passe para o padrão da fábrica. A Figura 45 representa em destaque a proposta da interface entre o cliente e a Fábrica que realiza inspeção e a equalização para garantir homogeneidade do nível de especificação (Costa, 2003).

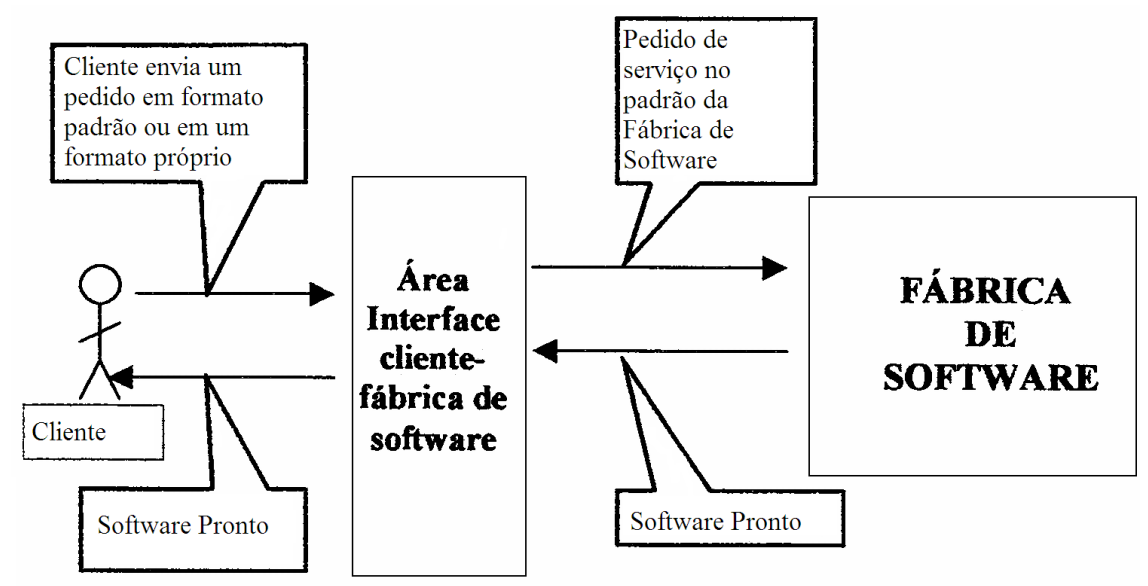

Figura 45 - Interface entre o cliente e a Fábrica de Software (Costa, 2003)

O processo proposto para a Fábrica de Software está a representado na Figura 46. Esta figura detalha como o processo pode ser implementado. Na parte interna estão os processos similares àqueles apresentados na Figura 44, e externamente foram colocados os processos de gerenciamento: gerenciamento de projetos, gerenciamento da qualidade, gerenciamento da configuração, e gerenciamento de riscos (Costa, 2003).

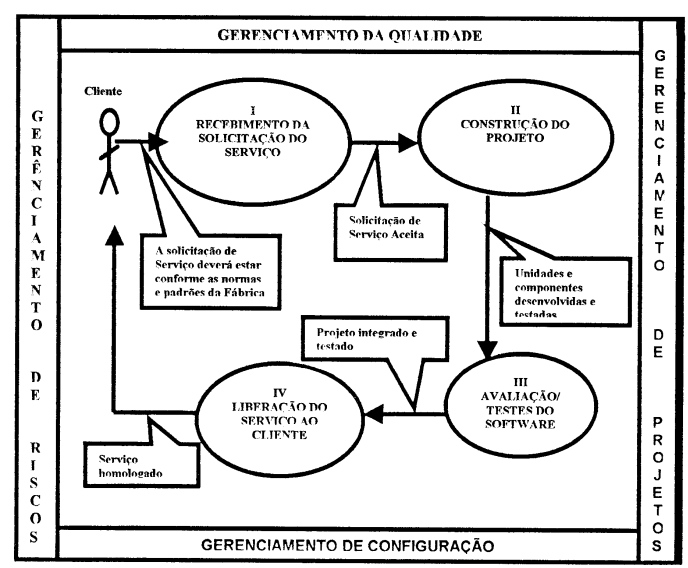

Figura 46 - Processos propostos para uma Fábrica de Software (Costa, 2003) 
O primeiro processo (Figura 46), de recebimento da solicitação do serviço, verifica a adequação às normas e padrões da Fábrica.

Um dos itens a ser verificado também é a questão do prazo para entrega. A Fábrica, possuindo dados históricos e utilizando métodos adequados de estimativas, como por exemplo, Pontos de Função ajustados através da Curva ABC (Costa, 2003 a), pode estimar com margem pequena de erro, qual o tempo necessário para a entrega da solicitação.

Caso a documentação não esteja adequada, um trabalho de equalização é realizado. No segundo processo, de construção, conforme já descrito, são codificados apenas os componentes que não existem e agregados os componentes existentes anteriormente na biblioteca. Ao final desse processo existem unidades desenvolvidas e testadas. O terceiro processo, avaliação e testes do software, é uma atividade que realiza a integração do produto e realiza os testes de integração. O quarto e último processo (acrescentado) é a liberação para o cliente cujo resultado é o software homologado (Costa, 2003).

Esse processo foi implementado em uma empresa que atua no mercado de sistemas de supervisão de tráfego aéreo. Esse tipo de software é crítico e o processo de desenvolvimento exige diversas etapas de verificação e validação

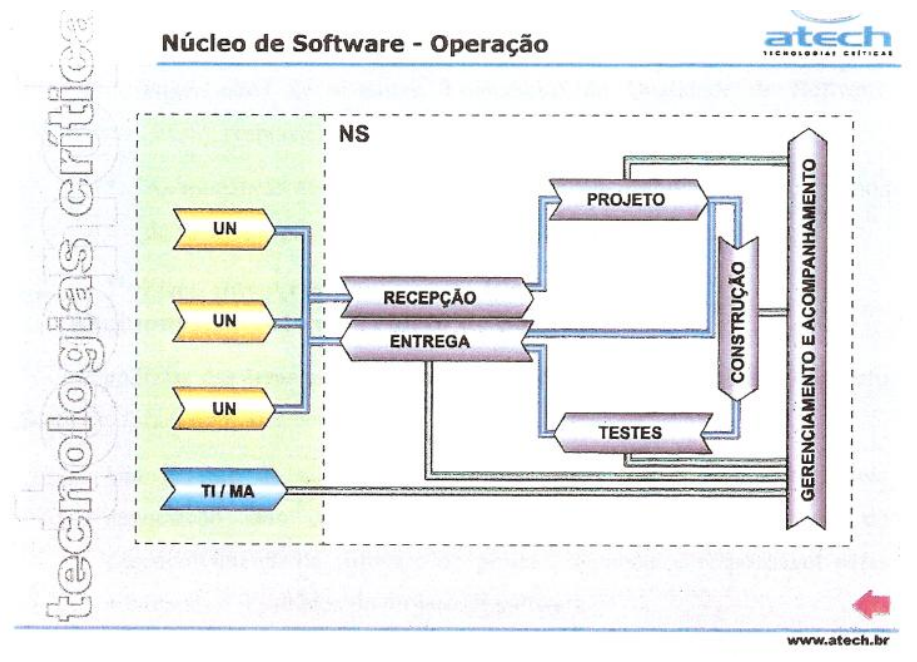

Figura 47 - Modelo implementado da Fábrica de Software (Costa, 2003)

A empresa possui várias unidades de negócio com núcleos separados de desenvolvimento de software e decidiu implementar um NS-Núcleo de Software. As 
diferentes unidades de negócio fazem as solicitações de serviço e demandam serviços para a Fábrica de Software, conforme ilustrado na Figura 47 (Costa, 2003).

$\mathrm{Na}$ estrutura da Fábrica foram concebidos quatro processos:

- Recepção e Entrega - responsável pelo recebimento das demandas das unidades de negócio -UN- e verificação se o material atende aos padrões, se o prazo e custo estão adequados. Esta área possui engenheiros de software que fazem a interface com os clientes. Quando o produto fica pronto, realiza a atividade de entrega.

- Projeto - responsável pela arquitetura de implementação do software, reuso, padrões de arquitetura (design patterns), montagem de componentes e frameworks.

- Construção - responsável pela construção de todos os códigos demandados pelas UNs. O trabalho é executado em bancadas de trabalho especializadas, ou seja, ambientes de desenvolvimento organizados por tecnologia. Os programadores poderão trabalhar em diversas bancadas diferentes, dependendo do perfil e do conhecimento das tecnologias utilizadas. Em casos especiais uma equipe poderá ser deslocada para formar uma célula específica para atender a um projeto.

- Testes - responsável pelos testes de integração e aceite do software junto aos clientes e pela homologação dos produtos.

Como pode ser observado, o modelo implementado é muito similar ao modelo conceitual. 


\section{VI.2 PROCESSO DE DESENVOLVIMENTO DE SOFTWARE}

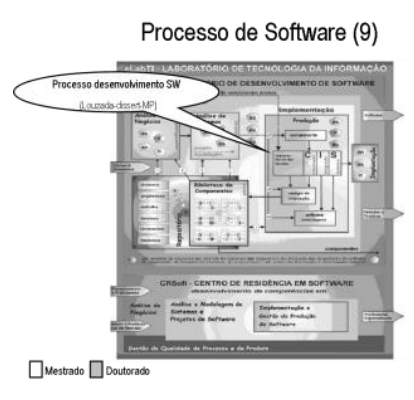

Lousada (2000) realizou uma pesquisa em empresas que possuem equipe própria de desenvolvimento. Foram entrevistadas 15 empresas. A primeira parte da pesquisa foi realizada em 1997 e a segunda em 1999. As mesmas empresas foram entrevistadas. Considerando os quadrantes de McFarlan (1984), foi identificado que 4 estão no quadrante estratégico ( 3 bancos e 1 consultoria), 3 estão no quadrante fábrica e 8 estão no quadrante suporte. Foram feitas perguntas sobre o uso de métodos de análise, formação do pessoal, se existe planejamento na informática, sobre a qualidade da documentação e as atividades de testes. Os resultados demonstraram que o uso de métodos de análise é muito baixo, que somente em $13 \%$ das empresas há um plano de treinamento. Com relação a planejamento formal da área de informática foi relatado que $20 \%$ não tem planejamento e $20 \%$ está em fase de implantação. De 1997 para 1999 houve uma redução de envolvimento com os usuários de $80 \%$ para $60 \%$. Apenas $27 \%$ das empresas citaram o uso de ferramentas CASE nas duas fases. 


\section{VI.3 PROCESSO DE DESENVOLVIMENTO PARA UMA FÁBRICA DE SOFTWARE}

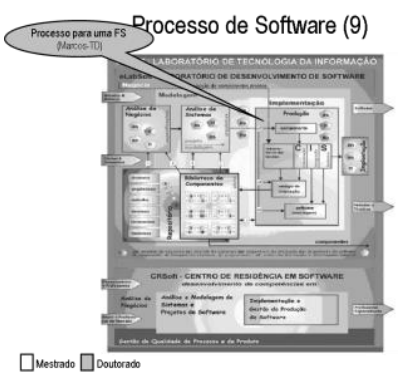

Rodrigues Silva (2005) desenvolveu uma pesquisa com dois pontos a serem destacados: levantamento do processo de desenvolvimento junto a Fábricas de Software e a proposta de um processo de desenvolvimento para Fábrica de Software.

\section{VI.3.1 Levantamento do processo de desenvolvimento de Fábricas de Software}

Foi realizada uma pesquisa junto a 5 Fábricas de Software de grande porte, através de visitas e entrevistas (RODRIGUES SILVA, 2005). Quatro dessas empresas utilizam o conceito de fábrica de Software, sendo que duas possuem processo bem estruturado, duas possuem o processo beirando a desorganização, e uma que não utiliza o conceito de Fábrica de Software, pois está organizada para confecção de software sob encomenda. Foi elaborado um questionário qualitativo que foi preenchido pelo próprio pesquisador durante contato com os profissionais entrevistados. O questionário possui um total de 64 perguntas e foi organizado em 8 blocos:

- (1a) Equipe de desenvolvimento - desenvolvedores

- (1b) Equipe de desenvolvimento - gerenciamento da equipe

- (2) Recebimento do Serviço e gerenciamento do backlog

- (3) Desenvolvimento - recebimento do serviço

- (4) Desenvolvimento -entrada na produção

- (5) Desenvolvimento - implementação (codificação)

- (6) Desenvolvimento - testes

- (7) Encerramento

- (8) Desenvolvimento - questões gerais

O questionário completo com as respostas tabuladas está no Apêncie A. A seguir está um resumo dos resultados obtidos (RODRIGUES SILVA, 2005):

(1a) Equipe de desenvolvimento - desenvolvedores

Nestas perguntas, o objetivo é verificar se as equipes de desenvolvimento trabalham de maneira fixa, especializados em ambientes ou linguagens, ou se ajustam à características dos clientes. 
Foi observado que as organizações trabalham com equipes multidisciplinares e os desenvolvedores possuem mais de uma habilidade (linguagem de programação) adequando-se às demandas dos clientes. Este procedimento dificulta e encarece a aquisição de novos elementos para o quadro de desenvolvedores. Na maioria das organizações, os serviços do cliente são aceitos alocadas diretamente para a equipe sem realizar nenhum tipo de análise. Se houvesse um padrão de recebimento de serviço, facilitaria a aceitação, o controle e o próprio desenvolvimento.

Foi observado também que nenhuma organização trabalha em pares (pair programming), salvo em casos especiais. Conforme a pesquisa, esta maneira de trabalhar proporciona qualidade, produtividade e maior satisfação no trabalho.

\section{(1b) Equipe de desenvolvimento - gerenciamento da equipe}

O objetivo é mostrar como as equipes são gerenciadas, quem efetua a alocação de recursos e quem realiza o report para controle.

As equipes são gerenciadas por um gerente de produção, que tem sob sua responsabilidade líderes de produção. Estes líderes são os encarregados de receber o serviço, efetuar o cadastramento, alocar os recursos disponíveis e, após o encerramento, realizar baixa no sistema de controle. As equipes de produção efetuam o apontamento de horas trabalhadas, que são utilizados para cobrança e registro histórico.

\section{(2) Recebimento do Serviço e gerenciamento do backlog}

A proposta é identificar como o pedido do cliente é trabalhado dentro da produção em termos de recebimento, gerenciamento e controle. Também verificar como é realizado o controle de produção: as filas de espera e a transição da fila de espera para a realização do serviço. Um outro ponto importante a ser analisado é a maneira com que são tratadas as interrupções das atividades em andamento para fazer o atendimento de serviços novos com maior prioridade.

O que foi observado é que a maioria das organizações possui uma metodologia de recebimento, embora não exija um padrão de preenchimento de formulários pois sempre procura atender todos os serviços dos clientes, independente de ambiente ou linguagem. Para que o serviço entre na produção também existe, definido no processo, uma seqüência a ser seguida, mostrando a existência de um padrão de 
recebimento. A grande maioria das organizações efetua 0 planejamento dos serviços aceitos.

Normalmente os líderes reportam sobre o andamento das atividades. Muitas vezes os prazos são superados e, nesses casos, são criados tratamentos de emergência na tentativa de correção ou renegociação com o cliente para um novo prazo. Quando ocorrem esses fatos, são efetuados registros dos motivos para futura melhoria de processo.

A maioria das organizações não adota um critério de composição de fila de espera nem um esquema de transição da fila de espera para a produção. Todos os serviços são passados diretamente para a produção e são executados conforme disponibilidade, não existindo para os desenvolvedores metas a serem cumpridas.

Quando entra na produção um serviço com maior prioridade, normalmente interrompe-se o serviço corrente, realiza-se um novo planejamento de emergência que possibilite a execução dos dois serviços. O risco de não cumprimento dos prazos dos serviços é muito grande.

\section{(3) Desenvolvimento - recebimento do serviço}

Recebimento do serviço (desmembramento em tarefas) o objetivo é analisar como a produção propriamente dita recebe o serviço do cliente e efetua a atualização do controle. O serviço do cliente é recebido pelo líder de produção que imediatamente realiza $\circ$ registro e entrega para o desenvolvedor que vai implementá-lo. Normalmente o desenvolvedor é encarregado de desmembrar o serviço em tarefas menores, para facilitar a implementação e testes. Conforme a metodologia são alocados recursos para os serviços que são identificados por um número de ordem de serviço. Em algumas organizações não há rigor quanto a padrões de implementação por ambiente de desenvolvimento ou por linguagem, pois as equipes são multidisciplinares e os profissionais são alocados como recursos que se adaptam ao ambiente ou linguagem conforme exigido pelo serviço.

Com relação a reuso de software, o reaproveitamento de código, do próprio cliente ou existente internamente é feito segundo a experiência e conhecimento do líder de produção, não existindo um processo para tanto. Em algumas organizações nem mesmo este procedimento é efetuado. Somente uma das organizações possui o recurso de framework como ferramenta de auxílio ao cliente. 


\section{(4) Desenvolvimento -entrada na produção}

Este conjunto de questões visa identificar como é feita a transição do serviço (tarefas) da fila de espera para a implementação propriamente dita.

As organizações, como trabalham com equipes multidisciplinares, entregam o serviço para os desenvolvedores conforme disponibilidade. $O$ desenvolvedor, juntamente com o líder de produção, efetua um planejamento que normalmente é seguido. As organizações possuem um processo de trabalho definido que é seguido pela equipe. As organizações que trabalham com CMM realizam o preenchimento dos formulários adequados de acompanhamento do processo. Nenhuma das organizações trabalha com a Norma ISO 9000 ou com o PSP (processo de software pessoal) e os processos para a obtenção de divulgação de medições referentes a produtividade praticamente não existem

\section{(5) Desenvolvimento - implementação (codificação)}

Para este tópico, o objetivo é entender como é o processo de passagem da fila de espera para a fila de implementação e se há algum processo para reuso de código.

Foi observado que todas as equipes de desenvolvimento, exceto uma, implementam o código da forma que o cliente definiu, não realizando nenhuma quebra em tarefas menores. Esta opção fica a cargo do desenvolvedor e não faz parte do processo.

Com relação à atividade de revisão de código, apenas uma organização possui esse processo (a mesma anterior).

\section{(6) Desenvolvimento - testes}

Estas perguntas têm o objetivo de verificar como as organizações organizam os processos de teste: quando são planejados, como são realizados.

Quando o desenvolvedor implementa o produto (que pode ser um programa, uma classe ou um componente), ele próprio realiza os testes unitários. Após a confecção dos produtos que compõem um serviço do cliente, individualmente são feitos os testes de integração. Este estudo visa verificar com as organizações se comportam antes dos testes de unidade e de integração.

Foi observado que praticamente todas as organizações trabalham com uma metodologia de testes alinhada com a metodologia de desenvolvimento. Quando é 
feito o planejamento do projeto, este inclui as atividades de testes. As estratégias de testes são cumpridas pelas equipes de desenvolvimento. Estas estratégias, visam normalmente uma massa grande de testes com testes longos. As massas de testes são criadas no instante do teste, ou seja, após a implementação do produto. Geralmente são os próprios desenvolvedores que realizam os testes de unidade. Como maioria das organizações trabalha focada no serviço do cliente, os testes de integração, quando necessárias, são criados no instante da sua execução e realizados pelo próprio desenvolvedor.

Os entrevistados questionados não acham que o processo de teste seja eficaz, apesar de serem demorados. Alguns conheciam e outros ficaram conhecendo a proposta do XP (extreme-programming) de criação de testes antes da implementação e deixaram claro que gostariam que experiências fossem feitas para identificar novos esquemas que sejam mais eficazes e menos demorados. Uma das organizações aplica a prática de testes da XP parcialmente, a contento, e está procurando incrementa-la gradativamente.

\section{(7) Encerramento}

Nesta etapa o objetivo é verificar se no encerramento são tomados alguns cuidados referentes a controle, qualidade e registro de dados históricos.

Normalmente, após o encerramento do serviço, os desenvolvedores participam da homologação junto ao cliente e, depois do aceite, os mesmos efetuam a atualização do planejamento, baixa no controle e a liberação dos recursos alocados. Para a maioria das organizações, neste instante é que são efetuados os registros da qualidade e produtividade.

Os registros para melhoria de processo, exceto em uma organização, não é normalmente efetuado, ficando para o desenvolvedor apresentá-las em reunião. Também não há um esquema de atendimento a estas melhorias, podendo ser efetuada a qualquer tempo. Geralmente, segundo os entrevistados, a maioria cai no esquecimento e até pode acontecer novamente. Raramente e somente em algumas situações os problemas encontrados e as soluções apresentadas são divulgadas oficialmente entre as diferentes equipes de desenvolvimento. Assim, como não há divulgação de atividades de melhoria, fica somente para os desenvolvedores divulgarem entre si, se acharem necessário. 


\section{(8) Desenvolvimento - questões gerais}

Análise de algumas questões que não foram abordadas nos tópicos anteriores por ser tratarem de uso geral tais como métricas, medição da produtividade, nível de retorno de serviço, verificação da eficácia das melhorias de processo.

Duas organizações relataram que o nível de retorno do cliente é relativamente alto, o que causa insatisfação do cliente.

A maioria das organizações se preocupa em saber qual o grau de satisfação do Cliente através de um processo de verificação. Em uma das organizações, até agora a mais organizada, houve conflito em três informações, mas percebe-se que, apesar de informarem que um nível de retorno de serviços é baixo, não possui nenhum processo de verificação da satisfação do cliente.

Somente uma das organizações foi clara nas respostas: que efetua uma análise e verificação das melhorias aplicadas nos processos produtivos. As demais mostraram que não possuem nenhum processo de análise e verificação.

\section{VI.3.2 Proposta de modelo de desenvolvimento para Fábrica de Software.}

Nesta seção é apresentado o modelo de processo proposto por Rodrigues Silva $(2001,2005)$. Este modelo foi construído a partir do levantamento conceitual sobre Fábrica de Software e a pesquisa de campo realizada.

VI.3.2.1 Conceitos gerais sobre uma fábrica de software.

Uma fábrica de software caracteriza-se por ter um modelo semelhante a um processo industrial, baseado na utilização de um processo de desenvolvimento, visando a padronização das atividades fabris, qualidade e produtividade, construindo produtos e software de maneira artesanal. Conforme Fernandes, Teixeira (2004) uma fábrica de software deve utilizar entre outros, os seguintes conceitos básicos para a produção de software sob encomenda:

- Processo padrão e definido para a implementação do produto de software;

- Uma entrada padronizada do serviço do cliente;

- Métodos e padrões de estimativas baseados em históricos; 
- O perfil dos desenvolvedores deve ser controlado e estar alinhado com as demandas;

- A produção deve possuir processos distintos para atendimento de demandas de natureza diferente;

- Possuir melhoria contínua de seus processos.

Outra característica importante da fábrica de software é o reuso sistematizado.

\section{VI.3.2.2 Conceitos utilizados no modelo proposto.}

\section{Serviço do cliente e tarefas}

É a solicitação demandada pelo cliente que deverá ser, pela gerência de produção, desmembrada em possíveis tarefas para a produção. Deve estar dentro de um padrão de aceitação, com definição clara e objetiva da proposta para o produto final. $\mathrm{O}$ artefato final de cada tarefa será o código implementado. O cliente receberá juntamente com a solicitação do serviço, a composição dos códigos das tarefas.

\section{Bancada de produção}

É a parte produtiva que recebe o serviço do cliente e o implementa através das linguagens de programação, criando o artefato final: o código.

A bancada de produção é composta por equipes para cada ambiente de desenvolvimento. Os profissionais devem ser habilitados para extrair o melhor de cada ambiente de produção ou linguagem de programação. Não é premissa deste modelo ter um quadro de desenvolvedores multifuncionais (que desenvolvem em vários ambientes).

\section{Bancada de produção ambiental}

A bancada de produção ambiental é o desmembramento da bancada de produção em bancadas que implementam o serviço do cliente em diferentes tipos de ambientes e de linguagens. Isto requer líderes de produção diferentes para poderem estar junto ao desenvolvimento nas tarefas de planejamento, acompanhamento e dando o apoio necessário. As bancadas ambientais devem ter claramente especificadas as principais definições para a construção do ambiente, como por exemplo: 
- perfis funcionais e atividades que serão desempenhadas;

- processo de desenvolvimento de software e os artefatos de entrada, saída e as medições de avaliação;

- material necessário para a instrumentação;

- sequenciamento de pedidos.

Um fator importante para um ambiente de produção é a seqüência em que o mesmo irá atender suas demandas. Trata-se da programação de atividades e a sua priorização.

\section{BACKLOG}

É o nome dado às pendências de atividades a serem realizadas. É a fila de serviços pendentes. Vide Figura 48.

\section{SCRUM}

Trata-se de um método ágil de desenvolvimento de software (Beedle apud Rodrigues Silva, 2005). Esse modelo é utilizado na Índia. O SCRUM divide um projeto (ou todas as tarefas do BackLog da organização) em repetições denominadas SPRINT com durações de, normalmente, 30 dias (no modelo proposto é uma semana). Mensalmente define-se a prioridade do BackLog em função das demandas e negociações com clientes, disponibilidade dos recursos (ambientes e pessoas). Definem-se as entregas durante o período. Diariamente são feitas reuniões com as equipes (tipicamente 15 minutos) para posicionamento e reporte sobre as atividades. Essas reuniões são um importante meio de comunicação entre os membros da equipe. Vide Figura 48.

\section{SPRINT}

SPRINT é o nome dado a uma programação de atividades de um período de funcionamento da Fábrica. Trata-se da coleção de pedidos pendentes que não deve ser alterado durante o período de programação. O SPRINT é o horizonte de programação de produção. O SPRINT é detalhado nas tarefas menores -SCRUMque são as atividades atomizadas para as pessoas. Vide Figura 48. 


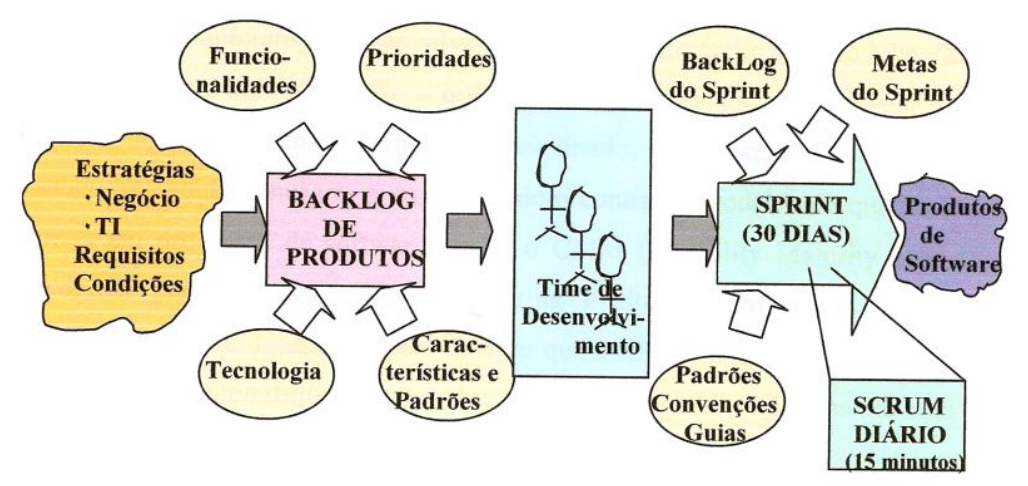

Figura 48 - Visão Geral do SCRUM (Rodrigues Silva, 2005)

\section{VI.3.2.3 Modelo proposto.}

\section{Equipe de desenvolvimento.}

A equipe de desenvolvimento deverá estar envolvida seguindo o processo de desenvolvimento definido para a Fábrica. A tecnologia XP deverá favorecer, juntamente com a utilização do modelo PSP, a montagem de equipes mais homogêneas possibilitando que se organize para um serviço do cliente, uma equipe compatível com a complexidade apresentada. Seus objetivos são o aproveitamento dos índices de produtividade, qualidade e eficiência para a montagem das equipes, bem como a estrutura de treinamento do pessoal desenvolvedor. A tecnologia XP possibilita, além do uso das práticas de implementação, o uso da prática de programação em pares, que contempla uma forma de trabalho mais qualitativa e alinhada com a satisfação e confiança do desenvolvedor.

\section{Gerenciamento do BackLog}

O gerenciamento das equipes será realizada seguindo a tecnologia SCRUM, da seguinte forma:

- Cada novo serviço será incorporado pelo gerente de produção ao Backlog da bancada ambiental;

- Os SPRINTS serão criados em reuniões semanais, ao invés de trinta dias como definido na metodologia SCRUM;

- Cada SPRINT resulta na meta da bancada ambiental em um planejamento para o horizonte que de uma semana; 
- Diariamente, o líder da equipe faz uma reunião de, no máximo 15 minutos, com sua bancada ambiental, posicionando o planejamento;

- A cada produto terminado será acionada a integração instantânea, quando for o caso;

- Sempre que os testes forem terminados deve ser efetuado um aviso ao líder;

- A cada produto terminado, será efetuada a aplicação atualização do planejamento, e como conseqüência, a atualização das metas da equipe e do BackLog (Sprint).

\section{Processo de desenvolvimento.}

Este processo deverá estar definido adequadamente, em um nível de detalhe suficiente para homogeneizar as tarefas.Isto deverá garantir itens com padrões de programação, como por exemplo critérios para nomear variáveis, além do controle das tarefas. $O$ processo proposto possui 5 processos que estão divididos em subprocessos menores detalhando as atividades para melhor compreensão

- (1) Processo de recebimento do serviço -esta atividade deverá ser realizada como um ato formal, seguindo o processo descrito em (Costa 2003).

- Disponibilização do serviço para a produção - a gerência de produção recebe o serviço e realiza atividade de desmembramento em tarefas a serem implementadas nas bancadas de produção.

- (2) Processo de entrada das tarefas nas bancadas ambientais de produção - os líderes recebem as tarefas definidas pelos clientes que são complementadas com os padrões da fábrica. Atualiza o recebimento das tarefas no controle, realiza reuniões SCRUM para a criação das metas da semana, prepara planejamento, plano da qualidade, verifica a possibilidade de reuso e disponibiliza para os desenvolvedores.

- Reuniões do SCRUM para a criação do SPRINT - os líderes das bancadas ambientais, juntamente com as suas equipes de desenvolvimento, separam do BackLog do SPRINT, qual será a meta 
estabelecida para a semana. Nestas reuniões devem ser consideradas as datas de entrega para os clientes.

- Pequenas versões - a definição do cliente é revista, no nível XP e é verificada a possibilidade de desmembramento tarefas grandes em pequenas tarefas. Este processo é efetuado pelos desenvolvedores da bancada ambiental, e comunicado ao cliente. A situação é atualizada no controle, cada um gastando seu tempo nas tarefas menores e liberando a tarefa grande.

- Planejamento do desenvolvimento da tarefa - de posse do SPRINT para a bancada, ou seja a meta para a próxima semana, efetua se o planejamento de cada tarefa. Neste processo é objetivo do líder de produção da bancada ambiental, juntamente com a equipe, estabelecer o plano detalhado, fazendo com que todos fiquem comprometidos com as tarefas. Isto deve ser feito considerando os níveis de produtividade, se possível, no nível individual.

- Plano da qualidade - o plano da qualidade deve ser a base para o acompanhamento da tarefa através de padrões mínimos exigidos na produção.

- Verificação do Framework - quando cada tarefa do serviço do cliente é concluída, ela é translada da biblioteca de produtos em desenvolvimento, para a biblioteca de produtos desenvolvidos. Se estas tarefas forem componentes, será também registrado no Framework, para efeito de montagem da estrutura de verificação da reusabilidade. Quando um novo serviço do cliente, nos mesmos moldes de composição entra para a produção, o objetivo deste processo é verificar através de navegadores próprios ou de pastas descritivas dos padrões existentes, se já existe alguma classe, método, componente, pattern com padrões que satisfaçam as necessidades da nova tarefa a ser desenvolvida. Esses padrões podem ser gerais (da própria produção) ou do cliente (em ambiente restrito). 
- Distribuição das tarefas para a bancada de produção ambiental - as tarefas, com seu planejamento e relatório de especificação técnica, são entregues aos desenvolvedores.

- (3) Processo de produção - a tarefa, definida pelo cliente, e pertencente à meta do SPRINT, é atualizada no controle e disponibilizada no BackLog da bancada ambiental, aguardando sua vez na fila de espera, para a implementação.

- Elaboração dos testes - seguindo a recomendação do XP, o plano de testes e os casos de testes devem ser elaborados antes da programação.

- Desenvolvimento das tarefas (implementação ) - este desenvolvimento pode ser para protótipo ou funções do projeto. É a produção em si, a codificação. Para a implementação propriamente dita, deve-se levar em conta o código recuperado do framework. Atualizar os formulários de apontamento das tarefas.

- Criação do ambiente e de testes - para verificação da exatidão dos códigos em relação aos requisitos do cliente, é necessário realizar testes de unidade e de integração .

- Realização dos testes - os testes devem ser realizados seguindo o plano preparado anteriormente, no ambiente adequado e os resultados devem ser registrados .

- Liberação da tarefa para a homologação com o cliente - Uma vez estando a tarefa codificada e testada deve ser devolvida para a gerência de produção. A gerência de produção, verifica se todas as tarefas foram concluídas com sucesso juntamente com o cliente.

- (4) Processos de encerramento - após a entrega ao cliente, são necessários alguns processos para encerramento, como por exemplo a disponibilização dos recursos técnicos e tecnológicos para novos serviços.

- Liberações - é a tarefa que realiza o translado do material de uma ordem de serviço mantido na biblioteca de produto em desenvolvimento para a biblioteca de produtos desenvolvidos. Liberar 
os recursos alocados em equipamentos, ambientes operacionais e humanos. O líder de produção da bancada ambiental deve acompanhar e verificar se as configurações estão sendo mantidas corretamente.

- Melhoria dos processos - com o encerramento do serviço do cliente, deve-se efetuar uma reunião entre a gerência de produção e o líder de produção e analisar as sugestões de melhoria e verificar se estas podem ser implementadas imediatamente ou em outra oportunidade. Estas melhorias devem ser acompanhadas pelo líder de produção da bancada ambiental onde o processo foi modificado, para verificação, medição, análise e acompanhamento da eficácia dessas alterações. A gerência de produção e as equipes de desenvolvimento devem ser comunicadas sobre a melhoria incorporada ao processo, o seu sucesso ou fracasso e os possíveis refinamentos.

- Divulgação - a divulgação pode ser em um único serviço do cliente, um grupo de serviços encerrados, uma tarefa ou em um período de tempo. Também pode cobrir especificamente uma bancada ambiental ou para toda a produção. A divulgação visa atingir um certo objetivo de chamada de atenção, de motivação ou simplesmente informativo. Fazer a divulgação dos índices obtidos como por exemplo eficiência, qualidade e produtividade, divulgar sucesso ou fracasso em atendimento às metas do SPRINT, mostrar as novas criações, novos padrões, patterns etc. Também é importante divulgar as melhorias sugeridas, quem as sugeriu e quais foram aproveitadas e como estão sendo aplicadas. Este pode ser utilizado como bom instrumento de motivação.

- (5) Processo de verificação da satisfação do cliente - periodicamente a gerência de produção encaminha aos principais clientes um questionário para verificar o grau de satisfação com relação aos serviços realizados. A tabulação e análise destas respostas podem facilitar a montagem de grupos de trabalho entre a gerência de produção, os líderes das bancadas ambientais e desenvolvedores alocados. O objetivo desses grupos de 
trabalho será verificar essas reclamações dos clientes e as possíveis melhorias no processo, necessárias para resolver as questões apontadas. 


\section{VI.4 ORGANIZAÇÃO DOS PROCESSOS DE UMA FS}

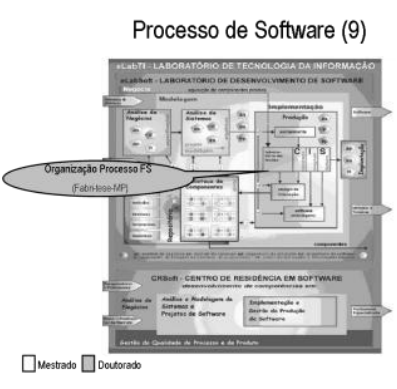

experiências anteriores.
A pesquisa desenvolvida com Fabri (2007) tem como objetivo estabelecer uma forma de "replicar" o processo de uma fábrica de software de uma localidade para outra. O problema colocado ocorre em empresas que possuem mais de um sítio de desenvolvimento, ou quando se deseja criar uma nova unidade de desenvolvimento de software a partir de

\section{VI.4.1 Considerações sobre Fábrica de Software}

Fabri (2007) identificou vários trabalhos acadêmicos sobre fábrica de software, dos quais é interessante observar o trabalho de Cusumano (1991), que foi um dos primeiros autores a publicar sobre este tema.

Outro autor estudado foi Basili apud Fabri (2007) que realizou pesquisas sobre produção de software com um enfoque, entretanto na organização do processo de produção. A proposta foi estabelecer uma Fábrica com dois processos: produção de componentes e produção de software (baseado em componentes). Este processo foi implementado na Universidade de Maryland, conforme modelo da Figura 49.

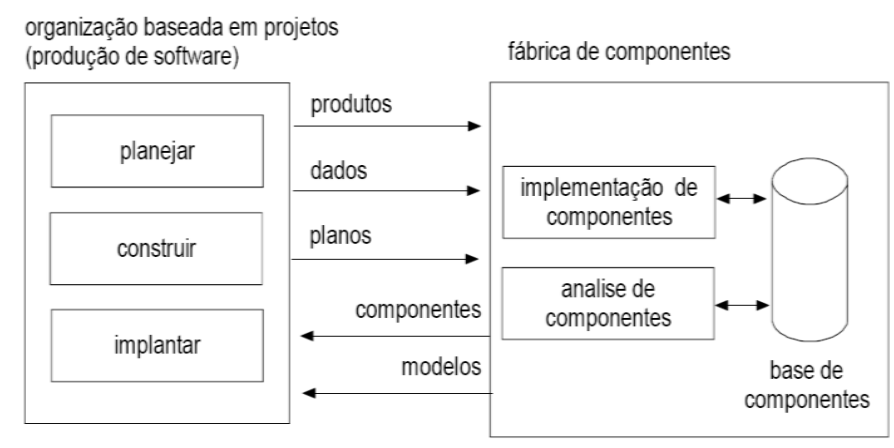

Figura 49 - Fábrica experimental de Basili (Fabri, 2007)

Fernandes e Teixeira (2004) propõe um modelo classificatório de fábrica de software cujo objetivo é definir qual o escopo de fornecimento de produtos (Figura 50). Este autor utiliza os termos fábrica de projetos ampliada, fábrica de projetos físicos, fábrica de programas, conforme os produtos que são fornecidos para os clientes.

- A fábrica de programas executa a atividade de codificação (e testes). 
- A fábrica de projetos físicos trata da construção do software a partir de uma especificação definida, depois de definidas as funcionalidades.

- A fábrica de projetos abrange todo o ciclo de vida, desde a análise até a implantação.

- A fábrica de projeto ampliada abrange o conceito de arquitetura da solução.

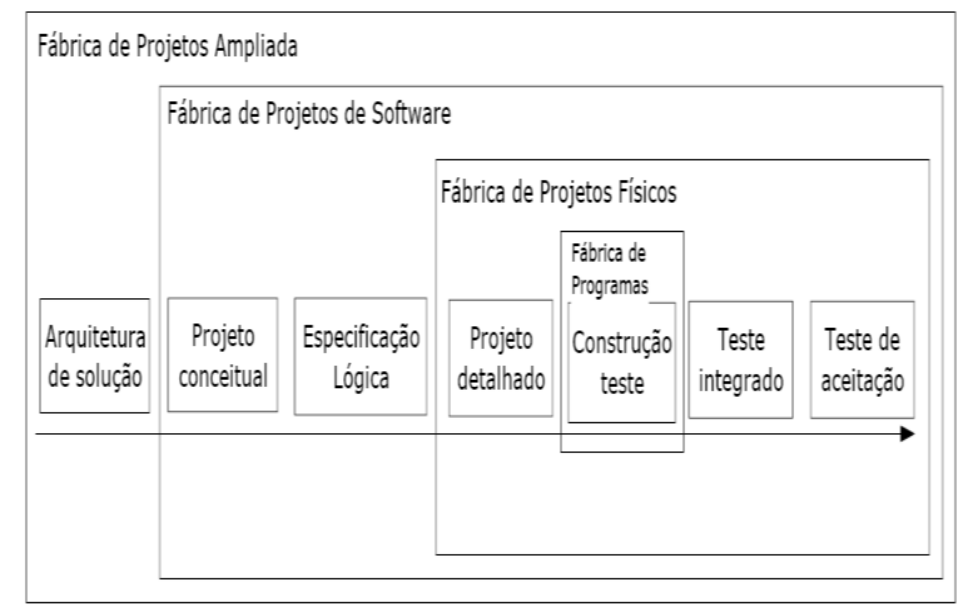

Figura 50 - Fábrica proposta por Fernandes e Teixeira (2004)

Nesse contexto, Fabri (2007) propõe um processo para a Fábrica de Software, conforme representado na Figura 51 . Esse modelo é formado por 4 quadrantes onde são realizadas as atividades relacionadas aos aspectos produtivos de software.

O primeiro quadrante tem como objetivo estabelecer as negociações para o desenvolvimento de um novo software. Efetuadas essas negociações é realizada modelagem do sistema pelo analista de sistemas e pelo analista de negócios

Tanto o levantamento de requisitos quanto a modelagem de sistema utiliza os componentes de modelagem (ativos de processos, regras, templates, algoritmos, caracterizadas como componentes de negócio, armazenados no repositório). Ao utilizar os componentes, os envolvidos com primeiro quadrante podem solicitar a alteração dos mesmos (ou propor novos), conforme sentir necessidade. Essas alterações de componentes ou construção de novos componentes, são realizados no quadrante 2. Por fim, após a modelagem do sistema de informação, o engenheiro de software e o engenheiro de produção desenvolvem o projeto do software a ser 
fabricado. As atividades relacionadas com o projeto de software estabelecem um elo entre os quadrantes um e três.

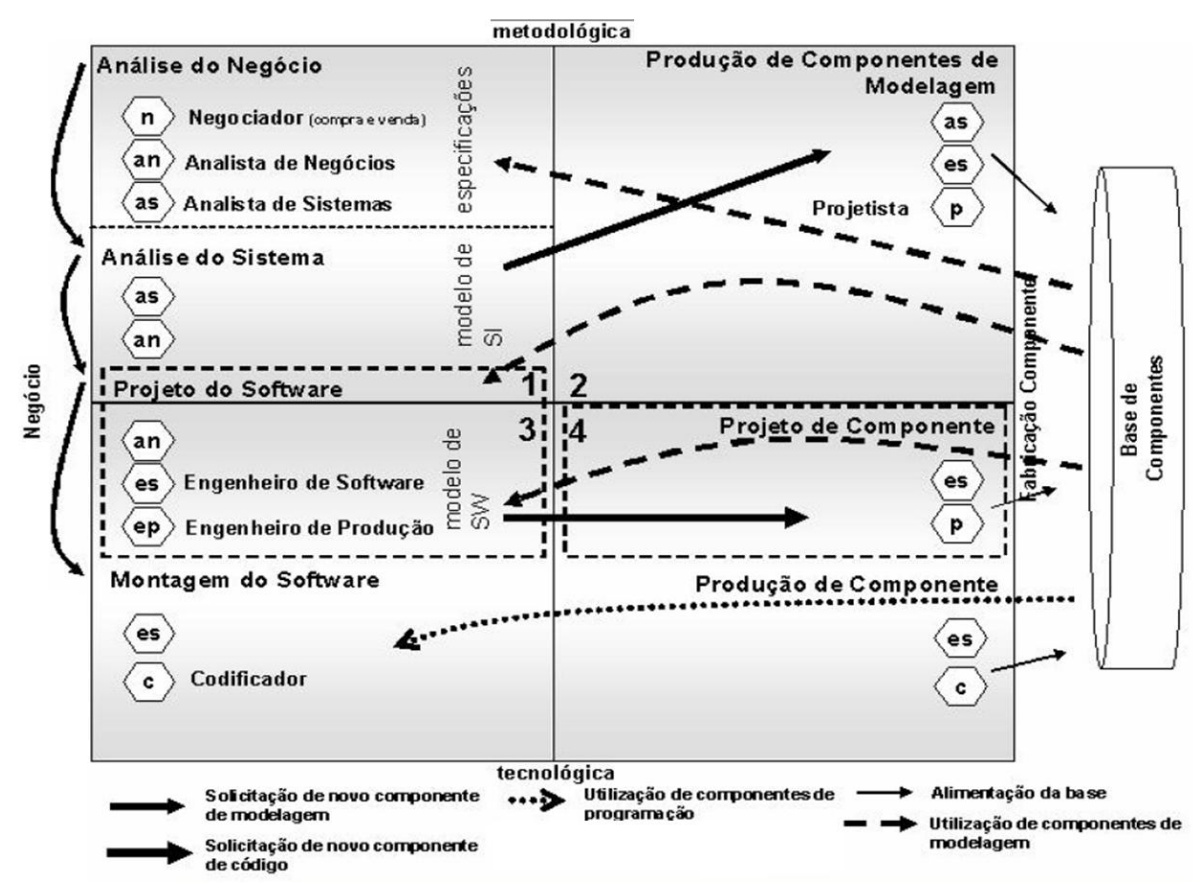

Figura 51 - Proposta de modelo para o eLab-TI (Fabri, 2007)

O segundo quadrante tem como objetivo desenvolver e manter os componentes de modelagem. As atividades relacionadas a este quadrante são encarregadas do desenvolvimento (padronizações, métodos, processos, técnicas de gerenciamento) e do provimento de subsídios para a estruturação da base histórica de projetos (o documento que relata o histórico de um processo, também, é armazenado na base de componentes). O desenvolvimento e a manutenção dos componentes de modelagem são estimulados pelos envolvidos com o primeiro quadrante. Uma vez desenvolvidos e aprovados pelos responsáveis pelo ambiente organizacional, os componentes são armazenados na base e disponibilizados para serem utilizados pelo processo de produção de software.

O terceiro quadrante foca a questão da fabricação dos programas, estes desenvolvidos com base em especificações advindas das atividades pertinentes ao projeto de software, atividades estas que provêm o elo entre a análise de negócio e a montagem do software. As atividades imersas em tal quadrante são disparadas pelos analistas de sistemas e engenheiros de software. 
O quarto quadrante tem como objetivo desenvolver componentes de código que comporão as unidades programáveis, desenvolvidas no quadrante 3. Encontram-se no quadrante 4 as atividades pertinentes ao projeto do componente, estas têm como objetivo desenvolver as especificações necessárias para que o componente seja codificado. A "completude" das especificações de um determinado componente estimula a produção do mesmo, e, se aprovado pelos responsáveis pelo ambiente organizacional, este será armazenado no repositório.

Outro aspecto interessante que pode ser observado na Figura 51, desenvolvida a partir da proposta de Basili (Fabri, 2007), é verificar as diferentes abordagens do processo de produção de software.

Os quadrantes 1 e 3 apresentam a questão do negócio do cliente se transformando em uma proposta de solução de TI.

Os quadrantes 3 e 4 apresentam a questão tecnológica, de ferramentas, linguagens e ambientes.

Os quadrantes 1 e 2 apresentam uma visão metodológica relacionada com as definições mais sistêmicas para a organização.

Finalmente, os quadrantes 2 e 4 apresentam a visão da organização dos componentes de software.

\section{VI.4.2 Processo fabril}

O processo de produção de software com características fabris denominado por Fabri et. Al. $\left(2004,2004^{a}, 2005,2007,2007^{a}, 2007 b, 2007 c\right)$ e Pessôa, (2004), simplesmente processo fabril, define que uma fábrica de software possui duas unidades: produção de software e produção de componentes (Figura 52). A unidade de produção de componentes possui como ciclo de produção as seguintes atividades:

Projetar componentes: Atividade que tem como objetivo modelar as funcionalidades, estrutura de dados e interface de um componente. Tal componente pode ser solicitado pela unidade de produção de software;

- Construir componentes: Atividade que tem como objetivo desenvolver componentes de código e de infra-estrutura (entende-se por componente 
de infra-estrutura, os ativos do processo, templates, formulários e algoritmos);

- Integrar componentes: Atividade que tem como objetivo verificar a qualidade funcional dos componentes. Em tal atividade são desenvolvidos os casos de teste, são preparados os dados de teste, os componentes são executados e, por fim, os dados resultados são comparados;

- Armazenar componentes: Esta atividade propõe que o administrador da base de componentes ("data base administrator component" (DBCA)) gerencie o armazenamento dos componentes, provendo permissões de acesso aos envolvidos com o modelo organizacional;

- Distribuir componentes: Existem duas formas de distribuição de componentes, o componente pode ser vendido ou entregue aos envolvidos com o processo de produção para que unidades de software sejam manufaturadas.

Fabri et. Al. (2004,2004a,2005,2007,2007a,2007b,2007c) salientam, explicitamente, que a unidade de produção de componentes alicerça a unidade de produção de software. Esta última possui as seguintes atividades:

- Análise de sistemas: Nesta atividade os eventos sistêmicos relacionados a empresa-cliente da fábrica de software são definidos;

- Projeto de software: Atividade que tem como objetivo desenvolver o projeto do software (funcionalidades, estrutura de dados, interface), após o desenvolvimento do projeto, o tamanho do software é definido;

- Construção do software: Objetiva o desenvolvimento das unidades programáveis. Nesta atividade são utilizados os subprocessos de manufatura;

- Integração: Atividade que tem como objetivo verificar a qualidade funcional das unidades programáveis. Em tal atividade, são desenvolvidos os casos de teste, são preparados os dados de teste, os componentes são executados e, por fim, os resultados obtidos são analisados; 
- Implantação: Atividade que objetiva implantar o software, utilizando técnicas de configuração e aspectos relacionados ao treinamento. $\mathrm{Na}$ atividade implantar está embutido o conceito de manutenção do software;

- Revisão: Atividade esta que tem como objetivo trocar o componente de um software que está implantado, por um outro, que provenha maior otimização (por exemplo: relação a tempo de reposta). Por meio da Figura 52, é possível verificar ainda, as atividades de gestão. Estas devem ocorrer em paralelo a cada atividade do processo de produção de software e de componentes. A concepção global da gestão também deve ser desenvolvida, fato este explicitado por Fabri et. Al. (2004,2004a,2005, 2007,2007a,2007b,2007c ).

Fabri (2007) ainda evolui este modelo para as atividades mais amplas como, por exemplo, contratação de um projeto e análise de negócio, porém este modelo não será detalhado aqui.

Fabri (2007) relata que o produto gerado pelo META-PROCESSO é um processo de software com características fabris, fato este explicitado, visualmente, por meio da Figura 53. Em tal figura, salienta-se a presença do ator engenheiro de processo, pessoa que percorre, diretamente, a estrutura proposta no META-PROCESSO, sendo responsável por todas as definições incorporadas ao processo de produção de software. Ao analisar a figura em questão, é possível dizer que o METAPROCESSO possui:

- entradas, caracterizadas como requisitos de um processo de software;

- processo transformador, responsável pela criação, organização, instanciação e adaptação do processo de software e;

- saída: processo de produção de software instanciado, que será percorrido quando um projeto for executado. 


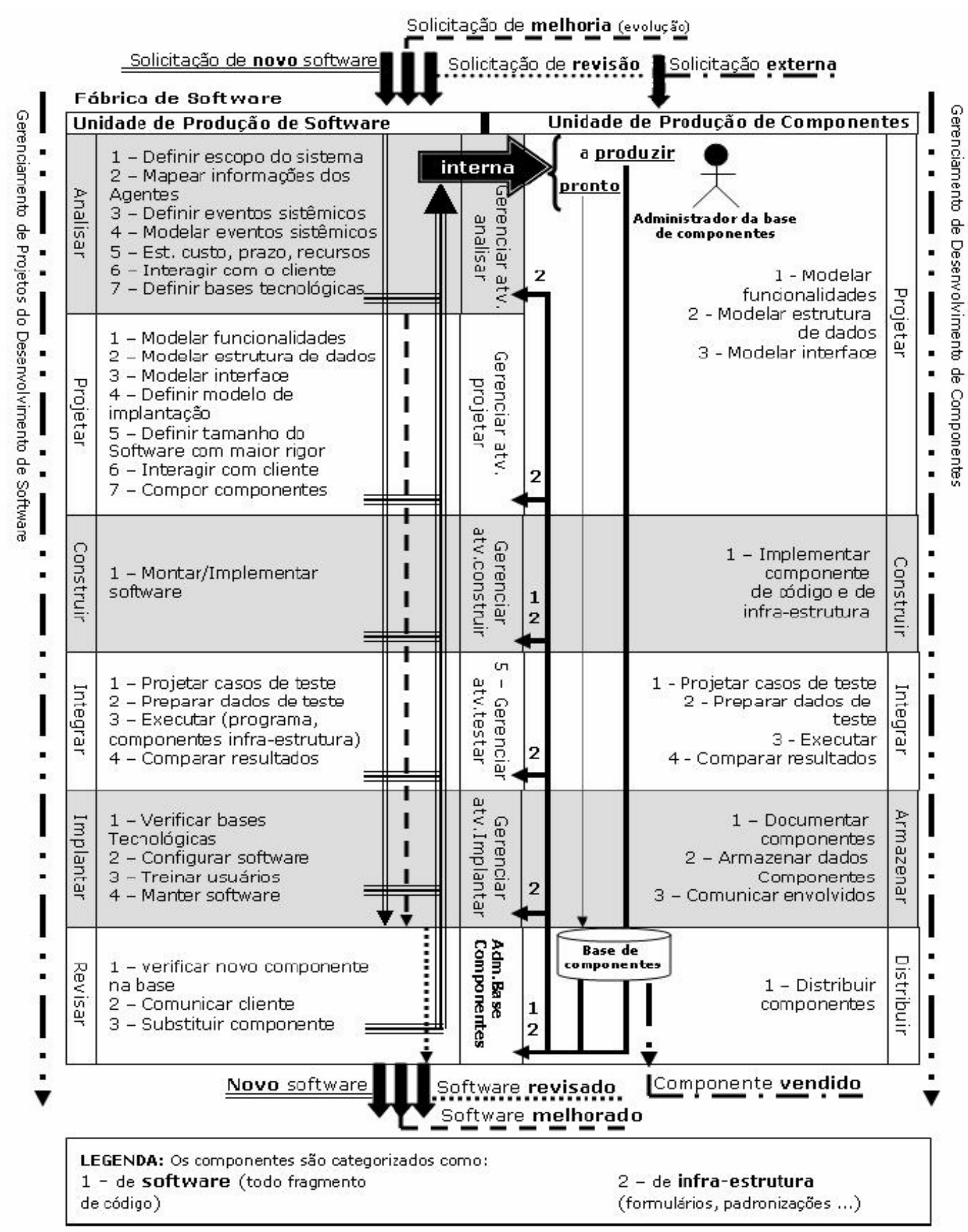

Figura 52 - Processo fabril (Fabri, 2007)

\section{VI.4.3 O modelo proposto de Meta-Processo para a Fábrica de Software}

A Figura 54 apresenta o modelo de Meta-Processo proposto por Fabri (2007). Esse modelo permite que seja criado um processo através de utilização dessa "máquina" Um meta-processo possui 6 atividades: modelagem, instanciação, simulação, execução, avaliação e armazenamento do processo. 


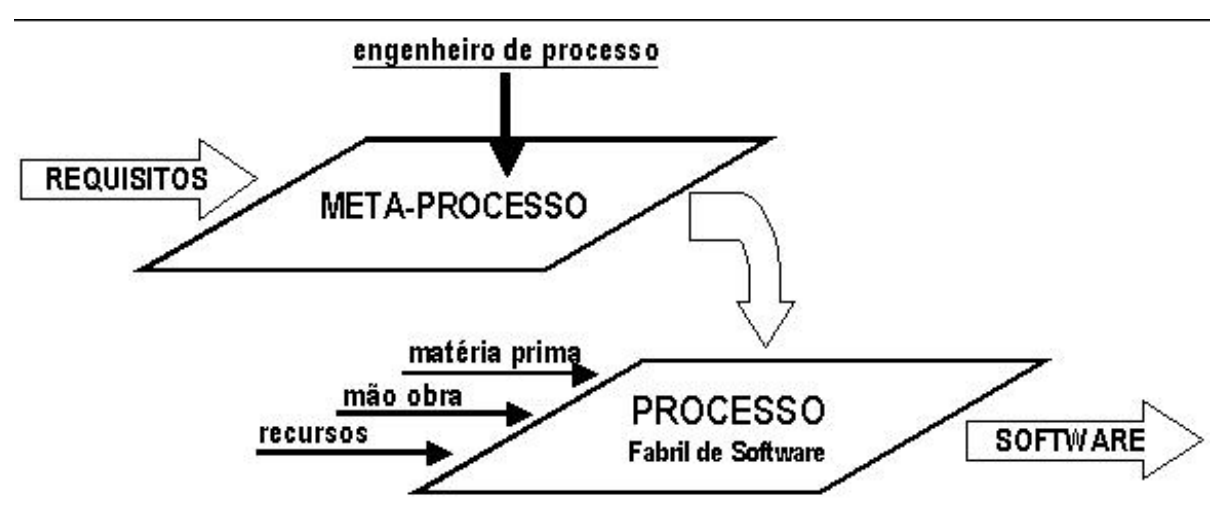

Figura 53 - Visão de meta-processo (Fabri, 2007)

Enfim, a Figura 54 apresenta o relacionamento das 6 atividades que compõem o META-PROCESSO. Ao analisar a figura, é possível constatar que o METAPROCESSO é representado por uma moenda, onde os requisitos são "despejados", e as atividades de modelagem, instanciação e simulação são "alavancadas", resultando em um processo executável, modelado com as perspectivas de fluxo de trabalho, fluxo de dados, recursos e habilidades. O processo é executado sobre um projeto, avaliado e, posteriormente, armazenado, juntamente, com a máquina de processo, em uma base de processos.

Outro ponto a ser observado como resultado desta pesquisa foi identificar que, do ponto de vista de organização dos processos, as Fábricas de Software brasileiras estudadas (em 2006 e 2007) pouco ou nada evoluíram em relação às empresas japonesas da década de 70 . 


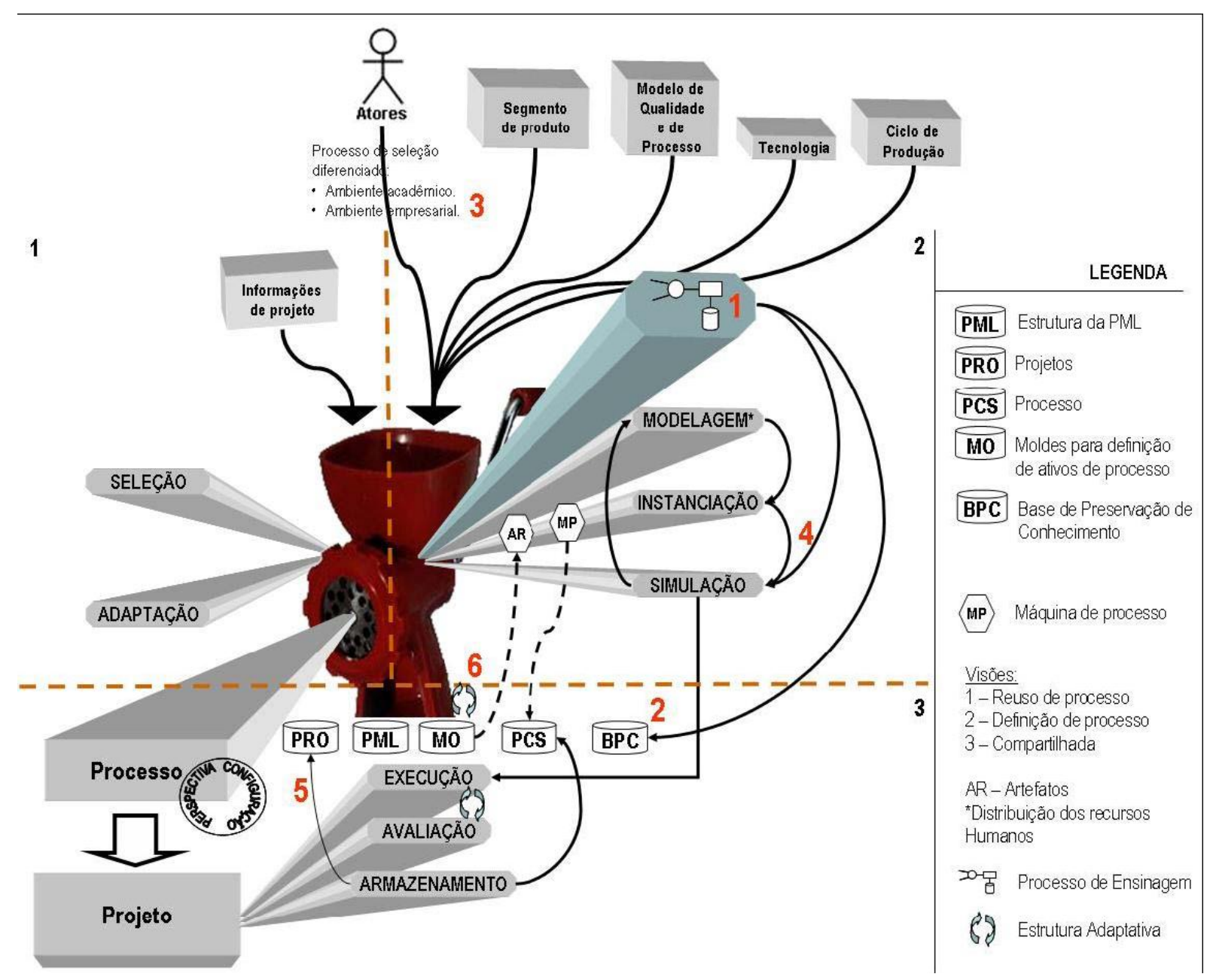

Figura 54 - Meta-processo proposto (Fabri, 2007) 


\section{VI.5 GESTÃO DO CONHECIMENTO EM FS}

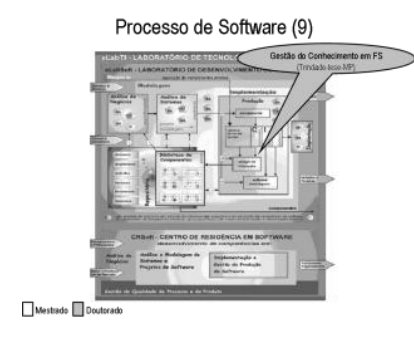

Na pesquisa desenvolvida com Trindade (2006), o foco foi a questão da rotatividade da equipe de desenvolvimento e a perda de qualidade das atividades realizadas na Fábrica de Software. A pergunta desta pesquisa foi: Como fábricas de software preservam o conhecimento?

A Figura 55 representa o binômio ensinagem, e aprendizagem. Embora aprendizagem seja um termo bem conhecido, que significa 0 ato de aprender, ensinagem é menos conhecido e possui o significado simétrico: o ato de ensinar. Nesta pesquisa o que interessa é o alinhamento entre os dois atos para fazer com que, no ambiente corporativo, cada pessoa da Fábrica de Software, ao executar suas atividades, esteja treinada, capacitada e preparada para realizá-la da melhor forma possível.

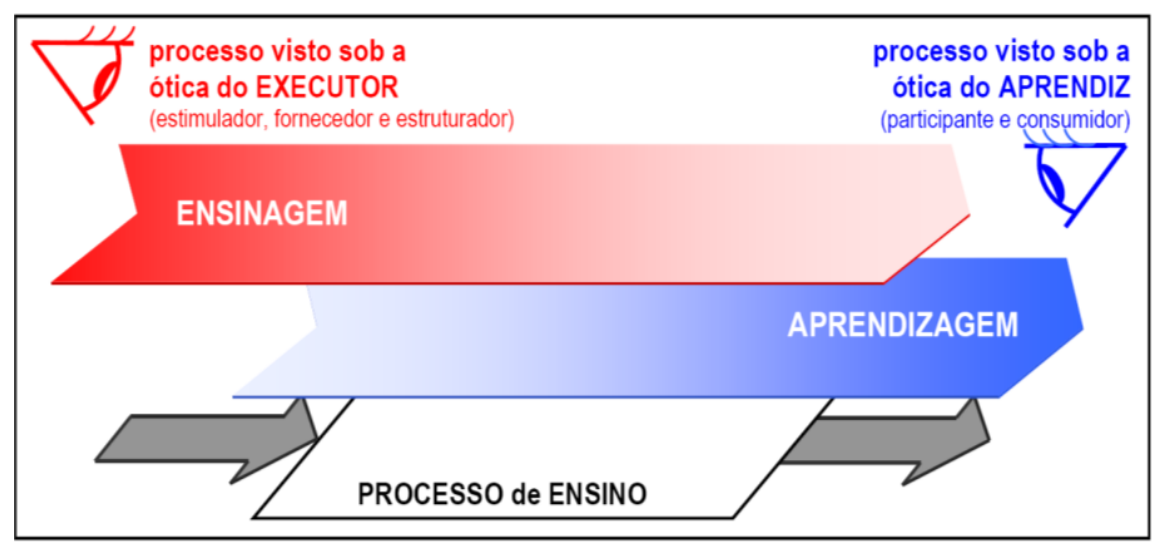

Figura 55 - 0 binômio ensinagem-aprendizagem (Trindade, 2006)

Nesta pesquisa, Trindade (2006) levantou um modelo teórico a partir da literatura, realizou um estudo de campo em quatro Fábricas de Software e propôs um modelo para o processo de ensinagem, visando a preservação do conhecimento nesse ambiente. A Figura 56 expressa o conhecimento de forma simplificada, na qual cada degrau representa um conhecimento (e com ele uma habilidade) a ser conquistado em processos de aprendizagem que, com acúmulos e sinergias, agregam competências.Essa figura não representa todos os degraus em simetria, pois os níveis de conhecimentos auferidos em cada etapa não são necessariamente iguais. Não há também como pensar em tal escada formando uma seqüência simples de ensinamentos em cadeados 


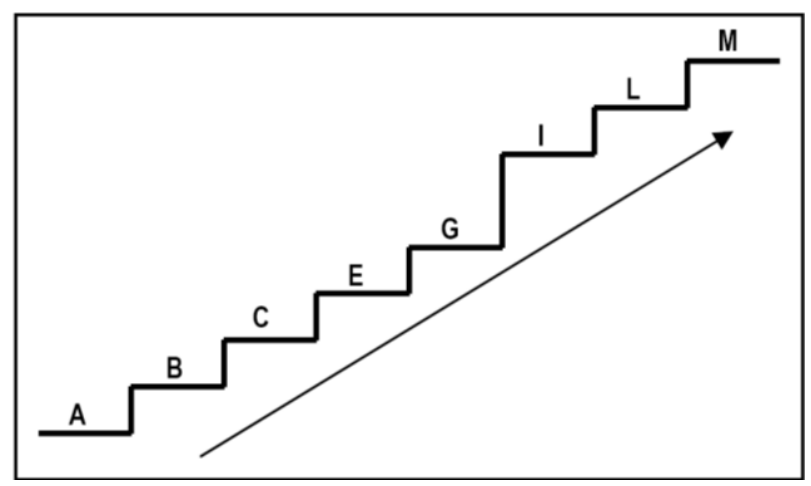

Figura 56 - A escada do aprendizado (Trindade, 2006)

Haverá, certamente, de acordo com cada ambiente, a política produtiva para cada conjunto de ferramentas, técnicas e métodos aplicáveis, um modelo diferenciado de combinações de conhecimentos que devem ser desenvolvidos por processos contínuos e contíguos de ensinagem. A Figura 57 exemplifica uma situação hipotética de combinações mostrando que um aluno pode percorrer um caminho diferente de outro aluno em função de sua trajetória, seu interesse e seus conhecimentos anteriores.

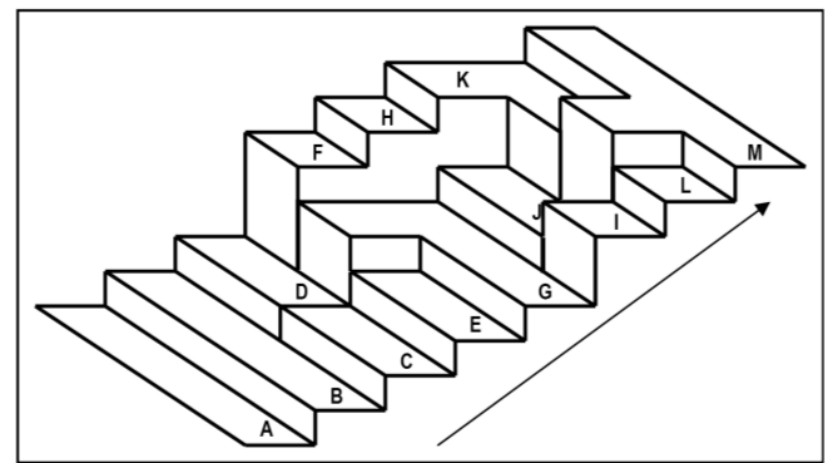

Figura 57 - A escada do aprendizado em perspectiva (Trindade, 2006)

A Figura 58 representa o modelo final de ensinagem. O que se admite neste modelo é que, no ambiente da fábrica, existe um certo grau de conhecimento e capacitação de cada colaborador para realizar um certo conjunto de tarefas.

Do ponto de vista de aprendizado ele entra no processo de ensinagem com conhecimento $(\mathrm{N}-1)$ e, decorrido um certo período, vai receber este conhecimento e vai subir para o degrau $(\mathrm{N})$ de conhecimento. 


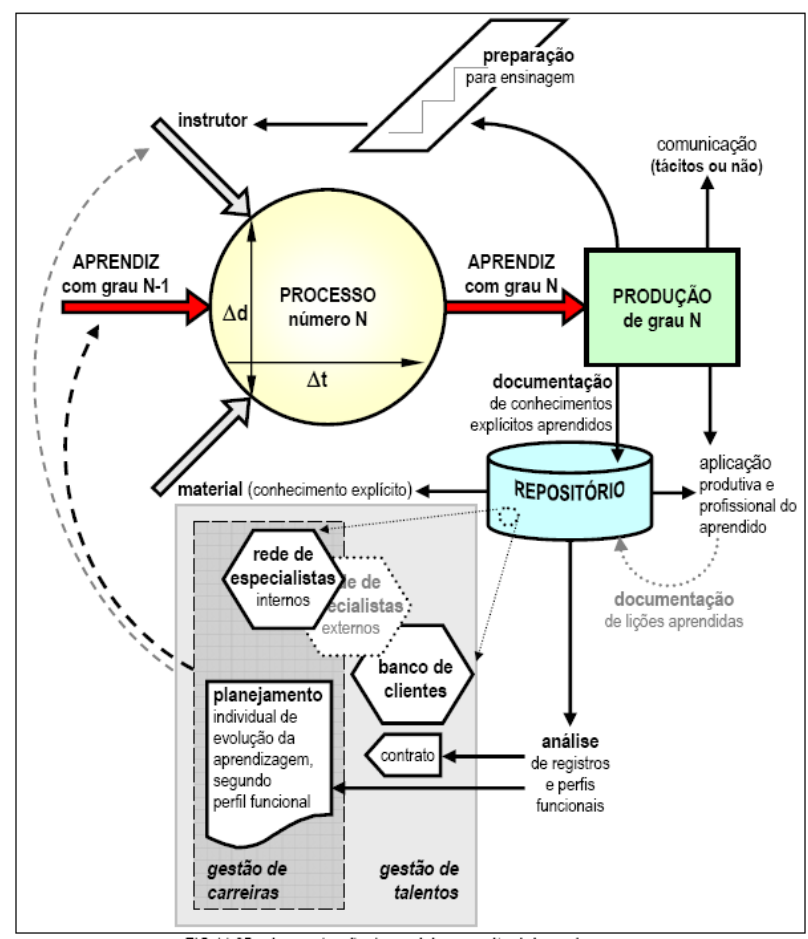

Figura 58 - Modelo final de ensinagem (Trindade, 2006)

Com isso será capaz de voltar para a fábrica e produzir um pouco melhor, ou uma outra atividade, em função deste aprendizado. Teoricamente, este processo acontece com todos os colaboradores e cada um possui um plano de carreira, o plano de aprendizado. Observando novamente a figura, no processo de aprendizado existe um instrutor ou não, conforme o tipo de aprendizado. Alguns instrutores podem ser as próprias pessoas a fábrica que recebem um treinamento específico para poderem ser instrutores. Existe um repositório onde são armazenadas todas as documentações dos materiais para a realização da ensinagem. Observar que existe no repositório, em destaque, a gestão de carreiras e gestão de talentos, envolvendo uma rede de especialistas que pode ter elementos fora da organização e um banco de clientes que forma a rede de aprendizado.

Observe a Figura 59 que mostra a escada do aprendizado juntamente com modelo de ensinagem. Cada degrau possui um ciclo de aprendizado do modelo (Figura 58. Em cima, à esquerda da Figura 59, pode-se observar que são três tipos de aprendizado que um elemento da fábrica deve receber: administração, processos e tecnologias.

A Figura 58 representa um exemplo do modelo de ensinagem sendo aplicado na escada dos conhecimentos. 


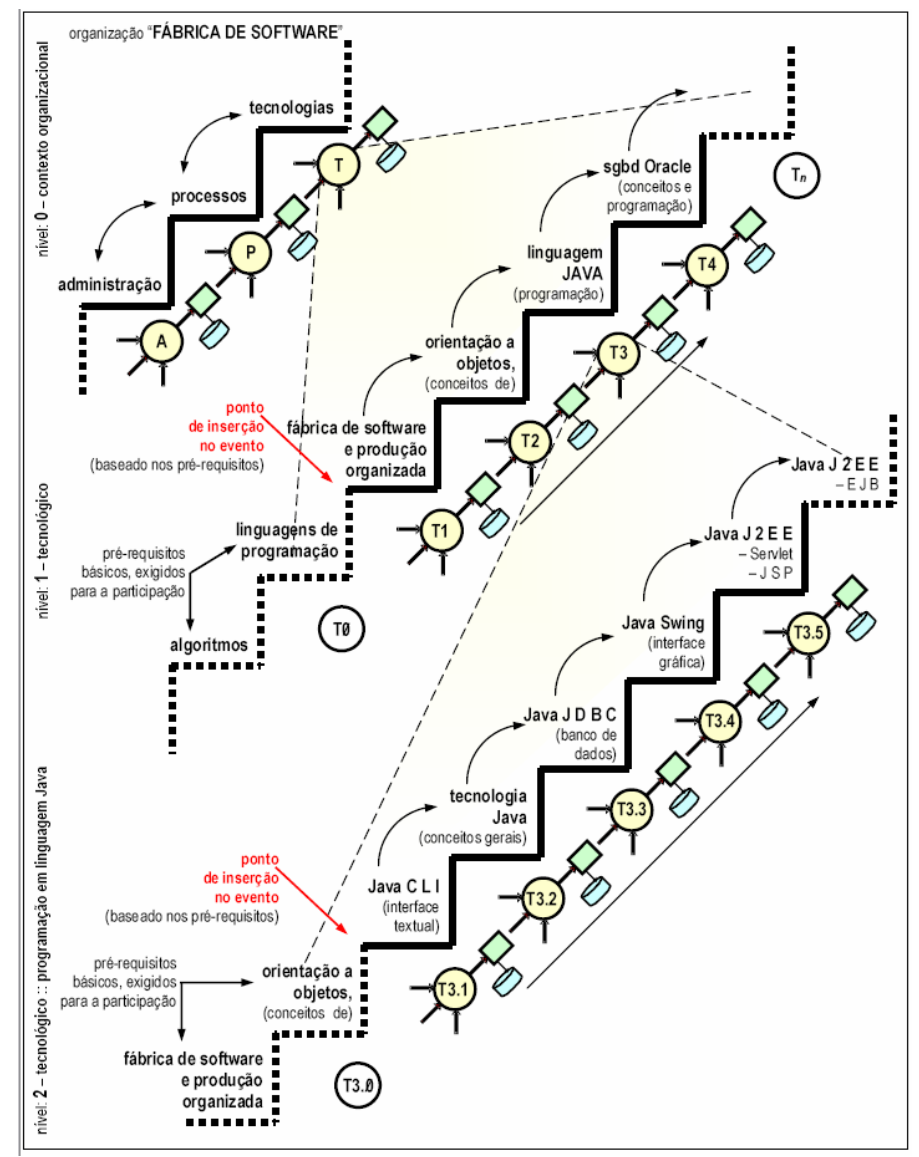

Figura 59 - Modelo de ensinagem e a escada de conhecimento com exemplo (Trindade, 2006)

No desenho está representada uma segunda escada, de tecnologia. Ao entrar na empresa, o profissional deverá ter seus conhecimentos mapeados para permitir e elaboração de um plano de carreira. Esse elemento deverá ter um ponto de inserção na escada devido aos conhecimentos que trouxe do mundo externo (como marcado no desenho).

Este ponto de inserção, e o plano de carreira, vão determinar qual a trajetória que será seguida. Pode-se observar que no exemplo da Figura existe um treinamento em tecnologia sobre orientação objeto, depois deverá aprender Java. Para aprender Java existe uma outra escada com maior detalhamento, e um ponto de inserção do elemento, e assim sucessivamente. 


\section{VI.6 DDS-DESENVOLVIMENTO DISTRIBUIDO DE SOFTWARE}

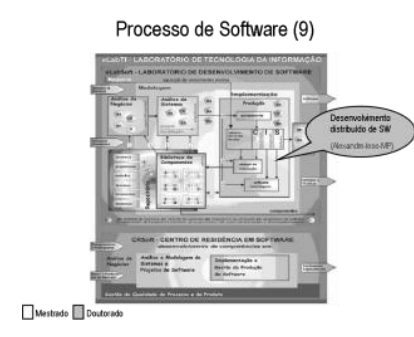

Na pesquisa de doutorado em andamento, desenvolvida com L'Érario (2006, 2007, 2008, 2009; PESSOA,2004c) está sendo explorada a questão do desenvolvimento de software distribuído, procurando responder a questão: Como as organizações desenvolvem software de maneira distribuída?

Esse tema de pesquisa surgiu ao se identificar que nas Fábricas de Software é muito comum a realização de serviços encomendados por terceiros, mostrando que a cadeia de desenvolvimento de sofwatre é maior que uma Fábrica isolada. Além disso, em função da necessidade de redução do tempo de desenvolvimento (time to market) está cada vez mais comum a distribuição de uma grande tarefa para vários grupos de projeto com o objetivo de paralelizar as atividades.

\section{VI.6.1 Propriedades de um DDS}

Segundo L'Érario (2006, 2008, 2009), há diversas propriedades que envolvem um ambiente DDS- Desenvolvimento Distribuído de Software (Figura 60). Cada propriedade determina o grau de complexidade de trabalho e revela consigo o quão difícil é produzir software em equipes fisicamente dispersas. Além disso, cada propriedade agrega consigo uma série de conceitos que são: quantidade de arcel (sítios), difusão do processo, grau de interação, distância física e granularidade do repasse.

- quantidade de sitios - quanto maior o número de arcel envolvidos, maior será a complexidade e dificuldade de gerenciamento. Para ser considerado DDS, no mínimo dois arcel precisam estar envolvidos.

- difusão do processo - esta propriedade trata das diferenças entre o ambiente de desenvolvimento entre os diversos arcel envolvidos no projeto. $\mathrm{Na}$ parte mais central está um ambiente heterogênio onde a padronização é de artefatos produzidos, ou seja, dos produtos elaborados no projeto. Na parte mais externa está um ambiente homogêneo, ou seja, os diversos arcel utilizam o mesmo processo de desenvolvimento. 


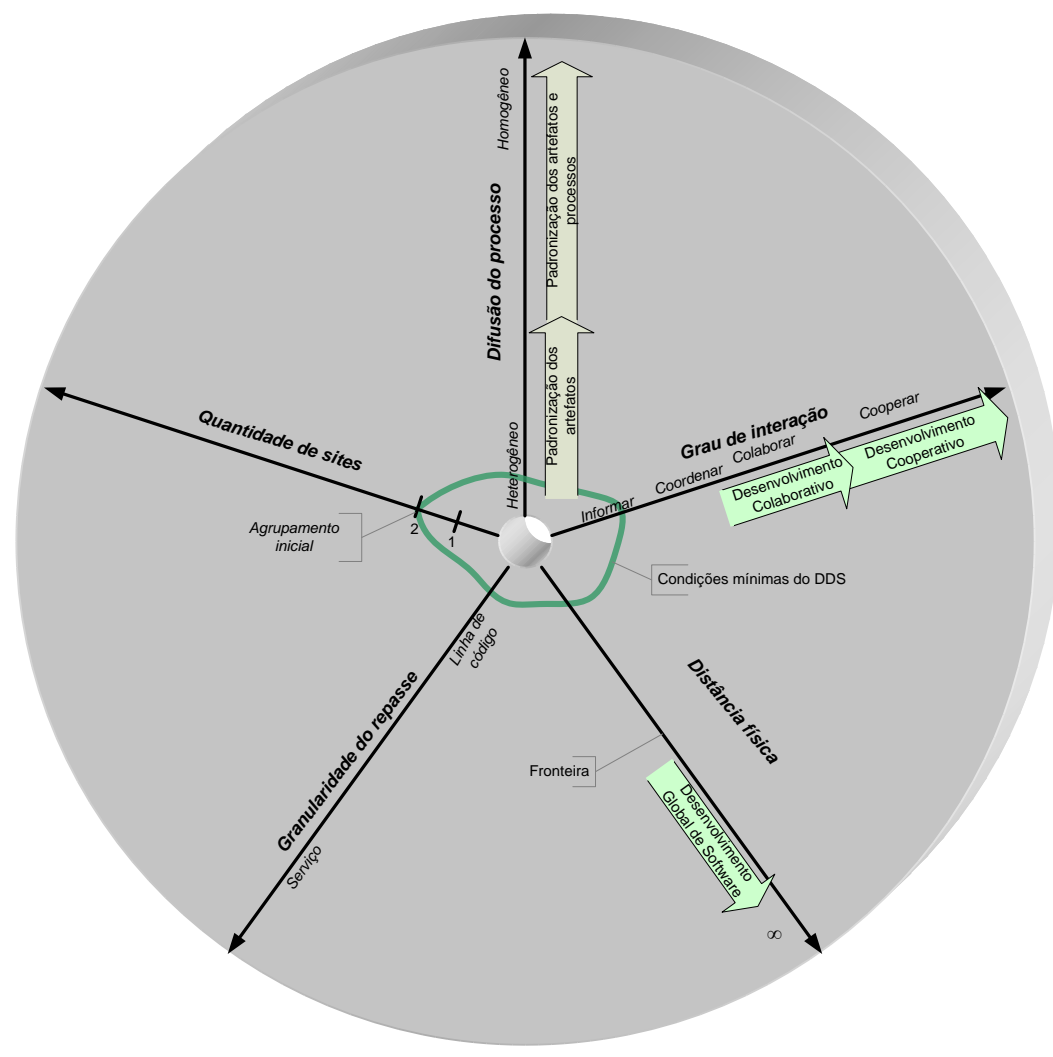

Figura 60 - Propriedades dos Ambientes DDS (L’Érario 2006)

- grau de interação - trata da interação que existe entre os grupos dos diversos arcel envolvidos no processo. Essa dimensão baseou-se em Borghoff (2000) que classifica o grau de comunicação ente os grupos, representado na Figura 61. O menor grau de comunicação seria apenas a ocorrência de informações entre os grupos. O DDS começa a ocorrer no segundo grau denominado Coordenar onde há um mínimo de organização entre os grupos para permitir a distribuição do trabalho. No terceiro grau, denominado Colaborar, as equipes trabalham em uma mesma obra e, no quarto -Cooperar- as equipes interagem com maior grau de intensidade visando uma associação para o bem comum: o projeto.

- distância física - dentro do país o desenvolvimento é denominado Onshore e fora do país, é denominado Offshore. Quanto maior a distância, mais complexo torna-se o projeto em função de língua, aspectos culturais e fuso horário (L'Érario, 2009). O caso de desenvolvimento distribuído offshore é denominado GSD - Global Software Development. 


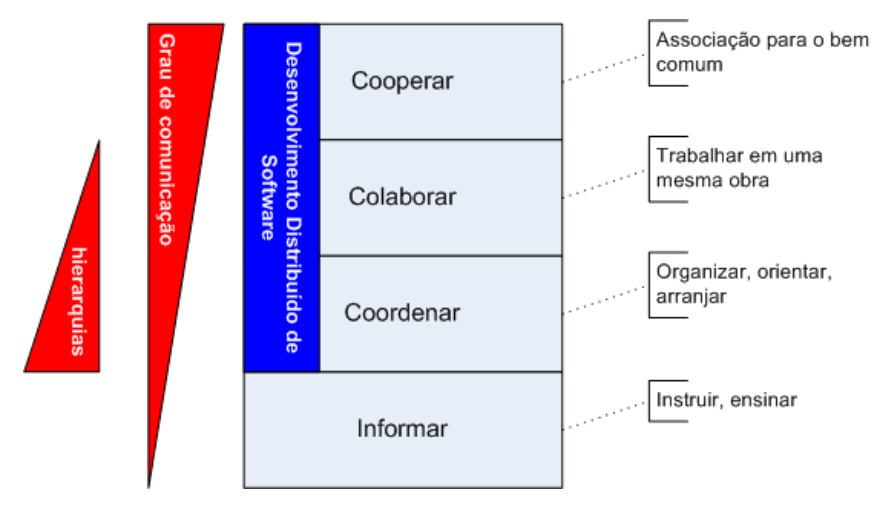

Figura 61 - Grau de comunicação entre os grupos (Borghoff, 2000)

- granularidade do repasse - está relacionada com a forma com que cada sitio entrega seu subproduto na rede. Em um extremo está a construção de código (mais ao centro), o que leva a uma necessidade de padronização de ferramentas. No outro extremo está o repasse do serviço como um todo. Essa granularidade pode também estar definida de maneira diferente entre os arcel (L’Érario, 2009).

Outra dimensão da Figura 60 trata da forma de coordenação entre os diversos arcel envolvidos com o(s) projeto(s), representado na Figura 62.

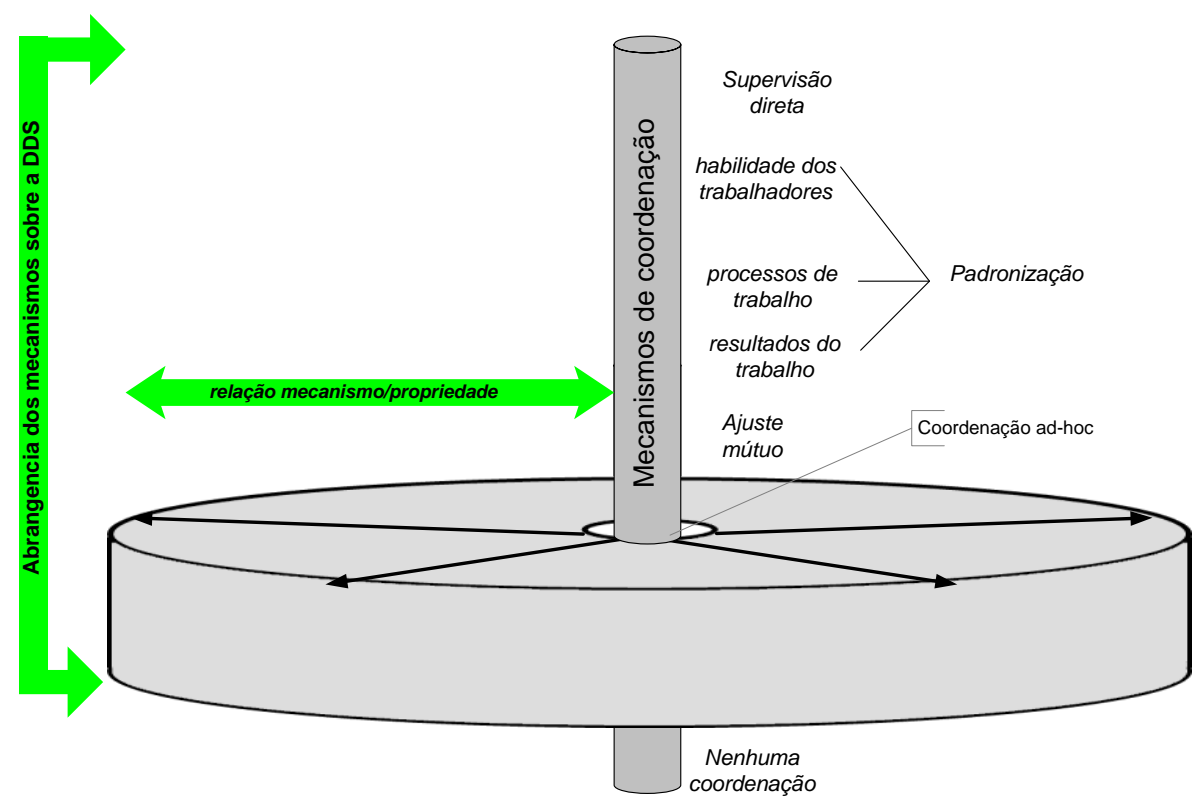

Figura 62 - Relação entre os Mecanismos de Coordenação e as propriedades do DDS (L’Érario, 2009) 
O nível mais pobre de coordenação está representado embaixo e trata de uma coordenação ad-hoc. Acima disso, há um ajuste mútuo entre os arcel de forma reativa realizando correções à medida que os problemas surgem. Em um grau um pouco melhor, há os diversos níveis de padronização, iniciando com a padronização dos artefatos produzidos (resultados do trabalho), dos processos de trabalho (padrões de processo) e padronização de habilidades dos trabalhadores (padrões dos perfis dos profisisonais) até a supervisão direta que corresponde a uma coordenação centralizada.

\section{VI.6.2 Modelo Proposto}

Nesta pesquisa foram realizados 6 estudos de caso abrangendo um projeto estritamente acadêmico que deu uma série de problemas por falta de coordenação, duas empresas multinacionais com diversos sítios em várias partes do mundo (ambas CMMI nível 5), uma multinacional que atua exclusivamente na área financeira para um cliente com vários sítios (CMMI níveis 2 e 4), uma multinacional que desenvolve software embarcado para celulares (CMMI níveis 3, 4 e 5) e uma empresa nacional qua atua na área financeira (CMMI nível 2).

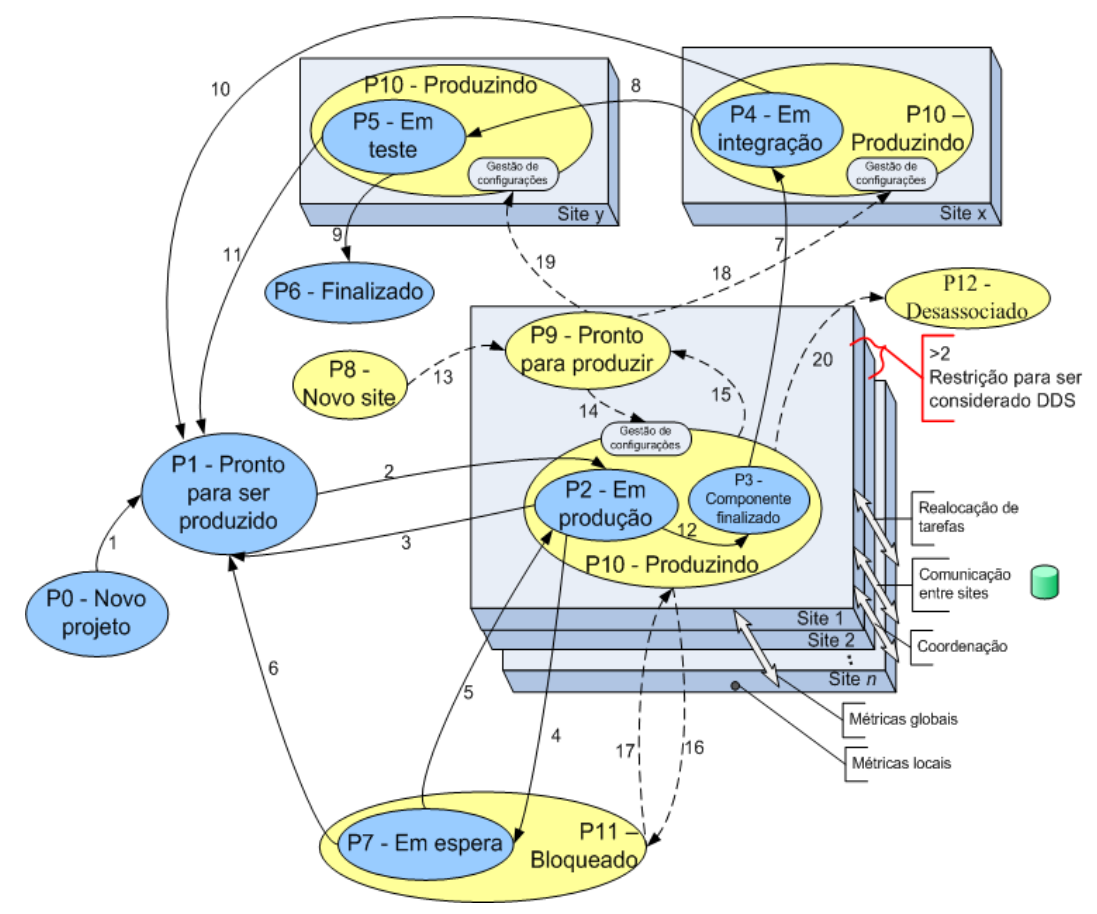

Figura 63 - Modelo proposto M3DS (L'Érario, 2009) 
L'Érario $(2006,2007,2008)$ propôs um modelo preliminar que representa o desenvolvimento de software distribuído sob a ótica do distribuidor de tarefas que coordena as ações entre os sítios envolvidos com DDS. Depois de realizados os estudos de caso, esse modelo evoluiu e foi denominado M3DS, representado na Figura 63 na forma de máquina de estados (L’Érario, 2009).

Na Figura 63 os quadrados azuis representam os sítios envolvidos com DDS. Cada sítio pode estar trabalhando com um ou mais projetos. As elipses na cor creme representam os estados do sitio e as elipses na cor azul representam os estados de um projeto. Os estados são denominados $\mathrm{Pi}$. As setas representam as transições Ti que, em determinadas condições, levam de um estado Pj para o estado Pk.

Os sítios possuem transições de estado em linha potilhada. Os estados de um sítio são: novo sítio (P8) quando entra no ambiente; desassociado (P12) quando sai do ambiente; pronto para produzir (P9); produzindo (P10); bloqueado (P11) quando está em condições de produzir e, por alguma razão, está aguardando algum evento para retornar à produção.

O projeto possui suas mudanças de estado com setas de linha cheia. O estado P0 é uma novo projeto a ser iniciado. Estabelecidas as definições iniciais do projeto, ele estará pronto para ser produzido (P1). Ao existir um sitio em condições de produzir (P9) e um projeto pronto para ser produzido, criaram-se as condições para o projeto entrar em produção (P2). Ao terminar uma parte chega-se ao estado P3 de componente finalizado. Há um estado especial onde um sitio fica bloqueado (P11) e o módulo do projeto fica em espera de alguma liberação (P7). Os componentes finalizados entram no estado de integração (P4) e testes -de integração- (P5). Ao terminar essa fase, o projeto fica finalizado (P6).

Esse modelo foi desenvolvido de maneira formal utilizando Rede de Petri para demonstrar de forma mais precisa o seu funcionamento. 


\section{VI.7 REUSO SISTEMATIZADO DE SOFTWARE}

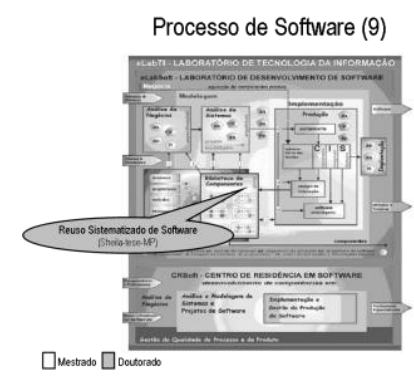

Repositório - o repositório da Fábrica de Software pode ser entendido como uma base de conhecimento onde está todo o acervo do conhecimento explícito. Aí estão localizados os processos de desenvolvimento propriamente ditos bem como o repositório dos projetos realizados, lições aprendidas, entre outros. A biblioteca de componentes também faz parte desse acervo. Nesse escopo foi desenvolvida uma pesquisa com Sheila Reinehr que selecionou como foco de estudo a área financeira por ser considerada, no Brasil, um dos setores que mais investe em TI. A pesquisa avaliou o grau de maturidade com que é feito o reuso de software e se há iniciativas referentes à definição de linha de produto de software.

\section{VI.7.1 Reuso de software}

À primeira vista, reuso pode ser compreendido como sendo o aproveitamento de um código de software já desenvolvido anteriormente. No entanto, o termo reuso admite diversos significados, conforme definido na Norma IEEE (1999): o uso de um ativo na solução de diferentes problemas. Essa definição é abrangente o suficiente para admitir reuso de código, estruturas de design, de implementação, especificações, transformações, entre outros. Segundo Basili e Rombach (1991) apud Reinehr (2008) limitar o reuso a apenas código comete-se o erro de ignorar a importância de se reusar toda a experiência adquirida em projetos anteriores, o que inclui, produtos, processos e outros conhecimentos.

A Figura 64 apresenta um resumo dos diversos autores que estabeleceram classificações das diferentes formas de reuso.

Ezram, Morisio e Trully (2002) apud Reinehr (2008) definiram que o reuso pode ser feito quanto ao domínio ou quanto à visibilidade. É bom lembrar que o reuso é de qualquer ativo, seja requisito, análise, design, código ou teste. 


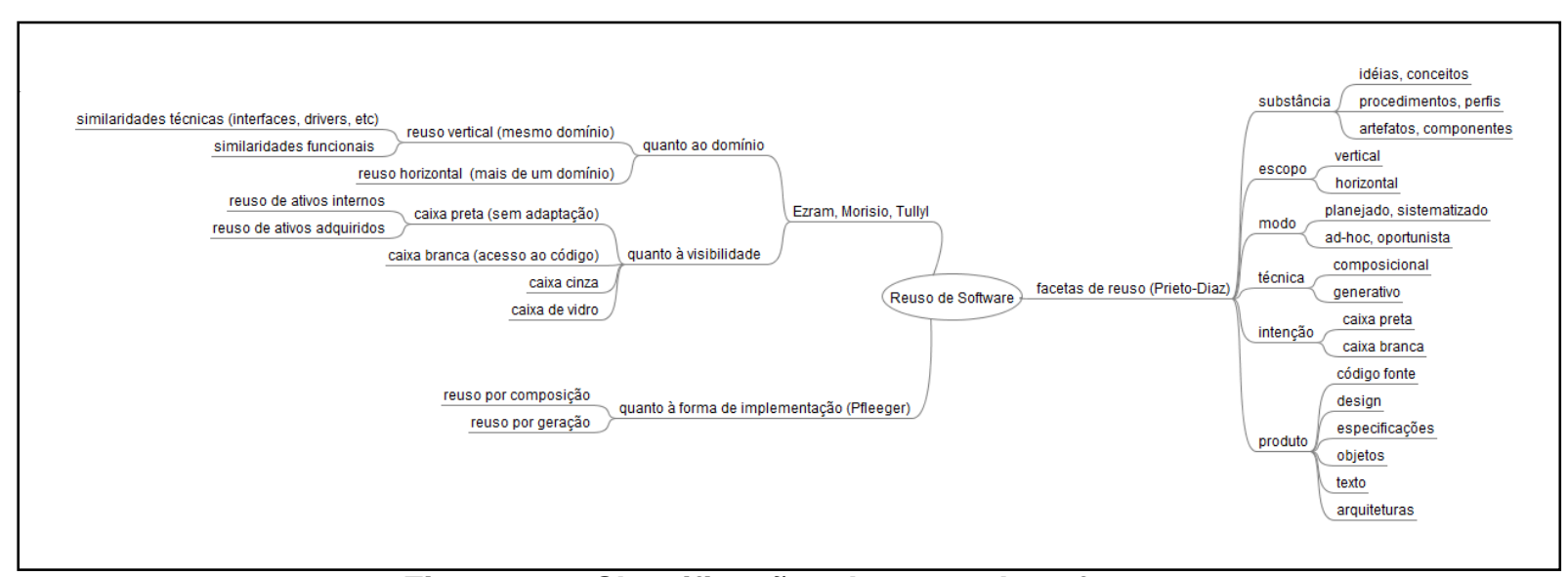

Figura 64 - Classificações de reuso de software

Quanto ao domínio, o reuso pode ser vertical, mesmo domínio ou área de aplicação ou horizontal (domínios diferentes).

O reuso vertical pode apresentar similaridades técnicas como interfaces, drivers ou similaridades funcionais.

O reuso horizontal trata do aproveitamento do mesmo ativo em diferentes domínios.

Quanto á visibilidade os autores classificaram o reuso em caixa preta, branca, cinza e de vidro.

O reuso caixa preta significa aproveitar o ativo sem alteração. Nesse caso pode ser reutilizado internamente ou adquirido de terceiros.

O reuso caixa branca significa que o ativo precisa de alterações.

$O$ reuso caixa cinza significa que 0 ativo precisa ser modificado e isso é feito através de parâmetros e não diretamente no código.

O reuso caixa de vidro significa aproveitar o ativo sem alterações, mas para compreender suas propriedades é necessário analisá-lo internamente.

Pfleeger (2004) definiu reuso quanto à forma de implementação: composição ou geração. 
O reuso por composição, onde os componentes são vistos como blocos de construção e o desenvolvimento é realizado bottom-up. Normalmente são utilizadas bibliotecas de componentes que são associados na aplicação nova. No reuso por geração os componentes são produzidos para tratar de necessidades específicas de uma aplicação e depois são disponibilizados para aplicações semelhantes.

Prieto-Diaz (1993) apud Reinerhr (2008) elaborou uma classificação por perspectivas, ou facetas que engloba praticamente as abordagens citadas anteriormente. Cada faceta trata de um interesse específico: substância, escopo, modo, técnica, intenção, e produto.

A faceta por substância significa o reuso de idéias, conceitos em uma visão mais abstrata. Também pode ser o reuso de procedimentos e perfis e, em um nível mais concreto, de artefatos e componentes.

A faceta por escopo pode ser horizontal ou vertical conforme já descrito acima.

A faceta por modo o reuso planejado, sistematizado ou oportunista, ad-hoc.

A faceta por técnica pode ser composicional ou por geração, conforme já apresentou Pfleeger (2004).

A faceta por intenção significa caixa preta ou caixa branca em função da alteração ou não do ativo.

A faceta por produto diz respeito a qual artefato é objeto de reuso: código fonte, design, especificações, objetos, testes ou arquiteturas.

Finalmente, com relação às estratégias de reuso, Ravichandran e Rothemberger (2003) apud Reinehr (2008) apresentaram uma orientação para a definição das estratégias de reuso a serem adotadas nas organizações, conforme ilustrado na Figura 65. É estabelecida uma relação entre o custo da aquisição de um ativo, custo de busca e de customização. 


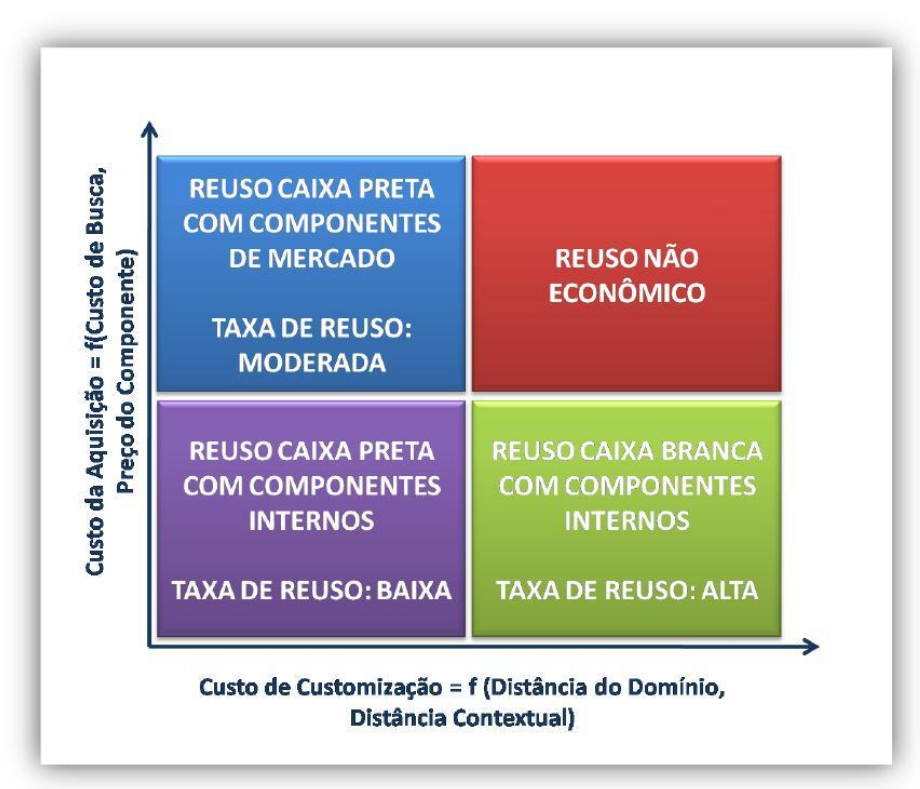

Figura 65 - Estratégias de Reuso (Reinehr, 2008)

\section{VI.7.2 Evolução do uso sistematizado de software}

A Figura 66 ilustra a evolução do uso sistematizado de software. Na década de 60 as primeiras iniciativas tratavam de criar sub-rotinas que ficavam disponibilizadas

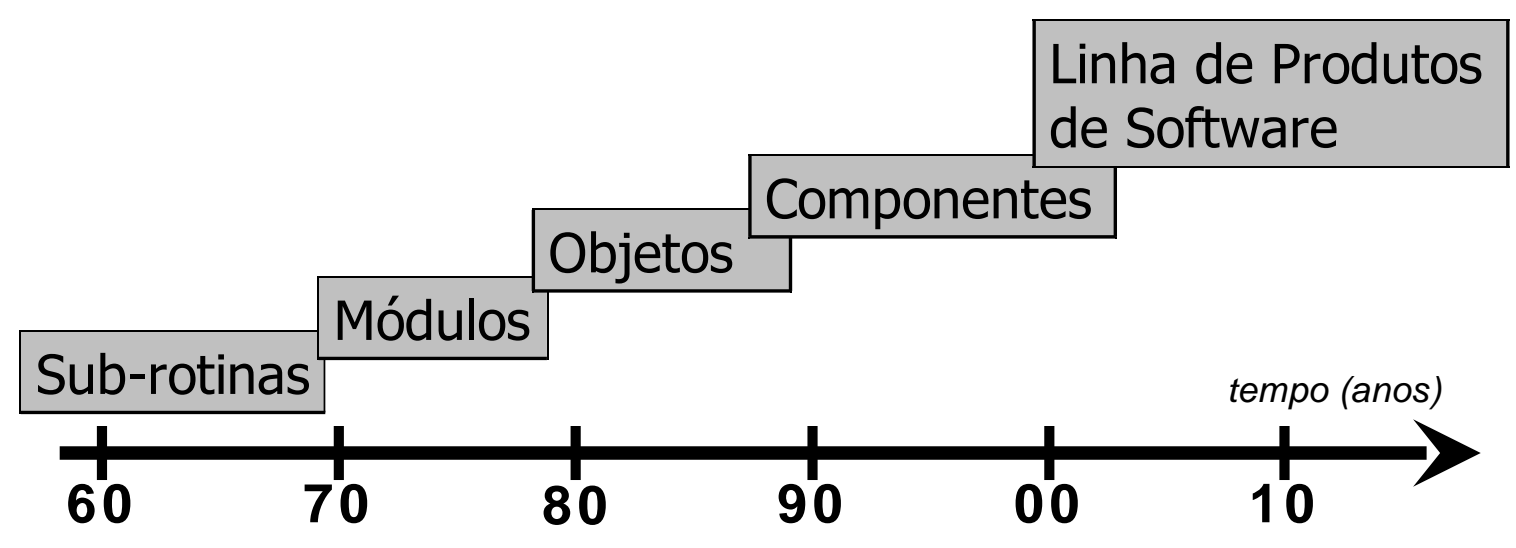

Figura 66 - Evolução do uso sistematizado de software

para reuso no ambiente da organização. Nos anos 70 surgiram os módulos. Nos anos 80 , com a mudança do método de análise para orientação a objetos, surgiram os objetos. Nos anos 90 a orientação a objetos possibilitou o uso dos componentes de software e nos anos 2000 estão vindo (ainda é muito restrito seu uso) as linhas de produto de software (REINEHR, 2008). 


\section{VI.7.3 Desenvolvimento de software baseado em componentes}

Componente de software é uma implementação em software que pode ser utilizada, sem modificação, em diferentes aplicações através das interfaces (API-Application Program Interface).

Bass (2001) apud Reinehr (2008) define tecnologia de componentes como sendo um ambiente onde os componentes são desenvolvidos, também chamado framework de componentes. Desenvolvimento de Software Baseado em Componentes (CBSD) é constituído dos passos técnicos de design e implementação necessários para desenvolver componentes, para montar componentes na forma de sistemas e para entregar os sistemas resultantes. Engenharia de Software Baseada em Componentes (CBSE) é o conjunto de práticas necessárias para executar o desenvolvimento de software baseado em componentes de forma repetitiva (ou repetível) para construir sistemas com propriedades previsíveis.

Reinehr (2008) descreve as principais características de um componente de software:

- é uma unidade de instalação independente

- é uma unidade de composição de terceira parte, ou seja, um componente pode ser combinado com outros componentes por uma terceira parte (que não desenvolveu o componente)

- não possui um estado externamente observável, ou seja, não pode ser distinguido de outras cópias de si mesmo

O desenvolvimento de um sistema com base em componentes, por sua vez, possui as características apresentadas na Figura 67:

- heterogeneidade - permite que um sistema seja construído a partir de diferentes componentes, escritos em diferentes linguagens, plataformas e até locais diferentes.

- disponibilidade de código fonte - componentes adquiridos de terceiros podem não oferecer acesso ao código fonte 


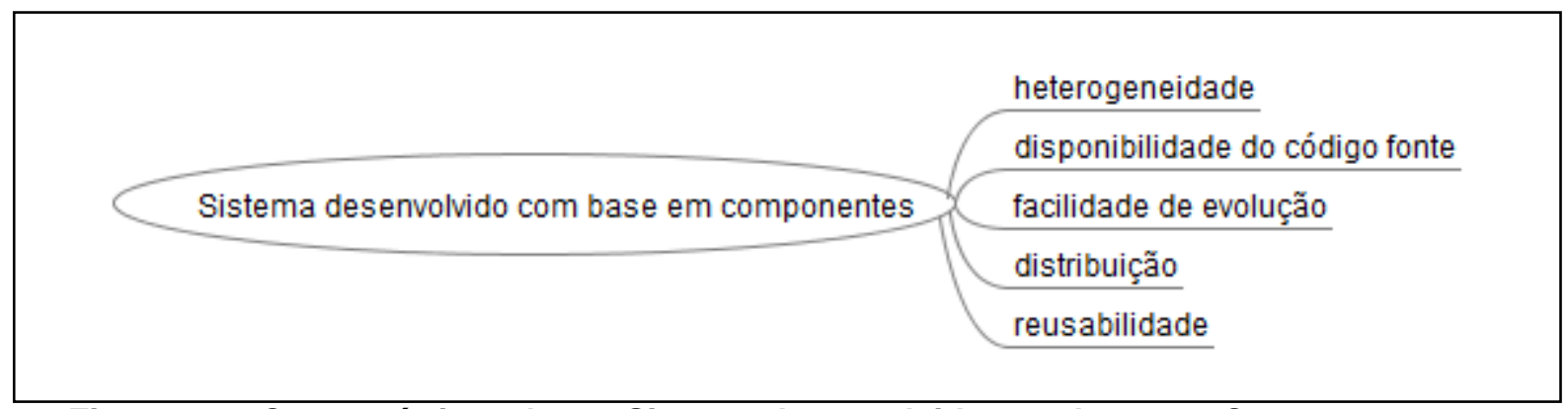

Figura 67 - Características de um Sistema desenvolvido com base em Componentes

- facilidade de evolução - esse tipo de desenvolvimento com o conceito plug and play facilita o esforço de manutenção de software

- distribuição - os sistemas baseados em componentes facilitam o processo de distribuição, particularmente pela internet

- reusabilidade - esse é um dos principais objetivos dos sistemas baseados em componentes, envolvendo componentes individuais e arquiteturas de componentes

\section{VI.7.3.1 O método Kobra}

O Kobra é um método para desenvolvimento de software baseado em componentes desenvolvido pelo Fraunhofer Institute for Experimental Software Engineering, baseado no conceito de linha de produtos de software (a ser descrito no próximo item). Os componentes Kobra são definidos em um grau de abstração mais alto, lógico e não no sentido tradicional dos componentes físicos que descrevem apenas os aspectos de tecnologia (Corba, DCOM+, J2EE). Representam os blocos de construção lógicos de um sistema de software. Por essa razão são denominados Komponentes para identificar que são componentes Kobra, conforme representado na Figura 68: especificação, realização e implementação (Reinehr, 2008). 


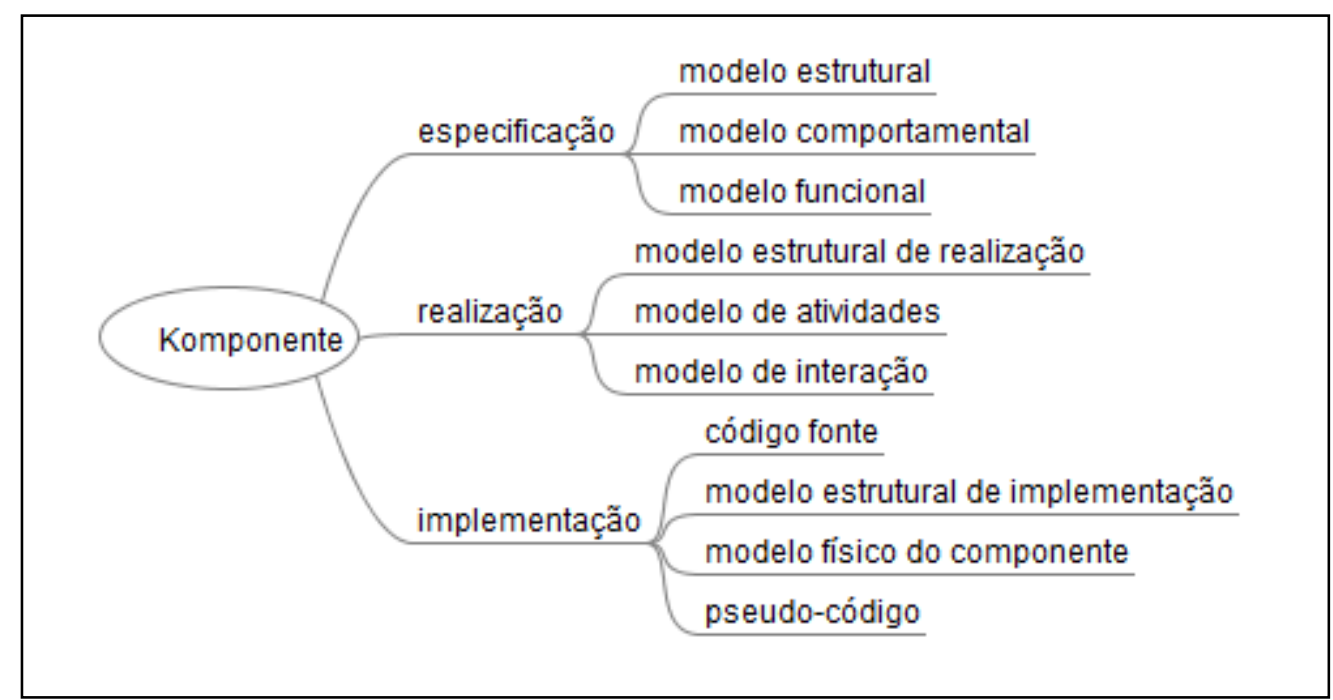

Figura 68 - Níveis de abstração de Komponente

Esses são os níveis de abstração de um componente Kobra:

- Especificação - consiste de um conjunto modelos que conjuntamente descrevem suas características:

- Modelo Estrutural de Especificação - no nível mais alto, a especificação do komponente é feita com a descrição das classes, relacionamentos com o ambiente e qualquer estrutura que seja visível através da interface

- Modelo Comportamental - mostra como o komponente se comporta em resposta a um estímulo externo

- Modelo Funcional - descreve os efeitos externamente visíveis das operações oferecidas pelo komponente

- Realização - descreve como uma instância do componente realiza suas especificações em termos de interações com outras instâncias do komponente. Deve ser especificada utilizando pelo menos os seguintes componentes:

- Modelo estrutural de realização - descreve a natureza das classes e dos relacionamentos a partir dos quais o komponente é realizado

- Modelo de atividades - descreve os algoritmos através dos quais as operações são realizadas 
- Modelo de interação - provê uma informação similar ao modelo de atividades sob a ótica de interação e não de controle de fluxo.

- Implementação - descreve como o komponente trabalha de forma que possa ser processado por ferramentas de compilação automatizadas. Representada pelos seguintes artefatos:

- Código fonte - o código propriamente dito

- Modelo estrutural de implementação - refinamento do modelo estrutural de realização descrito em um nível de abstração próximo ao código fonte

- Modelo físico de componente - refina o mapeamento dos komponentes lógicos Kobra em componentes físicos de acordo com o meio físico da implementação (Corba, COM +, JavaBeans, etc.)

- Pseudocódigo - descreve a implementação algoritmica do komponente de forma abstrata e em baixo nível de abstração

\section{VI.7.3.2 Tecnologias baseadas em componentes}

As tecnologias para desenvolvimento baseadas em componentes são relativamente novas e são elas que permitiram uma efetiva implementação desses conceitos. Segundo Reinehr (2008), especialmente no final dos anos 90, proliferaram as tecnologias que permitem uma utilização mais massiva do desenvolvimento baseado em componentes. As principais tecnologias utilizadas são o Corba, EJB e COM+.

O Corba-Common Object Request Borker Architecture é um padrão que estabelece a infraestrutura necessária para a interoperabilidade de diferentes implementações de objetos.

O EJB-Enterprise Java Beans - faz parte do ambiente de desenvolvimento da Sun Microsystems e são componentes que residem em um servidor de aplicações. São classes Java entregues através de um container.

COM+ Common Object Model - é o modelo de componentes utilizado pela Microsoft. Estabelece uma infraestrutura para implementação de componentes normalmente implementados em $\mathrm{C}++$ ou outra linguagem compatível. Esse modelo 
está presente no modelo proprietário da Microsoft, o .NET (dot net) e nas linguagens desse ambiente como o Visual Basic e C\#.

\section{VI.7.4 Família de produtos e linha de produtos de software}

Segundo Reinehr (2008), a Europa tem investido em grandes projetos de desenvolvimento de Linhas de Produto de Software com a participação de universidades e empresas: Esaps (1999-2001), Café (2001-2003) e Families (20032005) envolvendo recursos da ordem de $€ 100$ milhões.

Empresas como Bosch, Alcatel, Nokia, Siemens e Philips participaram desses projetos e desenvolveram famílias de produtos de software para seus respectivos domínios de aplicação. Nesses projetos foram identificadas carências estruturais como a falta de uma arquitetura de disseminação de práticas que permitissem a criação das famílias de produtos de software.

Um conceito importante criado no projeto Esaps foi a identificação da Engenharia de Domínio e a Engenharia de Aplicação como atividades distintas, conforme apresentado na Figura 69.

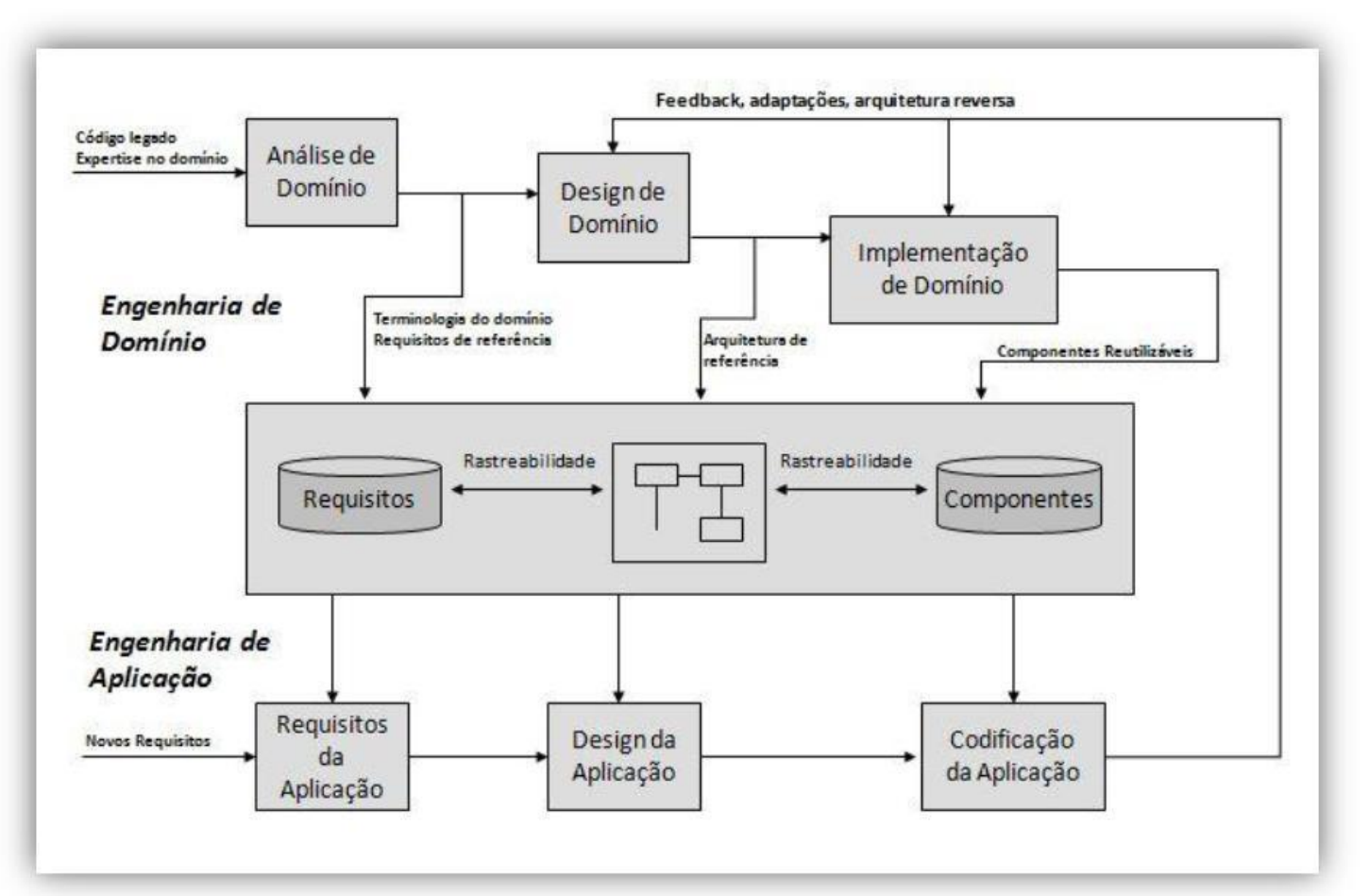

Figura 69 - Modelo de Referência do Processo do Esaps (Reinehr, 2008)

A Engenharia de Domínio aborda um domínio específico para analisar requisitos, projetar uma arquitetura adequada e implementar componentes para facilitar as 
aplicações. A Engenharia de Aplicação consiste na implementação de aplicações a partir dos requisitos do domínio e da biblioteca de componentes.

Um modelo criado no projeto Café com o objetivo de definir de forma sistêmica as preocupações da comunidade envolvida com o projeto foi o BAPO, representado na Figura 70.

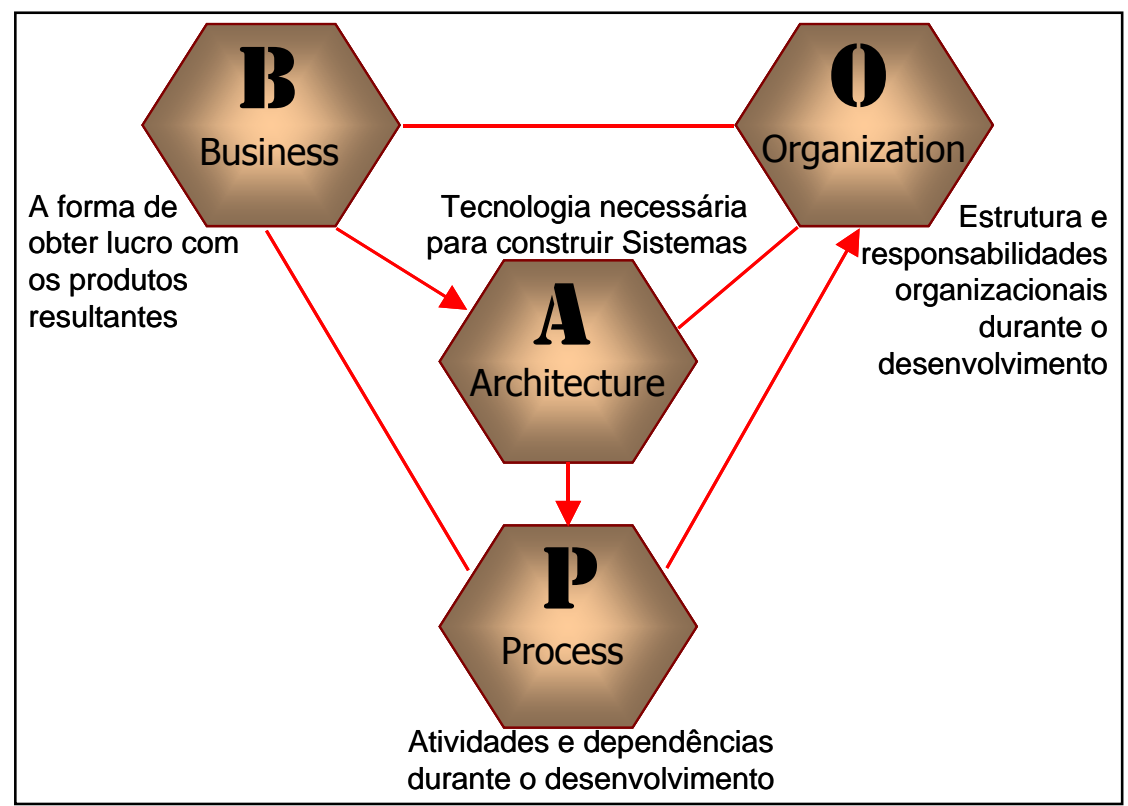

Figura 70 - Modelo Bapo (adaptado de Reinehr, 2008)

Esse modelo, de alguma forma, cria um alinhamento entre as atividades de projeto com as necessidades do negócio.

- B representa o negócio (business) que orienta para analisar como o lucro deve ser gerado

- A representa a arquitetura, que são as tencologias necessárias para construir o sistema

- P representa o processo com responsabilidades e dependências principalmente com relação à coordenação e colaboração entre a engenharia de domínio e engenharia de aplicação

- O representa a organização na qual o software é desenvolvido e o seu preparo para lidar com os papéis e responsabilidades referentes à separação da engenharia de domínio e engenharia de aplicação. 
Nos Estados Unidos a denominação utilizada para a família de produtos é SPLSoftware Product Line e foi desenvolvida pelo SEI-Software Engineering Institute (Reinehr, 2008). Dessa forma foi criado um processo denominado SPLP-Software Product Line Practice que possui processos com áreas práticas de Engenharia de Software, Gerenciamento Técnico e Gerenciamento Organizacional. Foi também criado um método (PLTP) para avaliar se uma empresa está pronta para mudar de paradigma e adotar as Linhas de Produto com sucesso (Reinehr, 2008).

\section{VI.7.5 Maturidade de reuso de software}

A adoção de uma abordagem de reuso pode ser avaliada também utilizando modelos de maturidade. Foram desenvolvidos diversos modelos como o FEF-Family Evaluation Framework. O grupo do C.E.S.A.R. ligado à Universidade Federal de Pernambuco propõem um modelo de referência para maturidade de reuso de software (RiSE:RM- Reuse in Software Engineering: Reference Model) que contém 4 níveis de maturidade (Reinehr, 2008):

- 1: incompleto

- 2: básico - técnicas e métodos básicos

- 3: definido - monitoramento e controle do processo de reuso

- 4: sistematizado - otimização do processo de reuso, controle de qualidade dos ativos, etc.

\section{VI.7.6 Estruturação da pesquisa realizada}

A pesquisa de campo foi realizada com o objetivo de verificar como o reuso de software é praticado nas organizações do setor financeiro. Uma segunda questão, derivada da primeira, é saber como se realizam os processos de reuso de software e como estes contribuem para o sucesso dos projetos. $O$ protocolo de pesquisa foi elaborado utilizando cinco proposições apresentadas na Figura 71. 


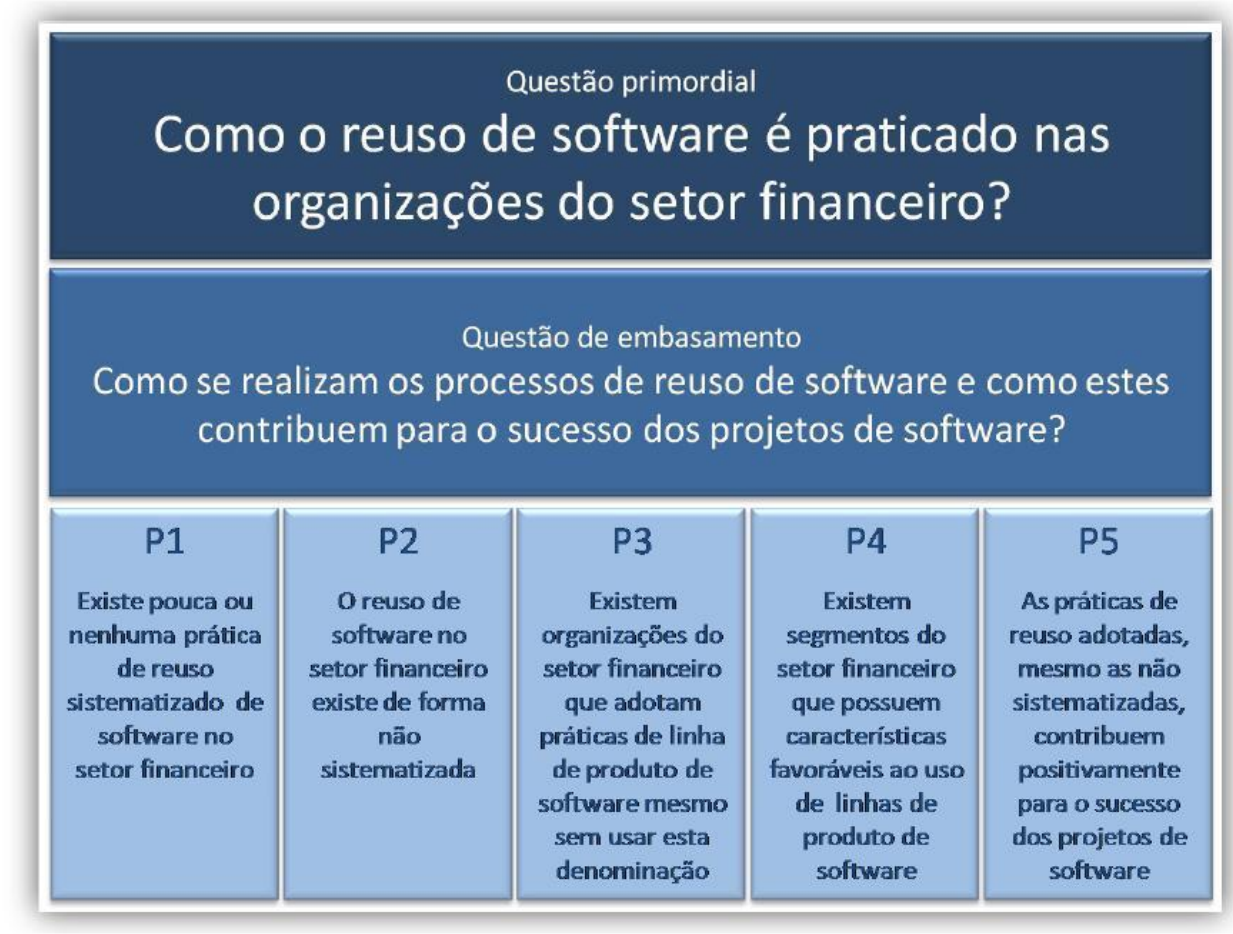

Figura 71 - Proposições da pesquisa de campo (Reinehr, 2008)

As proposições foram elaboradas a partir da literatura e considerou uma evolução da P1 (com pouca ou nenhuma prática de reuso) até a P5 (eficácia no reuso).

A pesquisa foi realizada em 5 bancos, relatados no próximo item. Cada empresa estudada recebeu uma carta de apresentação com termo de confidencialidade assinado pela pesquisadora e pelo orientador, uma descrição geral dos objetivos da pesquisa e uma descrição dos procedimentos operacionais (o que iria ser perguntado). Esse cuidado foi tomado para facilitar o acesso às empresas, uma vez que as informações necessárias para a pesquisa são, de certa forma, sigilosas. Para cada uma das proposições foram preparados pontos de análise que orientaram as entrevistas semi-estruturadas que foram realizadas nos bancos. Cada um dos pontos de análise foi cuidadosamente preparado contendo a origem (referencial teórico), descrição detalhada e quais as proposições relacionadas, conforme ilustrado na Figura 72. 


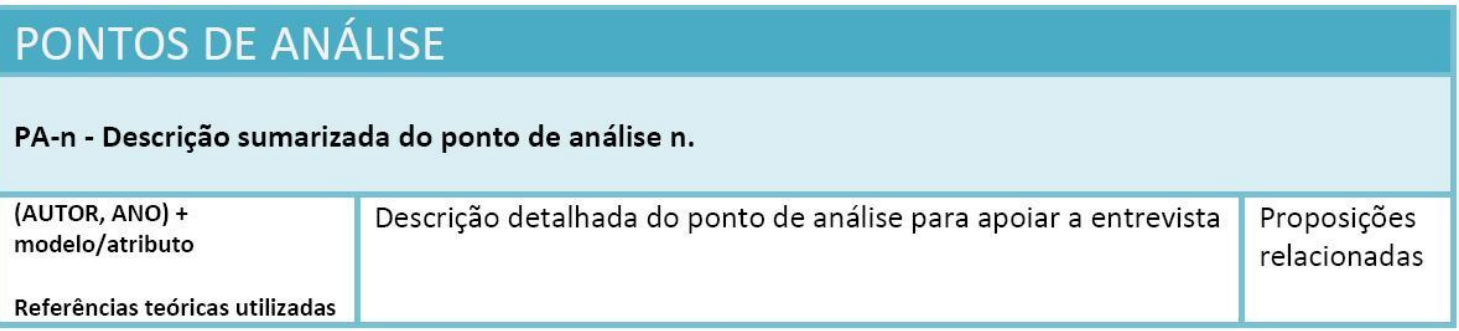

Figura 72 - Pontos de análise (Reinehr, 2008)

Foram, ao todo, elaborados 20 pontos de análise. Não cabe aqui detalhar tais pontos mas, a título de exemplo, pode-se observar que o ponto de análise PA-10 na Figura 73 refere-se a duas proposições.

\begin{tabular}{|l|l|c|}
\hline \multicolumn{2}{|l|}{ PA-10 - Existência de conceitos de Engenharia de Domínio e Engenharia de Aplicação. } \\
\hline & $\begin{array}{l}\text { - Existe o conceito de Engenharia de Domínio sendo praticado no } \\
\text { desenvolvimento de software? }\end{array}$ \\
\hline \multirow{3}{*}{ (CLEMENTS; NORTHROP, 2002) } & - Existem práticas de desenvolvimento que focam, não apenas o \\
(LINDEN, 2005) - BAPO-A - N3 ou & desenvolvimento do sistema em si, mas o desenvolvimento de \\
superior & artefatos (em qualquer grau de abstração) que podem ser \\
& reutilizados por vários sistemas dentro de um mesmo domínio? \\
& - Como são utilizados os artefatos desenvolvidos para o domínio no \\
& desenvolvimento de um novo sistema ou na manutenção de um \\
& sistema existente? \\
& - Existe uma arquitetura de referência para as aplicações do domínio \\
& (ou da família de sistemas)? \\
\hline
\end{tabular}

Figura 73 - Exemplo de Ponto de Análise PA-10 (Reinehr, 2008)

\section{VI.7.7 Resultados da pesquisa do setor financeiro}

A escolha do setor financeiro para realizar a pesquisa sobre reuso de software foi baseada no fato de que este setor realiza investimentos significativos em Tecnologia da Informação. Segundo a Febraban (2009), em 2007 foram investidos $R \$ 6,2$ bilhões nessa área como um todo, dos quais $\mathrm{R} \$ 2,26$ bilhões referem-se a software de terceiros, ou seja, software básico e aplicativos, fábricas de software, terceirizações, aquisições de software, desenvolvimento de novas aplicações e manutenção de sistemas.

Na pesquisa de Reinehr (2008) foram estudados 5 grandes bancos que, somados, representam $50 \%$ dos ativos totais do setor bancário, $46 \%$ do lucro líquido e $59 \%$ dos depósitos totais e 70\% de todas as agências do país (dados de 2006). Isto demonstra a importância dessas organizações no cenário nacional. Todos os cinco bancos são de grande porte, um de capital estrangeiro e três de capital privado. 
Foi identificado que quatro dos cinco bancos estudados tinham projetos de grande porte em andamento na área de TI. Esses projetos eram focados não somente em tecnologia, mas também em metodologias de desenvolvimento de software.

Os resultados são apresentados abaixo, por proposição com comentários específicos.

\section{VI.7.7.1 Proposição P1}

P1 - Existe pouca ou nenhuma prática de reuso sistematizado de software no setor financeiro

- Importância de uma iniciativa específica para implantação de reuso de software (BOSCH, 2000) e (PRIETO-DIAZ; 1991)

- Reuso sistematizado de software caracterizado pelos critérios de (EZRAN; MORISIO; TULLY, 2002)

- Nível 3 ou superior das dimensões BAPO-B (Negócios) e BAPO-O (Organização) e seus atributos, conforme proposto pelo modelo FEF - Family Evaluation Framework (LINDEN, 2005) e (LINDEN; SCHMID; ROMMES, 2007)

- Processos de reuso utilizados a partir do MR-MPS.BR - GRU (Nível E) e DRU (Nível C) (SOFTEX, 2007)

- Fatores críticos de sucesso na implantação de programas de reuso de software nas organizações sumarizados em (ALMEIDA et al., 2007)

- Fatores de risco na adoção de abordagens de reuso, modelo Reuse-Invest (MANSELL, 2006a)

- Necessidade de processo para reuso (IEEE, 1999)

- Taxonomia de reuso baseada em facetas de (PRIETO-DIAZ, 1993)

Figura 74 - Proposição P1 - (Reinehr, 2008)

$\mathrm{Na}$ Figura 74 estão listados os conceitos de apoio identificados na literatura. Foi observado que em 2 bancos esta proposição é verdadeira e nos demais 3 existem iniciativas mas não estão institucionalizadas por toda a organização. Também foi observado que os bancos estão em um momento de transição importante onde o reuso é um dos focos dessas mudanças.

\section{Vl.7.7.2 Proposição P2}

P2 - O reuso de software no setor financeiro existe de forma não sistematizada

- Todos os conceitos usados em P1, uma vez que são complementares

- Reuso não sistematizado de software caracterizado pelos critérios de (EZRAN; MORISIO; TULLY, 2002)

- Reuso oportunista conforme caracterizado em (IEEE, 1999)

- Níveis 1 ou 2 de todas as dimensões BAPO e seus atributos, conforme proposto pelo modelo FEF Family Evaluation Framework (LINDEN, 2005) e (LINDEN; SCHMID; ROMMES, 2007) 
Foi observado que existem práticas de uso não sistematizadas, mesmo nos bancos onde há uma maior institucionalização dessas práticas.

\section{VI.7.7.3 Proposição P3}

P3 - Existem organizações do setor financeiro que adotam práticas de linhas de produto de software, mesmo sem usar esta denominação

- Conceito de linha de produto de software de (CLEMENTS; NORTHROP, 2002)

- Diferenças de SPL com desenvolvimento de sistemas únicos de (LINDEN, 2005)

- Conceito de Variabilidade (BOSCH, 2000), (LINDEN; SCHMID; ROMMES, 2007) e (WEISS; LAI, 1999)

- Nível 3 ou superior da dimensão BAPO-A (Arquitetura) e seus atributos, conforme proposto pelo modelo FEF - Family Evaluation Framework (LINDEN, 2005) e (LINDEN; SCHMID; ROMMES, 2007)

- Conceitos do que não é SPL, proveniente do framework SPLP - Software Product Line Practice (NORTHROP et al., 2007)

Figura 76 - Proposição P3 - (Reinehr, 2008)

Foi identificado que existem práticas de linhas de produto de software uma vez que já podem ser identificadas algumas práticas de engenharia de domínio.

\section{VI.7.7.4 Proposição P4}

P4 - Existem segmentos do setor financeiro que possuem características favoráveis ao uso de linhas de produto de software

- Conceito de domínio, proveniente de (POHL; BÖCKLE; LINDEN, 2005) e (KÄKÖL̈̈; DUEÑAS, 2006)

- Atributo motivação encontrado nos relatos de experiências em (LINDEN; SCHMID; ROMMES, 2007)

- Análise de Risco do modelo Reuse-Invest, descrito em (MANSELL, 2006a)

- Critérios de seleção de domínios para SPL (GEPPERT; WEISS, 2003)

Figura 77 - Proposição P4 - (Reinehr, 2008)

Esta proposição foi considerada verdadeira pois existem fatores favoráveis ao uso de linhas de produto de software com relação a organização, pessoal, processo e produto. 


\section{VI.7.7.5 Proposição P5}

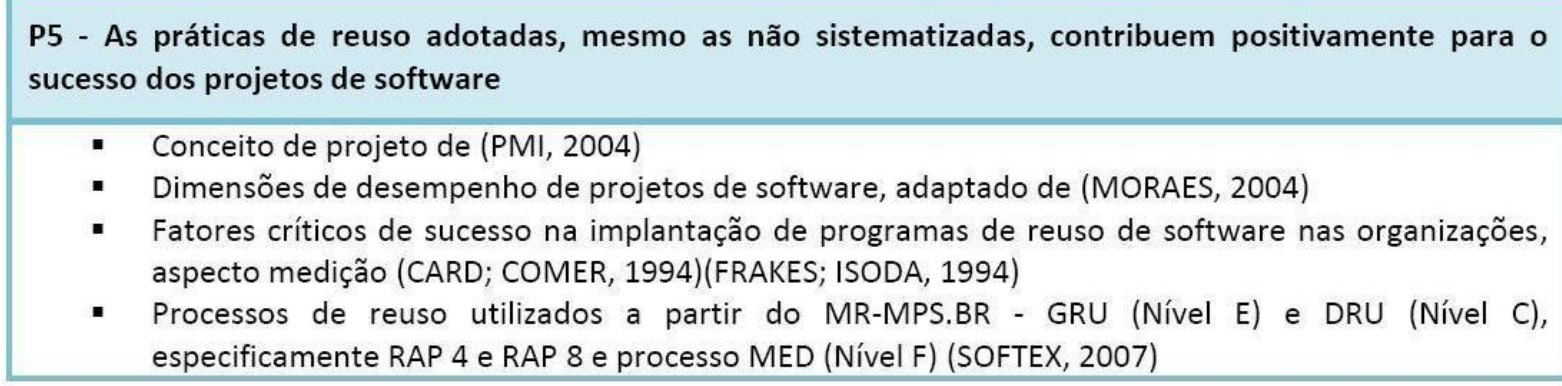

Figura 78 - Proposição P5 - (Reinehr, 2008)

Foi identificado que as práticas de reuso, mesmo as não sistematizadas contribuem positivamente para o sucesso dos projetos de software, embora não tenham sido encontradas medições sistematizadas em todos os bancos estudados que evidenciassem quantitativamente esta observação.

Vale notar que, embora em todas as proposições tenham sido encontradas iniciativas, há muito que caminhar ainda para o aperfeiçoamento do reuso sistematizado e caminhar para o conceito de linhas de produto de software. Os bancos (e foram estudados cinco dos dez maiores) até há pouco tempo atrás, utilizavam reuso de maneira ad-hoc e oportunista baseado na experiência dos profissionais ou equipes de projeto. Iniciativas no nível organizacional existiam restritos a atividades como administração de dados, sub-rotinas de uso comum e algumas iniciativas no sentido de padronização de arquitetura tecnológica como funções de infraestrutura (integridade de transações, log de aplicações e autenticação, por exemplo). Este era o quadro em 2005. Na época da elaboração desta pesquisa, conforme já relatado, grandes projetos de evolução tecnológica estavam em andamento, fato que atrapalhou a classificação das práticas como sistematizadas (a rigor não seriam), mas claramente esse tema de reuso passou a fazer parte das preocupações e estratégia das novas arquiteturas e dos novos processos.

Finalizando, é importante ressaltar que a adoção das Linhas de Produto de Software na área financeira constitui uma inovação, pois na literatura, os casos relatados referem-se principalmente a software embarcado das indústrias automobilística, aeronáutica, telecomunicações e equipamentos médicos de tratamento de imagens. A área financeira possui a peculiaridade de tratar sistemas de informações de forma 
centralizada com grande volume de transações de forma centralizada (em mainframes) e com grande índice de integração entre as empresas do setor, um perfil muito diferente dos casos acadêmicos publicados. 


\section{VI.8 PRODUTIVIDADE EM FS}

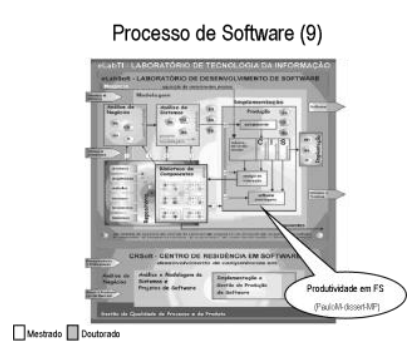

A pesquisa realizada com Moreira (2007) abordou os aspectos de produtividade na construção de código em uma Fábrica de Software. Uma das dificuldades para se gerenciar uma Fábrica de Software é a capacidade de realizar estimativas e medidas nas atividades realizadas. O desenvolvimento de software é intensivo em mão de obra e a produtividade depende dos profissionais envolvidos no trabalho pois, além dos aspectos técnicos, há os aspectos humanos a serem considerados. Tal fato é conhecido na manufatura há muitos anos, conforme relata Fleury (1983), mas nas atividades de desenvolvimento de software, o estudo desse tema é mais recente. Essa pesquisa teve por objetivo identificar os fatores que influenciam a produtividade, validar o grau de influência desses fatores, compará-los com a percepção das pessoas envolvidas com as atividades na Fábrica de Software, e propor um modelo de produtividade.

Foi desenvolvida uma pesquisa-ação em uma Fábrica de Software (FS) que estava implantando o nível 4 do CMMI. O CMMI, nesse nível, aborda aspectos de gerenciamento quantitativo, oportuno para a realização deste trabalho. Foram usados métodos estatísticos para avaliar as medidas realizadas no ambiente da Fábrica.

\section{VI.8.1 Fatores que influenciam a produtividade em uma FS}

Produtividade é a razão das unidades de saída produzida pelo esforço das unidades de entrada (MOREIRA, 2007). Os fatores que influenciam a produtividade na produção de software podem ser agrupados em três dimensões:

- fatores tecnológicos como linguagens de programação, ferramentas de projeto, ambientes de desenvolvimento e capacidade dos equipamentos utilizados

- fatores humanos onde são considerados o perfil, formação, motivação, comprometimento e capacitação das pessoas, além do modelo de gerenciamento utilizado 
- fatores organizacionais referentes aos processos de trabalho utilizados como metodologia, prática gerencial, ambiente físico referente a acomodações, conforto e bem estar dos recursos humanos

Um fator importante na medição das atividades de software está ligado com a capacidade de realizar estimativas. Entre os principais métodos existentes há a abordagem de linhas de código e a abordagem de pontos de função, já relatadas neste trabalho no Capítulo V.1.

Foram estudados dois modelos para realizar medições nos processos de software: GQM - Gol Question Metric (BERGHOUT, 1999 apud MOREIRA,2007) e PSM (McGARY, 2000 apud MOREIRA, 2007). Esses métodos estabelecem técnicas sistematizadas para a criação e uso de um sistema integrado de medições no processo de software a partir de metas e políticas definidas da organização.

Os fatores analisados da literatura que influenciam a produtividade em uma Fábrica de Software foram:

- Processos

- Maturidade

- Gerenciamento eficaz

- Uso de Métodos Estruturados

- Documentação (especificação)

- Equipes de Projeto e Estrutura Organizacional

- Capacidade de Análise de Requisitos

- Prototipação antes do desenvolvimento

- Flexibilidade no desenvolvimento

- Mudança de especificação

- Complexidade do produto

- Tamanho do produto

- Erros

- Custo de revisão

- Pessoas

- Treinamento

- Qualificação: competências e experiência

- Comprometimento (moral e remuneração das equipes)

- Rotatividade e redução de equipes

- Tecnologia

- Ambientes de desenvolvimento

- Existência de precedentes 
- Estratégia de Reuso

- Geradores de Código

Esses foram os fatores analisados nos projetos da Fábrica para identificar que fatores influenciam ou não na produtividade e servirem de base para elaboração do modelo.

\section{VI.8.2 A pesquisa realizada}

A pesquisa foi realizada em uma Fábrica de Software localizada em Salvador, Bahia. Esta fábrica possui certificação ISO 9001, o processo de desenvolvimento foi avaliado no nível 3 de maturidade do $\mathrm{CMMI}$ e no momento da realização da pesquisa estava trabalhando na implantação dos níveis 4 e 5 .

O ambiente estudado possui cerca de 150 profissionais, $83 \%$ da equipe tem até 30 anos, $71 \%$ do pessoal possui formação universitária completa. Tempo de casa médio da equipe é 36 meses e todos são contratados no modelo CLT.

A Fábrica trabalha na construção de código realizando as atividades de codificação e testes (fases anteriores como requisitos e análise são realizadas fora da Fábrica) e utiliza tecnologias Java e .Net da Microsoft (dot net).

Os projetos realizados na Fábrica são classificados por tamanho medidos em pontos de função. Projetos com mais de 1.500 PF são considerados grandes e abaixo de 200 PF são pequenos e entre os dois valores, médios. Nos projetos pequenos foi identificado que não há escala suficiente para diluir os custos de gerenciamento. Por essa razão há um processo simplificado para esses casos.

$\mathrm{Na}$ pesquisa foi realizada uma análise de variância utilizando uma ferramenta de estatística. A seguir são apresentados os resultados do levantamento realizado na Fábrica, organizados nas dimensões processos, pessoas e tecnologia.

\section{VI.8.2.1 Dimensão processos}

Foram analisados 33 projetos em um período de 30 meses onde a empresa evoluiu do nível de maturidade 2 até o 4 e 5 . Com isso foi possível separar os projetos realizados com processo nível 2, nível 3 e níveis 4 e 5 (esses considerados em conjunto). 
A Quadro 11- Produtividade x Nível de Maturidade mostra que houve uma pequena evolução na produtividade quando a Fábrica de Software evoluiu para os níveis mais altos de maturidade. Vale salientar que a produtividade aumentou, mas a variância também! Também é importante lembrar que no momento que foram realizadas as medidas os níveis 4 e 5 estavam em fase de implantação, ou seja, os processos ainda em fase de consolidação.

\begin{tabular}{|c|c|c|c|}
\hline Nível & Qt $^{\text {de }}$ projetos & Média & Desvio padrão \\
\hline 2 & 7 & 0,2395 & 0,0458 \\
\hline 3 & 19 & 0,2590 & 0,0688 \\
\hline 4 e 5 & 7 & 0,3687 & 0,1865 \\
\hline
\end{tabular}

Quadro 11- Produtividade x Nível de Maturidade (Moreira, 2007)

Não foram encontradas correlações significativas entre o esforço de gestão e a produtividade dos projetos.

Um processo padrão (estruturado) é aplicado a todos os projetos realizados. Praticamente não há variação de processo (tailoring) e portanto sob a ótica da produtividade não há variação significativa.

Todos os projetos possuem especificação documentada. O que varia é a qualidade desse documento. $O$ processo de revisão da especificação filtra possíveis erros para que na Fábrica de Software não entre especificação inadequada. A análise feita foi a correlação entre o esforço de equalização e os erros de especificação detectados. Foi encontrada correlação significativa e portanto este fator foi considerado no modelo.

Considerando que todos os projetos são realizados na mesma estrutura organizacional, o fator Equipes de Projeto e Estrutura Organizacional não foi considerado como influente na produtividade.

A FS não realiza a identificação e levantamento de requisitos e portanto a Capacidade de Análise de Requisitos não é um fator de influência na produtividade. A análise realizada no ambiente da Fábrica já foi considerada no fator documentação.

A prototipação antes do desenvolvimento foi desconsiderada no modelo pois $100 \%$ dos projetos pesquisados realizam esta atividade. 
O fator Flexibilidade no Desenvolvimento foi descartado pro se tratar de uma Fábrica com processo bem definido e com baixa flexibilidade para alterações.

As Mudanças de especificação foram identificadas que influem negativamente na produtividade e também foram consideradas no modelo.

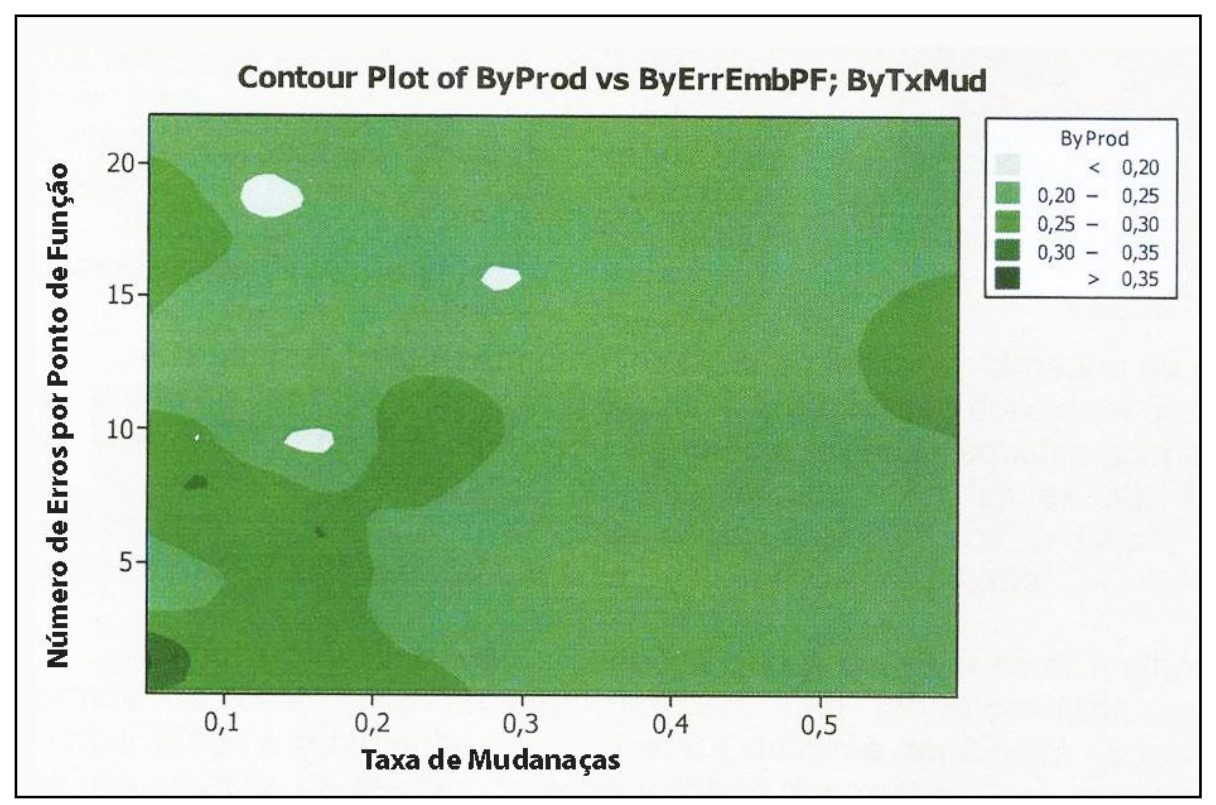

Figura 79 - Taxa de Mudança x Produtividade (Moreira, 2007)

O Gráfico de Contorno ilustrado na Figura 79 mostra que, quanto maior a taxa de mudanças, maior tende a ser o número de erros por ponto de função e menor a produtividade. No eixo $\mathrm{X}$ está representada a taxa de mudanças de um projeto, no eixo Y está representado o número de erros por ponto de função e na intensidade da cor verde observa-se a produtividade onde, quanto mais escura a cor, maior a produtividade. Nesse gráfico pode-se interpretar que quando há taxas baixas de mudanças (até aproximadamente $20 \%$ ), a produtividade é maior. A mancha escura à direita indica que outros fatores influíram na produtividade.

Os projetos que fazem parte da amostra coletada possuem classificação por complexidade. Foi possível constatar que a Complexidade do Produto influi negativamente com a produtividade, embora essa relação não seja muito significativa, e portanto esse fator foi desconsiderado no modelo.

Com relação ao Tamanho do produto versus a produtividade, a relação foi considerada fraca e portanto não foi incluída no modelo. 
É consenso que os erros podem ser retirados do software. Quanto mais cedo isto é feito, menor é seu efeito negativo na produtividade. Foi possível verificar que a eficácia dos testes é um fator importante para a produtividade, conforme ilustrado no Gráfico de Contorno da Figura 80. Nesta figura, o eixo X representa a produtividade, o eixo Y representa a eficácia dos testes e na intensidade da cor verde observam-se os erros embarcados por ponto de função onde, quanto mais escura a cor, maior o número de erros por Ponto de Função. Observar também que, a partir de uma eficácia nos testes de $92 \%$, o número de erros é constante e não varia com a produtividade. Dessa forma os erros foram considerados no modelo pois implicam em retrabalho e reduzem a produtividade. Aqui foram considerados os erros embarcados e erros internos.

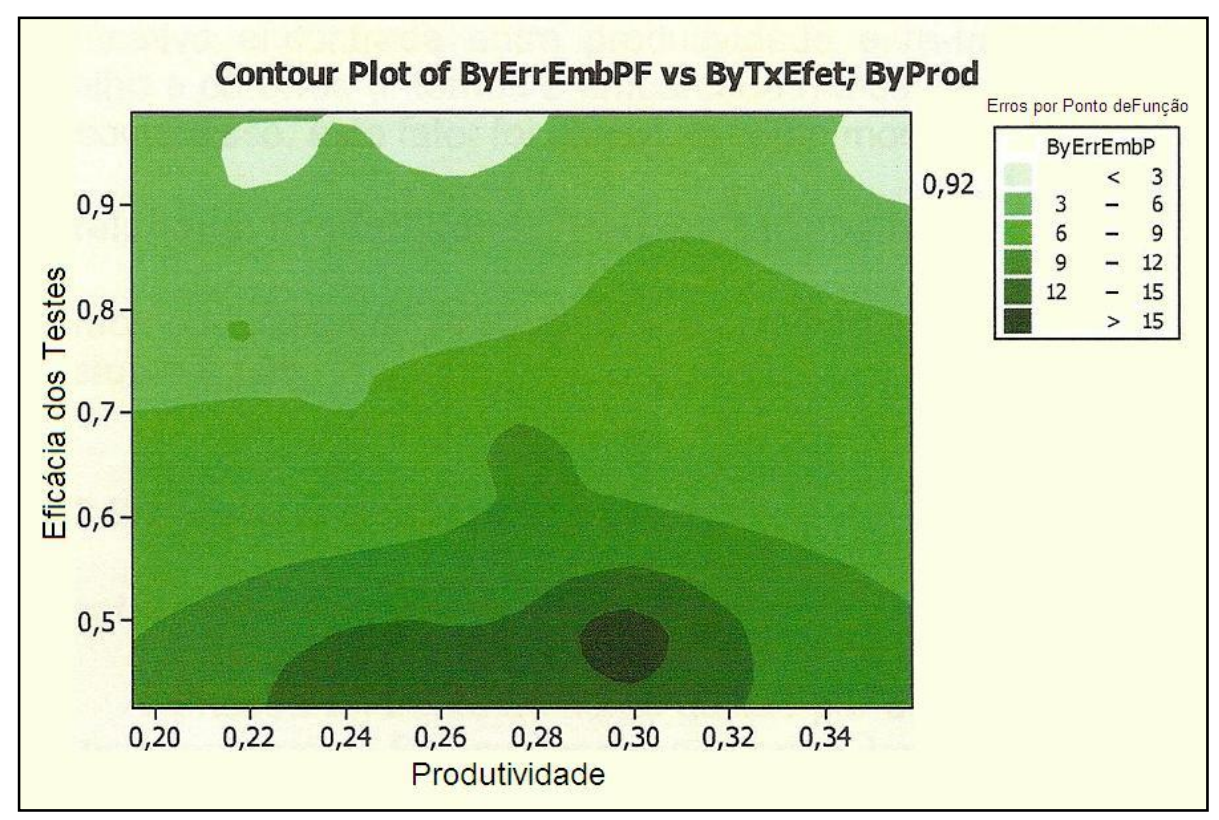

Figura 80 - Produtividade versus Taxa de Erros (Moreira, 2007)

Do ponto de vista conceitual da qualidade deve-se "fazer certo da primeira vez" (Deming, 1990). O Custo de Revisão, ou Retrabalho portanto é um fator importante de redução da produtividade e foi considerado no modelo.

\section{VI.8.2.2 Dimensão pessoas}

A amostra estudada foi em um período de 24 meses onde foram analisadas as horas gastas nos projetos e os treinamentos realizados.

Os treinamentos das pessoas foram considerados eficazes e contribuem para a qualificação dos profissionais. No estudo foram identificadas 2.214 horas de 
treinamento com avaliação positiva da ordem de $92 \%$. Como esse valor é homogêneo e eficaz, não foi considerado fator que influa na produtividade.

Foi identificado que a experiência dos profissionais influi na produtividade. No entanto, as pessoas mais experientes são alocadas para realizar atividades mais complexas, reduzindo a produtividade. Assim, no global a influência da competência e experiência é baixa e esse fator não foi considerado no modelo.

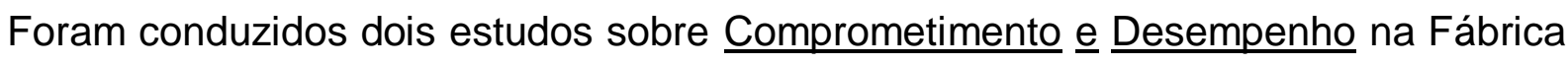
e foi identificado que o nível de comprometimento dos profissionais é alto. No entanto não foi possível identificar correlação entre esses temas e a produtividade, razão pela qual não foi considerada no modelo.

Foi calculada a correlação entre a média das horas alocadas em codificação e a produtividade de codificação e o resultado foi negativo. Isto significa que o fator Rotatividade é baixo e não considerado no modelo.

\section{VI.8.2.3 Dimensão tecnologia}

A amostra estudada foi de projetos realizados em um período de 24 meses.

Ambientes de desenvolvimento - foi identificado que as ferramentas do ambiente Microsoft são mais integradas. Embora na tecnologia Java o ambiente seja menos integrado, esse fator não foi considerado no modelo pois não foi considerado como influente na produtividade.

A Existência de Precedentes é verificada pela organização na sua base de conhecimento. Não foi possível estabelecer uma relação entre a precedência e a produtividade. Não foi considerado no modelo.

A Estratégia de Reuso mais significativa é o framework que possui utilização da ordem de $96 \%$. Não foi possível determinar o ganho obtido com o uso de framework, mas foi considerado no modelo uma queda de $10 \%$ de produtividade se não houver seu uso.

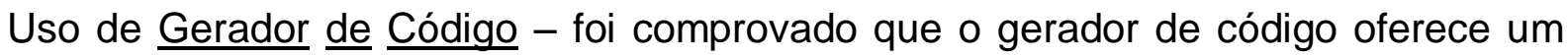
ganho de $45 \%$ de produtividade. Esse fator foi considerado no modelo. 


\section{VI.8.2.4 Fatores considerados no modelo}

A Tabela $\mathrm{X}$ apresenta um resumo dos fatores descartados e selecionados para uso no modelo.

\begin{tabular}{|c|c|c|c|c|}
\hline \multicolumn{5}{|l|}{ Dimensão Processos } \\
\hline Fator & Técnica & Significância & $\begin{array}{l}\text { R-Sq } \\
\text { (adj) }\end{array}$ & $\begin{array}{c}\text { Considerado } \\
\text { no Modelo } \\
\text { matemático }\end{array}$ \\
\hline 1.Maturidade & $\begin{array}{c}\text { Análise } \\
\text { Variância }\end{array}$ & $\begin{array}{l}F=3.66 \\
p=0.038\end{array}$ & $14,27 \%$ & Não \\
\hline 2.Gerenciamento eficaz & Correlação & $p=0.000$ & - & Sim \\
\hline 3.Uso de métodos estruturados & - & - & - & Não \\
\hline 4.Documentação (especificação) & $\begin{array}{c}\text { Análise } \\
\text { Regressão }\end{array}$ & $\begin{array}{l}F=2.33 \\
p=0.155\end{array}$ & $9,9 \%$ & Sim \\
\hline $\begin{array}{l}\text { 5.Equipes de projeto e estrutura } \\
\text { organizacional }\end{array}$ & - & - & - & Não \\
\hline 6.Capacidade de análise de requisitos & - & - & - & Não \\
\hline $\begin{array}{l}\text { 7.Prototipação antes do } \\
\text { desenvolvimento }\end{array}$ & - & - & - & Não \\
\hline 8.Flexibilidade no desenvolvimento & - & - & - & Não \\
\hline 9.Mudanças & Correlação & $p=0.041$ & - & Sim \\
\hline 10.Complexidade do produto & $\begin{array}{l}\text { Análise } \\
\text { Variância }\end{array}$ & $\begin{array}{l}F=2.25 \\
p=0.123\end{array}$ & $7,26 \%$ & Não \\
\hline 11.Tamanho do produto & $\begin{array}{l}\text { Análise } \\
\text { Variância }\end{array}$ & $\begin{array}{l}F=1,22 \\
p=0.311\end{array}$ & $1,33 \%$ & Não \\
\hline 12.Erros potenciais & Correlação & $p=0.586$ & - & Sim \\
\hline 13.Erros & Correlação & $p=0.001$ & - & Sim \\
\hline 14.Custos de revisão & Correlação & $p=0.075$ & - & Sim \\
\hline \multicolumn{5}{|l|}{ Dimensão Pessoas } \\
\hline $\begin{array}{l}\text { 15.Qualificação: Competências/ } \\
\text { Experiência }\end{array}$ & - & - & - & Não \\
\hline 16.Comprometimento & - & - & - & Não \\
\hline 17.Rotatividade/ Redução de equipes & Correlação & $p=0.005$ & - & Não \\
\hline \multicolumn{5}{|c|}{ Dimensão Tecnologia (Ferramentas) } \\
\hline 18.Ambientes de desenvolvimento & - & - & - & Não \\
\hline 19.Existência de precedentes & - & - & - & Não \\
\hline 20.Estratégias de reuso & - & - & - & Não \\
\hline 21.Geradores de código & Definido & $45,8 \%$ & - & Sim \\
\hline
\end{tabular}

Quadro 12 - Resumo dos fatores considerados no modelo (Moreira, 2007)

\section{VI.8.3 Modelo obtido}

A Figura 81 apresenta o modelo obtido a partir de uma amostra de 37 projetos 11 desenvolvidos com tecnologia Java e 16 com tecnologia Microsfot.

O modelo de produtividade obtido em Moreira (2007) tem relação negativa com erros embarcados. Ou seja, quanto maior a quantidade de erros embarcados, que representa o modelo da qualidade não enfocado por este trabalho, menor será a produtividade. Os fatores principais identificados como preditores da produtividade foram o retrabalho, a instabilidade dos requisitos (caracterizada pela taxa de mudança dos requisitos, que é a razão entre o tamanho total das mudanças e o tamanho do projeto), e a produtividade de codificação. $O$ retrabalho é positivamente 
pressionado pelos erros internos, qualidade da especificação e negativamente pelo esforço de gestão e de codificação. Ou seja, quanto mais se investe em codificação, menos retrabalho ocorre. Embora isso represente um paradoxo, remete diretamente à qualidade das atividades de codificação e a necessidade de maturar o código antes de enviá-lo para testes. A produtividade de codificação é impactada positivamente pelo uso de geradores de código.

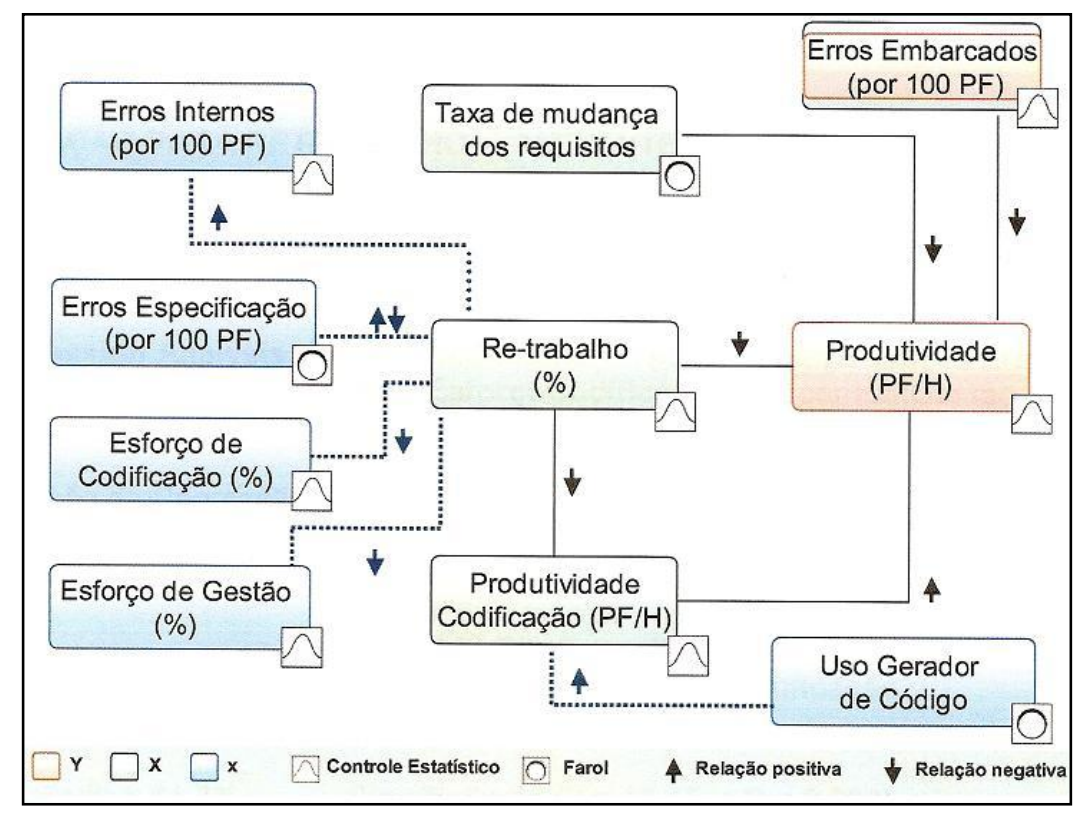

Figura 81 - Modelo de Produtividade obtido (Moreira, 2007)

As equações obtidas servem para estimativa de produtividade e de retrabalho nos projetos.

- Ambiente Microsoft:

\begin{tabular}{|ll|}
\hline Produtividade $=$ & $+0,230$ \\
& $+0,155$ ProdutividadeCodificação \\
& $-0,358$ PercentRetrabalho \\
& $-0,121$ Taxa Mudança \\
\hline
\end{tabular}

\begin{tabular}{|ll|}
\hline PercentRetrabalho $=$ & $+0,118$ \\
& $+0,0026$ Erros Internos PF \\
& $-0,00148$ Erros especifi PF \\
& $-0,0718$ Percentual Gestão
\end{tabular}


- Ambiente Java:

\begin{tabular}{|ll|}
\hline Produtividade $=$ & $+0,0449$ \\
& $+0,024$ ProdutividadeCodificação \\
& $-0,166$ PercentRetrabalho \\
& $-0,425$ Taxa Mudança \\
\hline
\end{tabular}

\begin{tabular}{|ll|}
\hline PercentRetrabalho $=$ & $+0,0645$ \\
& $+0,00281$ Erros Internos PF \\
& $-0,00377$ Erros Especif PF
\end{tabular}

Observar que há diferenças referentes à tecnologia utilizada.

Também foi desenvolvido um modelo da qualidade que faz a previsão de erros embarcados, conforme apresentado na Figura 82. Segundo Moreira (2007), o modelo da qualidade está baseado na eficácia dos testes, de mudança de requisitos e nos fatores de erros internos e embarcados.

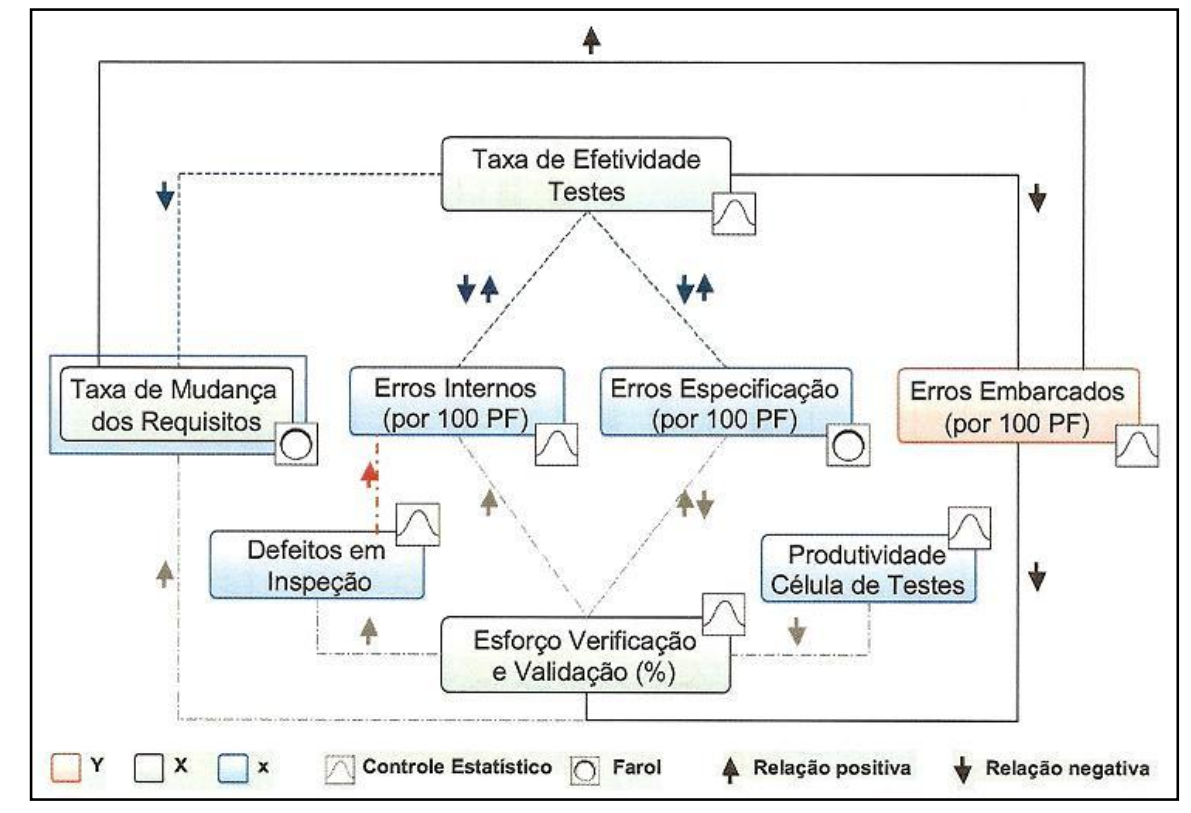

Figura 82 - Modelo da Qualidade obtido (Moreira, 2007)

Este modelo contribui para o entendimento da qualidade dos produtos gerados no ambiente da Fábrica estudada. Há uma relação negativa entre esses fatores . O modelo não é estratificado por tecnologia e possui apenas uma equação. Foi um resultado adicional interessante, pois não era objetivo da pesquisa.

A equação do modelo da qualidade é: 


\begin{tabular}{|ll}
\hline ErrosEmbarcados PF $=$ & $+28,5$ \\
& $-7,23$ TaxaMudança \\
& $-22,8$ TxEficácia Testes \\
& $-25,9$ PercentValidação
\end{tabular}

\section{VI.8.4 Percepção dos fatores de produtividade}

Um contraponto ao modelo quantitativo foi a identificação das percepções da equipe com relação aos fatores de produtividade (Moreira, 2007). Para tanto, foi passado um questionário para explorar qual a visão que os participantes do processo de software tinham com relação aos fatores apontados pela literatura, cujos resultados estão na Figura 83. Foi utilizada uma escala Likert com 7 níveis.

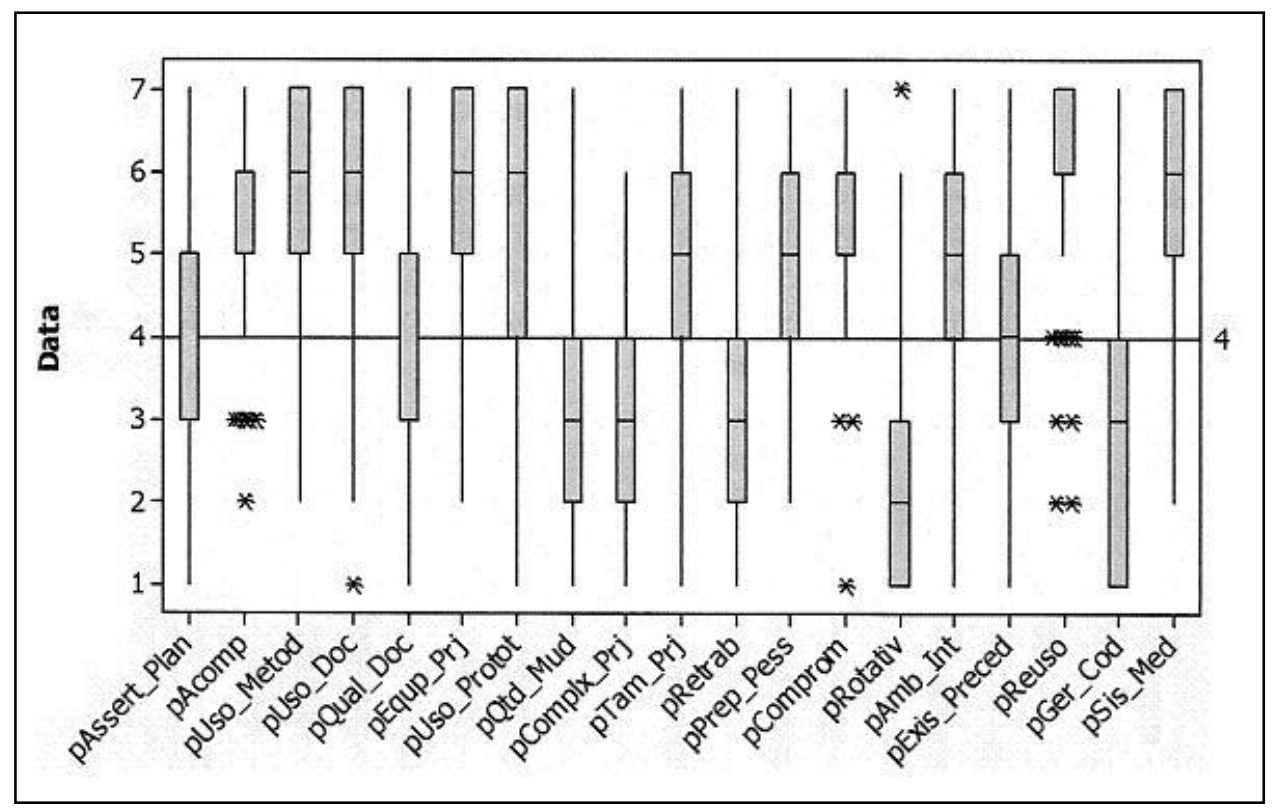

Figura 83 - Percepção da Equipe com relação aos fatores de Produtividade (Moreira, 2007)

A assertividade no planejamento das atividades apresenta variação na percepção de 3 a 5. O acompanhamento de projetos é percebido de forma clara e com baixa variação entre 5 e 6 . O uso de metodologias e de documentação, a existência de um sistema de métricas e a definição de equipes para projeto são altamente percebidos, embora haja variação na intensidade de 5 a 7 . A qualidade da documentação e a existência de precedentes (lições aprendidas) não têm percepção forte e focada. $O$ uso de protótipos é muito percebido. O fator complexidade dos projetos é considerado relevante, embora o tamanho dos projetos não sejam considerados grandes. 
O retrabalho é altamente percebido. A própria metodologia prevê $14 \%$ de retrabalho nos projetos, considerando que a Fábrica também é ambiente de formação de novos talentos.

\section{VI.8.5 Considerações sobre a pesquisa de Produtividade em Fábrica}

A pesquisa-ação desenvolveu um modelo bastante diferenciado pois na literatura há poucas publicações sobre resultados concretos. Particularmente esta pesquisa cumpriu plenamente seu papel pois, conforme já citado, a Fábrica estava em fase de implantação do nível 4 do CMMI que exige abordagem quantitativa e os resultados obtidos foram adotados para uso. A pesquisa, por sua vez, exigiu um estudo mais sistemático da teoria além de obrigar o domínio das ferramentas estatísticas que o pesquisador desconhecia antes desse trabalho.

Esta pesquisa foi bastante diferenciada em relação às demais por realizar um estudo quantitativo em um ambiente onde existem poucos trabalhos similares. $O$ modelo desenvolvido é bem específico para a Fábrica de Software estudada pois diversos fatores desprezados são claramente importantes em outros ambientes mas o importante desse trabalho foi a técnica desenvolvida para se chegar ao modelo. 


\section{VI.9 QUICKLOCUS: AVALIAÇÃO DE PROCESSO}

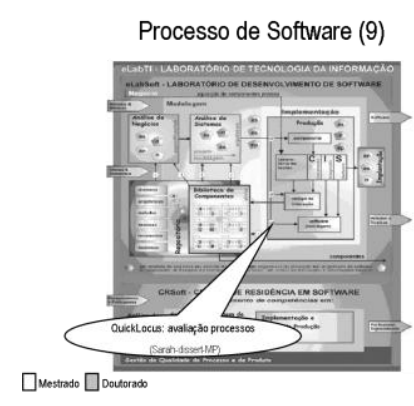

Na pesquisa desenvolvida com Kohan (2003) foi identificado que os processos de desenvolvimento de software são intensivos em trabalho humano e, além disso, dependem fortemente da compreensão clara do processo para que o mesmo seja realizado pelos profissionais de forma correta, com qualidade e produtividade. Dessa forma, com essa pesquisa foi proposto um método de avaliação de processo de desenvolvimento visando sua aplicação a pequenas organizações que desenvolvem software. Esse método foi denominado Quicklocus e é largamente utilizado nas atividades de consultoria em processo de software da Fundação Vanzolini.

\section{VI.9.1 Problemas na avaliação do processo de software}

Conforme já citado, o trabalho intensivo em mão de obra torna a sua qualidade fortemente dependente das pessoas. Considerando que a qualidade nos produtos de software pode ser obtida através de um bom processo, conforme já definido no capítulo II - visão do processo de software, surge a necessidade de fazer a avaliação do processo praticado. Em outras palavras, é necessário saber se as pessoas estão, no desenvolvimento de seu trabalho, seguindo o processo prescrito.

O foco desta pesquisa foi desenvolver um método adequado de avaliação de processo que possa oferecer uma visão confiável do processo praticado indicando os pontos que são atendidos e as divergências identificadas, específico para pequenas organizações. O foco nas pequenas organizações foi escolhido por duas razões:

- os métodos existentes são apropriados para grandes organizações que desenvolvem software, tanto pelo custo como pelo tempo necessário para realizar uma avaliação (Kohan, 2003);

- grande parte das empresas que desenvolvem software são pequenas organizações que não têm acesso a métodos de alto custo (Kohan, 2003). 


\section{VI.9.2 Os métodos de avaliação existentes}

Diversos métodos de avaliação foram estudados, classificados em três grupos:

- Métodos do SEI - Software Engineering Institute

- Métodos da ISO - International Organization for Standardization

- Outros métodos

Os métodos do SEl analisados talvez sejam os mais conhecidos em função da disseminação do CMMI. A Figura 84 ilustra os métodos analisados, mas vale ressaltar que hoje apenas o SCAMPI é utilizado e os demais ficaram obsoletos com a substituição do CMM pelo CMMI.

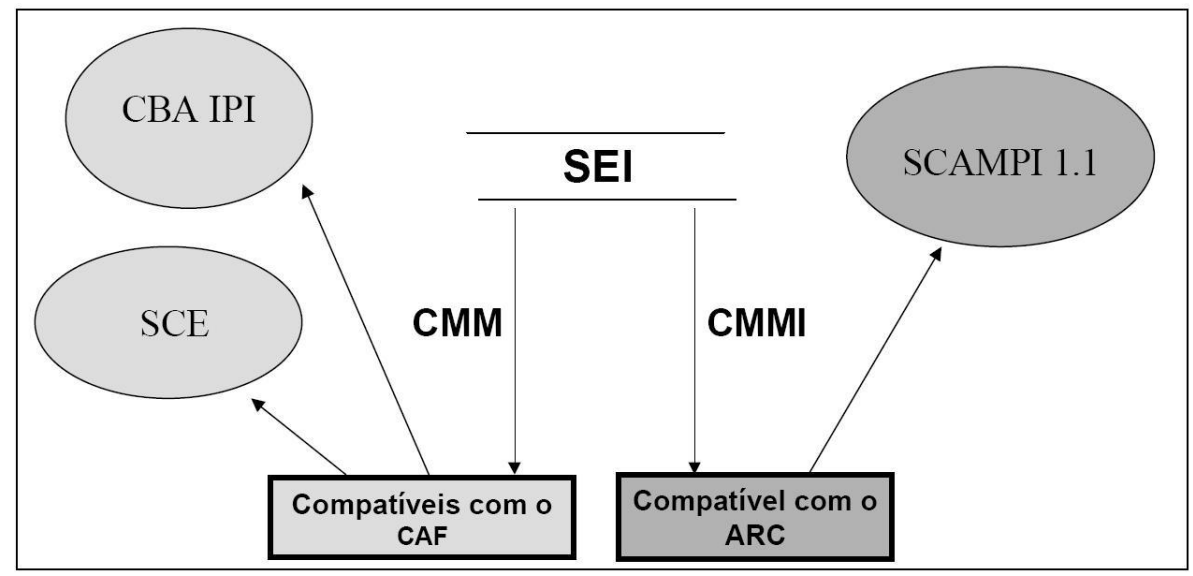

Figura 84 - Métodos de avaliação do SEI (Kohan, 2003)

Os métodos da ISO analisados estão relacionados na Figura 85. As avaliações para a ISO 9001 são muito genéricas para a finalidade desta pesquisa e vale ressaltar que a ISO 15504 na época da pesquisa estava em fase de elaboração, tendo sido publicada em 2004 (partes 1, 3 e 4) e, no Brasil, a ABNT publicou somente em 2008 (partes 1, 2, 3, 4 e 5). 


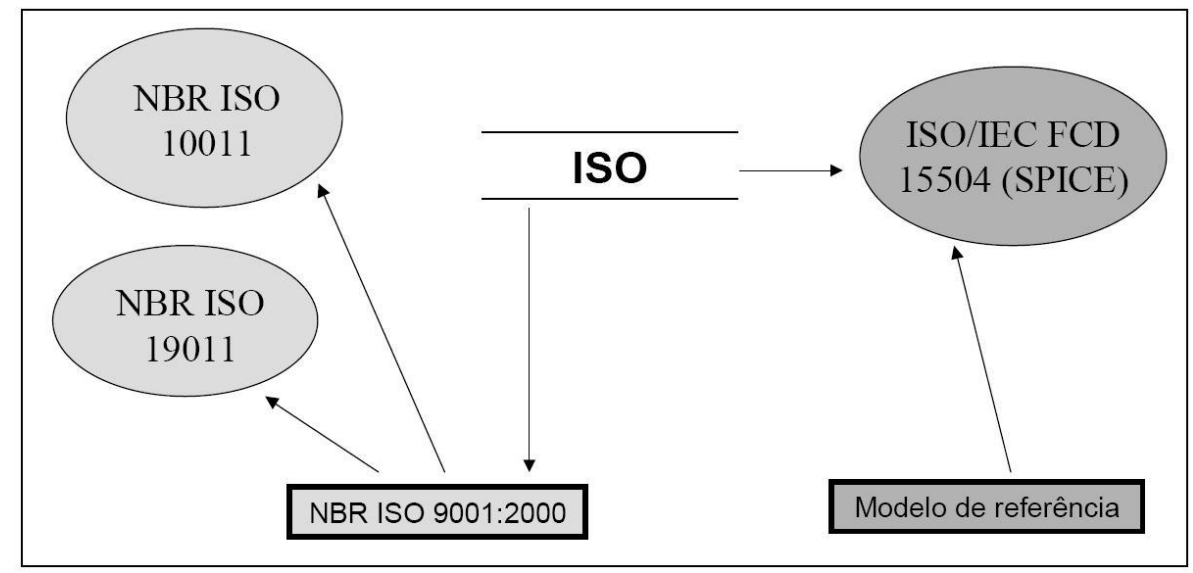

Figura 85 - Métodos de avaliação da ISO (Kohan, 2003)

Foram também analisados outros sete métodos não tão disseminados ou fora do foco deste trabalho.

\section{VI.9.3 Descrição do QuickLocus}

O desenvolvimento de um método para avaliação do processo de software exige algumas definições conceituais. Nielsen \& Pries-Heje apud Kohan (2003) estabeleceram alguns parâmetros para essa finalidade apresentando três dimensões para se definir a estratégia de avaliação, conforme a Figura 86.

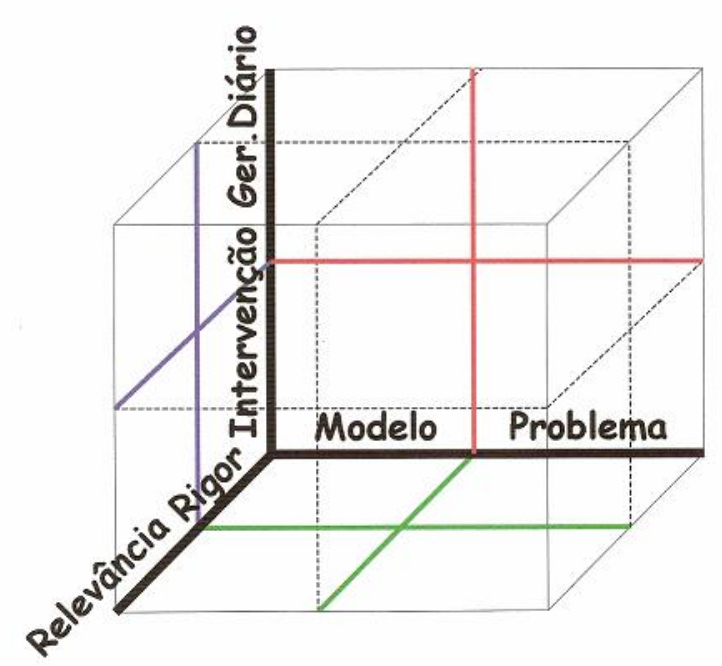

Figura 86 - Dimensões das estratégias de avaliação (Kohan, 2003) 
- Dimensão Modelo versus Problema, ou seja, utiliza-se como referência um modelo de boas práticas (como o $\mathrm{CMMI}$ ) ou avaliam-se os problemas existentes.

- Dimensão Relevância versus Rigor, ou seja, são destacadas para análise apenas questões mais relevantes ou a avaliação é exaustiva.

- Intervenção versus Gerenciamento Diário, ou seja, a avaliação é realizada através de uma intervenção na organização avaliada ou a avaliação é realizada continuamente durante a operação (por exemplo SQA).

No caso do QuickLocus foi escolhido um método baseado em modelo (podem ser utilizados diferentes modelos), as análises são realizadas com base na relevância dos itens analisados e a abordagem é por intervenção, embora esta seja minimizada.

O método foi desenvolvido abordando aspectos comportamentais e técnicos. As principais características do QuickLocus são (Kohan, 2008):

- Avaliação de pequenas organizações com até cerca de 50 desenvolvedores;

- Avaliação com escopo reduzido do modelo - 3 áreas de processo em um dia;

- Avaliação de até 4 diferentes processos existentes na organização;

- Tamanho da equipe de avaliação: 3 pessoas

- Duas fontes de dados: questionários e entrevistas

- Duração do trabalho na organização: um dia

- Graduação de práticas do modelo com maior grau de detalhe

Essas características dão uma idéia do que seja o método e mostra sua adequação a pequenas organizações. A avaliação sempre é realizada com pelo menos uma pessoa da organização que é deslocada para fazer parte da equipe de avaliadores.

O QuickLocus possui 3 fases:

- Preparação

- Avaliação 
- Pós-avaliação

A Figura 87 apresenta as 3 fases do QuickLocus com as principais atividades de cada uma.

\begin{tabular}{|l|}
\hline \multicolumn{1}{|c|}{ Fase 1: preparação } \\
\hline -Definir escopo \\
- Definir modelo de referência \\
- Selecionar processos do modelo \\
-Planejar a avaliação \\
- Treinar equipe de avaliação \\
\hline
\end{tabular}

\begin{tabular}{|l|}
\hline \multicolumn{1}{|c|}{ Fase 2: avaliação } \\
\hline -Colecionar dados fonte 1: \\
questionário \\
-Reunião abertura: orientação aos \\
participantes \\
-Coletar dados fonte 2: entrevistas \\
- Fazer graduação final \\
-Mostrar resultados preliminares \\
\hline
\end{tabular}

\begin{tabular}{|l|}
\hline \multicolumn{1}{|c|}{ Fase 3: pós-avaliação } \\
\hline \hline -Mostrar resultados finais \\
-Reunião de encerramento \\
-Armazenar resultados da avaliação
\end{tabular}

Figura 87 - Fases do QuickLocus

A fase de preparação define o escopo a ser avaliado, que áreas e projetos da organização serão analisados. O modelo de referência precisa ser escolhido, como por exemplo o CMMI ou o MPSBR. As áreas de processo precisam ser definidas, considerando que em um dia é possível avaliar apenas 3 (por exemplo planejamento de projeto, controle de projeto e garantia da qualidade). Em havendo necessidade de avaliar mais processos, haverá necessidade de mais tempo na organização. $O$ tempo de treinamento da equipe é de 2 a 4 horas considerando que os participantes conheçam o modelo e técnicas de melhoria de processo (essa atividade é focada no profissional da empresa avaliada). O planejamento da avaliação deve ser bem detalhado com dia, horário e locais bem definidos, em função do envolvimento de muitas pessoas. Nesse planejamento é recomendado realizar as entrevistas em uma sequência top-down, ou seja, da alta administração, passando pelos gerentes até os técnicos visando entender primeiramente o direcionamento estabelecido para em seguida observar as práticas reais.

A fase de avaliação se inicia com a análise da fonte 1 de dados, um questionário entregue para a empresa responder anteriormente à fase de entrevistas. Normalmente o questionário é respondido pelo responsável pela melhoria de 
processo. Uma reunião de abertura com todos os envolvidos é realizada visando comunicar com clareza os objetivos e orientar o comportamento de todos os entrevistados. As entrevistas são realizadas na organização no menor tempo possível (minimizar a intervenção) e as perguntas são focadas nos quesitos dos processos escolhidos, procurando objetividade e evidências nas respostas. É necessário obter a confirmação nas entrevistas para considerar uma prática do modelo atendida. Todas as respostas devem ser registradas em planilhas adequadas. A equipe de avaliação realiza uma graduação dos resultados utilizando consenso. Ao final das entrevistas é realizada uma reunião de fechamento apresentado os resultados obtidos.

A fase pós-avaliação consiste na elaboração do relatório final e uma reunião com a apresentação dos resultados (que pode ser realizada no final das entrevistas, se conveniente). Os resultados da avaliação são sigilosos e portanto a documentação utilizada deve ser inutilizada e armazenados apenas os resultados finais. Este cuidado é importante para evitar o registro de atribuições de declarações a pessoas específicas.

Um exemplo de resultado da avaliação é mostrado na Figura 88. Para apresentação desses resultados foi criada a metáfora do semáforo, com a utilização das cores: verde (conforme: E - a prática existe), amarela (parcialmente conforme: $\mathrm{M}$ - a prática existe mas precisa ser melhorada) e vermelha (não conforme: $\mathrm{N}$ - a prática não existe). Pode-se observar que esses gráficos dão uma boa visão do resultado da avaliação. O exemplo mostra uma avaliação dos processos referentes ao nível 2 do CMMI. Foi uma avaliação de 2 dias na organização. As barras empilhadas da direita mostram, por exemplo, que o processo de gerenciamento de requisitos (REQM) está completamente atendido e o processo medições e análise (MA) não é atendido. 

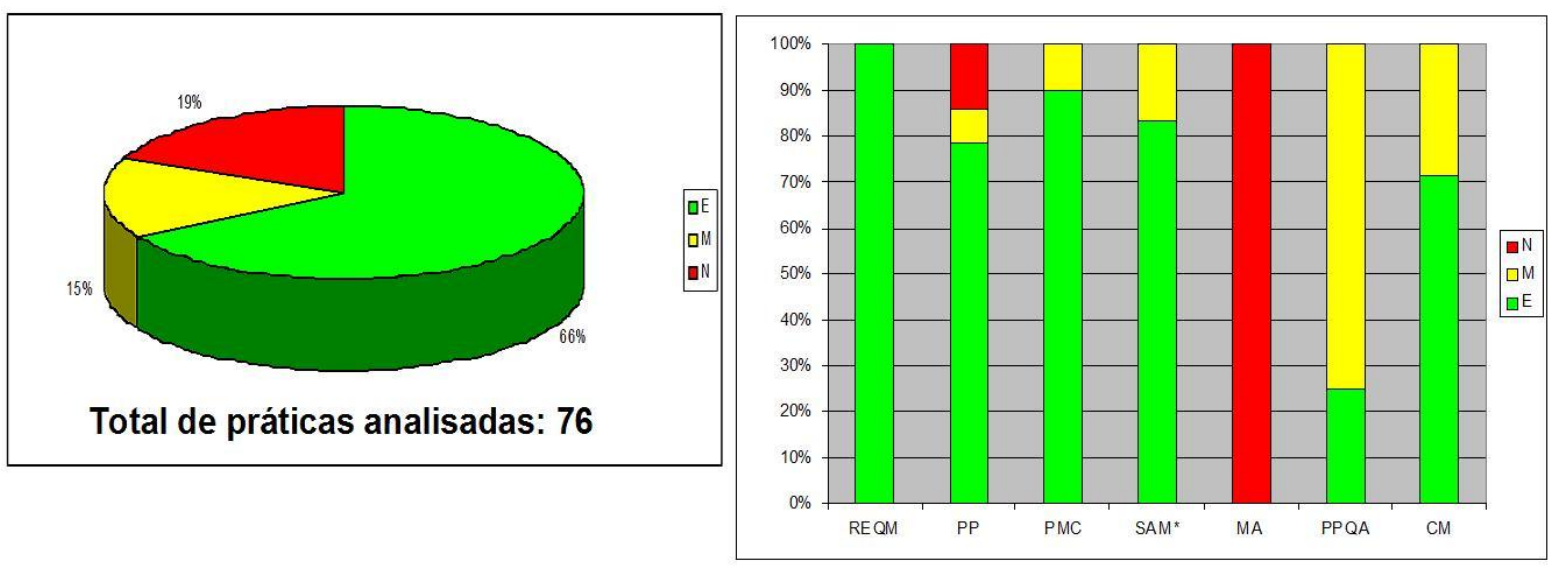

Figura 88 - Exemplo de resultado consolidado do QuickLocus

\section{VI.9.4 A medição de um processo de software}

Para melhor compreender $O$ ato de medir, é interessante verificar os conceitos utilizados na área de instrumentação. A ISO 5725-1 (Kohan, 2003; ISO 5725-1, 1994) define o termo accuracy (exatidão) como sendo a proximidade dos resultados com o valor verdadeiro (trueness), bem como sua dispersão (precision), conforme ilustrado na Figura 89. A precisão (precision) do resultado está ligada com a repetibilidade e reprodutibilidade.

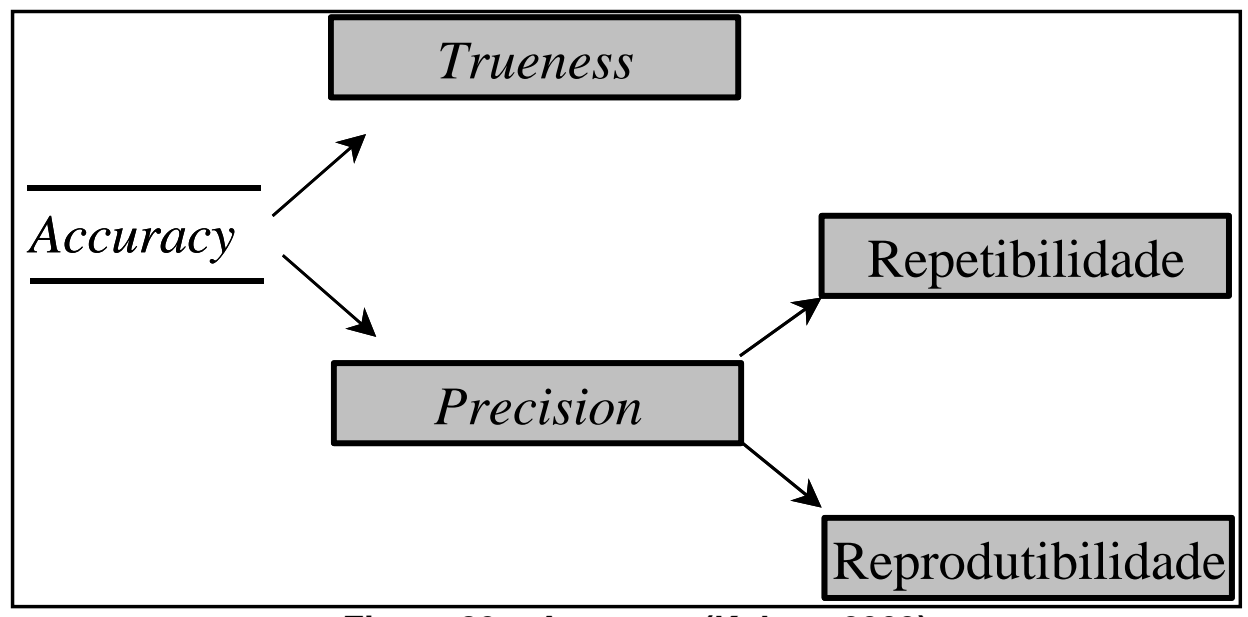

Figura 89 - Accuracy (Kohan, 2003)

A repetibilidade está ligada com os resultados independentes obtidos através da aplicação do mesmo método, no mesmo laboratório, sobre os mesmos itens de teste, pelo mesmo operador, utilizando-se os mesmos equipamentos, dentro de um curto intervalo de tempo. 
A reprodutibilidade são as condições nas quais os resultados de teste são obtidos com a aplicação do mesmo método, sobre os mesmos tópicos de testes, em laboratórios diferentes, com diferentes operadores, utilizando-se diferentes equipamentos.

No caso do QuickLocus essa preocupação é importante pois, embora não haja laboratório nem instrumentos de medição, há operadores utilizando métodos de medida. A troca de operadores (avaliadores) ou mesmo a escolha de diferentes documentos a serem analisados e diferentes pessoas a serem entrevistadas, devem levar a resultados se não iguais, ao menos similares.

Esses aspectos foram analisados na pesquisa de Kohan (2003). Goldenson apud Kohan (2003) identificou que as avaliações de processo possuem quatro principais fontes de erro:

1. Ocasiões diferentes

2. Avaliadores diferentes

3. Instrumentos diferentes

4. Conteúdo diferente em um mesmo instrumento

O uso de questionários padronizados e entrevistas planejadas à luz de quesitos de um modelo selecionado aumenta a reprodutibilidade e reduz o risco do item (2).

A utilização do consenso entre os avaliadores e a utilização de mais de um instrumento de coleta de dados para atribuição da graduação traz duplo benefício: as eventuais inconsistências de respostas se tornam objeto de questionamento posterior e que são resolvidos por consenso. Este quesito corresponde à repetibilidade da avaliação.

A definição de usar equipes experientes nas avaliações melhora a precisão (precision) dos resultados pois favorece as condições de reprodutibilidade $\mathrm{e}$ repetibilidade das avaliações realizadas.

O método original não utiliza como fonte de dados o exame de documentos, acarretando na perda de accuracy dos resultados. Essa foi uma decisão tomada para redução de custo e tempo de avaliação. Por outro lado, por não ser um método que leva à certificação e sim com o objetivo de realizar planos de melhoria e ou 
preparação para a avaliação formal, essa situação, nas entrevistas, leva as pessoas a terem uma postura mais aberta no sentido de não terem motivos para dissimular resultados nas entrevistas.

\section{VI.9.5 Resultados}

Desde o seu desenvolvimento, o QuickLocus vem sendo utilizado em atividades de consultoria em atividades de melhoria de processo de software. Esse método foi aplicado em mais de 40 avaliações nas mais diversas organizações, inicialmente pelas pessoas que desenvolveram o método, mas posteriormente por pessoas que foram treinadas e passaram a utiliza-lo. Interessante observar que nesses 6 anos de utilização, o método continua o mesmo. Para realizar melhoria de processo na organização, não há necessidade de alteração do método.

Quando o método é aplicado com a finalidade de verificar se a organização está pronta para uma avaliação oficial, entretanto, foi identificado que é importante acrescentar uma avaliação documental. A análise dos documentos é importante nessa situação.

O MPS BR, modelo brasileiro desenvolvido pelo Softex para pequenas empresas de software, utiliza um método de avaliação que teve como uma das referências o QuickLocus.

Essa pesquisa foi um trabalho que trouxe um grande número de benefícios práticos tanto do ponto de vista de melhor compreender o processo de avaliação, como do ponto de vista de aplicação em situações reais.

\section{VI.10 CONSIDERAÇÕES FINAIS SOBRE PROCESSO DE SOFTWARE}

Este capítulo encerra a apresentação sobre as pesquisas realizadas sobre o processo de software. Foram apresentados 9 trabalhos e, no próximo capítulo, é realizado uma análise crítica sobre os resultados obtidos com essas pesquisas todas, avaliando aspectos positivos e negativos. 


\section{ANÁLISE CRÍTICA DA OBRA}

Este capítulo tem por objetivo fazer uma análise crítica da obra, ou seja, um balanço geral sobre a experiência de ter realizado as pesquisas aqui relatadas, e identificar os pontos positivos e aqueles que poderiam ser melhorados. Dessa forma, esta análise será realizada sob os seguintes aspectos: o grupo de pesquisa, o conteúdo das pesquisas, os alunos pesquisadores e os resultados obtidos acadêmicos e não acadêmicos.

\section{VII.1 O GRUPO DE PESQUISA}

A existência do grupo de pesquisa GTI - Gestão em Tecnologia da Informação foi a estrutura que facilitou a realização dos trabalhos aqui apresentados. Este Autor realizou pesquisas no mestrado e no doutorado em duas áreas vinculadas à Engenharia Elétrica, onde a organização do grupo era natural, pela especialidade como foi o caso do LSD - Laboratório de Sistemas Digitais, e do PEA Departamento de Energia e Automação Elétrica. Na Engenharia de Produção, o espectro de assuntos é tão grande que, se não houver uma estruturação, fica difícil a formação natural de pontos de acumulação em torno dos temas. Antes de 1998, ano da criação desses grupos por iniciativa da Reitoria, existiam evidentemente as pesquisas e os grupos, mas estes eram informais. Particularmente a área de TI onde este pesquisador se encontra não tinha uma identidade e chegava a ser mal vista em algumas situações. Uma das primeiras recomendações que este Autor recebeu ao ingressar como docente no Departamento foi para não orientar nenhum trabalho de formatura onde o aluno fizesse software, pois isso era considerado computação e não engenharia de produção. Felizmente essa fase já passou e fica muito claro após todos esses anos de pesquisa e convivência - que o engenheiro de produção lida com métodos e com pessoas e muito disso se concretiza em informação, tornando necessário realizar a organização das informações e, ainda mais, utilizar a TI como ferramenta e não como um fim em si mesmo.

Entre todos os grupos de pesquisa talvez o GTI seja um dos que tenha mais usufruído dessa sinergia (da existência dos grupos de pesquisa). A estruturação do eLab-TI como Fábrica de Software - o grande tema de pesquisa - foi conseqüência natural da formação do grupo. Este Autor também considera que a oportunidade de 
realização desta tese trouxe, de uma forma sistemática, um resumo muito claro dos resultados alcançados.

Há, entretanto, correntes de pensamento que consideram os grupos de pesquisa segregacionistas, que impedem a realização de pesquisas multidisciplinares. Analisando a forma organizacional por especialidade, fica evidente que esta é uma estrutura natural em qualquer organização que congrega os especialistas em um mesmo grupo. Dentro dessa abordagem, o que falta é a montagem de uma estrutura matricial para a realização dos projetos multidisciplinares de pesquisa, como ocorre também nas organizações.

\section{VII.2 CONTEÚDO DAS PESQUISAS}

Com relação ao conteúdo das pesquisas realizadas, este Autor considera que são temas bastante atuais, embora também tenha sido evidenciado nesse trabalho que a preocupação com métodos de análise e projeto de software seja uma preocupação antiga. Ocorre entretanto que, de uma maneira geral, os profissionais de $\mathrm{TI}$ focam mais suas preocupações na tecnologia, deixando em segundo plano os aspectos organizacionais. Mesmo as pesquisas na área de computação têm sido, de uma maneira geral, com foco majoritariamente tecnológico: em várias dessas pesquisas de $\mathrm{TI}$ o foco é desenvolver uma ferramenta para dar suporte à atividade e não observá-la como um todo (visão sistêmica) considerando as pessoas e os processos de trabalho como parte integrante dessa atividade. Recentemente houve uma palestra da $\mathrm{IBM}^{8}$ no Departamento de Engenharia de Produção denominada Ciência de Serviços, onde o palestrante, um funcionário que tem como atividade realizar pesquisa (e não trabalhos técnicos profissionais) veio fazer um convite para participação em pesquisas desta empresa pois haviam "descoberto" que os sistemas desenvolvidos precisam ser analisados de uma forma mais abrangente. Até apresentaram um logo "human inside" parodiando o conhecido "Intel inside". Sem entrar no mérito da questão a engenharia de produção - e particularmente GTI - faz isso há muito tempo, como foi demonstrado nesta tese.

\footnotetext{
${ }^{8}$ Palestra ministrada pelo Dr. Cláudio Pinhanez em junho de 2009.
} 
Outro aspecto importante foi um claro amadurecimento com relação aos métodos utilizados para a realização das pesquisas. As primeiras pesquisas desenvolvidas por este Autor tiveram, do ponto de vista metodológico, alguns pontos que hoje poderiam ser questionados, pois o principal foco era sobre o tema em si, sem uma preocupação com a sistemática de obtenção de dados e sua validação. Interessante observar que esse foi um amadurecimento das pesquisas na área de gestão de operações em geral, tanto que foi criada há alguns anos a disciplina metodologia de pesquisa e, até os congressos internacionais desenvolvem hoje seções dedicadas a metodologia de pesquisa nessa área.

A experiência desse Autor tem sido na utilização dos métodos de estudo de caso e, ultimamente, pesquisa-ação, dependendo do tipo de trabalho desenvolvido. Analisando a forma com que o método de pesquisa é conduzido nos últimos trabalhos pode-se identificar claramente a melhoria da qualidade dos mesmos.

O modelo de referência desenvolvido para a Fábrica de Software é atual até hoje, embora tenha sido concebido por volta de 2001. Esse modelo é uma adaptação da aplicação dos conceitos de produção (manufatura) à produção de software e, conforme detalhado no texto, incorpora processos de trabalho bem definidos e preocupação com agilidade, produtividade, reuso, família de produtos, gestão de projeto, gestão do conhecimento, treinamento e capacitação estruturados, produção distribuída, análise de negócios e alinhamento com as necessidades da organização, gestão da informação, gestão de requisitos.

Costa (2003) em 2003 demonstrou em sua pesquisa que poucas Fábricas de Software utilizam concretamente os conceitos estabelecidos no modelo e, mais recentemente, Reinehr (2008) em 2008 identificou que a área financeira, considerada como uma das mais evoluídas na utilização em grande escala da Tecnologia da Informação, ainda incorpora poucos conceitos estabelecidos no modelo de referência.

O próprio modelo de referência teve evoluções quando Trindade (2006), Fabri (2007) e L'Erário (2009) ao desenvolverem suas pesquisas propuseram um detalhamento nos respectivos temas: gestão do conhecimento, criação e organização dos processos de uma Fábrica de Software e DDS - Desenvolvimento Distribuído de Software. 


\section{VII.3 OS ALUNOS PESQUISADORES}

Um levantamento para identificar o tipo de aluno que foi orientado por este Autor ofereceu os resultados aqui descritos.

A média de idade dos alunos que fizeram mestrado ou doutorado é cerca de 40 anos, mostrando um valor relativamente elevado. Talvez seja porque nesses últimos dez anos ocorreu uma exigência de titulação de professores das escola particulares (nas públicas isso já ocorria), fato que criou uma maior procura. O orientado mais velho tinha 62 anos na época da defesa e o mais novo 23 anos na entrada do programa.

Com relação ao tipo de atividade profissional que os alunos possuem, basicamente $36 \%$ é professor, $30 \%$ é analista de sistemas e $27 \%$ é consultor. Os demais especializaram-se em educação a distância. Dos consultores, quase todos são da área de TI mas alguns atuavam na área da qualidade e gestão de operações.

Com relação a bolsa de pesquisa, apenas $6 \%$ dos alunos possui. Este Autor acredita que esse baixo índice de bolsistas se deve ao fato do valor ser muito baixo para sustentar uma pessoa em São Paulo e as diversas oportunidades profissionais que surgem na área de TI não a tornarem atraente. A idade média de 40 anos mostra também que os valores das bolsas podem não viabilizar financeiramente 0 orientado.

Do ponto de vista de quem orienta, é interessante possuir orientados com experiência trabalhando lado a lado com pessoas mais jovens. Existe uma certa dificuldade com os consultores que muitas vezes tiram conclusões sem os necessários cuidados acadêmicos de embasamento. No entanto, vencida essa dificuldade, normalmente tornam-se bons pesquisadores. Os mais jovens têm a vantagem da grande energia que possuem, fato que compensa a falta de experiência.

De todos os alunos orientados $30 \%$ são egressos de graduação da USP e apenas $12 \%$ são egressos do Departamento de Engenharia de Produção.

Outro ponto interessante a se observar é o fato do aluno não ter dedicação total à pesquisa. Se por um lado é ruim em função da falta de tempo, por outro lado é bom 
pois as empresas nas quais os alunos trabalham podem se tornar bons objetos de pesquisa e as portas estão quase que automaticamente abertas.

Vale observar que a escolha do tema de pesquisa é muito importante pois necessita de um casamento entre a oportunidade e o interesse do aluno com as questões de pesquisa que o grupo está lidando. Antes da criação do GTI esses temas eram quase que uma espécie de "geração espontânea" onde o aluno trazia o seu "cenário" e daí se extraia a pesquisa a ser realizada. Hoje, com mais clareza do objeto de pesquisa ao qual o grupo se dedica, há uma seleção natural pois os alunos que procuram a equipe já leram e entenderam os temas de interesse do GTI e a convergência é mais rápida e natural.

\section{VII.4 RESULTADOS ACADÊMICOS}

A avaliação dos resultados acadêmicos é feita sobretudo através das publicações realizadas. Isso pode ser visto no memorial circunstanciado que acompanha este trabalho. Na opinião deste Autor a geração de conhecimento foi muito maior que as publicações realizadas, ou seja, muitas oportunidades de publicação não foram concretizadas, talvez por uma falta maior de foco nessa atividade. Houve dissertações que não geraram nenhuma publicação e são trabalhos de alto nível. Uma preocupação mais recente é sistematizar melhor esta atividade para que haja uma maior presença em revistas, particularmente internacionais. Hoje, trata-se de uma questão de sobrevivência para quem quer se manter nesse ambiente de pesquisa.

Por outro lado, há resultados também acadêmicos, que normalmente não são considerados nas avaliações, mas que são muito interessantes e merecem ser relacionados.

O primeiro deles é a formação de uma rede de pesquisadores que acaba se formando quase que naturalmente a partir de alunos egressos do programa. Assim, hoje há uma troca de informações com ex-alunos com os quais são elaborados artigos de interesse comum e, particularmente no momento da elaboração deste trabalho, encontra-se em andamento um projeto de pesquisa Proenge financiado pela Capes. 
Outro resultado importante é a criação na pós-graduação de disciplinas que nasceram de pesquisas realizadas ou que incorporam em seu conteúdo esses resultados. A disciplina PRO5768 - Planejamento, estratégia e gestão da tecnologia da informação nasceu com a vinda do Professor Piercarlo Maggiolini do Politécnico de Milano e, ao longo do tempo, foi incorporando diversos temas de pesquisa, particularmente do Prof. Fernando Laurindo.

A disciplina PRO5846 - Gestão da informação e do conhecimento: conceitos e estratégias é nova e tem feito muito sucesso entre os alunos. No ano de 2008 houve a procura de 50 candidatos. O conteúdo foi dividido com o Prof Fernando Laurindo e Davi Nakano e boa parte foi aproveitada das pesquisas desenvolvidas no GTI.

A graduação também se beneficiou dessas pesquisas pois hoje a disciplina PRO 2513 Gestão da tecnologia da informação foi criada a partir da PRO 5846 adaptada para a graduação, oferecendo aspectos mais práticos e de uso profissional para os alunos.

Outra disciplina que sempre recebe a incorporação de novos temas é a PRO 2511 Sistemas de informação, modernizada gradativamente à medida que novos métodos, processos e tecnologias vão se consolidando.

\section{VII.5 RESULTADOS NÃO ACADÊMICOS}

O principal resultado não acadêmico é a canalização do conhecimento para a comunidade não acadêmica através das atividades de extensão. Infelizmente esse tipo de atividade não é valorizada pela comunidade acadêmica, mas deveria ser. Afinal, o conhecimento gerado na academia apenas sendo publicado em artigos internacionais não traz diretamente benefícios para a comunidade que sustentou financeiramente o desenvolvimento do trabalho. Particularmente nos Estados Unidos e na Europa a academia está próxima das empresas na geração de tecnologia e conhecimento, conforme pode ser claramente observado no trabalho de Reinehr (2008).

Este Autor tem tentado aproximar a academia das empresas através da Fundação Vanzolini, entidade que foi criada para essa finalidade. No entanto há problemas culturais em ambos os lados mas alguns resultados podem ser relacionados. Aqui 
serão citados apenas três resultados que saíram diretamente das pesquisas realizadas.

O primeiro deles é o QuickLocus, um método de avaliação de processo de software que é até hoje utilizado para avaliar processo de desenvolvimento de software (já aplicado em mais de 40 avaliações). Deu origem a um método de avaliação do MPSBR, um modelo brasileiro de processo de desenvolvimento de software.

Um outro trabalho de impacto para a sociedade foi a avaliação do processo de adequação ao ano 2000 que nasceu de uma dissertação de mestrado (não detalhada nesta tese) (Prando, 1999) mas que gerou uma Norma de adequação (registrada no escritório de direitos autorais da Fundação Biblioteca Nacional) e uma série de atividades de certificação pela Fundação Vanzolini. Esse foi um caso de falta de publicação de textos acadêmicos sobre o tema.

O Curso de Capacitação em Análise de Negócio, por sua vez, nasceu a partir da pesquisa citada nesta tese sobre 0 analista de negócio. Este curso está em sua segunda turma e tem sido ministrado com sucesso pois preenche uma lacuna de conhecimento dos profissionais que exercem esse tipo de atividade.

\section{VII.6 CONSIDERAÇÕES FINAIS}

Este trabalho procurou apresentar uma análise crítica da obra acadêmica deste Autor que, embora tenha sido redigida apenas por uma pessoa, é o resultado do trabalho de uma equipe de pelo menos 37 pessoas que atuaram diretamente em diversas partes do mesmo, sem contar aqueles que tiveram também contribuições anônimas.

Foi apresentada a criação do GTI e logo a seguir da Fábrica de Software (eLab-TI) e mapeadas e apresentadas as pesquisas realizadas.

Neste trabalho não foram abordados aspectos de implantação e de operação da TI, mas apenas as pesquisas realizadas nas primeiras fases do ciclo de vida: análise de negócios, arquitetura da solução (análise de sistemas), implementação e aspectos internos de gestão dos projetos e repositório. No entanto, foram realizadas diversas pesquisas referentes a falhas em projetos de $\mathrm{TI}$, sistemas integrados de gestão 
ERP, implantação. $O$ que se nota em quase todas as pesquisas, é a carência de gestão em ambas as áreas: há um excesso de tecnologias que não funcionam direito, projetos que não chegam ao fim e processos de trabalho que não se alinham com as tecnologias. Esses são portanto os desafios para o futuro que podem ser divididos em dois grupos: o projeto de operações integradas e a capacitação das pessoas.

Com relação ao projeto de operações integradas o que está faltando é uma visão mais sistêmica das operações que são implementadas nas empresas considerando as estratégias das organizações, as necessidades organizacionais em termos de processos de trabalho, capacitação das pessoas e tecnologias coerentes de forma a se obter um sistema que opere de forma integrada. Engenharia de Sistemas é um tema que este Autor tem estudado nos últimos anos, tendo criado e ministrado diversas vezes uma disicplina com esse nome no curso de Gestão da Tecnologia da Informação. Pode-se observar que os alunos, na totalidade profisisonais de $\mathrm{Tl}$, pouco conhecem sobre visão sistêmica. Há também pesquisas em andamento sobre a produção de software sem código (código zero), onde a preocupação maior é com a engenharia de domínio, como é o caso da implantação de sistemas BPMS Business Process Management System. Outro desafio interessante seria a elaboração de um modelo de referência equivalente ao do eLab-TI centrado nas atividades de implantação e operação de Sistemas de TI.

Com relação à capacitação das pessoas há muito o que pesquisar pois, conforme definido no modelo de referência do eLab-TI pouco foi estudado sobre residência em software e capacitação de profissionais. A inovação, a nova palavra de ordem, sempre foi um problema para os profissionais de Tecnologia da Informação pois a formação profissional não é suficiente devido à rápida obsolescência de tecnologias e a vinda de novas outras que as integram ou substituem, fato que cria a obsolescência do conhecimento. Dessa forma, a manutenção de um profissional atualizado, a sua requalificação é um problema para as organizações e para os próprios profissionais, sendo estes temas desafiadores para novas pesquisas. Está em andamento uma pesquisa que vai analisar o tripé empresas, profissionais e escolas. 
O principal resultado de todo esse esforço é o conhecimento adquirido e a certeza de que, quanto mais se aprende, mais há a aprender. 


\section{REFERÊNCIAS}

(IEEE 1517) IEEE Computer Society. Standard for Information Technology Software Life Cycle Processes - Reuse Processes. New York. IEEE 1999.

(ISO 12207) INTERNATIONAL ORGANIZATION FOR STANDARDIZATION. ISO/IEC 12207 - Systems and software engineering - Software life cycle. Second Edition. Geneva, 2008.

(ISO 5725-1) INTERNATIONAL ORGANIZATION FOR STANDARDIZATION. ISO 5725-1 - Accuracy (trueness and precision) of measurement methods and results - Part 1: General Principles and Definitions. arce, ISO 1994.

ABNT ASSOCIAÇÃO BRASILEIRA DE NORMAS TÉCNICAS. NBR ISO/IEC 12207 - Tecnologia de Informação - Processos de Ciclo de Vida de Software. Rio de Janeiro: ABNT, 1997.

ALTER, Steteven - Information Systems: a Management Perspective. California: The Benjamin/Cummings Publishing Company Inc., 1992. Information, Decision Making and Models.

BABoK The Guide to the Business Analysis Body of Knowledge IIBA Interntional Institute of Business Analysis Version 2.0 Draft for Public Review 2008. 270p obtido em www.theibba.org/BABOK2 em 10 de abril de 2008.

BAUER, W.; JUNCOSA, M. ; PERLIS, A.J. ACM Publication Policies and Plans. Journal of the ACM 6; April, 1959.

BAUER,F.L.; BOLLIET, L.; HELMS, H.J Software Engineering Report NATO Science Committee. Garmisch, Germany. January, 1969. Disponível em : http://www.europrog.ru/book/nato1968e.pdf Acesso em 02 fev 2009.

BOEHM, Barry W. Software Engineering Economics Prentice Hall, Inc. 1981.

$\mathrm{BOOCH}$, Grady. Object Solutions - Manage the Object-Oriented Project. Addison Wesley. USA.1996. 
BORGHOFF, U., SCHLICHTER, J., Computer-Supported Cooperative Work Introduction to Distributed Applications. 1. ed. Berlin: Springer, 2000. 529 p.

BOYER, Carl B.. História da Matemática. Edgard Blucher,1974.

CARR, N. G. IT doesn't matter. Harvard Business Review, v81, n.5 , 2003.

CARVALHO, Marly Monteiro de ; PESSÔA, M. S. P. ; LAURINDO, Fernando José Barbin ; RABECHINI JR, Roque . Equivalência e completeza: análise de dois modelos de maturidade em gestão de projetos. RAUSP. Revista de Administração, v. 40, p. 289-300, 2005

CASTILHO FILHO, Antonio Francisco Ferreira de. Avaliação Uso de Novas Tecnologias de Informação nas Empresas - internet, Intranet e Extranet Estudo de Casos. 1998. 0 f. Dissertação (Mestrado em Engenharia -Engenharia de Produção) - Universidade de São Paulo. Orientador: Marcelo Schneck de Paula Pessôa

CMMI Product Team. Capability Maturity Model Integration (CMMI), Version 1.1: CMMI for Systems Engineering, Software Engineering, Integrated Product and Process Development, and Supplier Sourcing (CMMI-SE/SW/IPPD/SS, V1.1), Staged Representation (CMU/SEI-2002-TR-012, ESC-TR-2002-012). Pittsburgh, PA: Software Engineering Institute, Carnegie Mellon University, March 2002a.

(Disponível em http://www.sei.cmu.edu/publications/documents/02.reports/02tr012.html)

COAD, Peter; YOURDON, Edward. Análise Baseada em Objetos. Campus. Rio de Janeiro. 1992

COOKE, Cássio Sodré. Gestão de serviços proposição de um método para obtenção de vantagem competitiva através da fidelização do consumidor. 2000. Dissertação (Mestrado em Engenharia de Produção) - Universidade de São Paulo, . Orientador: Marcelo Schneck de Paula Pessoa

COSTA, Ivanir ; PESSÔA, M. S. P. ; SPINOLA, Mauro de Mesquita . Uso da Curva $A B C$ na Técnica de Análise por Pontos de Função nas Estimativas de Projetos de Software. In: XXIII ENEGEP - ENCONTRO NACIONAL DE ENGENHARIA DE PRODUÇÃO, 2003a, Ouro Preto, MG. Anais do XXIII ENEGEP - Encontro Nacional de Engenharia de Produção, 2003‥ 
COSTA, Ivanir. Contribuição para o Aumento da Qualidade e Produtividade de uma Fábrica de Software através da Padronização do Processo de Recebimento de Serviços de Construção de Softwares. 2003. Tese (Doutorado em Engenharia (Engenharia de Produção) - Universidade de São Paulo.

CUSUMANO, M.A. Japan's Software Factories. New York: Oxford University Press. 1991

DE MARCO, Tom. Análise estruturada e especificação de Sistema. Rio de Janeiro, Campus, 1989.

DEL MASCHI, Valério Fernandes. Diretrizes Estratégicas para Empresas Desenvolvedoras de Sofware com Foco em Produtro. São Paulo, 2009.Dissertação (Mestrado em engenharia de produção). Universidade Paulista UNIP. Orientador: Marcelo Schneck de PaulaPessôa.

DEMING, E. W. Qualidade: a Revolução da Administração. Rio de Janeiro. Marques-Saraiva. 1990

FABRI, J. A. ; TRINDADE, A.L.P.; DURSCKI, R. ; SPINOLA,, M. M. ; PESSOA, M. S. $P$. . Proposta de um Mecanismo de Desenvolvimento e Customização de uma Fábrica de Software Orientada a Domínios. In: XXXI Latin American Computing Conference, 2005, Cali. Anais do XXXI Latin American Computing Conference, 2005

FABRI, J. A. ; TRINDADE, A.L.P; SILVEIRA, M. ; PESSOA, M. S. P. . O Papel do CMMI na Configuração de um Meta-Processo de Produção de Software com Características Fabris: Um Estudo de Caso. In: VI Jornadas Iberoamericanas de Ingeniería del Software e Ingeniería del Conocimiento, 2007aㅡ, Lima - Peru. Anais das VI Jornadas Iberoamericanas de Ingeniería del Software e Ingeniería del Conocimiento, 2007a. V. 1. p. 375-383

FABRI, J. A.; SCHEIBLE, A. C. F.; MOREIRA, P. M. L., TRINDADE, A. L. P.; BEGOSSO, L. R.; BRAUN A. P.; PESSÔA, M S. de P. Meta-Process used for Production Process Modeling of a Software Factory: the Unitech Case. In: Managing Worldwide Operations and Communications with Information Technology - IRMA 2007b Proceedings. Vancouver, Canadá. 2007b

FABRI, J. A.; TRINDADE, A. L. P.; BEGOSSO, L. R.; PESSOA, M. S.; L'ERÁRIO, A. The Use of the IDEF-0 to Model the Process in a Software Factory. In: Managing 
Worldwide Operations and Communications with Information Technology - IRMA 2007c Proceedings. Vancouver, Canadá. 2007c

FABRI, J. A.; TRINDADE, A.L.P. ; BEGOSSO, L. R. ; LERARIO, Isso ; SILVEIRA, F. L. F. ; PESSOA, M. S. P. . Techniques for the Development of a Software Factory: Case CEPEIN-FEMA.. In: $17^{\text {th }}$ International Conference Software \& Systems Engineering and their Applications., 2004, Paris. Annals of $17^{\text {th }}$ International Conference Software \& Systems Engineering and their Applications, 2004. v. 3

FABRI, J. A.; TRINDADE, A.L.P; LERARIO, Isso ; PESSOA, M. S. P. - A Organização de uma Máquina de Processo e a Melhoria do Processo de Produção de Software em um Ambiente de Fábrica. In: VI Jornadas Iberoamericanas de Ingeniería del Software e Ingeniería del Conocimento, 2007, Lima - Peru. Anais das

FABRI, José Augusto ; L'ERARIO, Alexandre ; TRINDADE, André Luiz Presende ; PESSÔA, M. S. P. ; LAURINDO, Fernando José Barbin . O Alinhamento Estratégico de Negócios e Tecnologia da Informação nos Cursos de Computação, Administração e Engenharia de Produção. In: In: XI CONGRESSO CIESC 2003 - CONGRESSO IBERO-AMERICANO DE EDUCAÇÃO SUPERIOR EM COMPUTAÇÃO, 2003, La Paz. La Paz

FABRI, José Augusto ; TRINDADE, André Luiz Presende ; L'ERÁRIO, Alexandre ; PESSÔA, M. S. P. ; SPINOLA, Mauro de Mesquita. Desenvolvimento e Replicação de uma Fábrica de uma Software. In: VI Simpósio Internacional de Melhoria de Processo de Software - SIMPROS, 2004 a, São Paulo. Anais do VI Simpósio Internacional de Melhoria de Processo de Software - SIMPROS, 2004 a.

FABRI, José Augusto. Uma proposta de modelo para a criação e a organização de processos de produção em um contexto de fábrica de software.. 2007. Tese (Doutorado em Engenharia (Engenharia de Produção)) - Universidade de São Paulo, . Orientador: Marcelo Schneck de Paula Pessoa

FARBEY, B.; LAND, F.F.; TARGETT, D. A taxonomy of information systems applications: the benefits evaluation ladder. European Journal of Information Systems, v4, n1, 1995.

Febraban. Pesquisa - O Setor Bancário em Números. Acesso em 04/07/2009 a http://www.febraban.org.br/p5a 52gt34++5cv8 4466+ff145afbb52ffrtg33fe36455li54 $11 \mathrm{pp}+\mathrm{e} / \mathrm{sitefebraban/informacoes} \mathrm{do} \mathrm{setor.pdf}$ 
FELICIANO Neto, Isso; FURLAN, J. D.; HIGA, W. Engenharia da Informação: metodologia, técnicas e ferramentas. 2. ed. McGraw Hill, 1988.

FERNANDES, A.A. ; TEIXEIRA, D.S. Fábrica de Software:Implantação e Gestão de Operações. São Paulo, Editora Altas, 2004.

FERNANDES, A.A. O Paradigma da Fábrica de Software: Itens Qualificadores e Ganhadores de Pedido e Práticas das Empresas de Informática no Brasil. 2000. Tese (Doutorado em Engenharia de Produção) - Departamento de Engenharia de Produção - EPUSP.

FERREIRA, Aurélio Buarque de Holanda. Dicionário Aurélio. Rio de Janeiro, Editora Nova Fronteira, 1986.

FLEURY, Afonso Carlos Corrêa; VARGAS, Nilton. Organização do Trabalho: uma abordagem interdisicplinar. São Paulo, Atlas. 1983;

FOWLER, Martin; SCOTT, Kendall UML Distilled - Appplying the Standard Object Modeling Language. Addison Wesley. USA. 1997.

FREITAS, Luís Ricardo Napolitano. Projetos em Tecnologia da Informação: Como Acertar Através da Análise dos Erros. 2000. 175 p. Dissertação (Mestrado) Escola Politécnica, Universidade de São Paulo, São Paulo, 2000.

FRONTINI, Maria Alice Braga. A Fábrica de Software. 1988. 229 p. Trabalho de Formatura, Escola Politécnica, Universidade de São Paulo, São Paulo, 2000.

GANE, C.;SARSON, T. Análise Estruturada de Sistemas, Rio de Janeiro, Editora LTC, 1983.

GLOVER, Bill; HIMANSHU, Bhatt. Fundamentos de RFID, Rio de Janeiro, Alta Books, 2007.

GONÇALVES, Rodrigo Franco. Uma abordagem Sistêmica para o Processo de Produção em Engenharia Web, na fase de Concepção. 2009. Qualificação (Doutorado em Engenharia de Produção) - Universidade de São Paulo, . Orientador: Marcelo Schneck de Paula Pessôa 
GONÇALVES, Rodrigo Franco ; GAVA, Vagner Luis ; PESSÔA, M. S. P. ; SPINOLA, Mauro de Mesquita. Fundamentos de Engenharia Simultânea na Produção de Aplicações Web. In: XXVII ENEGEP - ENCONTRO NACIONAL DE ENGENHARIA DE PRODUÇÃO, 2007, Foz do Iguaçu, André197. XXVII ENEGEP - ENCONTRO NACIONAL DE ENGENHARIA DE PRODUÇÃO, 2007. p. 414.

GONÇALVES, Rodrigo Franco ; GAVA, Vagner Luis ; PESSÔA, M. S. P. ; SPINOLA, Mauro de Mesquita. Produção de Software para Web: uma proposta de processo. In: ENEGEP 2005 a - XXV ENCONTRO NACIONAL DE ENGENHARIA DE PRODUÇÃO, 2005 a, Porto Alegre. ENEGEP 2005a - XXV ENCONTRO NACIONAL DE ENGENHARIA DE PRODUÇÃO, 2005 a.

GONÇALVES, Rodrigo Franco ; GAVA, Vagner Luiz ; PESSÔA, M. S. P. ; SPINOLA, Mauro de Mesquita. Uma proposta de processo de produção de aplicações Web. Produção (São Paulo), v. 15, n. 3, p. 376-389, 2005.

GONÇALVES, Rodrigo Franco ; GAVA, Vagner Luiz ; Rita Cristina Ferreira ; PESSOA, M. S. P. . Ergonomic Challenges in Information System Implantation for Building Design Support: a Brazilian experience. In: ODAM IX 2008, 2008, Guarujá, São Paulo. IX Simpósio Internacional em Ergonomia no Projeto Organizacional e Gestão, 2008.

GONÇALVES, Rodrigo Franco ; PESSÔA, M. S. P. . Entropia em Postos de Trabalho:uma proposta de métrica para avaliação ergonômica. In: ENEGEP 2005c - XXV ENCONTRO NACIONAL DE ENGENHARIA DE PRODUÇÃO, 2005c, Porto Alegre.

GONÇALVES, Rodrigo Franco ; PESSÔA, M. S. P. ; SPINOLA, Mauro de Mesquita ; PRADO, José Pacheco de Almeida. A Importância de Representar Pessoas na Modelagem de Processos de Negócio. In: ENEGEP 2005b - XXV ENCONTRO NACIONAL DE ENGENHARIA DE PRODUÇÃO, 2005b, Porto Alegre. ENEGEP 2005b - XXV ENCONTRO NACIONAL DE ENGENHARIA DE PRODUÇÃO, 2005b.

HAUFFE, Thomas. Design: An Illuistrated Historical Overview. Barron's, 1996.

HEGEDUS, C. E. ; TAVARES, E. S. ; WILTEMBURG, C. S. ; PESSÔA, M. S. P. . Knowledge Management as a 197ndré197197197s element to implement ISO 9000 program. In: Proceedings of the $7^{\text {th }}$ International Conference on ISO 9000 and TQM, 2002, Melbourne. Change Management Proceedings of the $7^{\text {th }}$ International Conference on Iso 9000 \& Tqm (7-ICIT), 2002. p. 55-56. 
HENDERSON, J.C.; VENKATRAMAN, M. Strategic Alignment: Leveraging Information Technology for Transforming Organizations. IBM Systems Journal vol. 32 , 1993, pp. 4-16.

HUMPHREY, W. S. A discipline for software engineering. Reading, MA: AddisonWesley, 1995. (SEl series in software engineering).

HUMPREY, W. Managing the Software Process, Reading, MA: Addison Wesley, 1989

JACINTHO, José Carlos. Avaliação econômica dos investimentos em tecnologia da informação. 2000. Dissertação (Mestrado em Engenharia de Produção) Universidade de São Paulo, . Orientador: Marcelo Schneck de Paula Pessôa

JURAN, J.M.; GRYNA, F.M. Controle da Qualidade Handbook Conceitos, Políticas e Filosofia da Qualidade. $1^{\mathrm{a}}$ edição, São Paulo, Makron Books do Brasil , 1991.

KOHAN, Sarah. QuickLocus: Proposta de um Método de Avaliação de Processo de Desenvolvimento de Sofware em Pequenas Organizações. 2003. 235p. Dissertação (Mestrado Profissional) Instituto de Pesquisas Tencológicas do Estado de São Paulo, São Paulo, 2003.

KOHAN, Sarah; PESSÔA, Marcelo S.P.; SPINOLA, Mauro M. QuickLocus: a Software Development Process Evaluation Method for Small-sized Organizations. In: Oktaba, Hanna; Piatini, Mario. Software Process Improvement for Small and Medium Enterprises - Techniques and Case Studies - Chapter V: pgs 109-139. Ed. IGI Global. Hershey, USA. 2008.

KUNUTH, D.E. Computer Programming as an Art. Communications of the ACM New York, USA. Volume 17 Issue 12, December, 1974.

L'ERÁRIO, Alexandre. M3DS: Um modelo de dinâmica de desenvolvimento distribuído de software. 2009. Tese (doutorado em Engenharia de Produção) Departamento de Engenharia de Produção (no prelo).

L'ERARIO, Alexandre ; PESSÔA, M. S. P. . UM MÉTODO DE ENSINO E PRÁTICAS DE DESENVOLVIMENTO DISTRIBUÍDO DE SOFTWARE PARA CURSOS DE GRADUAÇÃO. In: COBENGE - Congresso Brasileiro de Educação 
em Engenharia, 2008, São Paulo. Anais do XXXVI Congresso Brasileiro de Educação em Engenharia, 2008.

L'ERARIO, Alexandre ; PESSOA, Marcelo Schneck de Paula . A dinâmica e as suas propriedades dos ambientes de desenvolvimento distribuído de software: um estudo de caso. In: XII Congreso Argentino de Ciencias de la Computación, 2006, San Luis. Anais do XII Congreso Argentino de Ciencias de la Computación, 2006. v. 1. p. $12-22$

L'ERARIO, Alexandre ; PESSOA, Marcelo Schneck de Paula . An Analysis of the Dynamics and Properties of the Distributed Development of Software Environments: A Case Study. In: SERP'07- The 2007 International Conference on Software Engineering Research and Practice, 2007, Las Vegas. Software Engineering Research and Practice, 2007. v. 2. p. 471-477

LAINO, C. P. ; FERNANDES, L. M. M. ; GONÇALVES, Rodrigo Franco ; COSTA, Ivanir ; PESSÔA, M. S. P. . Uso de ferramenta WIKI para gestão do conhecimento: um estudo de caso em instituição financeira. In: ENEGEP, 2008, Rio de Janeiro. XVIII Encontro Nacional de Engenharia de Produção, 2008.

LAURINDO, F.J.B.; ROTONDARO, R.G. Gestão Integrada de Processos e da Tecnologia da Informação. São Paulo: Atlas S.Isso, 2006.

LAURINDO, Fernando José Barbin. Tecnologia da Informação - Eficácia nas Organizações. São Paulo. Editora Futura, 2002.

LAURINDO, Fernando José Barbin. Um Estudo Sobre a Avaliação da Eficácia da Tecnologia da Informação nas Organizações. 2000. Tese (Doutorado) São Paulo, 2000. Departamento de Engenharia de Produção, Escola Politécnica, Universidade de São Paulo.

LELLO, J; LELLO, E.; Dicionário Prático Ilustrado. Porto, Editora Lello \&lrmão, 1968.

LOUZADA, Luiz Alberto de Campos. Contribuição ao Estudo do Processo de desenvolvimento de Software: A Aplicação dos Métodos de Engenharia de Software em empresas que possuem desenvolvimento próprio. 2000. Dissertação (Mestrado em engenharia de Produção) Universidade Paulista . 2000. 
MAGGIOLINI, Piercarlo. Planejamento e Gestão da Tecnologia da Informação. São Paulo, 1996. Escola Politécnica da USP. Apostila para Disciplina de Pósgraduação do Departamento de Engenharia de Produção PRO5805

MARÇULA, M. ; PESSÔA, M. S. P. ; BENINI FILHO, P. Isso . Metodologia para a Gestão do Conhecimento em Pequenas e Médias Empresas. In: VIII SIMPEP SIMPÓSIO DE ENGENHARIA DE PRODUÇÃO, 2001르, Bauru/SP, 2001ㄹ., 2001ㄹ.

MARÇULA, Marcelo. Metodologia para a Gestão do Conhecimento em Pequenas e Médias Empresas, apoiada pela Tecnologia da Informação. 2001. $160 \mathrm{f}$. Dissertação (Mestrado em Engenharia de Produção) - Universidade Paulista, . Orientador: Marcelo Schneck de Paula 200ndré200

MARTIN, J. Engenharia da Informação: introdução. Trad. Follow UP. Rio de Janeiro: Campus, 1991.

MC FARLAN, W. Information Technology Changes the Way You Compete. Harvard Business Review, v62, $n^{\circ} 3$ May/June, 1984.

MEDEIROS JR, Alberto de, PESSÔA, M. S. P., LAURINDO, F. J. B. Evolution Stages in Web Applications In: Encyclopedia of E-Commerce, E-Government, and Mobile Commerce ed.Hershey : Idea Group Reference, 2006, v.1, p. 1-7.

MEDEIROS JÚNIOR, Alberto de ; PESSÔA, M. S. P. ; LAURINDO, Fernando José Barbin. The Web Involved in Nolan's Stages. In: $16^{\text {th }}$ International Conference Information Resources Management Association - IRMA, 2005, San Diego, California. IRMA $-16^{\text {th }} 16^{\text {th }}$ International Conference Information Resources Management Association, 2005.

Medeiros Junior, Alberto de. Análise de Novas Tecnologias de Comunicação de Dados Utilizadas na Gestão da Cadeia de Suprimentos. 2002. 0 f. Dissertação (Mestrado em Engenharia (Engenharia de Produção)) - Universidade de São Paulo, . Orientador: Marcelo Schneck de Paula Pessoa.

MICHAELIS Moderno Dicionário Inglês Michaelis. Editora Melhoramentos. Acesso em 01/05/2009 a http://michaelis.uol.com.br/moderno/ingles/index.php

MOREIRA, Paulo Marcelo Lessa. Contribuição ao Estudo de Produtividade em Ambientes de Fábricas de Software. 129p. 2007. Dissertação (Mestrado 
Profissional) Instituto de Pesquisas Tecnológicas do Estado de São Paulo, São Paulo, 2007.

MOURA, Luciano Raizer. Gestão Integrada da Informação: proposição de um modelo de organização baseado no uso da informação como recurso da gestão empresarial. 117p. Dissertação de Mestrado. Escola Politécnica, Universidade de São Paulo, São Paulo, 1999.

NOLAN, R.L. Managing the Crisis in Data Processing Harvard Business Review, v.57, n2, Mar/Apr 1979.

NONAKA, I.; TAKEUSHI, H. Criação do Conhecimento na Empresa - como as empresas japonesas geram a dinâmica da inovação. Rio de Janeiro, 1997, Editora Campus 18 ${ }^{\mathrm{a}}$ edição.

OKUMURA, Fábio Massashi. Avaliação de Modelos Matemáticos de Dimensionamento no Planejamento de Sistemas de Informação. 1988. Trabalho de Formatura - Departamento de Engenharia de Produção. EPUSP.

OLIVEIRA, K. R. ; PESSÔA, M. S. P. . Implementando a Linguagem UML como uma Ferramenta de Definição de Processo do Workflow. In: VIII SIMPEP Simpósio de engenharia de Produção, 2001, Bauru/SP, 2001, 2001.

OLIVEIRA, K. R.; PESSÔA, M.S.P. Implementação de Cenários como Ferramenta de Elicitação de Requisitos nos processos de Workflow. In: VIII Simpósio de Engenharia de Produção - SIMPEP, 2002 a , Bauru/SP, 2002 a.

Oliveira, Kleber Rocha de. Engenharia de Requisitos: Um Estudo da Aplicação de Cenários no Rastreamento e Mudanças de Requisitos. 2002. 0 f. Dissertação (Mestrado em Engenharia de Produção) - Universidade Paulista, 2002 .

PAULA FILHO, Wilson de Pádua. Engenharia de Software. Rio de Janeiro, LTC, 2003.

PAULK, M. et al. The Capability Maturity Model. USA, Addison-Wesley, 1995. (SEI series in software engineering). 
PESSÔA, M. S. P. ; FABRI, José Augusto ; L'ERARIO, Alexandre ; SPINOLA, Mauro de Mesquita ; BEGOSSO, A . Desenvolvimento e Replicação de uma Fábrica de Software. In: IV Jornada Iberoamericanas de Ingenieria del Software e Ingenieria del Conocimiento, 2004b, Madrid. Actas de Las IV Jornadas Iberoamericanas de Ingeniería del Software e Ingeniería del Conocimiento, 2004b. V. 002.

PESSÔA, M. S. P.; FABRI, J. Isso; SPINOLA, M. M.; PRADO, T.F.; L'ERARIO, Isso. Desenvolvimento distribuído de software para sistemas pervasivos: um estudo de caso. In: I Simpósio Brasileiro de Sistemas de Informação (SBSI), 2004c. Anais-I SBSI. Porto Alegre. P. $163-170$.

PESSOA, M.S.P.; LAGUNA, F. ; MACEDO, G.C. Programa Formação do Analista de Negócios São Paulo: Fundação Vanzolini, Expertise, 40p; jan 2009. (apresentação de ementa de curso).

PESSOA, M.S.P; SPINOLA, M.M. Tipos de Produção São Paulo, EPUSP 2006. material didático da disicplina de graduação Automação e Controle - PRO 2512.

PESSÔA, Marcelo Schneck de Paula, SPINOLA, Mauro de Mesquita Aprender a aprender. Boletim Fundação Vanzolini. São Paulo, p.18 - 18, 1996.

PESSÔA, Marcelo Schneck de Paula. Fonte de Alimentação Chaveada para um Minicomputador. Dissertação de Mestrado. São Paulo, 1979. Departamento de Engenharia Elétrica, Escola Politécnica, Universidade de São Paulo.

PFLEEGER, Shari Lawrence. Engenharia de Software: Teoria e Prática. 2.ed. Prentice Hall, São Paulo, 2004.

PMBoK Project Management Institute. A Guide to the Project Manager Body of Knowledge (PMBOK Guide). Upper Darby, PA, 2000.

PMI - Project Management Institute A Guide to the Project Management Body of Knowledge. 2. ed. Newton Square. PMI Publications, 2004.

PORTELLA, E.; Bechara, E.C.; Costa, S.C. Vocabulário Ortográfico da Língua Portuguesa. Rio de Janeiro, Academia Brasileira de Letras, 4a. edição, 2004. Acesso em 01/05/2009 em http://www.academia.org.br 
PORTER, M.E. Vantagem Competitiva: criando e sustentando um desempenho superior. São Paulo, Campus, 1989.

POSTLEY, J.A. Letters to the Editor Communications of the ACM New York, USA. Volume 3 Issue 1, January 1960.

PRANDO, Gerson. Bug do Milênio - uma visão de engenharia. Dissertação (Mestrado em Engenharia de Produção) - Universidade de São Paulo, 1999. Orientador: Marcelo Schneck de Paula Pessôa

PRESSMAN, Roger S. Engenharia de Software. São Paulo, McGraw Hill, $6^{a}$ edição, 2006.

PRESSMAN, Roger S. Engenharia de Software. Tradução M.M.G. Travieso. Revisão J.C.Maldonado, P.C. Masiero, F.S.R.Germano. 5ed. São Paulo, Makron, 2002.

PRESSMAN, Roger S. Software Engineering: a Practitioner's Approach. Singapore. McGraw Hill International. $3^{\text {rd }}$. Edition, 1987.

PRIBERAN Dicionário Priberam da Língua Portuguesa. Acesso em 01/05/2009 a http://www.priberam.pt/dlpo/dlpo.aspx?pal=eliciar

PRO. Agrupamentos do Departamento de Engenharia de Produção EPUSP. 2009. Disponível em: http://www.pro.poli.usp.br/departamento/agrupamentos Acesso em 14 jan 2009.

RABECHINI JR, Roque ; LAURINDO, Fernando José Barbin ; PESSÔA, M. S. P. . Web Technology as a Tool for Enabling Strategic Changes in a Decentralized Manufacturing. In: IV SIMPOI/POMS-IV SIMPÓSIO DE ADMINISTRAÇÃO DA PRODUÇÃO LOGÍSTICA E OPERAÇÕES INTERNACIONAIS- INTERNATIONAL CONFERENCE OF THE PRODUCTION OPERATIONS MANAGEMENT SOCIETY, 2001, Brazil, Guarujá, 2001., 2001. p. 666-671

RABECHINI Jr, Roque ; PESSÔA, M. S. P. Um modelo estruturado de competências e maturidade em gestão de projetos. Produção (São Paulo), v. 15, p. $34-43,2005$ 
RABECHINI Jr, Roque. Competências e Maturidade em Gestão de Projetos: uma perspectiva estruturada.São Paulo, Ed. Annablume, Fapesp, 2005a․

RABECHINI Jr, Roque. Competências e Maturidade em Gestão de Projetos: Uma Perspectiva Estruturada. 2003. Tese (Doutorado em Engenharia (Engenharia de Produção)) - Universidade de São Paulo, . Orientador: Marcelo Schneck de Paula Pessoa

REINEHR, Sheila dos Santos. Reuso Sistematizado de Software e Linhas de Produto de Software mo Setor Financeiro: estudos de caso no Brasil. 2008. Tese (Doutorado em Engenharia de Produção) - Departamento de Engenharia de Produção.

ROCKART, J.F.. Chief Executives Define Their Own Data Needs. Harvard Business Review v.57, n2, Mar./Apr. 1979.

RODRIGUES SILVA, M.Isso, Marcos. Um Modelo de Produtividade e Qualidade na Produção Fabril de Software para utilização em Fábricas de Software por Encomenda 2005. 157 p. Tese (doutorado) São Paulo, 2005. Departamento de Engenharia de Produção, Escola Politécnica, Universidade de São Paulo.

RODRIGUES SILVA, Marcos Antonio ; COSTA, Ivanir ; PESSÔA, M. S. P. . Qualidade, Como Fator Preponderante para o Desenvolvimento de Software. In: ENEGEP 2001 - XXI ENCONTRO NACIONAL DE ENGENHARIA DE PRODUÇÃO, 2001, Salvador/BA, 2001., 2001.

SHLAER, S; MELLOR, Stephen J. Análise de Sistemas Orientados para Objetos. McGraw Hill: Newstec. 1990.

SHLAER, S; MELLOR, Stephen J. Object Lifecycles - Modeling the World in States. Yourdon Press Computing Series. Prentice Hall. New Jersey-USA. 1992.

SOMMERVILLE, lan. Engenharia de Software. São Paulo. Pearson Education do Brasil. $6^{\mathrm{a}}$ edição, 2003.

SPINOLA, Mauro de Mesquita. Processos de Produção de Software: da Definição à Gerência. Tese de Livre Docência. São Paulo, 2008. Departamento de Engenharia de Produção, Escola Politécnica, Universidade de São Paulo. 
TAVARES, Edval da Silva. Uma Contribuição para o Processo da Gerência de Projetos através do Conhecimento. 2003. Tese (Doutorado em Engenharia de Produção) - Departamento de Engenharia de Produção.

TAVARES, S.R.S. Da Crise do Software ao Projeto Estruturado: a Submissão Real do Trabalho em Programação. In: FLEURY, A..C; VARGAS, N. Organização do Trabalho, São Paulo, 1983.

THIOLENT, Michel. Pesquisa-Ação nas Organizações. 1ª edição São Paulo, Atlas, 1997.

TRINDADE, André Luiz Presende ; PESSÔA, M. S. P. ; SPINOLA, Mauro de Mesquita . COCOMO II Uma Compilação de Informações Sobre a Nova Métrica. In: V INTERNATIONAL CONGRESS ON INFORMATION ENGINEERING, 1999a, Buenos Aires. Anales Proceedings $V$ International Congress on Information Engineering, Buenos Aires: ICIE'99 (University of Buenos Aires)., 1999a. p. 24-38

TRINDADE, André Luiz Presende. Métricas para Orçamento e Planejamento da Produção de Software. Dissertação de Mestrado. São Paulo, 1999. Departamento de Engenharia de Produção, Escola Politécnica, Universidade de São Paulo.

TRINDADE, André Luiz Presende. Uma contribuição para o entendimento do papel da ensinagem na preservação do conhecimento em ambientes de fábrica de software. 2006. Tese (Doutorado em Engenharia de Produção) - Departamento de Engenharia de Produção.

WEINBERG, G.M. Software com Qualidade. Makron Books. São Paulo. 1994

YOURDON, Edward. Object-Oriented Systems Design - An Integrated Approach. Prentice Hall. New Jersey-USA. 1994. 


\section{APÊNDICE A - QUESTIONÁRIO DA PESQUISA DE SILVA (2004)}

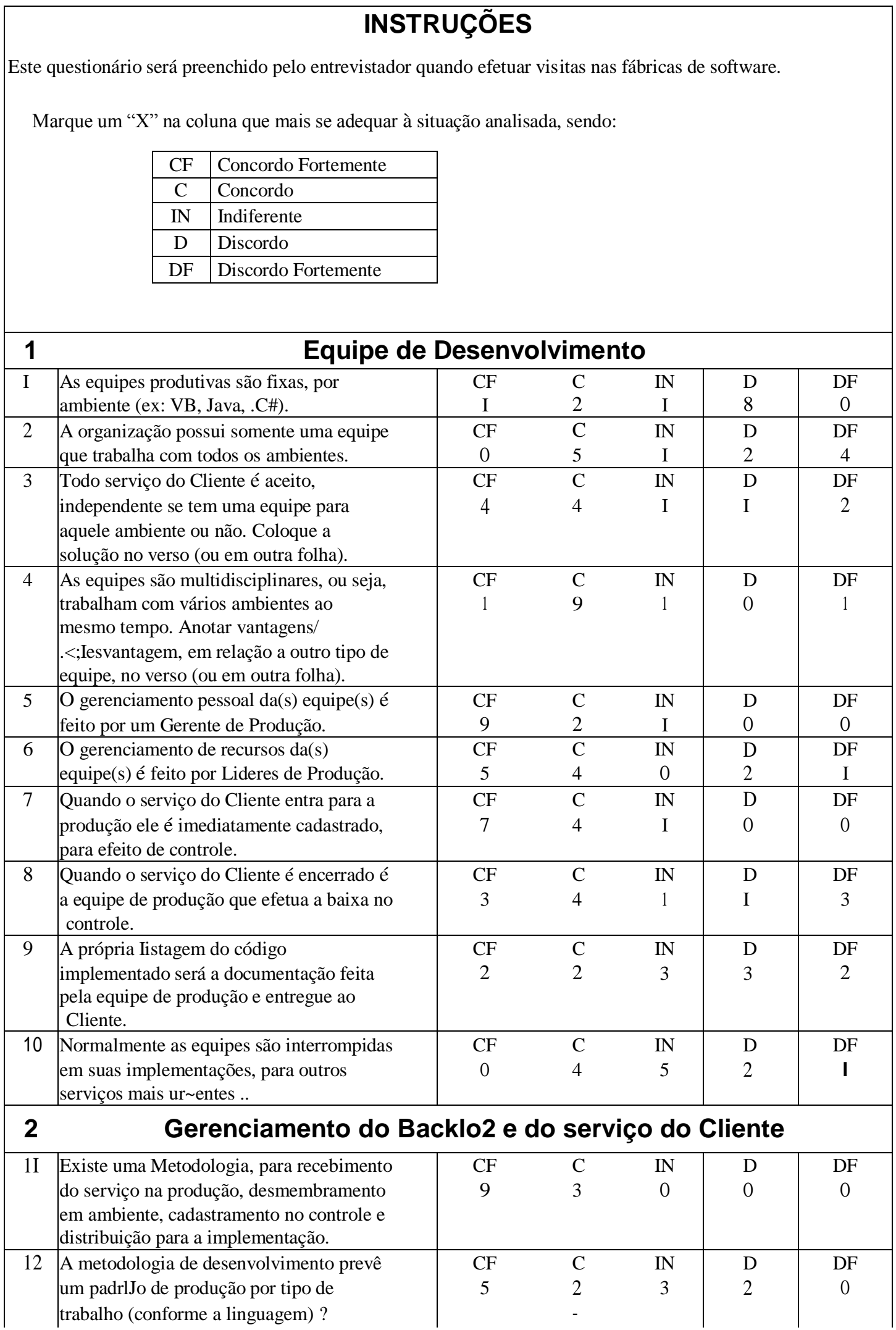

Folha 1 de 5 - Questionário sobre processo de Fábrica de Software

(Silva, 2004) 


\begin{tabular}{|c|c|c|c|c|c|c|}
\hline 13 & $\begin{array}{l}\text { Existe um critério de formação da fila de } \\
\text { espera (ex: primeiro que entra primeiro } \\
\text { que sai). Se for outro critério, anote no } \\
\text { verso (ou em outra folha). }\end{array}$ & $\begin{array}{c}\mathrm{CF} \\
2\end{array}$ & $\begin{array}{l}\mathrm{C} \\
4\end{array}$ & $\begin{array}{c}\mathrm{IN} \\
0\end{array}$ & $\begin{array}{l}\mathrm{D} \\
5\end{array}$ & $\begin{array}{c}\mathrm{DF} \\
\mathbf{I}\end{array}$ \\
\hline 14 & $\begin{array}{l}\text { Existe um esquema automático para a } \\
\text { transição da fila de espera para a } \\
\text { implementação (serviço'do Cliente). Anote } \\
\text { no verso (ou em outra folha). }\end{array}$ & $\begin{array}{c}\mathrm{CF} \\
0\end{array}$ & $\begin{array}{l}\mathrm{C} \\
1\end{array}$ & $\begin{array}{c}\text { IN } \\
2\end{array}$ & $\begin{array}{l}\mathrm{D} \\
8\end{array}$ & $\begin{array}{c}\mathrm{DF} \\
1\end{array}$ \\
\hline 15 & $\begin{array}{l}\text { Para o serviço do Cliente é feito um } \\
\text { planejamento. Qualquer outra situação, } \\
\text { anote no verso (ou em outra folha). }\end{array}$ & $\begin{array}{c}\mathrm{CF} \\
9\end{array}$ & $\begin{array}{l}\mathrm{C} \\
0\end{array}$ & $\begin{array}{c}\text { IN } \\
2\end{array}$ & $\begin{array}{l}\mathrm{D} \\
1\end{array}$ & $\begin{array}{c}\mathrm{DF} \\
0\end{array}$ \\
\hline 16 & $\begin{array}{l}\text { Quando surge um serviço do Cliente com } \\
\text { maior prioridade, efetua-se um novo } \\
\text { planejamento, encaixando-isso }\end{array}$ & $\begin{array}{c}\mathrm{CF} \\
5\end{array}$ & $\begin{array}{l}\mathrm{C} \\
5\end{array}$ & $\begin{array}{c}\text { IN } \\
\mathbf{I}\end{array}$ & $\begin{array}{l}\mathrm{D} \\
1\end{array}$ & $\begin{array}{c}\mathrm{DF} \\
0\end{array}$ \\
\hline 17 & $\begin{array}{l}\text { Diariamente é efetuado um } \\
\text { posicionamento com a equipe de produção } \\
\text { para verificar eventuais discrepâncias. } \\
\text { Qualquer outra situação. Anote no verso } \\
\text { (ou em outra folha). }\end{array}$ & $\begin{array}{c}\mathrm{CF} \\
6\end{array}$ & $\begin{array}{l}\mathrm{C} \\
2\end{array}$ & $\begin{array}{c}\text { IN } \\
\text { I }\end{array}$ & $\begin{array}{l}\mathrm{D} \\
3\end{array}$ & $\begin{array}{c}\mathrm{DF} \\
0\end{array}$ \\
\hline 18 & $\begin{array}{l}\text { Quando um prazo estimado é superado, } \\
\text { registra-se o porquê e traça-se } \\
\text { imediatamente um plano de emergência } \\
\text { para recupera-to. Anotar o esquema no } \\
\text { verso (ou em outra folha). }\end{array}$ & $\begin{array}{c}\mathrm{CF} \\
6\end{array}$ & $\begin{array}{l}\mathrm{C} \\
5\end{array}$ & $\begin{array}{c}\text { IN } \\
1\end{array}$ & $\begin{array}{l}\mathrm{D} \\
0\end{array}$ & $\begin{array}{c}\mathrm{DF} \\
0\end{array}$ \\
\hline 19 & $\begin{array}{l}\text { Quando há uma superação do prazo } \\
\text { estimado, aproveita-se o registro do } \\
\text { motivo e esquematiza-se uma melhoria } \\
\text { nos processos que levaram à anomalia. }\end{array}$ & $\begin{array}{c}\mathrm{CF} \\
4\end{array}$ & $\begin{array}{l}\mathrm{C} \\
6\end{array}$ & $\begin{array}{c}1 N \\
2\end{array}$ & $\begin{array}{l}\mathrm{D} \\
0\end{array}$ & $\begin{array}{c}\mathrm{DF} \\
0\end{array}$ \\
\hline 3 & \multicolumn{6}{|c|}{ Desenvolvimento - Recebimento do Servi o } \\
\hline 20 & $\begin{array}{l}\text { Existe um esquema de recebimento dos } \\
\text { tipos de serviço (programas, classes, } \\
\text { componentes, etc). Anotar o esquema no } \\
\text { verso (ou em outra folha). }\end{array}$ & $\begin{array}{c}\mathrm{CF} \\
6\end{array}$ & $\begin{array}{l}\mathrm{C} \\
4\end{array}$ & $\begin{array}{c}\text { IN } \\
2\end{array}$ & $\begin{array}{l}\mathrm{D} \\
0\end{array}$ & $\begin{array}{c}\mathrm{DF} \\
0\end{array}$ \\
\hline 21 & $\begin{array}{l}\text { Quem recebe o serviço para } \\
\text { implementação é o Lider de Produção. Se } \\
\text { houver outra opção anotar no verso (ou em } \\
\text { outra folha). }\end{array}$ & $\begin{array}{c}\mathrm{CF} \\
3\end{array}$ & $\begin{array}{l}\mathrm{C} \\
5\end{array}$ & $\begin{array}{c}\text { IN } \\
0\end{array}$ & $\begin{array}{l}\mathrm{D} \\
\mathbf{I}\end{array}$ & $\begin{array}{c}\mathrm{DF} \\
3\end{array}$ \\
\hline 22 & $\begin{array}{l}\text { A metodologia de desenvolvimento prevê } \\
\text { um padrão de produção por tipo de serviço } \\
\text { ou tarefa (conforme a lin ua uem). }\end{array}$ & $\begin{array}{c}\mathrm{CF} \\
4\end{array}$ & $\begin{array}{l}\mathrm{C} \\
3\end{array}$ & $\begin{array}{c}\text { IN } \\
2\end{array}$ & $\begin{array}{l}\mathrm{D} \\
3\end{array}$ & $\begin{array}{c}\mathrm{DF} \\
0\end{array}$ \\
\hline 23 & $\begin{array}{l}\text { A metodologia de desenvolvimento ai oca } \\
\text { as equipes por serviço ou tarefa. }\end{array}$ & $\begin{array}{c}\mathrm{CF} \\
6\end{array}$ & $\begin{array}{l}\mathrm{C} \\
5\end{array}$ & IN & $\begin{array}{l}\mathrm{D} \\
0\end{array}$ & $\begin{array}{c}\mathrm{DF} \\
0\end{array}$ \\
\hline 24 & $\begin{array}{l}\text { Um número de Ordem de Serviço } \\
\text { identifica o mesmo na produção (ou as } \\
\text { tarefas desmembradas do serviço) }\end{array}$ & $\begin{array}{c}\text { CF } \\
7\end{array}$ & $\begin{array}{l}\mathrm{C} \\
3\end{array}$ & $\begin{array}{c}\text { IN } \\
2\end{array}$ & $\begin{array}{l}\mathrm{D} \\
0\end{array}$ & $\begin{array}{c}\mathrm{DF} \\
0\end{array}$ \\
\hline 25 & $\begin{array}{l}\text { Se houver divergência entre padrões e/ou } \\
\text { prazo estimado de término e planejamento, } \\
\text { há um esquema para a devolução do } \\
\text { serviço para a renegociação com o Cliente. } \\
\text { Anotar no verso (ou em outra folha) como } \\
\text { é feito. }\end{array}$ & $\begin{array}{c}\mathrm{CF} \\
7\end{array}$ & $\begin{array}{l}\mathrm{C} \\
2\end{array}$ & $\begin{array}{c}\text { IN } \\
0\end{array}$ & $\begin{array}{l}\mathrm{D} \\
3\end{array}$ & $\begin{array}{c}\mathrm{DF} \\
0\end{array}$ \\
\hline
\end{tabular}

Folha 2 de 5 - Questionário sobre processo de Fábrica de Software (Silva, 2004) 


\begin{tabular}{|c|c|c|c|c|c|c|}
\hline 4 & \multicolumn{6}{|c|}{ Desenvolvimento - Entrada na Produção } \\
\hline 26 & O serviço do Cliente (ou as tarefas) é & $\mathrm{CF}$ & $\mathrm{C}$ & TN & $\mathrm{D}$ & $\overline{\mathrm{DF}}$ \\
\hline & $\begin{array}{l}\text { recebido na Produção pelo Líder de cada } \\
\text { ambiente e entregue aos recursos alocados. } \\
\text { Se houver outra forma, anotar no verso (ou } \\
\text { em outra folha). }\end{array}$ & 4 & 3 & 2 & 1 & 2 \\
\hline 27 & $\begin{array}{l}\text { O serviço do Cliente é desmembrado na } \\
\text { produção, por ambiente (ou linguagem) } \\
\text { para efeito de implementação. }\end{array}$ & $\begin{array}{c}\mathrm{CF} \\
4\end{array}$ & $\begin{array}{l}\mathrm{C} \\
4\end{array}$ & $\begin{array}{l}1 \mathrm{~N} \\
\mathbf{I}\end{array}$ & $\begin{array}{l}\mathrm{D} \\
\mathbf{I}\end{array}$ & $\begin{array}{c}\text { DF } \\
2\end{array}$ \\
\hline 28 & $\begin{array}{l}\text { Existe uma biblioteca com códigos } \\
\text { genéricos para reuso (framework), } \\
\text { facilitando a implementação. }\end{array}$ & $\begin{array}{c}\mathrm{CF} \\
5\end{array}$ & $\begin{array}{l}\mathrm{C} \\
2\end{array}$ & $\begin{array}{l}\text { IN } \\
3\end{array}$ & $\begin{array}{l}\mathrm{D} \\
\mathrm{I}\end{array}$ & $\begin{array}{c}\text { DF } \\
\text { I }\end{array}$ \\
\hline 29 & $\begin{array}{l}\text { O Líder de Produção executa o processo } \\
\text { de aproveitamento de código. }\end{array}$ & $\begin{array}{c}\mathrm{CF} \\
4\end{array}$ & $\begin{array}{l}\mathrm{C} \\
2\end{array}$ & $\begin{array}{l}\text { IN } \\
\text { I }\end{array}$ & $\begin{array}{l}\mathrm{D} \\
2\end{array}$ & $\begin{array}{c}\mathrm{DF} \\
3\end{array}$ \\
\hline 30 & $\begin{array}{l}\text { O serviço, quando entra efetivamente para } \\
\text { implementação, é devidamente registrado } \\
\text { e a sua distribuição se faz segundo um } \\
\text { esquema de disponibilidade (por ambiente } \\
\text { ou lingua em). }\end{array}$ & $\begin{array}{c}\mathrm{CF} \\
7\end{array}$ & $\begin{array}{l}\mathrm{C} \\
5\end{array}$ & $\begin{array}{l}\text { IN } \\
0\end{array}$ & $\begin{array}{l}\mathrm{D} \\
0\end{array}$ & $\begin{array}{c}\text { DF } \\
0\end{array}$ \\
\hline 31 & $\begin{array}{l}\text { Para alocação dos recursos para o serviço } \\
\text { é efetuado um planejamento entre a } \\
\text { Produção e o recebimento (Líder, } \\
\text { Gerente ... ). }\end{array}$ & $\begin{array}{c}\mathrm{CF} \\
8\end{array}$ & $\begin{array}{l}\mathrm{C} \\
4\end{array}$ & $\begin{array}{l}\text { IN } \\
0\end{array}$ & $\begin{array}{l}\mathrm{D} \\
0\end{array}$ & $\begin{array}{c}\text { DF } \\
0\end{array}$ \\
\hline 32 & $\begin{array}{l}\text { As equipes de produção trabalham por } \\
\text { ambiente (ou linguagem) e não pelo } \\
\text { serviço todo do Cliente. }\end{array}$ & $\begin{array}{c}\mathrm{CF} \\
4\end{array}$ & $\begin{array}{l}\mathrm{C} \\
\mathrm{I}\end{array}$ & $\begin{array}{l}\text { IN } \\
4\end{array}$ & $\begin{array}{l}\mathrm{D} \\
2\end{array}$ & $\begin{array}{c}\mathrm{DF} \\
\mathbf{I}\end{array}$ \\
\hline 33 & $\begin{array}{l}\text { A fábrica utiliza uma Metodologia de } \\
\text { Desenvolvimento. Anotar no verso (ou em } \\
\text { 6utra folha) qual é a metodologia (própria } \\
\text { ou outra). }\end{array}$ & $\begin{array}{c}\mathrm{CF} \\
8\end{array}$ & $\begin{array}{l}\mathrm{C} \\
4\end{array}$ & $\begin{array}{l}\text { IN } \\
0\end{array}$ & $\begin{array}{l}\mathrm{D} \\
0\end{array}$ & $\begin{array}{c}\text { DF } \\
0\end{array}$ \\
\hline 34 & $\begin{array}{l}\text { Alinhados com a Metodologia de } \\
\text { Desenvolvimento, há processos de } \\
\text { lançamento e controle histórico de } \\
\text { produtividade e qualidade (ex: PSP). }\end{array}$ & $\begin{array}{c}\mathrm{CF} \\
8\end{array}$ & $\begin{array}{l}\mathrm{C} \\
0\end{array}$ & $\begin{array}{l}\text { IN } \\
1\end{array}$ & $\begin{array}{l}\mathrm{D} \\
2\end{array}$ & $\begin{array}{c}\mathrm{DF} \\
\mathbf{I}\end{array}$ \\
\hline 35 & $\begin{array}{l}\text { Nesse momento são efetuados os } \\
\text { lançamentos iniciais de qualidade (ISSO, } \\
\text { CMM, PSP, etc.). Anotar no verso (ou em } \\
\text { outra folha) quais. }\end{array}$ & $\begin{array}{c}\mathrm{CF} \\
7\end{array}$ & $\begin{array}{l}\mathrm{C} \\
2\end{array}$ & $\begin{array}{l}\text { IN } \\
0\end{array}$ & $\begin{array}{l}\mathrm{D} \\
3\end{array}$ & $\begin{array}{c}\text { DF } \\
0\end{array}$ \\
\hline 36 & $\begin{array}{l}\text { A Produção executa um processo de } \\
\text { framework (verificação da existência de } \\
\text { códigos reusáveis, do próprio Cliente ou } \\
\text { da fábrica) e disponibiJiza-os para } \\
\text { incorporação na implementação ou nos } \\
\text { testes de integração. }\end{array}$ & $\begin{array}{c}\mathrm{CF} \\
5\end{array}$ & $\begin{array}{l}\mathrm{C} \\
4\end{array}$ & $\begin{array}{l}\text { IN } \\
\text { I }\end{array}$ & $\begin{array}{l}\mathrm{D} \\
2\end{array}$ & $\begin{array}{c}\mathrm{DF} \\
0\end{array}$ \\
\hline 5 & Desenvolvimento - In & ente & & & & \\
\hline 37 & $\begin{array}{l}\text { Quando a Produção recebe o serviço do } \\
\text { Cliente, procura dissolver em produtos } \\
\text { menores (rotinas, classes, componentes, } \\
\text { etc.), facilitando a implementação e os } \\
\text { testes. }\end{array}$ & $\begin{array}{c}\mathrm{CF} \\
4\end{array}$ & $\begin{array}{l}\mathrm{C} \\
3\end{array}$ & $\begin{array}{l}\text { IN } \\
3\end{array}$ & $\begin{array}{l}\mathrm{D} \\
\mathrm{I}\end{array}$ & $\begin{array}{c}\mathrm{DF} \\
\mathbf{I}\end{array}$ \\
\hline 38 & $\begin{array}{l}\text { Quando a Produção recebe o serviço do } \\
\text { Cliente, implementa-o de maneira única, } \\
\text { conforme a definição do Cliente, ou seja } \\
\text { um produto para cada definição. }\end{array}$ & $\begin{array}{c}\mathrm{CF} \\
4\end{array}$ & $\begin{array}{l}\mathrm{C} \\
6\end{array}$ & $\begin{array}{l}\text { IN } \\
1\end{array}$ & $\begin{array}{l}\mathrm{D} \\
0\end{array}$ & $\begin{array}{c}\text { DF } \\
\text { I }\end{array}$ \\
\hline 39 & Os desenvolvedores possuem mais de $\sim$ a & $\mathrm{CF}$ & $\mathrm{C}$ & IN & $\mathrm{D}$ & DF \\
\hline
\end{tabular}

Folha 3 de 5 - Questionário sobre processo de Fábrica de Software

(Silva, 2004) 


\begin{tabular}{|c|c|c|c|c|c|c|}
\hline & habilidade (ambiente ou linguagens). & 9 & 3 & 0 & 0 & 0 \\
\hline 40 & $\begin{array}{l}\text { Para alavancar a metodologia trabalha-se } \\
\text { com alguma ferramenta de produtividade } \\
\text { (gerador de códigos, modelos, testes, } \\
\text { biblioteca, etc.). Anotar no verso (ou em } \\
\text { outra folha) quais ferramentas. }\end{array}$ & $\begin{array}{c}\mathrm{CF} \\
7\end{array}$ & $\begin{array}{l}\mathrm{C} \\
2\end{array}$ & $\begin{array}{l}\text { IN } \\
\text { I }\end{array}$ & $\begin{array}{l}\mathrm{D} \\
2\end{array}$ & $\begin{array}{c}\mathrm{DF} \\
0\end{array}$ \\
\hline 41 & $\begin{array}{l}\text { Alinhados com a Metodologia de } \\
\text { Desenvolvimento há processos de revisão } \\
\text { de código. }\end{array}$ & $\begin{array}{c}\mathrm{CF} \\
5\end{array}$ & $\begin{array}{l}\mathrm{C} \\
\mathrm{I}\end{array}$ & $\begin{array}{l}1 \mathrm{~N} \\
4\end{array}$ & $\begin{array}{l}\mathrm{D} \\
2\end{array}$ & $\begin{array}{c}\mathrm{DF} \\
0\end{array}$ \\
\hline 42 & $\begin{array}{l}\text { Um desenvolvedor pode parar o serviço } \\
\text { que está implementando substituindo-o por } \\
\text { outro serviço do Cliente, mais prioritário. } \\
\text { Existe uma metodologia de testes alinhada } \\
\text { com a Metodologia de Desenvolvimento. }\end{array}$ & $\begin{array}{c}\mathrm{CF} \\
8\end{array}$ & $\begin{array}{l}\mathrm{C} \\
4\end{array}$ & $\begin{array}{l}\text { IN } \\
3 \\
\text { IN } \\
2\end{array}$ & $\begin{array}{l}\mathrm{D} \\
\mathrm{I}\end{array}$ & $\begin{array}{c}\mathrm{DF} \\
\mathrm{I}\end{array}$ \\
\hline 44 & $\begin{array}{l}\text { O processo de planejamento de testes é } \\
\text { integrado com o plan } \sim \text { jamento do } \\
\text { desenvolvimento. }\end{array}$ & $\begin{array}{c}\mathrm{CF} \\
7\end{array}$ & $\begin{array}{l}\mathrm{C} \\
2\end{array}$ & $\begin{array}{l}\text { IN } \\
3\end{array}$ & $\begin{array}{l}\mathrm{D} \\
0\end{array}$ & $\begin{array}{c}\mathrm{DF} \\
0\end{array}$ \\
\hline 45 & $\begin{array}{l}\text { As estratégias de testes de unidade são } \\
\text { efetivamente cumpridas pelas equipes de } \\
\text { Produção. }\end{array}$ & $\begin{array}{c}\mathrm{CF} \\
5\end{array}$ & $\begin{array}{l}\mathrm{C} \\
4\end{array}$ & $\begin{array}{l}\text { IN } \\
3\end{array}$ & $\begin{array}{l}\mathrm{D} \\
0\end{array}$ & $\begin{array}{c}\mathrm{DF} \\
0\end{array}$ \\
\hline 46 & $\begin{array}{l}\text { A massa de testes de unidade é criada } \\
\text { antes da confecção do código, pela equipe } \\
\text { de Produção. }\end{array}$ & $\begin{array}{c}\mathrm{CF} \\
\mathrm{I}\end{array}$ & $\begin{array}{l}\mathrm{C} \\
2\end{array}$ & $\begin{array}{l}\text { IN } \\
2\end{array}$ & $\begin{array}{l}\mathrm{D} \\
3\end{array}$ & $\begin{array}{c}\mathrm{DF} \\
4\end{array}$ \\
\hline 47 & $\begin{array}{l}\text { Os testes de unidade são executados pelas } \\
\text { equipes da Produção após a confecção do } \\
\text { código (do serviço do Cliente). }\end{array}$ & $\begin{array}{c}\mathrm{CF} \\
3\end{array}$ & $\begin{array}{l}\mathrm{C} \\
9\end{array}$ & $\begin{array}{l}\text { IN } \\
0\end{array}$ & $\begin{array}{l}\mathrm{D} \\
0\end{array}$ & $\begin{array}{c}\mathrm{DF} \\
0\end{array}$ \\
\hline 48 & $\begin{array}{l}\mathrm{O}(\mathrm{s}) \text { produto(s) do desenvolvimento do } \\
\text { serviço do Cliente e os testes são } \\
\text { armazenados para reaproveitamento em } \\
\text { outro serviço posterior (framework). Se for } \\
\text { entregue ao Cliente, anotar no verso (ou } \\
\text { em outra folha). }\end{array}$ & $\begin{array}{c}\mathrm{CF} \\
4\end{array}$ & $\begin{array}{l}\mathrm{C} \\
3\end{array}$ & $\begin{array}{l}\text { IN } \\
2\end{array}$ & $\begin{array}{l}\mathrm{D} \\
3\end{array}$ & $\begin{array}{c}\mathrm{DF} \\
0\end{array}$ \\
\hline 49 & $\begin{array}{l}\text { Os testes têm sido realmente eficazes, } \\
\text { sendo executados a contento para a } \\
\text { organização, não havendo necessidade de } \\
\text { estudo de arc-Ios antes do código. }\end{array}$ & $\begin{array}{c}\mathrm{CF} \\
3\end{array}$ & $\begin{array}{l}\mathrm{C} \\
2\end{array}$ & $\begin{array}{l}\text { IN } \\
2\end{array}$ & $\begin{array}{l}\mathrm{D} \\
4\end{array}$ & $\begin{array}{c}\mathrm{DF} \\
\mathrm{I}\end{array}$ \\
\hline 50 & $\begin{array}{l}\text { Os testes de integração são feitos pelos } \\
\text { próprios desenvolvedores na medida em } \\
\text { que terminam os produtos e os mesmos } \\
\text { são disponibilizados para as integrações, } \\
\text { não havendo a necessidade do término de } \\
\text { todos os produtos. }\end{array}$ & $\begin{array}{c}\mathrm{CF} \\
3\end{array}$ & $\begin{array}{l}\mathrm{C} \\
5\end{array}$ & $\begin{array}{l}\text { IN } \\
1\end{array}$ & $\begin{array}{l}\mathrm{D} \\
3\end{array}$ & $\begin{array}{c}\mathrm{DF} \\
0\end{array}$ \\
\hline 51 & $\begin{array}{l}\text { Após o término de cada serviço (ou tarefa) } \\
\text { o próprio desenvolvedor efetua a liberação } \\
\text { do mesmo (no controle) para a integração. } \\
\text { Qualquer outra situação, anotar no verso } \\
\text { (ou em outra folha). }\end{array}$ & $\begin{array}{c}\mathrm{CF} \\
0\end{array}$ & $\begin{array}{l}\mathrm{C} \\
8\end{array}$ & $\begin{array}{l}\text { IN } \\
0\end{array}$ & $\begin{array}{l}\mathrm{D} \\
1\end{array}$ & $\begin{array}{c}\mathrm{DF} \\
3\end{array}$ \\
\hline 6 & Desenvolvimento - Er & II & & & & \\
\hline 52 & $\begin{array}{l}\text { O pessoal da produção, que implementou } \\
\text { o serviço (ou tarefa), participa da } \\
\text { homologação junto com o cliente. } \\
\text { Após o último serviço (011 tarefa) ter } \\
\text { terminado a Produção efetua no controle a }\end{array}$ & $\begin{array}{c}\mathrm{CF} \\
6 \\
\mathrm{CF} \\
4\end{array}$ & $\begin{array}{l}\mathrm{C} \\
4\end{array}$ & $\begin{array}{l}\text { TN } \\
0 \\
\text { IN } \\
0\end{array}$ & $\begin{array}{l}\mathrm{D} \\
2\end{array}$ & $\begin{array}{c}\mathrm{DF} \\
0\end{array}$ \\
\hline
\end{tabular}

Folha 4 de 5 - Questionário sobre processo de Fábrica de Software

(Silva, 2004) 


\begin{tabular}{|c|c|c|c|c|c|c|}
\hline & $\begin{array}{l}\text { liberação do serviço do Cliente para } \\
\text { homologação. }\end{array}$ & & & & & \\
\hline 54 & $\begin{array}{l}\text { Após o último serviço (ou tarefa) ter } \\
\text { terminado a Produção efetua os } \\
\text { lançamentos de encerramento do } \\
\text { planejamento e a conseqüente liberação } \\
\text { dos recursos alocados. } \\
\end{array}$ & $\begin{array}{c}\mathrm{CF} \\
7\end{array}$ & $\begin{array}{l}\text { C } \\
5\end{array}$ & $\begin{array}{c}\text { IN } \\
0\end{array}$ & $\begin{array}{l}\mathrm{D} \\
0\end{array}$ & $\begin{array}{c}\mathrm{DF} \\
0\end{array}$ \\
\hline 55 & $\begin{array}{l}\text { Após o último serviço (ou tarefa) ter } \\
\text { terminado a Produção efetua os } \\
\text { lançamentos de qualidade e } \\
\text { produtividade.. }\end{array}$ & $\begin{array}{c}\mathrm{CF} \\
5\end{array}$ & $\begin{array}{l}\text { C } \\
4\end{array}$ & $\begin{array}{c}\text { IN } \\
\mathbf{I}\end{array}$ & $\begin{array}{l}\mathrm{D} \\
2\end{array}$ & $\begin{array}{c}\mathrm{DF} \\
0\end{array}$ \\
\hline 56 & $\begin{array}{l}\text { Após o témlino do serviço (ou tarefas) } \\
\text { inicia-se um esquema de melhorias dos } \\
\text { processos produtivos. }\end{array}$ & $\begin{array}{c}\mathrm{CF} \\
3\end{array}$ & $\begin{array}{l}\text { C } \\
\text { I }\end{array}$ & $\begin{array}{c}\text { IN } \\
4\end{array}$ & $\begin{array}{l}\mathrm{D} \\
\mathbf{I}\end{array}$ & $\begin{array}{c}\mathrm{DF} \\
3\end{array}$ \\
\hline 57 & $\begin{array}{l}\text { Após o término do serviço (ou tarefas) é } \\
\text { feita a divulgação dos problemas } \\
\text { encontrados e suas possfveis soluções e/ou } \\
\text { resultados e/ou relatório estatfstico e/ou } \\
\text { novas soluções,. }\end{array}$ & $\begin{array}{c}\mathrm{CF} \\
3\end{array}$ & $\begin{array}{l}\text { C } \\
3\end{array}$ & $\begin{array}{c}\mathrm{IN} \\
3\end{array}$ & $\begin{array}{l}\mathrm{D} \\
2\end{array}$ & $\begin{array}{c}\mathrm{DF} \\
\mathbf{I}\end{array}$ \\
\hline \multicolumn{7}{|c|}{ Conhecimentos Gerais } \\
\hline 58 & $\begin{array}{l}\text { Há processos métricos que avaliam e } \\
\text { controlam a produtividade e qualidade do } \\
\text { pessoal da Produção. }\end{array}$ & $\begin{array}{c}\mathrm{CF} \\
6\end{array}$ & $\begin{array}{l}C \\
2\end{array}$ & $\begin{array}{c}\text { IN } \\
0\end{array}$ & $\begin{array}{l}\mathrm{D} \\
4\end{array}$ & $\begin{array}{c}\mathrm{DF} \\
0\end{array}$ \\
\hline 59 & $\begin{array}{l}\text { Após a homologação do serviço com o } \\
\text { Cliente (término), o mesmo pode retomar } \\
\text { à fábrica para acertos. Esse nfvel de } \\
\text { retomo é muito baixo. }\end{array}$ & $\begin{array}{c}\mathrm{CF} \\
3\end{array}$ & $\begin{array}{l}\mathrm{C} \\
4\end{array}$ & $\begin{array}{c}\mathrm{IN} \\
3\end{array}$ & $\begin{array}{l}\mathrm{D} \\
2\end{array}$ & $\begin{array}{c}\mathrm{DF} \\
0\end{array}$ \\
\hline 60 & $\begin{array}{l}\text { Há um processo constante de verificação } \\
\text { da satisfação do Cliente para com a } \\
\text { fábrica. }\end{array}$ & $\begin{array}{c}\mathrm{CF} \\
5\end{array}$ & $\begin{array}{l}\mathrm{C} \\
2\end{array}$ & $\begin{array}{c}\text { IN } \\
\mathbf{I}\end{array}$ & $\begin{array}{l}D \\
4\end{array}$ & $\begin{array}{c}\mathrm{DF} \\
0\end{array}$ \\
\hline 61 & $\begin{array}{l}\text { Durante os processos de implementação o } \\
\text { pessoal produtivo anota as sugestões de } \\
\text { melhorias dos processos e as propõe no } \\
\text { final do serviço do Cliente. }\end{array}$ & $\begin{array}{c}\mathrm{CF} \\
3\end{array}$ & $\begin{array}{l}\mathrm{C} \\
4\end{array}$ & $\begin{array}{c}\text { IN } \\
4\end{array}$ & $\begin{array}{l}\mathrm{D} \\
\mathbf{I}\end{array}$ & $\begin{array}{c}\mathrm{DF} \\
0\end{array}$ \\
\hline 62 & $\begin{array}{l}\text { Durante os processos produtivos os } \\
\text { desenvolvedores efetuam lançamentos de } \\
\text { dados do serviço (inicio, horas } \\
\text { trabalhadas, término, etc.) que servirão de } \\
\text { base para os planejamentos futuros (PSP). }\end{array}$ & $\begin{array}{c}\mathrm{CF} \\
4\end{array}$ & $\begin{array}{l}\mathrm{C} \\
5\end{array}$ & $\begin{array}{c}\text { IN } \\
\mathbf{I}\end{array}$ & $\begin{array}{l}\mathrm{D} \\
2\end{array}$ & $\begin{array}{c}\mathrm{DF} \\
0\end{array}$ \\
\hline 63 & $\begin{array}{l}\text { Um tempo após terem sido feitas, são } \\
\text { analisadas as melhorias de processos } \\
\text { efetuadas pela fábrica, participando dessa } \\
\text { avaliação alguns desenvolvedores, os } \\
\text { lideres e a gerência de produção. }\end{array}$ & $\begin{array}{c}\mathrm{CF} \\
4\end{array}$ & $\begin{array}{l}\text { C } \\
\text { I }\end{array}$ & $\begin{array}{c}\text { IN } \\
3\end{array}$ & $\begin{array}{l}\mathrm{D} \\
3\end{array}$ & $\begin{array}{c}\mathrm{DF} \\
\mathbf{I}\end{array}$ \\
\hline 64 & $\begin{array}{l}\text { Os desenvolvedores trabalham em pares, } \\
\text { em cada serviço do Cliente. }\end{array}$ & $\begin{array}{c}\mathrm{CF} \\
0\end{array}$ & $\begin{array}{l}\mathrm{C} \\
0\end{array}$ & $\begin{array}{c}\text { IN } \\
5\end{array}$ & $\begin{array}{l}\mathrm{D} \\
2\end{array}$ & $\begin{array}{c}\mathrm{DF} \\
5\end{array}$ \\
\hline
\end{tabular}

Folha 5 de 5 - Questionário sobre processo de Fábrica de Software (Silva, 2004) 